\title{
Hermatypic Corals of Japan
}
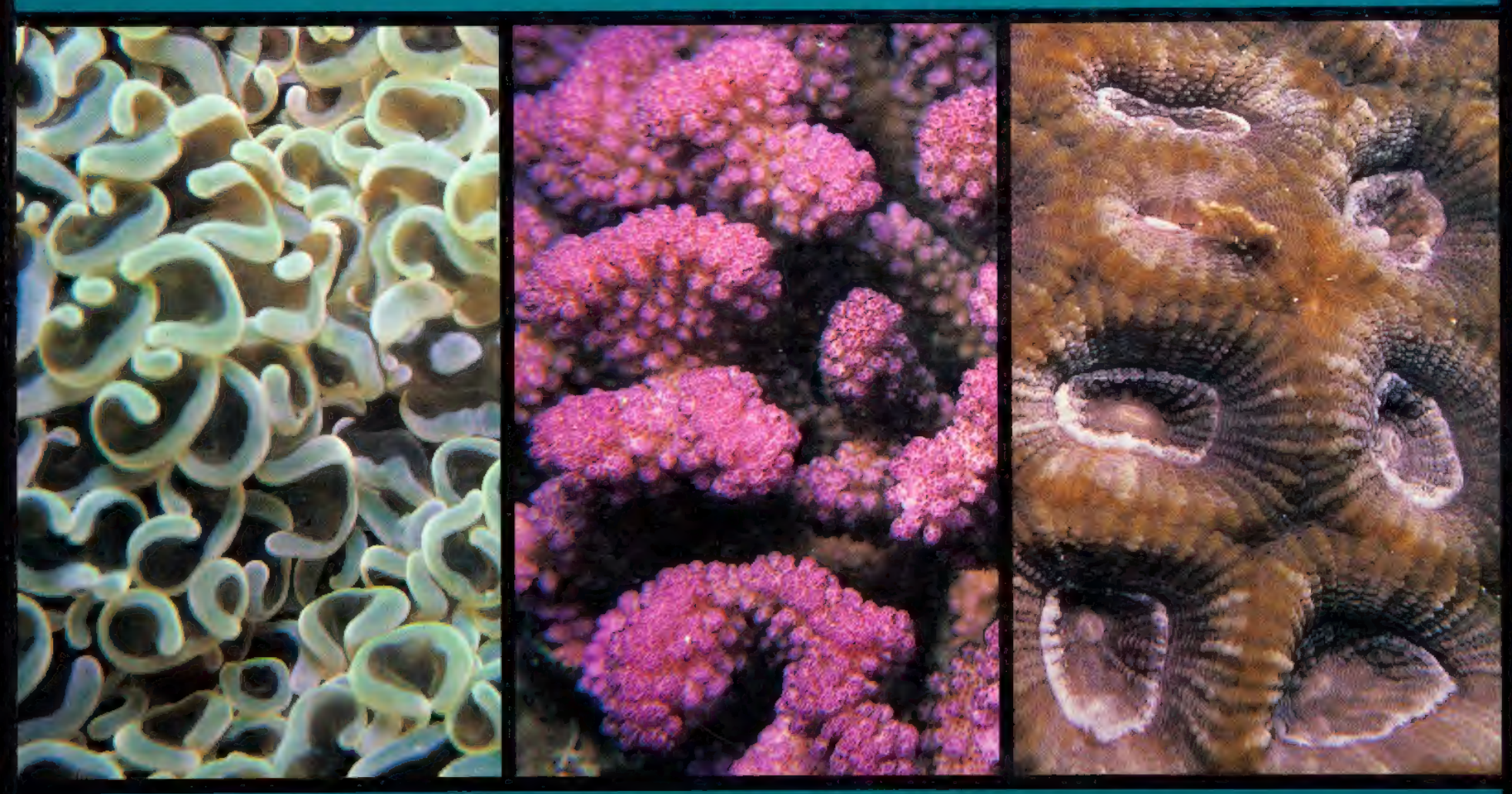

J.E.N. Veron

IIIII MONOGRAPH SERIES Volume 9 

Hermatypic Corals of Japan 



\section{AUSTRALIAN INSTITUTE OF MARINE SCIENCE MONOGRAPH SERIES \\ Volume 9}

\section{Hermatypic Corals of Japan}
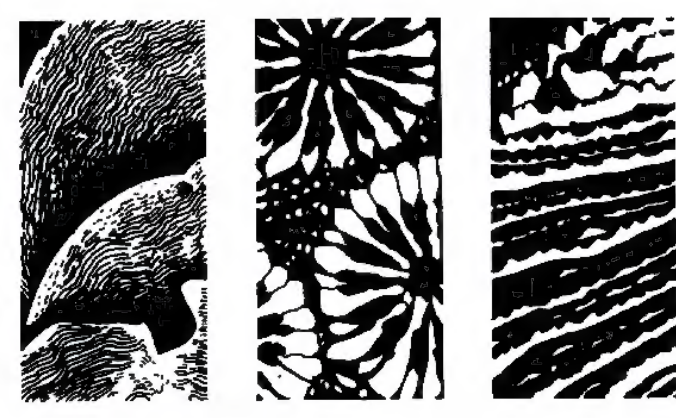

J.E.N. Veron

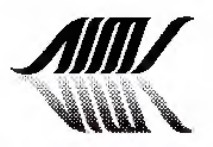

Australian Institute of Marine Science 1992 
First published in Australia in 1992

Printed in Australia by Merino Lithographics Pty Ltd for the Australian Institute of Marine Science, Cape Ferguson, Queensland. PMB No 3, Townsville Mail Centre, 4810.

(c) Australian Institute of Marine Science 1992

This book is copyright. Apart from any fair dealing for the purpose of study, research, criticism, or review, as permitted under the Copyright Act, no part may be reproduced by any process without written permission. Inquiries should be made to the publisher.

National Library of Australia Cataloguing-in-Publication data

Veron, J.E.N. (John Edward Norwood).

Hermatypic corals of Japan.

Bibliography.

Includes index.

ISBN 0642170835

1. Corals - Japan. 2. Corals - Japan - Identification.

I. Australian Institute of Marine Science. II. Title. (Series:

Monograph series (Australian Institute of Marine Science);

no. 9).

593.6

Australian Institute of Marine Science Monograph Series

ISSN 1037-3047

Cover photographs, from left: Euphyllia ancora; Pocillopora verrucosa; and, Favia veroni.

(c) J.E.N. Veron 


\section{I \\ Contents}

Abstract 1

1 Introduction 3

2 Historical Resumé 5

3 Sea Surface Currents and Temperatures 13

4 Spatial and Temporal Patterns 17

5 Collecting Stations 25

Editorial Note 32

6 Family Astrocoeniidae 33

Genus Stylocoeniella 33

7 Family Pocilloporidae 37

Genus Pocillopora 37

Genus Seriatopora 39

Genus Stylophora 40

Genus Palauastrea $\quad 41$

Genus Madracis $\quad 42$

8 Family Acroporidae 43

Genus Montipora 43

Genus Anacropora $\quad 56$

Genus Acropora $\quad 58$

Genus Astreopora $\quad 84$

9 Family Poritidae 89

Genus Porites 89

Genus Goniopora 97

Genus Alveopora $\quad 102$

10 Family Siderastreidae 105

Genus Pseudosiderastrea 105

Genus Psammocora $\quad 105$

Genus Coscinaraea $\quad 108$

11 Family Agariciidae 111

Genus Pavona 111

Genus Leptoseris $\quad 115$

Genus Gardineroseris $\quad 119$

Genus Coeloseris $\quad 119$

Genus Pachyseris $\quad 120$ 
12 Family Fungiidae

Genus Cycloseris $\quad 123$

Genus Diaseris $\quad 127$

Genus Heliofungia 128

Genus Fungia $\quad 128$

Genus Ctenactis 133

Genus Herpolitha 134

Genus Polyphyllia 134

Genus Sandalolitha $\quad 135$

Genus Halomitra 135

Genus Zoopilus 136

Genus Lithophyllon $\quad 136$

Genus Podabacia $\quad 138$

13 Family Oculinidae $\quad 139$

Genus Galaxea 139

Genus Acrhelia $\quad 140$

14 Family Pectiniidae $\quad 141$

Genus Echinophyllia $\quad 141$

Genus Oxypora 143

Genus Mycedium 144

Genus Physophyllia $\quad 145$

Genus Pectinia $\quad 145$

15 Family Mussidae 147

Genus Blastomussa $\quad 147$

Genus Cynarina $\quad 148$

Genus Scolymia 148

Genus Australomussa $\quad 149$

Genus Acanthastrea $\quad 149$

Genus Lobophyllia $\quad 152$

Genus Symphyllia $\quad 154$

16 Family Merulinidae 157

Genus Boninastrea $\quad 157$

Genus Hydnophora $\quad 157$

Genus Merulina 159

17 Family Faviidae 161

Genus Caulastrea $\quad 161$

Genus Favia $\quad 162$ 
Genus Barabattoia $\quad 168$

Genus Favites $\quad 168$

Genus Goniastrea $\quad 171$

Genus Platygyra 174

Genus Leptoria $\quad 177$

Genus Oulophyllia $\quad 178$

Genus Montastrea $\quad 179$

Genus Oulastrea $\quad 181$

Genus Plesiastrea $\quad 181$

Genus Diploastrea 182

Genus Leptastrea $\quad 182$

Genus Cyphastrea $\quad 184$

Genus Echinopora $\quad 188$

18 Family Trachyphylliidae 191

Genus Trachyphyllia $\quad 191$

19 Family Caryophylliidae 193

Genus Euphyllia 193

Genus Catalaphyllia 195

Genus Plerogyra 196

Genus Physogyra 197

Genus Gyrosmilia 197

20 Family Dendrophylliidae 199

Genus Turbinaria $\quad 199$

Genus Heteropsammia 202

Acknowledgements 203

Literature Cited 205

Index 219 


\section{简 \\ Abstract}

Original studies, together with a review of past studies, are combined in a species-level account of all known Japanese hermatypic corals. Original studies were made at 98 collecting stations. These include the three groups of the Ryukyu Is.: the Yaeyama Is., Okinawa Is. and Amami Is., all of which have extensive fringing reefs, and seven regions of mainland Japan and neighbouring islands, which have nonreefal coral communities: Tanegashima, the Amakusa Is. (Kyushu), Tosashimizu (Shikoku) and Shirahama, Kushimoto, Izu Peninsula and Tateyama (Honshu). A total of 400 confirmed species are recorded from the Ryukyu Is. and mainland Japan; an additional 9 species have been recorded from previous studies from other Japanese localities or with doubt from the Ryukyu Is. All previous studies from Japanese localities are reviewed and locality records (of both past and present studies), taxonomic data, and in situ appearance are recorded. The major oceanographic control of distribution and abundance of species, the Kuroshio Current, is discussed in light of detailed data on sea surface temperature and available data on circulation patterns. Distribution changes during the Holocene and recent, including humanand Acanthaster planci-related effects, are discussed.

Species diversity progressively attenuates from the southern-most (Yaeyama) islands ( 359 species) to the northernmost extremity of coral occurrences near Tokyo. There are major differences between the corals of the Ryukyu Is., which mostly occur in reefal communities, and those of mainland Japan, which occur on terrigenous substrates. Analysis of presence/absence data indicates that species distributions are primarily correlated with sea surface temperature and secondly correlated with the presence of reefal environments and degree of regional isolation. 



\section{Introduction}

Historically, Japanese coral reef biologists and geologists have made a major contribution to the study of Indo-Pacific reef corals. Two very distinct periods are reflected in the literature. The first, centered on the studies of Yabe and his colleagues, mostly pre-dates the Second World War and ranks internationally as one of the most taxonomically important groups of studies of the time. The second is made up of a relatively recent complex of mostly geographically discrete smaller studies undertaken from university marine research stations and public aquaria.

The first period is pre-SCUBA; the second spans the introduction of SCUBA in both taxonomic studies and field surveys and have primarily been undertaken by divers collecting corals for subsequent identification by non-diving taxonomists, using the taxonomic framework of Yabe and his colleagues with only minor modifications.

One overall outcome of these two periods combined, is that Japanese coral fauna as a whole is well-known relative to most other countries with major coral reefs. A second outcome, however, is that the taxonomic framework is not well integrated with the reality of the reef. As with most coral taxonomic studies undertaken without the use of extensive in situ observation, there is little understanding of environmentcorrelated intraspecific variation. As a result, reliable species identifications are mostly restricted to families or genera were species are few in number or are relatively distinct. Thus, major genera which display extensive intraspecific variation (notably Montipora, Acropora, Porites and Turbinaria) are largely identified according to the British Museum Catalogues (of Bernard and Brook). In contrast, other genera that were more fully studied (eg. Caulastrea and Lithophyllon), have been given a complex of species and sub-species names which do not reflect true intraspecific variation and which belies the fact that similar variation occurs in most other hermatypic genera.

A final historical outcome of Japanese coral studies, along with that of all other regional studies up to the time of Wells (1954), is that they give a false impression of regional isolation. This study, and that of Veron and Hodgson (1989) and Veron (1988) respectively show that the corals of the Ryukyu Is. are essentially similar to that of the Philippines and, to a lesser extent, the Great Barrier Reef, yet any biogeographic study based on previous accounts would indicate a relatively minor species similarity between these regions.

The aim of the present study was initially a biogeographic one: to integrate the coral fauna of Japan with that of other countries and thus span the latitudinal range of the Indo-west Pacific centre of scleractinian diversity. In this context, the Ryukyu Is. and the southern coastline of the mainland islands are almost ideally placed, 
forming a continual arc from high diversity tropical reefs to the high latitude extremes of coral distribution.

A second and equally important aim, which evolved during the course of the present work, has been to provide a taxonomic framework for other areas of coral research, much of which is urgently needed for conservation purposes. Based on data from the present publication, Veron (in press a) has concluded that $30 \%$ of all Japanese species are uncommon throughout their range in Japan and are at some risk of regional extinction, $28 \%$ additional species are rare, or are restricted to the Yaeyama Is., where they occur only in very limited areas of high diversity or in species-specific refuges, and 5 of the 8 known regional endemics are primarily restricted to speciesspecific refuges. The inevitable conclusion is that this is an unstable situation and that, in the long term, at least one third of all Japanese hermatypic corals are threatened with regional or total extinction.

Nishihira and Veron are preparing a fully illustrated field guide to Japanese corals based on the present publication. 


\section{2 Historical Resumé}

An unpublished manuscript (Fujiwara, 1979) is the most comprehensive account of the generic distributions of corals in Japan. Veron (1988, Table 1) gives an updated version of this, after conversion to the present taxonomic framework. Generic records are, however, of little value other than as a crude measure of regional diversity and subsequent distributions recorded here are at species level.

As mentioned above, there have been two distinct periods of coral taxonomic research in Japan, the first being overwhelmingly dominated by the prolific writings of Yabe and his colleagues at Tohoku University. Yabe and Sugiyama (1935c) give a detailed tabulation of the distribution of species throughout Japan and Yabe et al. (1936) and Yabe and Sugiyama (1941) give an expanded, well illustrated taxonomic account of about half the species involved. This series was terminated by the Second World War, leaving the biogeography of some major taxa, notably families Acroporidae and Poritidae (which mostly follows Bernard 1903, 1905, 1906 and Brook, 1893), without a clear taxonomic base. Yabe and his group published some 14 studies on the extant corals of Japan and many more on fossil corals. Several of these are taxonomic papers concerning specific genera, others are primarily updated versions of earlier publications.

Yabe et al. (1936) give many references to their collecting localities in the Ryukyu Is. (Fig. 1) (as the Sakisima, Okinawa and Osima Subgroups, now usually referred to as the Yaeyama, Okinawa and Amami Is.). Even so, their collections from the Ryukyu Is. is not as comprehensive as it is from mainland Japan, with only 4, 3 and 4 sites (respectively) for each island group, to which Yabe and Sugiyama (1941) added one additional site for each of the Okinawa and Amami Is.. Not surprisingly, their records from the Ryukyu Is. do not indicate the true diversity of the region. They give only a brief account of the collecting that was undertaken, none of it being by the authors themselves and, although specific grid references are given, there is no indication of how extensive individual collecting stations were. The authors also note that identifications were made from the literature, without references to type specimens. Identifications are, however, generally consistent (after Yabe and Sugiyama, 1935a) throughout the publications of Yabe's group, allowing most to be interpretable in the present taxonomic framework.

Original records from the Yaeyama Is. are exclusively those of Yabe and his colleagues (Yabe et al., 1936); all subsequent studies are relatively recent. Suzuki (1972) gives the first, brief, account of the corals of Iriomote I.; Eguchi (1974) lists 84 species from Iriomote and Ishigaki Is.; Eguchi (1975a) lists the genera recorded at that time, noting that he has 'discriminated some 240 species', including a hermatypic and 


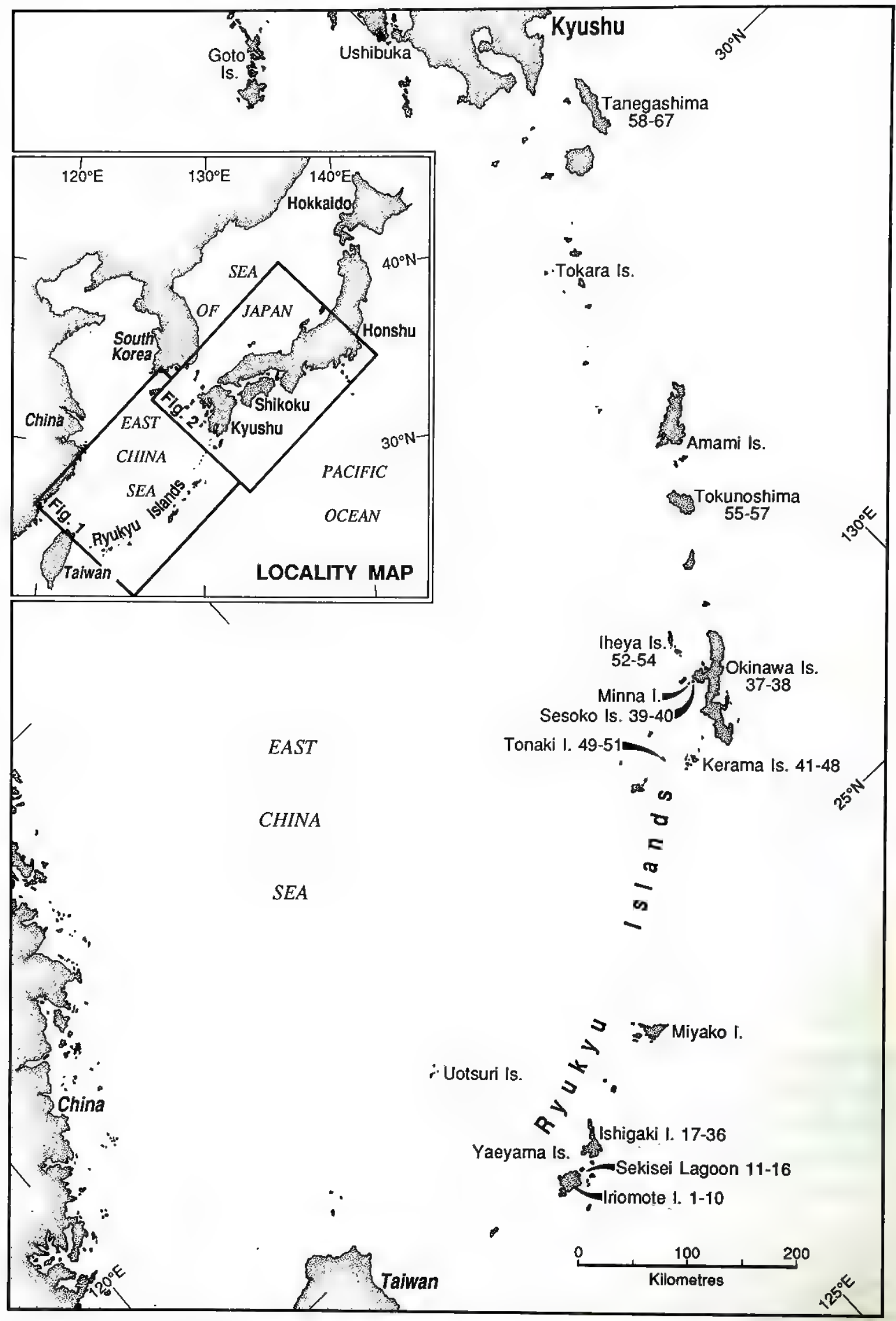

Figure 1. The Ryukyu Islands, showing place names cited in the test and collection stations 1-57. Inset: locations of Figures 2 and 3. 


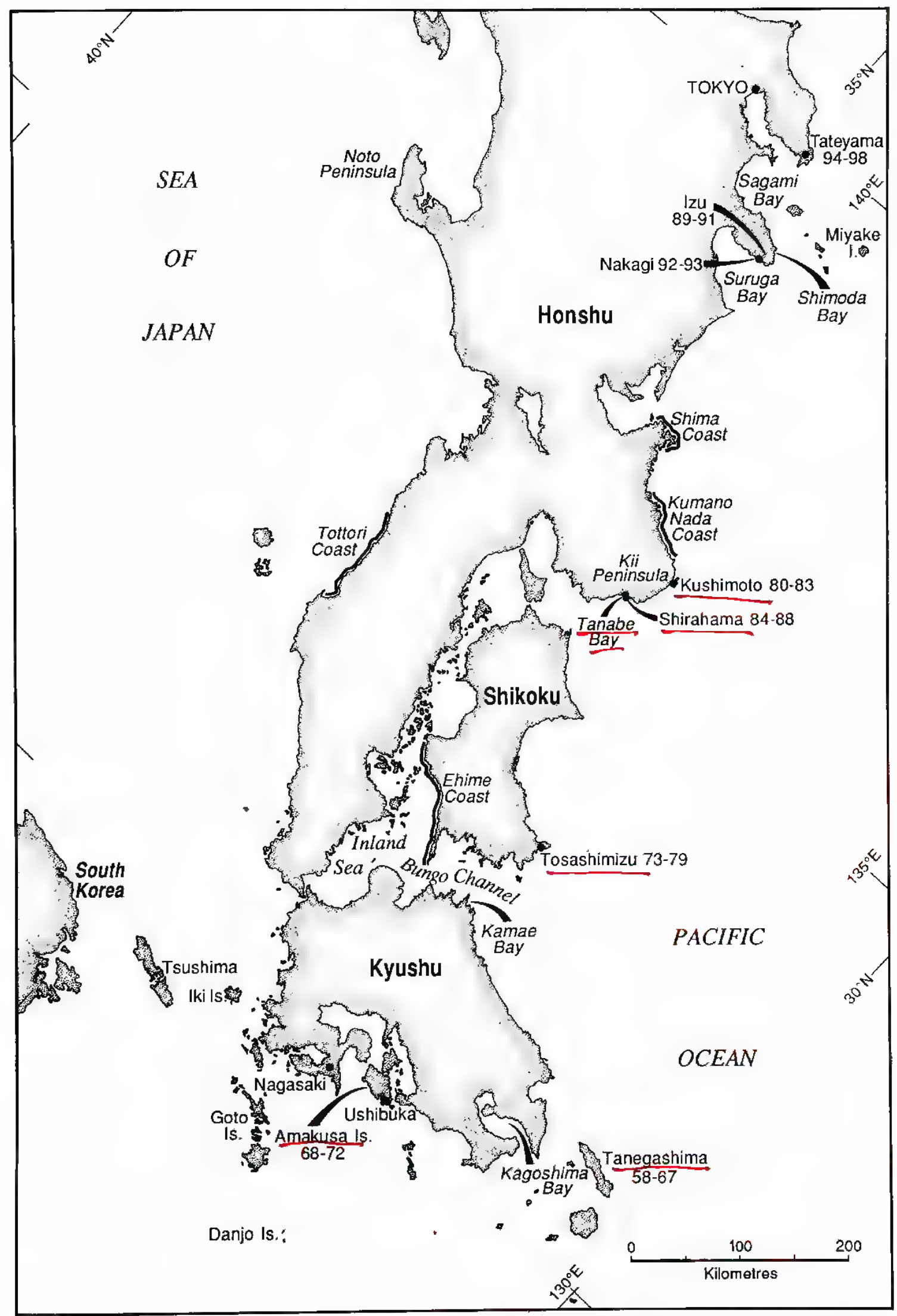

Figure 2. Southern mainland Japan, showing place names cited in the text and collecting stations 58-98. 
non-scleractinian species. Takahashi and Koba (1978) give the first general description of the zonation of southern parts of Ishigaki I.; Horikoshi et al. (1975), Horikoshi (1979), Takahashi (1983), Shirai (1980) and Kawaguti (1983) give additional records from Ishigaki I. Nakamori (1986) gives a detailed analysis of community structures of Ishigaki I. and Sekisei Lagoon; 144 species of 51 genera are recorded and 11 community types discriminated. There have been several brief reports of the corals and coral communities of Shiraho Lagoon, Ishigaki I., including Muzik, 1984a, 1984b; Shirai and Sano, 1985 (primarily from notes taken on a preliminary survey by Veron and Kühlemann); Masuda, 1986 and Yasumoto, 1986). Veron (1988) gives a summary of the corals of Ishigaki, to which the present account is a substantial update based on additional field work at collecting stations 1-16 and 25 .

There have been two recent studies of the corals of Iriomote Is. based on the taxonomic framework of the present study and included in the results of the present study: Habe (1989) lists 93 species from Amitori Bay, Iriomote I. (collecting stations 210 of the present study) and Nishihira and Yokochi (1990) list 191 species from the adjacent Sakiyama Bay.

Yamazato et al. (1982) gives an account of the coral communities of the remote Uotsuri Is. to the north of the Yaeyama group, apparently very depauperate reefs as only 37 hermatypic species are listed.

As with the Yaeyama Is., the original publications of Okinawa and Amami Is. corals are those of Yabe and his colleagues. Subsequently, Eguchi (1974) listed 84 hermatypic species from the Kerama Is., and there have been several quantative studies of coral communities around the Okinawa Islands, some of them (Yamazato 1971, 1978; Nakasone et al. 1974; Nishihira et al., 1974; Yamazato, et al., 1974, 1976, 1978, 1980), listing the species found. More recently, Nishihira et al. (1987) Sakai and Yamazato (1987) and Chou and Yamazato (1990) give lists of species of Kudaka I. and Sesoko I., using the taxonomic framework of the present study.

The only publication on the corals of the Amami Is. since Yabe are brief observations (Hirata and Oosako, 1968a, 1968b and Ooishi and Yagi 1964).

Tanegashima, $30 \mathrm{~km}$ from the southern tip of Kyushu, is treated in the present study as geographically part of mainland Japan (Fig. 2). Corals of Tanegashima have not been previously studied but Tokioka (1953), Baba (1954) and Utinomi (1956) give brief accounts of the shallow-water corals of the Tokara Islands approximately $30 \mathrm{~km}$ to the south-west, recording in total only 14 hermatypic species. Hirata et al. (1969) lists 17 hermatypic species, many with illustrations, from Kagoshima Bay immediately north of Tanegashima. All species that are identifiable were recorded from Tanegashima during the present study.

As noted above, mainland Japan corals have received much more attention from Yabe and his colleagues than those of the Ryukyu Is. For this work, Sugiyama and others collected from 20 localities around Kyushu and their records are relatively complete, at least at generic level. Since then, Kikuchi (1968), also Kikuchi and Araga (1980) (identified by Eguchi) published a list of the corals around the Amakusa 
Marine Biological Laboratory, Eguchi (1971) lists the corals of Goto Is., north- west of the Amakusa Is. and Fukuda and Iwase (1984) give a brief account of the corals of the Danjo Is. to the south-west. Eguchi (1975b) gives a general account of the corals of Nagasaki Prefecture.

A branch of the Kuroshio Current flowing into the Sea of Japan via the narrow Strait of Korea, passes either side of Tsushima. Eguchi (1970a) gives a brief list of mostly ahermatypic corals from Tsushima strait, listing only 2 hermatypic species. In a survey around Tsushima itself, Eguchi (1973) recorded 26 hermatypic species, a fauna similar to that of the Tateyama at the far east extremity of hermatypic coral distribution. Eguchi and Fukuda (1972) list 21 hermatypic species at Iki Island, between Tsushima and north-west Kyushu. Eguchi (1970b) lists 5 corals from the Tottori coast of the southern Sea of Japan, none of them being hermatypic. The northernmost record of a hermatypic coral in the Sea of Japan is Oulastrea crispata from the Noto Peninsula (Yajima et al, 1986).

Yagi (1970), Shirai (1971) and Utinomi (1971) give accounts of the corals of different locations of eastern Kyushu. The most complete of these studies is that of Utinomi (1971) who gives an account of 42 hermatypic species of Kamae Bay, northeast Kyushu, which is, however, well below the number that might be predicted from the present studies at Tosashimizu, approximately $100 \mathrm{~km}$ to the east.

Yabe et al. (1936) list 6 collecting localities of Shikoku which probably include all major coral outcrops except those of the south-west coast adjacent to the Bungo Channel. Utinomi (1965a) gives a brief list of the corals of this region; Utinomi (1965b) gives a fuller account of a collection from approximately $60 \mathrm{~km}$ from the author's study site at Tosashimizu, as well as collections from Tosashimizu itself. He recorded 33 species as opposed to the 121 species recorded by the author, primarily a reflection on the advantages of SCUBA in compiling a full species inventory. Even so, he records two species (Caulastrea tumida and Montipora digitata) which were not recorded by the author. Tokioka (1968) gives an account of a 'giant' colony of Pavona decussata (as Pavona frondifera) from Tatsukuchi Marine Park, near Tosashimizu. Utinomi (1970) also lists and illustrates the corals of the Ehime coast, 45 species being hermatypic. Among these are species at their distribution extremes: Acropora echinata, A. loripes and three free- living fungiids (Ctenactis echinata, Fungia fungites and Fungia ?concinna), none of which were recorded by the author. The Ehime coast may have a semi-transitory coral fauna as it normally receives a small branch of the Kuroshio Current extending into the southern Inland Sea. Warm conditions are sufficiently unstable to make it possible that these species are no longer present in the region.

Yabe et al. (1936) and Yabe and Sugiyama (1941) include 9 collection localities from southern Honshu. All but three of these (Suruga Bay, Sagami Bay and Tateyama) are from the Kii Coast between Tanabe Bay and the Shima coast (Hahazima). The most important biogeographic factor of the Kii coast is the difference in oceanographic conditions between the south-west coast (between Shirahama and the Kushimoto region) and the eastern coast. The latter periodically has relatively low sea 
temperatures, depending on the movements of the Kuroshio Current, and corals are much less prolific.

Many studies have been made of the corals of Shirahama-Kushimoto coast: originally by Yabe's group (Yabe and Sugiyama 1935a), and subsequently by Sakaguchi (1954), Utinomi (1966, 1968, 1972), Eguchi (1972b), Eguchi and Miyawaki (1975), Anonymous (1977), Shirai (1986) and a large number of notes in the journal Pavillion. Eguchi and Miyawaki (1975), following Utinomi (1966), give a relatively detailed account including colour, Indo-Pacific distributions and depth ranges (which are generally inaccurate and are probably just the depth ranges of collected specimens) and Anonymous (1977) give good illustrations, including colour photographs of most species in situ. Miyawaki (1978) adds an additional 5 records, only one of which (Goniastrea retiformis) is hermatypic.

The relatively depauperate east (Kumano-nada) coast of Kii Peninsula has received relatively little recent study (Shirai et al., 1965; Shin, 1979; Shirai, 1986). Shirai (1986), using the taxonomic framework of the present study, lists 53 hermatypic species from the Kii coast as a whole, confirming this region as the present eastern mainland distribution limit of several genera: Caulastrea, Cynarina, Pocillopora, Lithophyllon, Lobophyllia, Madracis, Pectinia, Stylophora, Trachyphyllia and Turbinaria and also species of more widely ranging genera, including Acropora glauca, A. loripes, Cyphastrea microphthalma and Pavona decussata. Four of these genera (Caulastrea, Lithophyllon, Stylophora and Turbinaria) have been previously recorded from Tateyama (see below), but may no longer be present there.

The corals of Izu have been recorded by Eguchi (1972a) who lists 12 hermatypic species.

Eguchi (1968) gives a detailed account of the Milleporina, Stylasterina and Scleractinia of Sagami Bay, the latter being largely ahermatypic. Twenty-one hermatypic species are recorded and their distributions within and beyond Japan listed. However, only eight species are from the Sagami Bay itself (6 originally recorded by Eguchi, 1935a, 1935b), the other records being from surrounding peninsulas, including Tateyama, after Hamada (1963b).

The corals of Tateyama have long been of interest because they are at the extremity of hermatypic coral distribution and because a substantial outcrop of Holocene fossils occurs there (Yabe and Sugiyama, 1931, 1935a, 1935c; Hamada 1963a, 1963b Eguchi and Mori, 1973 and Veron, in press b). A total of 35 species have been recorded by these authors; the identities of 23 of these have been confirmed.

The distribution of corals along the Izu Rise, which forms a chain of islands running south from Tokyo across the path of the Kuroshio Current, is known from only two studies. Tribble and Randall (1986) give an account of the corals of Miyake I., a small volcanic island $160 \mathrm{~km}$ south of Tokyo, where they collected 80 hermatypic species. Because the island lies directly in the path of the Kuroshio Current, sea temperatures are markedly higher than that of adjacent mainland localities and this presumably also allows for enhanced recruitment of propagules from tropical 
localities. The island however, is subject to ENSO-related temperature decreases which probably cause periodic decrease in hermatypic coral diversity. Takahashi (1983) gives a brief generic level account of the corals around Hachijo I., also on the Izu Rise, some $300 \mathrm{~km}$ south of Tokyo.

The Ogasawara (or Bonin) and Volcano Is. are a series of mountainous islands approximately midway between the Mariana Is. and Tokyo, nearly $1,000 \mathrm{~km}$ to the north. The corals were originally studied by Yabe and Sugiyama (1935c, 1941), Yabe et al. (1936) and Sugiyama (1937). There was little Japanese contact with the islands for 20 years after the war until an expedition was sent there in 1968 . There are several descriptions of Ogasawara I. corals immediately after that time: Imajima (1969, 1970a) made reports for the establishment of a marine national park and Imajima (1970b) is a public version of these reports. Ooishi (1970) gives a brief synopsis covering 29 species; Kurata et al. (1969) gives a more comprehensive although still very incomplete account. Tachikawa (pers. comm, 1991) has prepared a substantial tentative list of species, most of which are included below. 



\section{Sea Surface Currents and Temperatures}

Oceanographic conditions throughout the northern Philippines, the Ryukyu Is. and southern Japan, are overwhelmingly dominated by the warm Kuroshio Current, the core of which 'begins' at Luzon (Philippines) (Nitani, 1972), enters the East China Sea through the strait between Taiwan and the Yaeyama Is, flows northward along the continental shelf edge break of eastern Asia (100-200 km west of the Ryukyu Is. chain) (recently reviewed, Bingxian, 1986), then veers to the east and flows along the south coast of mainland Japan before entering the northern Pacific as the Kuroshio Extension (Fig. 3). This is the northern limit of hermatypic coral distribution, where the Kuroshio interfaces with the cold southward flowing Oyashio current of eastern Honshu. Within Japan, there are three aspects of the Kuroshio which are particularly important to coral dispersal: (1) the current is one-directional although it generates a complex of unstable return gyres, (2) with the exception of the variations described below, its main path, and to a lesser extent its speed, shows less seasonal or inter-annual variation than other western boundary currents and (3) it maintains relatively high temperatures in high latitudes.

The primary influence on surface circulation around the Ryukyu Is. is the core of the Kuroshio to the west; secondary influences are meso-scale gyres from the core path creating periodic southward reversals in the prevailing northward current and weak periodic currents from the eastern Philippines Sea. Current maps of the Japan Oceanographic Data Center (from 1986) seldom show currents over $0.9 \mathrm{~m} / \mathrm{sec}$. In theory at least, current records demonstrate the possibility of transport in both directions along the Ryukyu Is. chain. In the region of the northern limit of reef formation, Konaga et al. (1980) has recorded large geostrophic returns from the Tokara Strait south of Tanegashima to the Amami Is. which have the northernmost coral reefs. Beyond the Tokara Strait, the Kuroshio influence is one-directional.

To the west of Kyushu, the Tsushima current, a small branch of the Kuroshio, flows north through Korea Strait, after which it mixes with the cold waters of the North Korean Current in the Sea of Japan (Moriyasu, 1972). The Tsushima, combined with strong tidal influences, forms complex eddies which may allow for return currents from west Kyushu to the east. The main Kuroshio path crosses from the Ryukyu Islands to the south mainland coast primarily in the vicinity of the Tokara Strait where currents always flow strongly, the surface velocity and geostrophic transport varying according to the path of the current to the east. 
One of the most distinctive characteristics of the Kuroshio, not found in other western boundary currents, is that in the south of central Japan, it has essentially five paths (Fig. 3). The first is a straight path virtually parallel to the south coast; the least direct path has a major offshore meander between south-west Shikoku and Tateyama, accompanied by a large cold eddy off the Kii coast. These paths are unusual for western boundary currents in that they last for several years, reflecting the Kuroshio's inlet velocity and viscosity and, in turn, more global variations of the atmosphere, oceans and cryosphere, including ENSO events (Kawabe, 1980, 1985, 1986; Yoon and Yasuda, 1987).

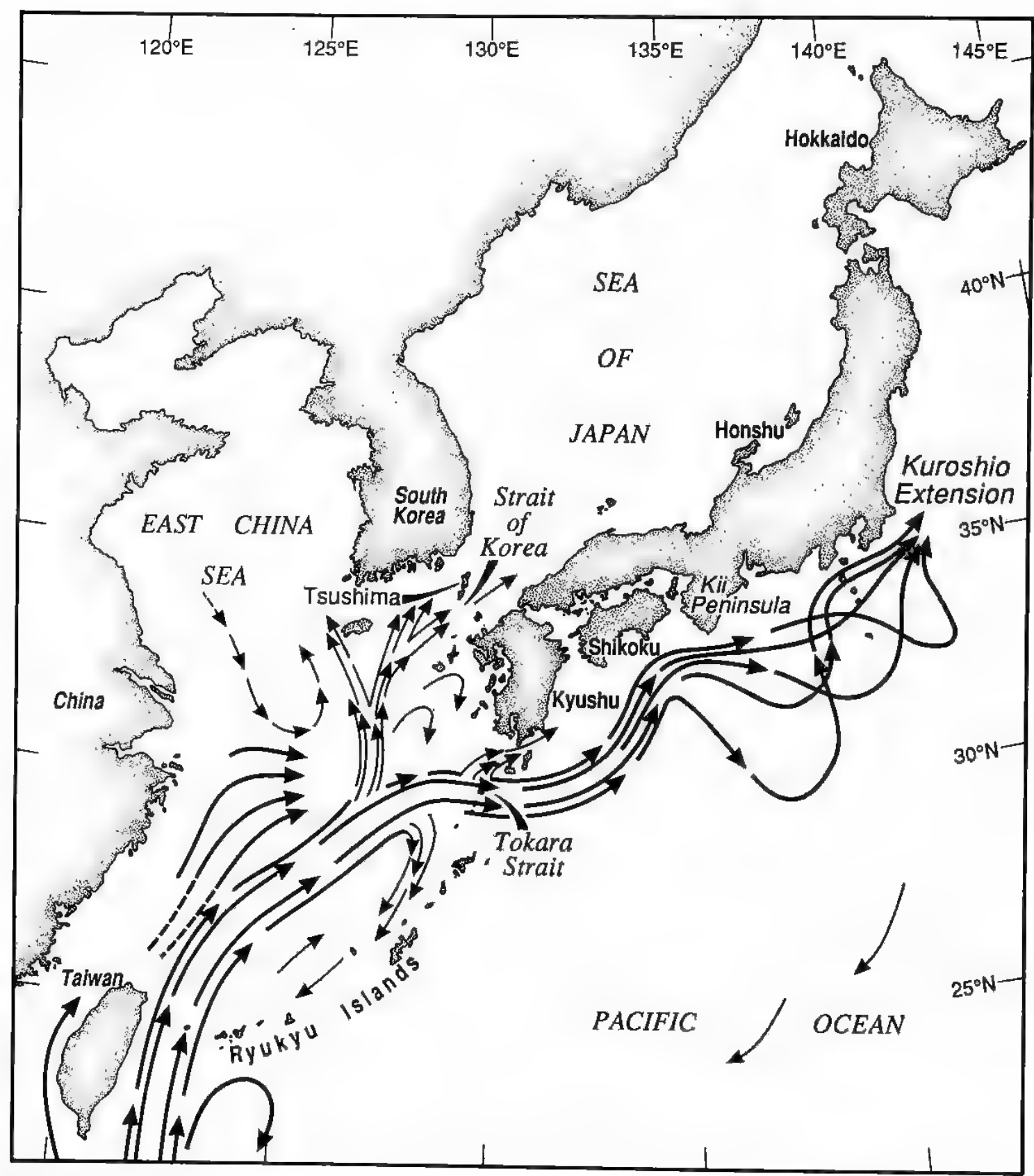
Figure 3. Generalised diagrammatic representation of the surface patterns associated with the
Kuroshio Current. 
The large meander path of the Kuroshio is the more prevalent, having been present over 35 years between 1895 and 1984 (Kawabe, 1985); it has a relatively low volume transport and a greatly increased transport time east of the Kii coast. However, all paths, and most recorded variations of them, provide transport between Tanegashima, southern Kyushu, southern Shikoku and Kushimoto. The meandering path, forming a loop between Kushimoto and Izu or (less frequently) Tateyama, is accompanied by the 'Kyucho', a cold sudden current which may have catastrophic effects on the coastal biota east of Kushimoto (Uda, 1953; Ishino and Otsuka, 1970; Otsuka 1985). Temperatures in Sagami Bay are high during transition from the direct to a less direct meander path and cold during the reverse transition (Kawabe and Yoneno, 1987).

Southward of the eastern Kuroshio, the surface circulation in the subtropical eastern Philippines Sea is dominated by many eddies, but net movement is west towards the Kuroshio (Otsuka and Ishino, 1988), providing transport from the Ogasawara Is. to the Ryukyu Is., but not the reverse.

Extensive sets of temperature data have been recorded throughout Japan, and these, along with current data, have been correlated with the coral distributions of the present study by Veron and Minchin (in press). 



\section{Spatial and Temporal Patterns}

There have been few biogeographic accounts of Japanese corals, or comparisons between them and those of other countries, since the studies of Yabe and his colleagues. Yamazato (1985) gives an integrated summary of comparisons between the corals of Japan and the Great Barrier Reef, together with ecological observations. Veron (1988) specifically address comparisons between Japanese and Australian corals, the latter publication being preliminary to the present one.

Table 1 , on page 20, summarises the distribution of corals in the principal geographic zones of this study. Data are from the present study and confirmed records of previous studies. Figure 4 is a classification of these zones. These results, collectively, show a well defined spatial pattern dominated by an orderly reduction of species diversity in a progressive drop-out sequence from the Yaeyama Is. to Tateyama. There is a much higher degree of similarity between between Kushimoto and the distant Amakusa Is. than there is between Kushimoto and nearby Shirahama, indicating that, at high latitudes, physical environment has a greater control over species diversity than geographic proximity. These data are further analysed by Veron and Minchin (in press).

Temporal patterns are much less well defined. On an ecological time scale, the distribution limits of many species, especially regionally rare species in high latitudes, are likely to be in a natural state of flux. As noted above, species of Acropora, Pavona and Fungia have been recorded from the Ehime coast by Utinomi (1970) but were not found there during the present study. Moyer (pers. comm.) has observed the disappearance of Cycloseris somervillei, recorded by Tribble and Randall (1986) from Miyake I. in what was attributed to and ENSO-related temperature decrease, and several species including Blastomussa wellsi, Euphyllia ancora, Pavona venosa, Acanthastrea lordhowensis, Hydnophora bonsai, Mycedium elephantotus and Oxypora lacera, recorded by the author from Izu and/or Tateyama, are sufficiently rare to be only transitory populations.

Environment-correlated changes in coral distributions due to oceanographic conditions are, however, likely to be very minor compared with those resulting from Acanthaster planci predation and recent human influences. Outbreaks of Acanthaster planci (reviewed, Yamaguchi 1986) have cause extensive damage to coral communities throughout the Ryukyu Is. and in most mainland Japan locations. Land clearing for agriculture and changes to the coastline of most major islands resulting from a wide range of foreshore constructions are presently rapidly accelerating. The 
effects of this on species abundances are difficult to determine. Of all studies of reefal corals, those based at Sesoko 1. (Yamazato et al., 1978; Sakai and Yamazato, 1987 and Chou and Yamazato, 1990) are of particular interest as they provide quantative evidence of biodiversity decrease resulting from Acanthaster predation and coastal construction.

Regional estimates of abundance recorded subjectively during the present study (Veron in press), indicate that a group of 149 species, which occur in small, perhaps disjunct populations, or are otherwise uncommon are also usually uncommon throughout most of their Indo-Pacific distribution ranges and thus their low abundance in Japan may represent no significant departure from other countries and perhaps no significant departure from a pristine state. A second group of 107 species, or $27 \%$ of the total species complement of Japan, are either rare throughout the Ryukyu Is. ( 69 species) or restricted to the Yaeyama Is. (38 species). The latter are mostly occur in small biotopes of high diversity, such as a moat on the south side of Kuroshima (several branching Montipora), a deep water site of Amitori Bay, Iriomote I. (Leptoseris amitoriensis), perhaps a single embayment of Ishigaki I. (Zoopilus echinatus). (Siderastrea sp.). These species are presently threatened with regional extinction and it follows that an unknown number of other species, including many of those recorded from the Philippines, but not Japan, may have already become regionally extinct.

Of 8 species which are relatively common in mainland Japan as opposed to the Ryukyu Is., Catalaphyllia jardinei and Acropora stoddarti have not been found in the Ryukyu Is. and are dependant on small isolated outcrops for their continued existence in Japan. Both species must have occurred in the Ryukyu Is. at some past time, but there is no evidence as to when. Although there is increasing evidence that many if not most species from high latitude locations undergo normal sexual reproduction (Heyward, pers. comm.), colonisation may, in the long term, be dependant on recruitment from the Ryukyu Is. in the event of widespread death from low temperatures.

Of the species that may be endemic to mainland Japan and adjacent Asian countries, only Alveopora japonica, Goniastrea deformis and, perhaps, Hydnophora bonsai, are sufficiently widely distributed to not be at risk of total extinction (Veron, in prep.a).

Beyond the ecological time-scale, comparison between Holocene and extant faunas of Tateyama (Hamada, 1963b; Eguchi and Mori, 1973 and Veron, in press b) reveals a major change in species distributions and apparent relative abundance. Tateyama is not only the site of the world's most northern outcrop of hermatypic corals but is also the site (in the Numa beds) of a substantial outcrop of Holocene fossil corals with a radiocarbon date of $5,000-6,000$ years BP. This extraordinary cooccurrence has provided the opportunity for a detailed reconstruction of environmental change during the Holocene, especially change in sea surface temperature. The Numa beds have 70 species, of which 51 have been positively 
identified, and 35 species extant species have been recorded at Tateyama, of which 23 have been positively identified. Nearly one-third of all Numa bed species have remained extant at Tateyama, $85 \%$ are extant as far north as the Kii Peninsula and all except two have been recorded extant somewhere in mainland Japan. There has been a major change in species dominance at Tateyama. Analysis of species complements show that the Numa bed fauna has only a slightly closer affinity with the extant coral of Tateyama than with those of Izu and that a temperature increase of only $1.2-1.7^{\circ} \mathrm{C}$ would be adequate for the observed faunal change at Tateyama.

The Ryukyu Is. have widespread Pleistocene reefs containing corals that have received relatively extensive study, including comparisons with extant corals. Yabe and Sugiyama (1935b) and Nakamori (1986) give accounts of pre-war and recent studies respectively. With few exceptions, however, the Ryukyu Limestones do not contain sufficiently well-preserved corals to allow for detailed comparisons between fossil and extant community compositions.
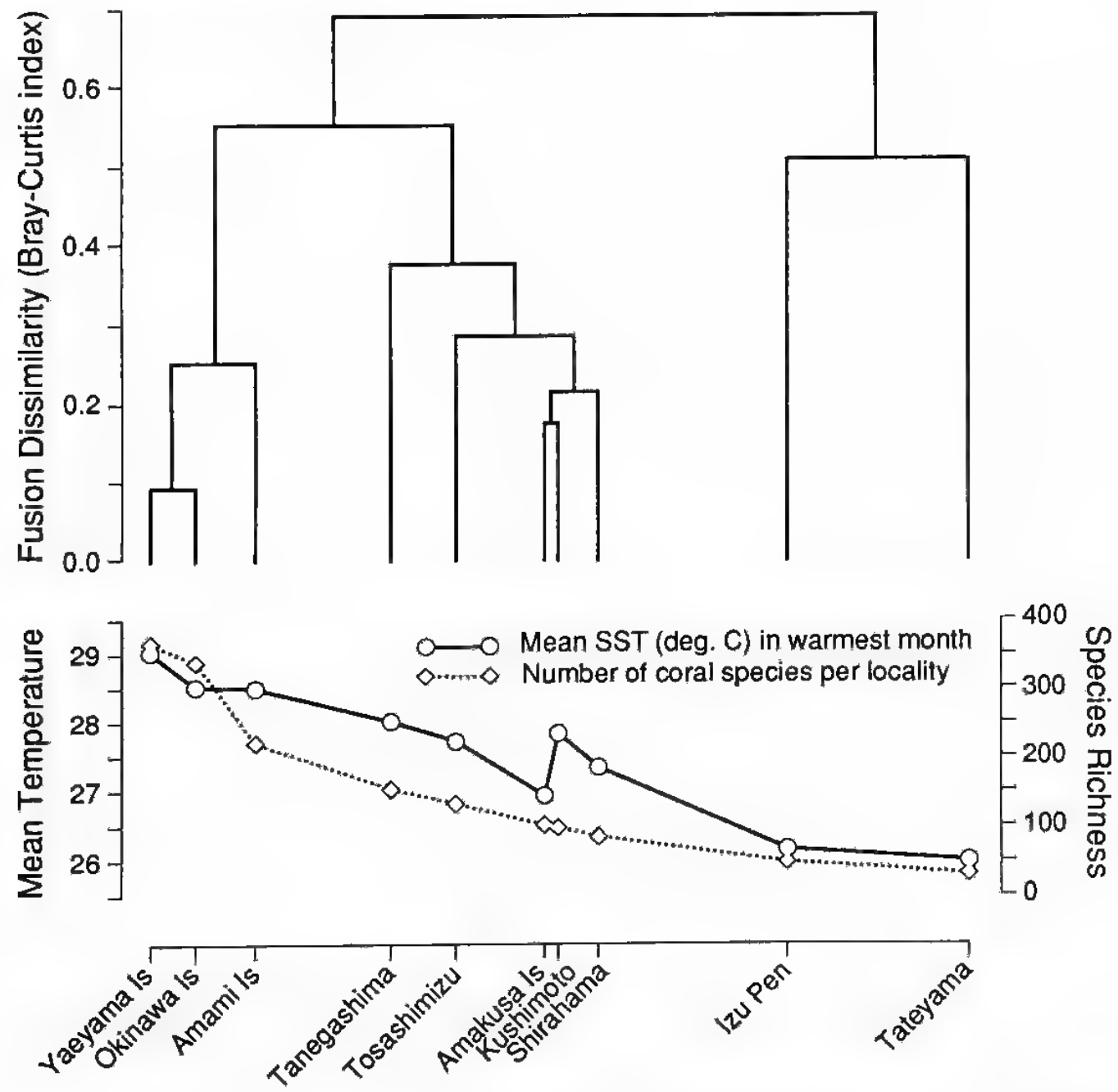

Figure 4. Average linkage clustering and unidimensional NMDS ordination of coral composition data from the 10 localities indicated. Also shown are the trends of SST (average mean of the warmest months) and species richness along the ordination axis (after Veron and Minchin, in press). 
Table 1. Summary of the distribution of hermatypic corals in the principal geographic zones of the Ryukyu Is. and mainland Japan.

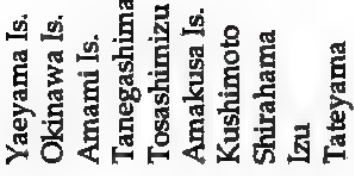

Acanthastrea amakusensis $\mathrm{X}=\ldots \times \mathrm{X} \times \mathrm{X} \times \mathrm{X}$.

Acanthastrea bowerbanki $\mathrm{x} \times$ - - $\mathrm{XX}$ X - - -

Acanthastrea echinata $\quad \mathrm{X} \times \mathrm{X} \times \mathrm{X} \times \mathrm{X} \times-\mathrm{X}^{1}$

Acanthastrea hemprichii $\quad \mathrm{X} \times \mathrm{X} \times \mathrm{XXX}$ X -

Acanthastrea hillae $\quad \mathrm{X} X \mathrm{X} X-\mathrm{X} X \mathrm{X}$ - -

Acanthastrea ishigakiensis $\mathrm{X} X \mathrm{X} X$ - - - -

Acanthastrea lordhowensis - $\mathrm{X} \times \mathrm{X} \times \mathrm{XX}-\mathrm{X}$ -

Acanthastrea rotundoflora $\times 1 \times \times \times \ldots$

Acrhelia horrescens

Acropora abrolhosensis

Acropora aculeus

Acropora accuminata

Acropora akajimensis

Acropora an thocercis

Acropora aspera

Acropora austera

Acropora brueggemanni

Acropora carduus

Acropora cerealis

Acropora clathrata

Acropora copiosa

Acropora cuneata

Acropora cytherea

Acropora danai

Acropora dendrum

Acropora digitifera

Acropora divaricato

Acropora echinata

Acropora elegans

Acropora elseyi

Acropora exquisita

Acropora florida

Acropora formosa

Acropora gemmifera

Acropora glauca

Acropora grandis

Acropora granulosa

Acropora horrida

Acropora humilis

Acropora hyacinthus

Acropora insignis

Acropora kirstyae $x+\cdots$

$x \times \ldots$

$x \times \ldots$

$x \times \cdots$

$\mathrm{x} \times \mathrm{x} \times \mathrm{x}^{-\ldots}$

$X X X-X X, X X-$

$x \times$ - . . - -

$x \times \ldots$

$x \times x \ldots$

$x \times x \ldots$

$\mathrm{X} X \ldots$

$x x-x-\cdots$

$x x-x-\ldots$

$x \times x \cdots$

$x \times x$ - - - - -

$\mathrm{X}$ - - $\mathrm{X} \times \mathrm{X} \times \mathrm{X}$ -

$X X X X-X-\cdots$

$\mathrm{X} \times \mathrm{X} \times \mathrm{X} \times$ - - -

$x \times \cdots \times-\cdots$

$\mathrm{X} X-\ldots$

$x-\ldots-\ldots$

$\mathrm{X} \times \mathrm{X}-\cdots$

$X \times X \times X \times X X$

$x \times x$ - . - .

$x \times x+\cdots$

- - XXXX - .

$\mathrm{X} X \mathrm{X}-\cdots$

$x \times x-\cdots$

$x^{1} x \ldots$

$x \times \ldots$

$\mathrm{X} \times \mathrm{X} \times \mathrm{X} \times \mathrm{X} \times$ -

$X X X=X$ - - .

$\mathrm{X} X$
$\mathrm{X} \mathrm{x}$ - - - . -

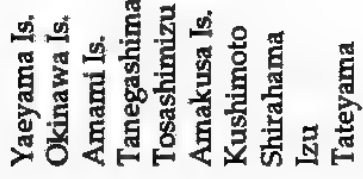

Acropora latistella

Acropora listeri

Acropora longicyathus

Acropora loripes

Acropora microclados

Acropora microphthalma

Acropora millepora

Acropora mirabilis

Acropora monticulosa

Acropora nana

Acropora nasuta

Acropora nobilis

Acropora palifera

Acropora paniculata

Acropora parilis

Acropora pruinosa

Acropora pulchra

Acropora robusta

Acropora rosaria

Acropora samoensis

Acropora samentosa

Acropora secale

Acropora sekiseiensis

Acropora selago

Acropora solitaryensis

Acropora stoddarti

Acropora striata

Acropora subglabra

Acropora subulata

Acropora tanegashimensis

Acropora tenella

Acropora tenuis

Acropora teres

Acropora tumida

Acropora valenciennesi

Acropora valida

Acropora vaughani

Acropora verweyi

Acropora wallacene

Acropora willisae

Acropora yongei

Acropora sp. 1

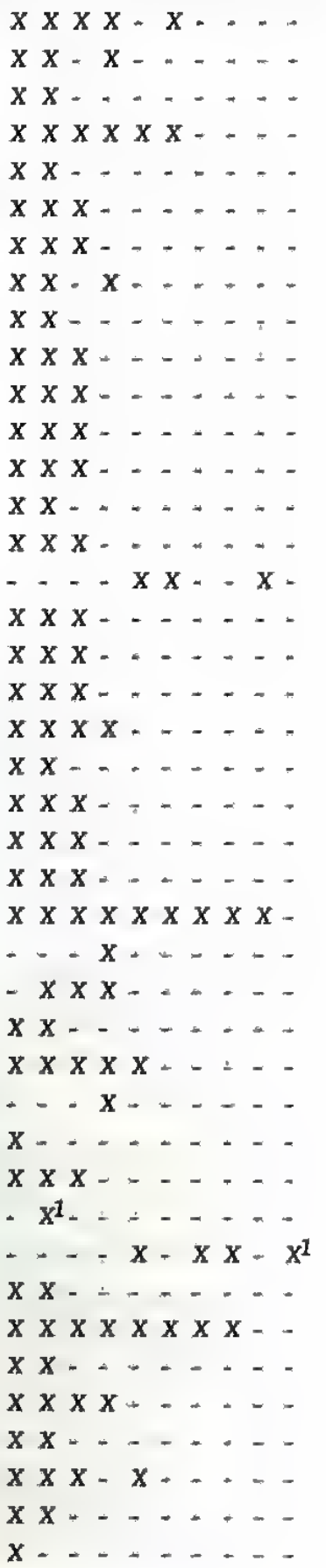

X X X X

X X - + - + -

$\mathbf{X} \times \mathbf{X} \times \mathbf{X} \times$

$\mathbf{X} \mathbf{X}+\cdots+\cdots$

$\mathbf{X} X \mathbf{X}-\cdots+\cdots$

$\mathbf{X} \boldsymbol{X} \cdot \mathbf{X} \cdots \cdots$

$\boldsymbol{X} X-\cdots+-\cdots$

$\mathbf{X} \mathbf{X}+\cdots+-$

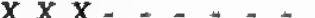

$\mathbf{X} X-\cdots+\cdots$

$\mathrm{X} \times \mathrm{X}-\cdots$

$\mathbf{X} \times \mathbf{X} \times \ldots$

X X - - - - -

$\mathbf{X} \mathbf{X}$ X - - - -

$X \mathbf{X} \times-\cdots$

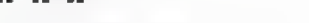

$-\cdots+x+\cdots+\cdots$

$-\boldsymbol{X} \mathbf{X} \boldsymbol{X}-\ldots+\cdots$

$\boldsymbol{X} X--\infty+\cdots$

$X \times X \times X+\cdots$

$X_{-}-\ldots+\ldots$

X X X - - - -

- $\mathbf{X}^{1}+\ldots-\ldots$

$---X-X X-X^{I}$

$\mathbf{X} \mathbf{X}-\div-\cdots$

$\mathbf{X} \times \mathbf{X} \quad \mathbf{X} \quad \mathbf{X} \quad \mathbf{X} \mathbf{X}=$

$\mathbf{X} X-\infty-\cdots+$

$X X X=-0=0$

$\boldsymbol{X} \mathbf{X}-\mathbf{X} \cdots \cdots$

X - - - . - . 


\section{SPATIAL AND TEMPORAL PATTERNS}

Acropora sp. 2

Alveopora allingi

Alveopora catalai

Alveopora excelsa

Alveopora japonica

Alveopora spongiosa

Aloeopora tizardi

Alveopora verrilliama

Anacropora forbesi

Anacropora matthai

Anacropora puertogalerae

Anacropora reticulata

Anacropora spinosa

Anacropora sp.

Astreopora explanata

Astreopora gracilis

Astreopora incrustans

Astreopora listeri

Astreopora macrostoma

Astreopora myriophthalma

Astreopora ocellata

Astreopora suggesta

Australomussa rowleyensis

Barabattoia amicorum

Blastomussa merleti

Blastomussa wellsi

Catalaphyllia jardinet

Coulastrea curvata

Caulastrea echinulata

Caulastrea furcata

Caulastrea tumida

Coeloseris mayeri

Coscinaraea columna

Coscinaraea crassa

Coscinaraea exesa

Coscinaraed hahazimaensis

Coscinaraea monile

Coscinaraea wellsi

Crenactis crassa

Ctenactis echinata

Cycloseris costulata

Cycloseris curata

Cycloseris cyclolites

Cycloseris hexagonalis

Cycloseris patelliformis

Cycloseris sinensis

Cycloseris vaughani

Cycloseris sp.

Cynarina lacrymalis

Cyphastrea agassizi

Cyphastrea chalcidicum

Cyphastrea decadia

Cyphastrea japonica
436 T.

$x \mathrm{X} \cdots \cdots$

$x \ldots \ldots$

$X X X X-X X-$

- $x x^{1} X X X X X$

$X X X-X-X-$

$x-\cdots$

$\mathrm{X} \times \mathrm{X} \cdots \cdots$

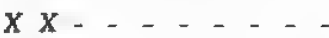

$\mathrm{X} \times$ - - - - .

$\mathrm{X} X \ldots \ldots$

$\mathrm{X}-\ldots$

$x$ - . - . . -

$x-\cdots \cdot-\cdots$

$x--x-\cdots$

$x \times x-x^{1}-x-\cdots$

$X \times X X X-X X-$

$x \times x \cdots$

- $x-x-\cdots$

$x \times \times X x^{1} x^{1} \ldots$

$\mathrm{X}-\cdots$

$\mathrm{X}-\cdots-\cdots$

$x \times x-\cdots$

$\mathrm{X} \times \mathrm{X} \times \times \times \times \times$ - -

$x \times x \cdots$

$\mathrm{X}^{1} \mathrm{X} \times \mathrm{X} \times \mathrm{X} \mathrm{X}-\mathrm{X}$

- - - - $x$ x -

- $\mathrm{x}-\cdot-\cdot-\cdot$

$x \times x \cdots$

$x \times x-\cdots$

$\mathrm{X} \times \mathrm{x} \times \mathrm{x}^{1} \mathrm{X} \times \mathrm{X}-\mathrm{x}^{1}$

$x x \cdots$

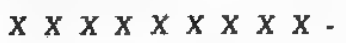

- $x \times x-$ - $x$ - -

- $x$ - - - . - -

- - $X x-X-x-$

$-x-x x-x^{I}$.

- $x--x-\ldots$

$x \times x \cdots$

$\mathrm{x} \times \mathrm{x}-\mathrm{x}^{1} \ldots$

$\mathrm{x} x \ldots$

$\mathrm{x} \times$ - . . . -

$-x x^{1}-x^{1} x^{1} x^{1} x^{1} x^{1}$

$x-\cdots$

$x x-x-\ldots$

$\mathrm{X} x$ - - - - -

$x \times x \ldots$

- - $x \ldots$

$x \times-x \times x \times x-$

$x \times x$ - . - -

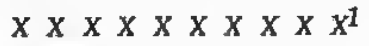

$x \times$ - - - - -

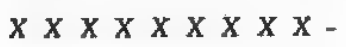

Cyphastrea microphthalma $\mathrm{X} \times \mathrm{X} \times \mathrm{X} \times \mathrm{X}-\mathrm{X}^{1}$

Cyphastrea ocellina

Cyphastrea serailia

$x-\cdots$

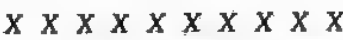

$x \times$ - - . - -

Diaseris distort

Diaseris fragilis

Diploastrea heliopora

Echinophyllia aspera

$x x^{1} \ldots \ldots$

$x \times \ldots$

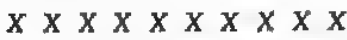

Echinophyllia echinata

$x \times x-x x-\cdots$

Echinophyllia echinoporoides $\mathrm{X}$ X X - . - -

Echinophyllia nishihirai $\quad \mathrm{X} X-\mathrm{X}_{-\cdots}-{ }_{-}$

Echinophyllia orpheensis

Echinophyllia patula

Echinopora gemmacea

Echinopora lamellosa

Echinopora mammiformis

Echinopora pacificus

Euphyllia ancora

Euphyllia cristata

Euphyllia divisa

Euphyllia glabrescens

Euphyllia paraglabrescens

Euphyllia yaeyamaensis

Favia danae

Favia faous

Favia helianthoides

Fungia fungites

Fungia granulosa

Fungia moluccensis

Fungia paumotensis

Fungia repanda

Fungia scabra

Fungia scruposa

Fungia scutaria

Fungia spinifera

Fungia valida

Galaxea astreata

Galaxea fascicularis

Gardineroseris planulata

Goniastrea aspera

Goniastrea australensis

Goniastrea deformis

Goniastrea edwardsi

Goniastrea faroulus

Goniastrea pectinata

Goniastrea retiformis

Goniopora burgosi

Goniopora cellulosa

Goniopora columna

Goniopora djiboutiensis

Goniopora fruticosa

Goniopora lobata

Goniopora minor

Goniopora pandoraensis
$X X \ldots-\cdots$

$\mathrm{x} x-\mathrm{X} \cdots$

$x \times x \cdots$

$\mathrm{X} \times \mathrm{x} \times \mathrm{x}$ - . -

$x$ - . - . - -

$\mathrm{X} \times \mathrm{X} \ldots$

$X \times X \times X X X x^{1}-x$

$x \times \cdots$

$x \ldots \ldots$

$x \times \times \cdots$

- - X - . - -

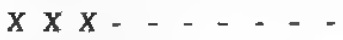

$X X-X X \ldots$

$X \quad X \quad X \quad X \quad X \quad X \quad X \quad X \quad-$

$x X-\quad x x x-\cdots$

$x \times x-x^{1}-\cdots$

$\mathrm{x} \times \mathrm{x}$ - - - -

$\mathrm{x} \times \ldots \ldots$

$x \times x \ldots$

$x \times x \ldots$

$x \times \cdots$

$x \times x^{1} \ldots$

$x \times x \times$ - - - -

- $x$ - - . - -

$\mathrm{X} X \mathrm{X}=\cdots$

$x X-x \cdots$

$\times \times \times \times x \cdots$

$\mathrm{x} \times \mathrm{x} \times \mathrm{x} \cdots$

$x \times x \times x-x^{1}-x$ -

$\mathrm{X} X \mathrm{X} \times \mathrm{X} \times \mathrm{X} \times \mathrm{X}$ -

- - XXXXXXX

$\mathrm{X} X \mathrm{X}-\mathrm{X}$ - - - -

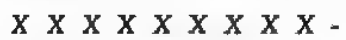

$\mathrm{x} \times \mathrm{x} \times \mathrm{x}$ - . -

$x \times \times \times \times x^{1} x^{1}-\cdots$

$x \times \ldots$

- $-x \times x+\ldots$

X X X - - - X X

$x-x x \cdots$

$x \times \ldots$

$x \times-x \times x \times x-$

$\mathrm{x} \times \mathrm{x} \cdots \cdots$

$\mathrm{X} \ldots \ldots$ 
Goniopora pendulus

Goniopora polyformis

Goniopora somaliensis

Goniopora stokesi

Goniopora stutchburyi

Goniopora tenuidens

Goniopora sp.

Gyrosmilia interrupta

Halomitra pileus

Heliofungia actiniformis

Herpolitha limax

Herpolitha weber

Heteropsammia cochlea

Hydnophora bonsai

Hydnophora exesa

Hydnophora microconos

Hydnophora rigida

Leptastrea bewickensis

Leptastrea inaequalis

Leptastrea pruinosa

Leptastrea purpurea

Leptastrea transversa

Leptoria irregularis

Leptoria phrygia

Leptoseris amitoriensis

Leptoseris explanata

Leptoseris foliosa

Leptoseris gardineri

Leptosetis hawaiiensis

Leptoseris incrustans

Leptoseris mycetoseroides

Leptoseris papyracea

Leploseris scabra

Leptoseris solida

Leptoseris yabei

Lithophyllon lobata

Lithophyllon undulatum

Lobophyllia corymbosa

Lobophyllia hatait

Lobophyllia hemprichii

Lobophyllia pachysepta

Lobophyllia robusta

Madracis asanoi

Merulina ampliata

Merulina scabricula

Montastrea annuligera

Montastrea curta

Montastrea magnistellata

Montastrea multipunctata

Montastrea oalenciennesi

Montipora aequituberculata

Montipora altasepta

Montipora angulata

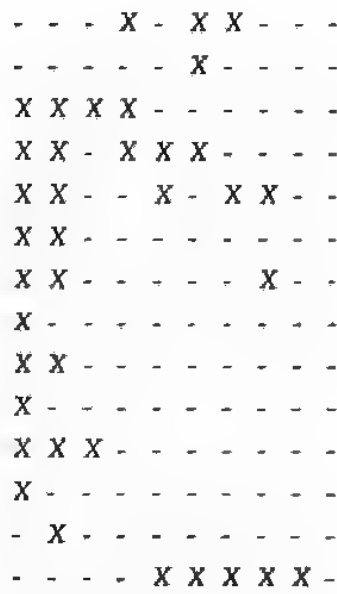

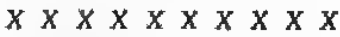

$X \times x-\cdots$

$x \times x \cdots$

$\mathrm{x} \times \times \times \times \ldots$

$x \times \ldots$

$X X X-X \cdots X-$

$X \times \times \times \times \times \times \times X x^{1}$

$x \times x \ldots$

$X \times X \cdots$

$X \times X$ - - - -

$x-\ldots$

$x \times x \ldots$

$x \times x-\cdots$

$x \ldots \ldots-\ldots$

$X \times \times \times \cdots$

$x=-\cdots$

$X \times X \times X \times X \times X X$

$x \times \ldots$

$x \times x-x \cdots$

$x x-x \ldots$

$X \times X \times \cdots$

$x \times x \ldots$

$x x-x x^{1} X X X-X^{1}$

$x \times x \times \cdots$

$X X X X=X X-\cdots$

$X X X X-X X X-$

$x x \ldots \ldots$

$x \times x \times-x x^{1}-\cdots$

- - - - $x-\cdots$

$x \times x \times \cdots$

$x \times \times \times \ldots$

$x \times \ldots$

$X \times X \times X \times X \times$ -

$X \times X \times X$ - . .

$x \times-x \cdots$

$x \times x \times x \times x^{1} x^{1}$ - .

$x \times x \times \cdots$

$x \cdots \cdots$

$x \times x=x-\cdots$
Montipora cactus

Montipora caliculata

Montipora capitata

Montipora cebuensis

Montipora danae

Montipora digitata

Montipora efflorescens

Montipora effusa

Montipora foliosa

Montipora foreolata

Montipora friabilis

Montipora gaimardi

Montipora grisea

Montipora hirsuta

Montipora hispida

Montipora hoffmeisteri

Montipora incrassata

Montipora informis

Montipora mactanensis

Montipora malampaya

Montipora millepora

Montipora mollis

Montipora monasteriata

Montipora peltiformis

Montipora samarensis

Montipora spongodes

Montipora spumosa

Montipore stellata

Montipora tuberculosa

Montipora turgescens

Montipora undata

Montipora venosa

Montipora verrucosa

Montipora sp.

Mycedium elephantotus

Mycedium robokaki

Oulastrea crispato

Oulophyllia bennettae

Oulophyllia crispa

Oxypora glabra

Oxypora lacera

Pachyseris gemmae

Pachyseris nugosa

Pachyseris speciosa

Palauastrea ramosa

Pavona bipartita

Padona cactus

Parone clacus

Paroma danai

Pavona decussata

Parona explanulata

Pavona frondifera

Proona maldivensis
$\mathrm{XX}-\cdots \cdot \cdots$

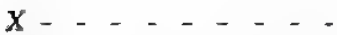

$x \ldots \ldots$

$X \cdots \cdots$

$X X X X X-X-\cdots$

$x \times x+\cdots$

$X x \cdots+\cdots$

$X X X-X X X-\cdots$

$X \times X \cdots$

$x \times \times \cdots$

$X X-X \ldots$

$x \times \ldots$

$\mathrm{X} x \ldots$

$\mathrm{x} x$ - - - . -

$X \times X X X X X X$

$x \times x \times \cdots$

$X \times X X \ldots$

$x \times-X \times x \times x$.

$x$ - - - . -

$\mathrm{X}=\ldots-\ldots$

$X X-X X X X$

$X \times X X X X X X$

$X X+X X \cdots$

$x \times \ldots$

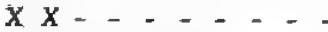

$X--X X \times X X$.

$\mathrm{x} \times \mathrm{x} \times \mathrm{X}-\mathrm{X}$ -

$x \times X \ldots$

$X X \ldots$

$X \times X \times X X X X X$

$x \times \times \times x$ - . .

$x \times x \ldots$

$\mathrm{X} \times \mathrm{x}$ - . - .

$x \times x \cdots$

$X \times X X X X X X X$

X . . . . . -

$X \times X X X X X X X X$

$x \times x \ldots$

$\mathrm{x} \times \mathrm{X} \times \mathrm{X}^{1} \mathrm{X} \times \mathrm{X}$ - -

$x$ - - - - - -

$X \times X \times X \times X \times X$.

$x x$ - - . -

$x \times x \ldots$

$x \times \times \times x-\cdots$

$x \times \ldots$

$x \times$ - . . - .

$\mathrm{x} \times \mathrm{x} \times \mathrm{x} \ldots$

$x \times-\cdots$

$x \times \ldots$

$X \times X \times X \times X$. -

$X \times X X X X-1$.

$x \times \times x$ - - -

$-X X X-\cdots$ 


\begin{tabular}{|c|c|c|c|c|c|}
\hline Paoona minuta & $X \times X X$ & $x$ & - & - & \\
\hline Pavona varians & $X X X X$ & - & - & - - & $x$ \\
\hline Pavona venosa & $x \times x$ & - & - & - - & \\
\hline Pectinia alcicornis & $X X--$ & 1 & 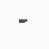 & $\because$ & \\
\hline Pectinia lactuca & $X \times X-$ & $x^{1} X$ & $x$ & $x^{1}$ & \\
\hline Pectinia paeonia & $X X X$ & $-x$ & & & \\
\hline Pectinia teres & $x--$ & - & - & - & \\
\hline Physogyra lichtensteini & $x \times--$ & -- & - & - - & \\
\hline Physophyllia ayleni & $x=-$ & $x^{1} x$ & $x$ & & \\
\hline Platygyra contorta & $X \times X X$ & $X X$ & $\mathrm{x}$ & $x 2$ & $x-$ \\
\hline Platygyra daedalea & $X \times X \times$ & $X X$ & & & $x^{1}-$ \\
\hline Platygyra lamellina & $\mathrm{x} \times-$ & - & - & - & \\
\hline Platysyra pini & $X X X-$ & $x \times$ & - & - & \\
\hline Platy\&yra ryukyuensis & $x \times x$ & $-\cdot$ & - & $-\cdots$ & \\
\hline Platygyra sinensis & $X X X X$ & $-\cdot$ & & - & \\
\hline Platygyra verweyi & $X X X X$ & - & - & - - & \\
\hline Platygyra yaeyamaensis & $x x-$ & - & - & $-\cdots$ & - \\
\hline Plerogyra eurysepta & $-x=$ & $-\cdot$ & - & -- & - \\
\hline Plerogyra sinuosa & $X \times X$ & -- & - & - - & . \\
\hline Plesiastrea versipora & $X X X X$ & $X X$ & $x$ & $x>$ & $X X$ \\
\hline Pocillopora damicomis & $x \quad x \quad x \quad x$ & $x x$ & $x$ & $x$ & - \\
\hline Pocillopora eydouxi & $\mathrm{X} \times \mathrm{X}$ & $x^{1}-$ & 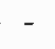 & - & - \\
\hline Pocillopora meandrina & $X X-\cdots$ & - & - & - & - \\
\hline Pocillopora verrucosa & $x \times x \times$ & $x^{1}-$ & - - & - - & - \\
\hline Pocillopora woodjonesi & $x-\cdots$ & $-\cdot$ & - & - & - \\
\hline Podabacia crustacea & $x \times x-$ & - & - & - & - \\
\hline Podabacia motuporensis & $x--\cdot$ & $-\cdot$ & - & - & - \\
\hline Polyphyllia talpina & $X X X-$ & -- & - & - & - \\
\hline Porites annae & $X X--$ & $-\cdot$ & - & - & - \\
\hline Porites aranetai & $x \times--$ & - & - & - - & - - \\
\hline Porites attenuata & $X X X-$ & -- & - & - - & - \\
\hline Porites australiensis & $X X--$ & - & - & - & \\
\hline Porites cylindrica & $x x-$ & $x^{1}$ & - - & - & - \\
\hline Porites deformis & $x---$ & $-\cdot$ & 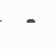 & - & \\
\hline Porites eoermanni & $x \times \cdots$ & - & - & - & \\
\hline Porites heronensis & $-X X X$ & $X X$ & $x x$ & $x$ & $X X$ \\
\hline Porites horizontalata & $X X-$ & - & - & - & \\
\hline Porites latistella & $x$ & - & -5 & - & \\
\hline Porites lichen & $x x$ & - & - & - & \\
\hline Porites lobata & $x \times X$ & $\mathrm{X}^{1}$ & 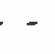 & 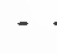 & \\
\hline Porites lutea & $x \times X$ & $x-$ & 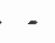 & - & \\
\hline
\end{tabular}

Porites mayeri
Porites murrayensis
Porites negrosensis
Porites nigrescens
Porites okinawensis
Porites rus
Porites sillimaniani
Porites solida
Porites stephensoni
Porites vaughani
Psammocora contigua
Psammocora decussata
Psammocora digitata
Psammocora haimeana
Psammocora nierstraszi
Psammocora profundacella
Psammocora superficial is
Psammocora vaughani
Pseudosiderastrea tayamai
Sandalolitha robusta
Scapophyllia cylindrica
Scolymia pitiensis
Seriatopora caliendrum
Seriatopora hystrix
Stylocoeniella armata
Stylocoeniella cocosensis
Stylocoeniella guentheri
Stylophora pistillata
Stylophora sp.
Symphyllia agaricia
Symphyllia radians
Symphyllia recta
Symphyllia oalenciennesii
Trachyphyllia geoffroyi
Turbinaria frondens
Turbinaria irregularis
Turbinaria mesenterina
Turbinaria peltata
Turbinaria reniformis
Turbinaria stellulata
Zoopilus echinatus

$x \cdots \cdots$

$\mathrm{X} X-\cdots$

$x-\cdots$

$\mathrm{x} \times \mathrm{x} \ldots \ldots$

- $x-\ldots-\ldots$

$x \times x \cdots$

$x \times \cdots-\ldots$

$x \times \ldots$

$x \times \ldots$

$x \times \cdots \cdots$

$x \times x \times \cdots$

- $x x \ldots$

$\mathrm{x} \times \mathrm{x} \times \ldots$

$\mathrm{X} X$ - - - - -

$X X-X-\cdots$

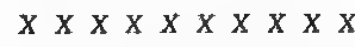

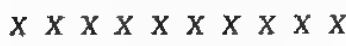

$x \times$ - - - . -

$x \times$ - - . -

$x \times x \cdots$

$x \times x \cdots$

$x \times \ldots$

X $\mathrm{x} \times \mathrm{X}_{\cdots} \cdots$

$x \times x \ldots$

$\mathrm{x} x-\mathrm{x}^{1}-\mathrm{x}^{1} \mathrm{x}^{1} \mathrm{X}^{1}$ -

$x$ - . - . -

$\mathrm{X} \times \mathrm{x} \times \mathrm{x} \times \mathrm{x} \times \mathrm{x} \times \mathrm{x}$

$\mathrm{X} \times \mathrm{x} \times \mathrm{x} \times \mathrm{x}-\cdots$

- $x-\cdots$

$x \times x \times x \cdots$

$\mathrm{X} \times \mathrm{x} \times \mathrm{x} \times \mathrm{x}_{-\cdots} \cdot-$

$x \times x-x^{1} \cdots$

$\mathrm{X} X \mathrm{X}-\mathrm{X} X \mathrm{XX}$ - -

$x x-x^{1} x x^{1} x x-$

$X X X X X X-X$

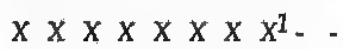

$\mathrm{X} \times \mathrm{X} \times \mathrm{X}$ - . -

- $X \times x \times x \times$ - -

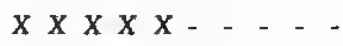

$X X X X X-X X-$

$x-\ldots$

${ }^{1}$ A record from a previous study (see text). Doubtful records from previous studies are not included, although these may be included in the text under 'Previous studies', Numerical data and analyses are from this table. 


\section{5 Collecting Stations}

All collections were made using SCUBA, with 1-6 dives at each of the collecting stations listed below. Repeated dives were made in areas of highest diversity or when specific taxa were sought. Divers with good local knowledge (see Acknowledgements) helped to select diving sites in all places except Ishigaki I. where sites were selected systematically.

This study also involved examination of a wide range of previous collections held in Japanese universities, museums and aquaria (see Acknowledgements). Essential specimens of Yabe and his colleagues were examined at Tohoku University, Sendai. This very extensive collection, occupying several large rooms, is in the process of restoration and was not generally accessible to the author at the time of the present study.

Voucher specimens of all species, together with specimens of particular taxonomic interest, were sent to the Australian Institute of Marine Science for laboratory study. Available type specimens were obtained where appropriate (see text).

\section{The Ryukyu Islands}

Well-developed coral reefs are mostly restricted to the Ryukyu Is. (Fig. 1) and (not included in this study), the Ogasawara and Volcano Is. The Ryukyu Is. are a mountainous chain of islands, forming the eastern margin of the East China Sea and the western margin of the Philippine Sea. Almost all are surrounded by welldeveloped fringing reefs and these form an island arc which is continuous with the east and west coasts of Kyushu and the southern coast of Shikoku and Honshu. Other islands in this region, including Tanegashima and Miyake I., have actively accreting areas of reefal limestone, but these are not coral reefs in a functional sense.

\section{Yaeyama Islands}

The Yaeyama Islands consist of two mountainous islands, Iriomote I. in the west and Ishigaki $\mathrm{I}$, in the east, separated longitudinally by a $22 \mathrm{~km}$-wide complex of small, low islands and shallow reefal areas, collectively known as Sekisei Lagoon. The whole of the Yaeyama Islands is surrounded by $246 \mathrm{~km}$ of fringing reef, $1-1.5 \mathrm{~km}$ offshore, broken only by narrow embayments and passes. The coastline of the two main islands is complex and the fringing reef is likewise complex, giving a wide range of reefal environments including very exposed to very protected biotopes.

The greatest complexity of coastline is on the western side of Iriomote I, and includes Sakiyama and Amitori Bays and a complex of small islands to the north of 
Amitori Bay. This study was concentrated in Amitori Bay but it also incorporates collections from Sakiyama Bay from a survey by Nishihira and Yokochi (1990). Most localities for study at Iriomote I. were selected from the results of unpublished surveys of Acanthaster outbreaks.

Study sites in Sekisei Lagoon were also selected on the basis of studies of Acanthaster outbreaks (Ui, 1985; Kamezaki et al. 1987; Nomura and Kamezaki, 1987 and Iwase and Nomura, 1988), and include the localities of highest coral diversity of the region.

Studies at Ishigaki I. (Veron, 1988) were concentrated in and around the entrance to Kabira Bay where coral diversity is at its highest. Other sites visited include most of the coastline except the northern peninsula, but virtually all coral communities except those of reef flats have been extensively damaged by Acanthaster and, on the south side of the island, by construction work and water pollution. Distribution and abundance records of Shirai and Sano (1985) are partly based on notes from a preliminary survey undertaken by Veron and Kühlemann which were not intended for publication.

1. Sakiyama Bay, Iriomote I., partly exposed slope, moderate diversity, 2-25m.

2. Amitori Bay, Iriomote $\mathrm{I}_{,}$, protected slope, high diversity, $5-20 \mathrm{~m}$.

3. Amitori Bay, Iriomote I., exposed outer slope, moderate diversity, 4-20m.

4. Amitori Bay, Iriomote I., protected slope, high diversity, $2-20 \mathrm{~m}$.

5. Amitori Bay, Iriomote $I_{,}$, very protected, low diversity, $2-15 \mathrm{~m}$.

6. Amitori Bay, Iriomote I., protected, low diversity, $2-20 \mathrm{~m}$.

7. Amitori Bay, Iriomote I, partly exposed, very low diversity, 2-35m.

8. Amitori Bay, Iriomote 1., very exposed outer slope, high diversity, 5-15m.

9. Amitori Bay, Iriomote I., mostly protected, low diversity, $5-30 \mathrm{~m}$.

10. Amitori Bay, Iriomote I., very exposed outer slope, very high diversity, 5-28m.

11. Kayama I, Sekisei Lagoon, exposed outer slope, very high diversity, $10-27 \mathrm{~m}$.

12. Kayama I,, Sekisei Lagoon, very protected lagoon, low diversity, 1-2m.

13. Kuroshima, Sekisei Lagoon, in reef mote, low diversity, 0-3m.

14. Kuroshima, Sekisei Lagoon, exposed outer slope, very low diversity, 0-25m.

15. Sekisei Lagoon, west side, very protected, luxuriant Acropora and Anacropora growth on sides of mud banks, 0-9m.

16. Aragusuku I., south side, Sekisei Lagoon, exposed outer slope, moderate diversity, 5-15m.

17. Entrance to Kabira Bay, Ishigaki I., high diversity, 0-25m.

18. Kabira Bay channel, Ishigaki I., high diversity, 2-10m.

19. Yoshiwara, Ishigaki I., partly exposed, high diversity, 2-25m.

20. Yonehara Bank, Ishigaki I., partly exposed, very high diversity, 5-35m.

21. Datefu Point, Ishigaki I., partly exposed, low diversity, $5-20 \mathrm{~m}$.

22. Yasura Point, Ishigaki I., reef flat and lagoon, low diversity, $1-8 \mathrm{~m}$.

23. Tamatori Point, Ishigaki I., reef flat and lagoon, low diversity, 1-15m.

24. Golf Course, Ishigaki I, reef flat and lagoon, low diversity, 1- 12m. 
25. North Shiraho, Ishigaki I., reef flat and outer slope, high diversity dominated by Porites cylindrica and Heliopora coerulea, 1- 15m.

26. Shiraho, Ishigaki I., reef flat, low diversity, 1-8m.

27. Miyara, Ishigaki I., reef flat,low diversity, 1-6m.

28. Oh-hama, Ishigaki I., reef flat, very low diversity, 1-8m.

29. Sakura Passage, Ishigaki I., low diversity, $5-15 \mathrm{~m}$.

30. Kannon Point, Ishigaki I., coral mostly dead, 0-4m.

31. Nagura Bay, Ishigaki I., mostly dead arborescent Acropora, 1-5m.

32. North Nagura, Ishigaki I., mostly dead, formerly very diverse, $3-15 \mathrm{~m}$.

33. Ohsaki Point, Ishigaki I., partly exposed, low diversity, 5-25m.

34. Ogan Point, Ishigaki I., partly exposed, moderate diversity, 5-35m

35. Sakieda Bay, Ishigaki I., partly exposed, moderate diversity, $5-18 \mathrm{~m}$.

36. Ishi Point, Ishigaki I., partly exposed, moderate diversity, $5-20 \mathrm{~m}$.

\section{Okinawa Islands}

The Okinawa Islands are dominated by Okinawa I., the largest of the Ryukyu Islands. The distribution of corals around Okinawa is not well known. The coastline of the northern half of the island (east and west sides) contains few bays and thus fringing reefs are exposed to heavy wave action. The most protected coastlines (east and west sides) are found midway along the east and west coasts (Nago Bay).

The Okinawa Is. also includes several small island archipelagos to the west, of which the Kerama Is. have the most luxuriant coral. The Kerama Is. are a complex of high islands interconnected by fringing reefs forming a wide variety of biotopes. Coral recovery since Acanthaster outbreaks in the early 1980's has been more extensive than observed in the Yaeyama Islands.

37. Cape Zanpa, Okinawa I., exposed outer slope, moderate diversity, 0-35m.

38. Minna I., partly protected, moderate diversity, $5-10 \mathrm{~m}$.

39. Sesoko I, boat harbour, moderately low diversity, 0-3m.

40. Sesoko $I_{\text {, }}$ patch reef, low diversity, $3-25 \mathrm{~m}$.

41. Ginanotatejyan, Aka I., protected reef flat, very high diversity, 1- $5 \mathrm{~m}$.

42. Ago Bay, Zamami I., very protected, soft substrate, low diversity, $16-25 \mathrm{~m}$.

43. Fukaji $I$, west side, fringing reef, moderate diversity, $3-14 \mathrm{~m}$.

44. Between Geruma and Fukaji Is., west side, fringing reef, very high diversity, 4-15m.

45. Ago Bay, Zamami I., very protected, soft substrate, low diversity, 18-25m.

46. Yakarahama, Aka I., fringing reef, high diversity, $8-16 \mathrm{~m}$.

47. Kuba I., west side, fringing reef, high diversity, $8-20 \mathrm{~m}$.

48. Ginanohama, Aka I., fringing reef, high diversity, $2-20 \mathrm{~m}$.

49. Tonaki $I_{\text {, }}$ reef flat lagoon, moderate diversity, $1-5 \mathrm{~m}$.

50. Tonaki I., north-west side, fringing reef outer slope, high diversity, $5-20 \mathrm{~m}$.

51. Tonaki I., south-east side, fringing reef, low diversity, $5-20 \mathrm{~m}$.

52. Cape Dana, Iheya I., soft substrate, low diversity, $5-8 \mathrm{~m}$. 
53. Cape Yone, Iheya I., fringing reef, low diversity, 3-25m.

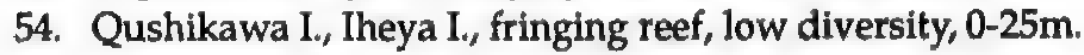

\section{Amami Islands}

The Amami Islands are composed of Amami I. and Tokunoshima I., together with many smaller islands. Amami I., to the north, together with a complex of adjacent smaller islands, makes up the largest land mass of the group. These islands were not included in the present study. Tokunoshima I., to the south, is approximately oval in shape. The coastline, and consequently the reefs, of the western side, are relatively straight and the habitat diversity low. The central eastern side has a complex of irregular reefs which form a very wide range of biotopes.

55. Ikema, Tokunoshima I., protected fringing reefs, high diversity, 3-15m.

56. Kaminomine, Tokunoshima I., outer reef slope, very high diversity, 5-35m.

57. Kan'nishi Point, Tokunoshima I., protected reefs, high diversity, $0-14 \mathrm{~m}$.

\section{Mainland Japan}

The corals of mainland Japan (Fig. 2) grow directly on terrigenous rock substrata and thus lack the range and quality of habitats normally associated with large coral reefs, especially lagoons with areas of soft substrate protected from strong wave action, and slopes which have good exposure to light but which are sufficiently steep to restrict wave surge and the associated abrasion of coarse terrigenous sediment. There are several other major differences between reefal and non-reefal coral communities: the latter may have a very high percentage cover in shallow water, but these are usually Acropora-dominated to the exclusion of almost all other species; they have a low species diversity, and, because non-reefal communities cannot form their own substrate, they are generally restricted to small areas within narrow environmental constraints (commonly a $2-8 \mathrm{~m}$ depth range, with exposure to some current and moderate but not strong wave action). The benthos of most high latitude mainland localities studied was dominated by macro-algae, notably Sargassum spp. and Ecklonia cava. In these cases, competitive exclusion between corals and macroalgae appears to be of primary importance to both local distribution and the abundance of most coral species. The dominance of macro-algae causes most nonreefal and reefal coral communities to exist in very different trophic environments, the former likely to be greatly affected by seasonal cycles.

Tanegashima is of particular biogeographic interest as it is situated immediately north of the northern limit of true coral reef development. The island is elongate in a north-south direction and has an irregular, rocky coastline for most of its length. There are small patches of reefal limestone along the south-east coast, but most coral; including that of the richest areas (around Ojioya Port) grows directly on non-carbonate rock substrate, mostly sandstone and conglomerates. As with most non-reefal locations, corals are very restricted in their local distribution, with a high proportion of the coastline having few, or no colonies. 
The Amakusa Islands of west Kyushu have few corals except for the small rock outcrop of O-gase and the relatively diverse outcrop on the west coast of Kuwashima, near Ushibuka. The latter is an bed of coral extending from an extensive area of tabular Acropora in shallow water to and area of maximum diversity at $11 \mathrm{~m}$ depth, where rock substrate meets sand.

Corals of south-west Shikoku are situated in several small areas in a wide range of bathymetry and exposure to wave action and currents. In the present study, corals were collected from a series of rocky promontories and embayments within $4 \mathrm{~km}$ of the city of Tosashimizu. In some areas, notably collecting station 78 , grazing echinoids had removed virtually all benthos including corals and macro-algae, in others, notably collecting station 74, Acropora almost totally covers the substrate as it does at Kuwashima (Amakusa Is.) and Kushimoto.

The Kushimoto Marine Park and some places around Shirahama contain pockets of corals growing on irregular rock outcrops. Most occur in shallow, partly protected biotopes. At Kushimoto, these pockets are extensive in places, with corals being the dominant benthos.

The environmental diversity of the Izu Peninsula is very great, reflecting the irregular mountainous terrain both above and below water. Only four corals were found at Nabeta and Shimoda Bays: Oulastrea crispata, Porites heronensis, Porites okinawensis and Alveopora japonica. Oulastrea is uncommon and forms small colonies only at collecting station 91 . The other species were also at this station and Porites heronensis was also found in intertidal rock pools at the western entrance to the Bay. The high coral diversity areas of Izu are either side of the entrance to Nakagi Port. The western entrance is very rugged and exposed to strong wave action. Corals, intermixed with algae, are predominantly in the most exposed areas and most occur to depths of at least $30 \mathrm{~m}$. The highest diversity of all, collecting station 92, is at the northern tip of Hirido island, which forms the eastern edge of Nakagi Port, at the southern tip of the peninsula. Most species were found at this station, at various depths between 2 and $22 \mathrm{~m}$, the depth limit of rock substrate.

There is less environmental diversity at Tateyama than at any of the other principal geographic regions studied. The foreshore consists of small beaches interspersed between low rocky promontories. All intertidal and subtidal areas are likewise either sand or flat rock, mostly protected from strong wave action but with relatively turbid water. The proportion of rock substrate gradually decreases offshore. It is dominated by kelp (Ecklonia and Sargassum) at depths of approximately $10 \mathrm{~m}$ or less and the coral fauna is restricted to occasional colonies of Favia speciosa, Psammocora profundacella, Oulastrea crispata and Alveopora japonica. At greater depth the benthos gradually becomes more diverse until, at $15 \mathrm{~m}$ or more, it is dominated by a wide diversity of mostly temperate fauna of sponges and coelenterates. The abovementioned species remain the most common corals along with Cyphastrea serailia, Echinophyllia aspera, Hydnophora exesa, Porites heronensis and Psammocora superficialis. Other species listed in Table 1 are recorded from one (in the case of 
Blastomussa wellsi) or a few colonies only. The highest diversity observed (collecting station 96) was at 16-18 $\mathrm{m}$ depth where the substratum was deformed giving vertical and undercut surfaces. The water is much less turbid in this region than at shallower depths.

58. Sumiyoshi, Tanegashima, exposed rock substrate, low diversity, $2-7 \mathrm{~m}$.

59. North of Ojioya Port, Tanegashima, exposed rock substrate, low diversity, 25-35m.

60. South of Ojioya Port, Tanegashima, exposed rugged rock substrate, high diversity, $1-9 \mathrm{~m}$.

61. South of Ojioya Port, Tanegashima, protected rock substrate, low diversity, 1-9m.

62. South of Ojioya Port, Tanegashima, exposed rugged rock substrate, high diversity, 5-25m.

63. North of Ojioya Point, Tanegashima, very exposed submerged rock substrate, low diversity, $5-25 \mathrm{~m}$.

64. South of Ojioya Point, Tanegashima, rocky shore, moderate diversity, 2$15 \mathrm{~m}$.

65. $10 \mathrm{~km}$ south of Tanegashima, very exposed submerged rock substrate, low diversity, $10-27 \mathrm{~m}$.

66. South of Kumano Harbour, Tanegashima, exposed rock substrate, moderate diversity, $5-17 \mathrm{~m}$.

67. East of Kumano Harbour, Tanegashima, protected rocky ridge, moderate diversity $3-12 \mathrm{~m}$,

68. Kuwashima, Amakusa Is., partly protected bay, partly protected rocky slope, high diversity, $2-11 \mathrm{~m}$.

69. O-gase, Amakusa Is., exposed rock substrate, moderate diversity, 0-15m.

70. Otomekokashi, Amakusa Is., partly exposed, very low diversity, $0-15 \mathrm{~m}$.

71. Tsuji I., Amakusa Is. protected, very low diversity, 2-12m.

72. Tomioka Point, Amakusa Is,, very protected, very low diversity, 3-7m.

73. South of lighthouse, Shimizu Port, Shikoku, rugged rock terrain sloping to sand, partly exposed, moderate diversity, 4-18m.

74. Unohae, Tosashimizu, Shikoku, rugged rock terrain, exposed, Acropora very dominant at $<8 \mathrm{~m}, 7-16 \mathrm{~m}$.

75. Hirabae, Tosashimizu, Shikoku, rugged rock pinnacle, exposed, moderate diversity, $15-28 \mathrm{~m}$.

76. North of lighthouse, Shimizu Port, Shikoku, irregular rock substrate sloping to sand, $0-12 \mathrm{~m}$.

77. Adjacent to lighthouse, Shimizu Port, Shikoku, irregular rock substrate sloping to sand, $0-15 \mathrm{~m}$.

78. Hinare, Tosashimizu, Shikoku, very rugged terrain, strong currents, low diversity, 10-30m. 
79. Ichinohae, Tosashimizu, Shikoku, irregular rock substrate, low abundance but high diversity, 15-25m.

80. Near the Sabiura Marine Park Research Station (Kushimoto region), partly protected, moderate diversity, $1-14 \mathrm{~m}$.

81. north-west coast of Shionomisaki (Kushimoto region), partly protected, low diversity with conspicuous Catalaphyllia, 2-12m.

82. $1 \mathrm{~km}$ east of the Sabiura Marine Park Research Station (Kushimoto region), partly protected, moderate diversity, especially Faviidae, 0-4m.

83. West Shionomisaki (Kushimoto region), algal dominated irregular rock slope, moderate diversity, $15-20 \mathrm{~m}$.

84. Off west tip of Sirahama, partly protected, moderate diversity, 0-6m.

85. Detached rock outcrop, south-west Tanabe Bay (Shirahama region), exposed, very low diversity, $5-20 \mathrm{~m}$.

86. South of Shirahama, partly protected low diversity, $2-12 \mathrm{~m}$.

87. South Kanayama Bay (Shirahama region), exposed, moderate diversity, 10-25m.

88. Adjacent to the Seto Marine Biological Laboratory (Shirahama region), partly protected, moderate diversity, $0-8 \mathrm{~m}$.

89. West side Nabeta Bay, Shimoda, Izu, rock face, partly protected, sloping steeply to sand, no coral, $0-15 \mathrm{~m}$.

90. Shimoda Bay, Shimoda, Izu, rock face, very protected, sloping to sand, no coral, $0-8 \mathrm{~m}$.

91. East side, Nabeta Bay, Shimoda, Izu, irregular rock substrate, protected, low diversity, $0-5 \mathrm{~m}$.

92. Tonai, Nakagi, Izu, rugged rock pinnacles, very exposed, has most species of the region, $0-25 \mathrm{~m}$.

93. Hirido, near Nakagi, Izu, rugged rock substrate sloping to sand, partly exposed, has the highest diversity of the region, $2-22 \mathrm{~m}$.

94. Opposite Banda Marine Laboratory, Tateyama, flat rock substrate sloping to sand at $9 \mathrm{~m}$, partly protected, low diversity.

95. Hasama, Tateyama, flat rock substrate surrounded by sand, partly protected, low diversity, $14-18 \mathrm{~m}$.

96. Hasama, Tateyama, flat rock substrate surrounded by sand, partly protected, low diversity, $12-15 \mathrm{~m}$.

97. Hasama, Tateyama, flat rock substrate surrounded by sand, partly protected, low diversity, 14-18m.

98. Near Banda Marine Laboratory, Tateyama, irregular rock substrate surrounded by sand, partly protected, has most species of the region, $16-22 \mathrm{~m}$. 


\section{票 \\ Editorial Note}

\section{Locality Records}

Locality records listed under 'This study' are from the principal coral zones indicated above. They are primarily from the author's original field work (including Veron, 1988), but also include various additional records from recent collections, publications and unpublished surveys on which the author has worked.

Locality records listed under 'Previous records' are from publications previous to the present authors work and are intended as a guide only. In most cases, collected coralla have not been re-examined and thus they are not synonymies. Only original records are listed.

Locality records from all sources are combined in Table 1. The species inventory for each of the resulting zones is considered to be highly representative.

References to colour illustrations are given to aid field identifications. Incorrect or doubtful references are not noted except where there is particular need to do so. 


\section{6 \\ Family \\ Astrocoeniidae \\ Koby, 1890}

The genus Stylocoenia Edwards and Haime, 1848 was used by Yabe and Sugiyama (1932) for S. japonica Yabe and Sugiyama, 1932 and S. hanzawai Yabe and Sugiyama, 1933. The former species was originally described as 'two small fragments', 'more or less abraded' from the north-eastern Izu coast (Yabe and Sugiyama, 1932b, 1932c) which appear to have been lost, but which are probably synonyms of S. armata. The latter species was placed in Astrocoenia by Wells (1935) and Stylocoeniella by Yabe and Sugiyama (1935b).

\section{Genus Stylocoeniella}

Yabe and Sugiyama, 1935

\section{Stylocoeniella guentheri}

Bassett-Smith, 1890

Generally common throughout the distribution range, especially on outer slopes. Is very polymorphic. Colonies have encrusting to massive or columnar growth forms with nodular surfaces and are commonly up to $1 \mathrm{~m}$ diameter throughout the distribution range. Encrusting colonies have superficial, widely spaced corallites and relatively weak development of coenosteum styles. Columellae are boss-like and fused to first cycle septa to thin, style-like, and not superficially fused. Second cycle septa are sub-equal to abortive. Much of this variation may occur in different parts of a single large corallum. Calice structures are usually highly granulated. No geographic variation in structure was observed. Colonies are mostly mottled dark green. Rarely red, brown or cream colonies, with or without light blue tentacles occur in mainland localities. Illustrated in colour: Nishihira (1988), Uchida and Fukuda (1988a).

The holotype of Stylocoeniella hanzawai (Yabe and Sugiyama, 1932), the type species of Stylocoeniella, was re-examined during the present study and found to be a junior synonym of S. guentheri, not S. armata as indicated by Wells (1966a) and 
subsequent authors. It was initially described by Yabe and Sugiyama (1932c) as Stylocoenia hanzawai and subsequently placed in the genus Stylocoeniella by Yabe and Sugiyama (1935b).

\section{Records:}

This study: Yaeyama, Okinawa and Amami Is., Tanegashima, Amakusa Is., Kushimoto, Shirahama.

Previous studies: Yabe and Sugiyama (1932c) (as Stylocoenia hanzawai): Amami Is.; Yabe et al. (1936): (as S. hanzawai) North to Suruga Bay; Eguchi (1973) (as S. hanzawai): Tsushima; Yamazato et al. (1978): Okinawa; Tribble and Randall (1986): Miyake I.; Kawaguti (1983) (as S. hanzawai): Yaeyama Is.

\section{Stylocoeniella armata}

(Ehrenberg, 1834)

Much less common than $S$. guentheri; usually encrusting. Corallites are larger than those of $S$. guentheri, septa are thick, sub-equal, and have margins which either slope gradually to the columella, or plunge steeply. All coralla studied have at least some corallites with well-developed 'pseudo-pali', as described by Yabe and Sugiyama (1935b). Usually pale cream or green. Illustrated in colour: Nishihira (1988).

\section{Records:}

This study: Yaeyama and Okinawa Is.

Previous studies: ?Yabe and Sugiyama (1932a, b) (as Stylocoenia japonica): Izu; Utinomi (1966, 1971): north-east Kyushu and Kii coast; Eguchi (1971): Goto I.; Eguchi (1974): Yaeyama Is.; Eguchi and Miyawaki (1975) and Anonymous (1977): Kushimoto.

\section{Stylocoeniella cocosensis}

Veron, 1990

A rare and very cryptic species recorded only from the Ryukyu Is. and the Cocos (Keeling) Is. Coralla are encrusting. Corallites are irregular in size, shape and orientation, and are inclined on the corallum surface. Calices are oval or crescentshaped, depending on the degree of development of the associated style and degree of inclination on the corallum surface. The coenosteum is covered by spinules similar in size and appearance to those of other Stylocoeniella, except that their tips have Palauastrea-like elaborations. Most corallites on convex surfaces have style-like hoods. Septa are in two sub-equal cycles, similar to those of $S$. armata. 
Pseudo-pali are weakly developed in some corallites. Columellae are weakly developed. The only recorded colour is greenish-brown.

\section{Records:}

This study: Yaeyama Is.

Previous studies: Veron (1990): Yaeyama Is. 


\section{7 \\ Family
Pocilloporidae \\ Gray, 1842}

\section{Genus Pocillopora}

Lamarck, 1816

\section{Pocillopora damicornis}

(Linnaeus, 1758)

Very common throughout the Ryukyu Is., generally uncommon at Tanegashima and mainland localities. Commonly forms compact clumps on upper reef slopes exposed to strong wave action. Ryukyu Is. coralla have a similar range of variation as those from the Great Barrier Reef; mainland coralla are mostly small and thick-branched, as are coralla from the higher latitudes of eastern and western Australia. Usually pale to dark brownish-purple or green, sometimes pink in the Ryukyu Is. and Tanegashima, dark yellow-grey to brownish-purple in mainland localities. Recorded in most studies north to Shirahama. Illustrated in colour: Masuda and Hayashi (1989), Nishihira (1988), Uchida and Fukuda (1988a).

\section{Records:}

This study: Yaeyama, Okinawa and Amami Is., Tanegashima, Tosashimizu, Amakusa Is., Kushimoto, Shirahama.

Previous studies: Yabe et al. (1936): north to near Kushimoto; Utinomi (1965b, 1971): north-east Kyushu and south-west Shikoku; Ooishi (1970): Ogasawara and Volcano Is.; Kikuchi (1968): Amakusa Is.; Yagi (1970): south-west Shikoku; Anonymous (1970): Ehime coast; Eguchi (1974): Yaeyama Is. and Kerama Is.; Eguchi and Miyawaki (1975) and Anonymous (1977): Kushimoto; Yamazato et al. (1978): Okinawa; Kawaguti (1983): Yaeyama Is.; Tribble and Randall (1986): Miyake I.; Shirai (1986): Kii coast; Habe (1989): Iriomote I.; Chou and Yamazato (1990): Okinawa; Tachikawa (in prep., 1991): Ogasawara Is. 


\title{
Pocillopora verrucosa
}

(Ellis and Solander, 1786)

Common on exposed upper reef slopes throughout the Ryukyu Is., rare at Tanegashima. Has a similar range of variation on the Great Barrier Reef. A single corallum collected from Tanegashima shows no distinctive characters. Usually brown or pink in shallow water. Illustrated in colour: Shirai (1980) (as P. setchelli), Nishihira (1988), Uchida and Fukuda (1988a).

\section{Records:}

This study: Yaeyama, Okinawa and Amami Is., Tanegashima.

Previous studies: Yabe et al. (1936) (as P. meandrina nobilis, $P$. setchelli and $P$. verrucosa): Ryukyu, Ogasawara and Daito Is.; Ooishi (1970): Ogasawara and Volcano Is.; Anonymous (1970): Ehime coast; Eguchi (1974) (as P. verrucosa and P. meandrina nobilis): Yaeyama Is.; Habe (1989): Iriomote I.; Chou and Yamazato (1990): Okinawa; Tachikawa (in prep., 1991): Ogasawara Is.

\section{Pocillopora meandrina}

\author{
Dana, 1846
}

Common on some exposed reef slopes. Has a similar range of variation on the Great Barrier Reef. As in other countries, this species may be difficult to separate from $P$. verrucosa unless both occur in close proximity. Usually pale brown in colour. Illustrated in colour: Nishihira (1988), Uchida and Fukuda (1988a).

\section{Records:}

This study: Yaeyama and Okinawa Is.

Previous studies: Eguchi (1974) (as P. meandrina nobilis): Kerama Is.; Habe (1989): Iriomote I.

\section{Pocillopora woodjonesi}

Vaughan, 1918

Rare, difficult to distinguish from $P$. eydouxi and has ill-defined corallite characters requiring further study. Has a more lax growth form than $P$. eydouxi in the same biotope. Colonies were green at Aragusuku I., Yaeyama Is.

\section{Records:}

This study: Yaeyama Is.

Previous studies: Kawaguti (1983): Yaeyama Is.; Habe (1989): Iriomote I. 


\section{Pocillopora eydouxi}

Edwards and Haime, 1860

Generally uncommon except on some upper reef slopes and shallow biotopes subject to strong currents. Has a similar range of variation on the Great Barrier Reef and has the same environment preferences. Shows no geographic variation. Uniform brown or pink in colour, the latter occurring in shallow water only, the same as $P$. verrucosa. Illustrated in colour: Shirai (1980) (as $P$. modumanensis), Masuda and Hayashi (1989), Nishihira (1988), Uchida and Fukuda (1988a).

\section{Records:}

This study: Yaeyama, Okinawa and Amami Is.

Previous studies: Yabe et al. (1936) (as P. modumanensis): Ryukyu Is.; Anonymous (1970): Ehime coast; Eguchi (1974) (as P. modumanensis): Yaeyama Is.; Kawaguti (1983): Yaeyama Is.; Habe (1989): Iriomote I.; Tachikawa (in prep., 1991): Ogasawara Is.

\section{Genus Seriatopora}

Lamarck, 1816

\section{Seriatopora hystrix}

Dana, 1846

Common throughout the distribution range except in high energy environments, where it is seldom found. Colonies may show wide, continuous variation within the same biotope, especially in deeper ( $>20 \mathrm{~m}$ depth, eg, station 42 ) or very protected water (eg. station 15), where colonies are finely branched, but show considerable variation in branch thickness. An early re-coloniser, along with Pocillopora damicornis and Stylophora pistillata after Acanthaster damage. Colonies frequently contain gall-forming crabs (Hapalocarcinus marsupialis). They are mostly cream or yellow, sometimes pink, especially in shallow water. Illustrated in colour: Shirai (1980) (as S. crassa, S. octopera, S. hystrix, and S. caliendrum var. subtilis), Masuda and Hayashi (1989), Nishihira (1988), Uchida and Fukuda (1988a).

\section{Records:}

This study: Yaeyama, Okinawa and Amami Is.

Previous studies: Yabe et al. (1936): Ryukyu Is.; Eguchi (1974); Yaeyama Is. and Kerama Is.; Yamazato et al. (1978) (as S.); Habe (1989): Iriomote I. S. hystrix and S. angulata): Okinawa; Kawaguti (1983) (as S. angulata and S. hystrix): Okinawa; Chou and Yamazato (1990): Okinawa. 


\section{Seriatopora caliendrum}

Ehrenberg, 1834

Relatively common on some lower reef slopes. Coralla are similar to those from the Great Barrier Reef. Colonies are usually cream in colour. Illustrated in colour: Nishihira (1988), Uchida and Fukuda (1988a).

\section{Records:}

This study: Yaeyama, Okinawa and Amami Is.

Previous studies: Yabe et al. (1936): north to Okinawa Is.; Eguchi (1974): Yaeyama Is. and Kerama Is.; Kawaguti (1983): Yaeyama Is.

\section{Genus Stylophora}

Schweigger, 1819

There appears to be no significant differences between the Stylophora of Japan and that of the Philippines. Further study (as indicated in Veron and Hodgson, 1989) suggests that Stylophora dendritica Nemenzo is not a Stylophora, but a synonym of Seriatopora caliendrum.

\section{Stylophora pistillata}

(Esper, 1797)

Rare in exposed biotopes; seldom (never in higher latitudes) forms thickbranched colonies common in tropical localities. Common on lower reef slopes throughout the distribution range except Amakusa Is. Shallow water colonies are usually deep pink; finely branching colonies from deeper or protected water are commonly pale cream, sometimes pink, rarely green at Tanegashima. Illustrated in colour: Shirai (1980) (as S. pistillata and S. mordax), Masuda and Hayashi (1989), Nishihira (1988), Uchida and Fukuda (1988a).

\section{Records:}

This study: Yaeyama, Okinawa and Amami Is., Tanegashima, Tosashimizu, Amakusa Is. (laboratory specimen only).

Previous studies: Yabe et al. (1936) (as S. pistillata and S. mordax): north to south-west Shikoku; Eguchi (1968) (as Stylophora sp.); Sagami Bay; Kikuchi (1968): Amakusa Is.; Anonymous (1970): Ehime coast; Eguchi and Mori (1973): Tateyama; Eguchi (1974): Kerama Is.; Yamazato et al. (1978): Okinawa; Kawaguti (1983): Yaeyama Is.; Habe (1989): Iriomote I. ; Chou and Yamazato (1990): Okinawa. 


\section{Stylophora sp.}

Variation within this supposed species has been studied from a series of nine specimens from Ago Bay. At one extreme these have all the characters of Seriatopora, including corallites arranged in rows. At the other they integrade with a deep water ecomorph of Stylophora pistillata. Specimens from the Philippines are clearly the same species, but this cannot be named until the present species is better defined, especially in relation to S. pistillata. Several nominal species of both Stylophora and Seriatopora have similar structure, the closest being Stylophora flabellata Quelch, 1886 from the Philippines, believed by Veron and Hodgson (1989) to be a junior synonym of $S$. pistillata. Very pale brown or cream in colour.

\section{Records:}

This study: Okinawa Is.

Previous studies: Not recorded.

\section{Genus Palauastrea}

Yabe and Eguchi, 1941

\section{Palauastrea ramosa}

Yabe and Sugiyama, 1941

Forms large stands at Sakiyama Bay, Iriomote I. (Nishihira, in prep.); commonly forms compact colonies up to $0.5 \mathrm{~m}$ diameter in Sekisei Lagoon (station 12 and 13) and also commonly forms lax colonies $>2 m$ diameter in Ago Bay (station 42). Shallow water colonies are mostly mottled dark cream and green; deeper water colonies mostly pale cream or brown. Illustrated in colour: Shirai (1980) (as P. ramosa and P. ramosa iwayamaensis), Uchida and Fukuda (1988a).

There is substantial variation in coralla from different environments. Coralla from shallow water have short compact branches with proliferous coenosteum styles (analogous to those of Stylocoeniella) on their tips, have corallites that are relatively deep and have two clearly developed (even sub-equal) septal cycles. Coralla from deep water have finer, open branches, form larger colonies, and have relatively superficial corallites with abortive second cycle septa. The former is at the extreme of the range of variation found on the Great Barrier Reef. As this variation is continuous and clearly environment-correlated, it appears that only one species is involved. The subspecies Palauastrea ramosa iwayamaensis Yabe and Sugiyama, 1941 is not clearly correlated with this variation. 


\section{Records:}

This study: Yaeyama and Okinawa Is.

Previous studies: Kawaguti (1983): Yaeyama Is.; Habe (1989): Iriomote I.

\section{Genus Madracis}

Edwards and Haime, 1849

\section{Madracis asanoi}

Yabe and Sugiyama, 1941

It is not known if this is a hermatypic species or not. The only corallum studied had fine, irregular branches, a growth form more suggestive of an ahermatypic species than the much more robust (hermatypic) $M$. kirbyi. Yabe and Sugiyama (1936) list characters separating this species from M. kauaiensis Vaughan (from Hawaii), most of which are ill-defined in the present specimen.

\section{Records:}

This study: Kushimoto (laboratory specimen only, from $40 \mathrm{~m}$ depth).

Previous studies: Eguchi (1968): Sagami Bay; Anonymous (1977): Kushimoto; Miyawaki (1978): Kushimoto; Shirai (1986): Kii coast. 


\section{8 \\ Family
Acroporidae \\ Verrill, 1902}

\section{Genus Montipora}

de Blainville, 1830

\section{Montipora monasteriata}

(Forskål, 1775)

Common on upper reef slopes. Forms tiers of brown plates in Sekisei Lagoon (station 15). Is primarily distinguished from $M$. tuberculosa by having smaller corallites, a coarse reticulum and a relatively uniform cover of papillae (or tuberculae) which are not concentrated around the corallites. Is often brightly coloured eg. pale pink with orange polyps. Has a similar range of variation on the Great Barrier Reef.

\section{Records:}

This study: Yaeyama and Okinawa Is., Tanegashima, Tosashimizu.

Previous studies: Habe (1989): Iriomote I.; Tachikawa (in prep., 1991): Ogasawara Is.

\section{Montipora tuberculosa}

(Lamarck, 1816)

Common. Corallites are both immersed and exsert and are surrounded (partly or entirely) by thecal papillae which are more abundant than reticulum papillae. Commonly mauve or pale brown in colour, sometimes with white reticulum papillae. Collected specimens are similar to Great Barrier Reef coralla. Illustrated in colour: Uchida and Fukuda (1988a).

\section{Records:}

This study: Yaeyama and Okinawa Is.

Previous studies: Kawaguti (1983): Yaeyama Is.; Chou and Yamazato (1990): Okinawa. 


\section{Montipora hoffmeisteri}

Wells, 1954

Common in the Yaeyama Is., especially in exposed sites (eg. stations 11 and 14). Colonies are usually encrusting. Corallites are minute and are imbedded in tuberculae. Has a wide range of colours: grey or brown or bright red, green or purple. Collected specimens are similar to Great Barrier Reef coralla.

Records:

This study: Yaeyama, Okinawa and Amami Is., Tanegashima

Previous studies: Tachikawa (in prep., 1991): Ogasawara Is.

\section{Montipora millepora}

Crossland, 1952

Probably common in the Yaeyama Is., especially in exposed sites, where colonies are usually encrusting. Tuberculae seldom contain corallites. Collected specimens are similar to Great Barrier Reef coralla. Usually dark brown in colour. Illustrated in colour: Uchida and Fukuda (1988a).

Records:

This study: Yaeyama and Okinawa Is., Tosashimizu, Amakusa Is., Kushimoto, Shirahama

Previous studies: Tachikawa (in prep., 1991): Ogasawara Is.

\section{Montipora mollis}

Bernard, 1897

Columnar growth forms of this species have previously been called Montipora sp. 1 by Veron and Wallace (1984) and Veron and Hodgson (1989). Further collecting in Japan has established that this growth-form is a shallow-water ecomorph of M. mollis. Illustrated in colour: Uchida and Fukuda (1988a).

Colonies are encrusting or are of indeterminate shape or consist of irregular, compact, highly fused columnar or nodular upgrowths. Corallites are widely spaced, immersed, the theca indistinguishable, or nearly so. They are small $(0.5-$ $0.7 \mathrm{~mm}$ diameter) and uniform in appearance. There are no thecal or reticulum papillae, the coenosteum being uniformly spongy, medium-fine, with moderately to highly elaborated outer tips. Primary septa are well-developed, up to $3 / 4$ the calice radius, each consisting of a row of inward projecting spines, becoming plate-like 
near the theca. One pair of primary septa may be slightly larger than the others. Second cycle septa are weakly developed, usually incomplete, $<1 / 3$ the calice radius.

\title{
Records:
}

This study: Yaeyama, Okinawa and Amami Is., Tanegashima, Tosashimizu, Amakusa Is., Kushimoto, Shirahama.

Previous studies: Yamazato et al. (1978) (? as M. crista-galli): Okinawa; Tachikawa (in prep., 1991): Ogasawara Is.

\section{Montipora spongodes}

\author{
Bernard, 1897
}

Uncommon but distinctive. Colonies are flat plates with finger-like upgrowths. Septa are better developed in Japanese coralla than in those from the Great Barrier Reef. Uniform pale to medium brown in colour.

Records:

This study: Yaeyama Is., Tanegashima, Tosashimizu, Amakusa Is., Kushimoto, Shirahama.

Previous studies: Tachikawa (in prep., 1991): Ogasawara Is.

\section{Montipora peltiformis}

Bernard, 1897

Common throughout the distribution range. Colonies are usually flat plates with columnar vertical branches. Pale brown in colour. Has a similar range of variation in the Philippines and Great Barrier Reef.

Records:

This study: Yaeyama and Okinawa Is.

Previous studies: Kawaguti (1983): Yaeyama Is.

\section{Montipora turgescens}

Bernard, 1897

Probably common, but has not been studied in situ in detail. Colonies are usually small; coralla show no differences from those from the Great Barrier Reef. Mostly mottled brown or purple in colour. Illustrated: Nishihira (1988). 
Records:

This study: Yaeyama, Okinawa and Amami Is., Tanegashima, Tosashimizu, Amakusa Is., Kushimoto, Shirahama, Izu.

Previous studies: Eguchi and Miyawaki (1975) and Anonymous (1977) (as M. mollis): Kushimoto; Kawaguti (1983): Yaeyama Is.; Tribble and Randall (1986): Miyake I.; Chou and Yamazato (1990): Okinawa; Tachikawa (in prep., 1991): Ogasawara Is.

\title{
Montipora effusa
}

Dana, 1846

Common throughout Ryukyu Is.; less common in mainland localities, Colonies are submassive or plate-like, superficially characterised by having $M$. turgescens-like corallites with thecal and/or reticulum papillae (visible in situ). Usually dark greenish-brown but may be pale cream and other colours.

\section{Records:}

This study: Yaeyama, Okinawa and Amami Is., Tosashimizu, Amakusa Is., Kushimoto.

Previous studies: Not recorded.

\section{Montipora spumosa}

\author{
(Lamarck, 1816)
}

Rare, does not form large colonies. Reticulum spinules are similar to those of Philippine coralla and generally less coarse than of Great Barrier Reef coralla. The only recorded colour is pale brown.

\section{Records:}

This study: Yaeyama, Okinawa and Amami Is., Tanegashima, Kushimoto.

Previous studies: Kawaguti (1983): Yaeyama Is.

\section{Montipora undata}

\section{Bernard, 1897}

Sometimes common in Amitori Bay and Tanegashima, generally uncommon elsewhere. Large colonies with prominent reticulum ridges have not been seen in Japan. Coralla, like those from the Philippines, have slightly finer structures than those from the Great Barrier Reef. Otherwise, specimens collected show no geographic variation. Colonies are brown with pale margins and have the same 
appearance in situ as those on the Great Barrier Reef. Illustrated in colour: Nishihira (1988), Uchida and Fukuda (1988a).

\section{Records:}

This study: Yaeyama, Okinawa and Amami Is., Tanegashima, Tosashimizu.

Previous studies: Tachikawa (in prep., 1991): Ogasawara Is.

\section{Montipora mactanensis}

Nemenzo, 1979

Common at Amitori Bay and Sekisei Lagoon, especially common at station 15. Coralla are similar to those from the Philippines, consisting of thin plates with fine, radiating reticulum ridges. Pale brown or off-white in colour.

Records:

This study: Yaeyama Is.

Previous studies: Not recorded.

\section{Montipora danae}

(Edwards and Haime, 1851)

Generally uncommon. Verrucae may be tightly compacted in colonies exposed to strong wave action, but variation is generally the same in coralla from the Philippines and the Great Barrier Reef. Mostly a uniform pale brown at the Ryukyu Is., or dark brown at Tanegashima. Illustrated in colour: Shirai (1980), Nishihira (1988), Uchida and Fukuda (1988a).

\section{Records:}

This study: Yaeyama, Okinawa and Amami Is., Tanegashima, Tosashimizu, Kushimoto.

Previous studies: Yamazato et al. (1978): Okinawa; Tribble and Randall (1986): Miyake I.; Kawaguti (1983): Yaeyama Is.; Chou and Yamazato (1990): Okinawa.

\section{Montipora verrucosa}

(Lamarck, 1816)

Generally rare; environmental and geographic variation have not been studied. Illustrated in colour: Uchida and Fukuda (1988a). 
Records:

This study: Yaeyama, Okinawa and Amami Is.

Previous studies: Eguchi (1974) (as M. conferta and M. verrucosa): Yaeyama Is. and Kerama Is.; Kawaguti (1983): Yaeyama Is.; Chou and Yamazato (1990): Okinawa; Tachikawa (in prep., 1991): Ogasawara Is.

\section{Montipora capitata}

Dana, 1846

Found only at stations 12,19 and 20 , the first site at $1.5 \mathrm{~m}$ depth, where many colonies are dispersed along a shallow shoreline for approximately $50 \mathrm{~m}$. Coralla are very similar to those from the Philippines while those from Vanuatu tend to have thicker branches. Uniform pale cream in colour.

Records:

This study: Yaeyama Is.

Previous studies: Not recorded.

\section{Montipora incrassata}

(Dana, 1846)

Generally uncommon. Colonies in the Ryukyu Is. tend to be submassive, without sub-digitate upgrowths as are sometimes found on the Great Barrier Reef. Thecal tuberculae are less well-developed.

Records:

This study: Yaeyama, Okinawa and Amami Is., Tanegashima.

Previous studies: Not recorded

\section{Montipora foveolata}

(Dana, 1846)

Generally uncommon, colonies are usually plate-like or submassive. Usually found on upper reef slopes. Corallites are very similar to those of Philippines coralla and smaller than those from the Great Barrier Reef. Less distinct from $M$. venosa than on the Great Barrier Reef. Usually creamy pink, pale brown or fawn. Illustrated in colour: Uchida and Fukuda (1988a).

Records:

This study: Yaeyama, Okinawa and Amami Is.

Previous studies: Yamazato et al. (1978): Okinawa; Kawaguti (1983): Yaeyama Is. 


\section{Montipora venosa}

(Ehrenberg, 1834)

Rare, less easily distinguished from $M$. foveolata than on the Great Barrier Reef. Usually cream coloured (station 14). Illustrated in colour: Nishihira (1988), Uchida and Fukuda (1988a).

jmjRecords:

This study: Yaeyama, Okinawa and Amami Is.

Previous studies: Chou and Yamazato (1990): Okinawa; Tachikawa (in prep., 1991): Ogasawara Is.

\section{Montipora caliculata}

(Dana, 1846)

Uncommon or rare, recorded only on exposed upper slopes of Sekisei Lagoon (notably station 11). The reticulum of a collected corallum is finer than that of most Great Barrier Reef coralla; corallites are very similar.

\section{Records:}

This study: Yaeyama Is.

Previous studies: ?Utinomi (1971): north-east Kyushu; Yamazato et al. (1978): Okinawa; Tachikawa (in prep., 1991): Ogasawara Is.

\section{Montipora angulata}

(Lamarck, 1816)

Generally uncommon except in some shallow lagoons (notably station 13). Environmental and geographic variation has not been fully studied. Usually pale brown in colour with whitish reticulum ridges towards branch tips.

\section{Records:}

This study: Yaeyama, Okinawa and Amami Is., Tosashimizu.

Previous studies: Tachikawa (in prep., 1991): Ogasawara Is. 


\section{Montipora cactus}

Bernard, 1897

Generally common in protected shallow biotopes throughout the distribution range (eg. station 13 and in the small boat harbour, Aka I.). Branches are usually upright and irregularly contorted and bases are usually massive. The range of variation is very similar to that of Philippine colonies. Colonies are cream or brown in colour with white branch ends and white reticulum papillae.

Records:

This study: Yaeyama and Okinawa Is.

Previous studies: There are many incorrect references to this species. In situ photographs in Eguchi and Miyawaki (1975) and Anonymous (1977) (Kushimoto) resemble this species, but collected coralla are $M$. informis; Yamazato et al. (1978): Okinawa; Kawaguti (1983): Yaeyama Is.

\section{Montipora samarensis}

Nemenzo, 1967

Forms extensive stands (station 13), where colonies have branches $>300 \mathrm{~mm}$ in length. Probably rare in the Okinawa Is. The reticulum is covered with papillae with elaborated tips, especially towards branch ends where they have a frosted appearance. These are visible in situ. Usually pale brown, yellow-brown or brown with white papillae. Colour differences between colonies may confuse species recognition in situ.

As well as resembling $M$. altasepta and $M$. digitata (see below), this species also resembles $M$. stellata which also has elaborated reticulum papillae but has smaller, usually more contorted branches.

Records:

This study: Yaeyama and Okinawa Is.

Previous studies: ?Utinomi (1965b) (as M. ramosa): south-west Shikoku; Habe (1989): Iriomote I.

\section{Montipora altasepta}

Nemenzo, 1967

Forms extensive stands (Sekisei Lagoon, station 13) with $M$. samarensis. Not recorded elsewhere. Branches are of variable size and shape. In thick stands of 
Montipora, branches may be long and straight; in more isolated colonies, branches usually become short and irregular. Corallites are of variable size; septa are generally exsert. Corallites of Japanese coralla tend to be more excavated than those from the Philippines. Pale brown or grey in colour.

This species is readily confused with $M$. samarensis and $M$. digitata, especially where all three co-occur and have the same growth form and branch size. Montipora digitata has a smooth reticulum surface without papillae; $M$. altasepta has simple papillae without elaborated ends; $M$. samarensis has highly elaborated papillae.

\section{Records:}

This study: Yaeyama Is.

Previous studies: Not recorded.

\section{Montipora digitata}

(Dana, 1846)

Very common in protected shallow (subtidal) water throughout the distribution range and has a similar range of variation on the Great Barrier Reef. Colonies are pale brown, grey-brown or cream in colour. May be confused with $M$. samarensis and $M$. altasepta in situ (see above). Illustrated in colour: Masuda and Hayashi (1989), Nishihira (1988).

\section{Records:}

This study: Yaeyama, Okinawa and Amami Is.

Previous studies: Eguchi (1974) (as M. levis and M. ramosa): Yaeyama Is.; Yamazato et al. (1978) and Kawaguti (1983) both record a series of synonyms of $M$. digitata from Okinawa: (Yamazato et al. (1978) as M. compressa, M. fruticosa, M. levis, M. marenzelleri, $M$. ramosa and $M$. rubra; Kawaguti (1983) as $M$. divaricata, $M$. fruticosa, $M$. indentata, $M$. marenzelleri, $M$. ramosa and $M$. tortuosa). These specimens have not been re-examined during the present study and are presumed to refer, in part, to other branching Montipora. Chou and Yamazato (1990): Okinawa; Tachikawa (in prep., 1991): Ogasawara Is.

\section{Montipora gaimardi}

\section{Bernard, 1897}

Uncommon; variation has not been fully determined. Like M. digitata but with short, contorted branches. 


\title{
Records:
}

This study: Yaeyama and Okinawa Is.

Previous studies: Not recorded.

\section{Montipora hispida}

(Dana, 1846)

Generally uncommon in the Ryukyu Is. except in Sekisei Lagoon, especially station 13; common at Kushimoto. Colonies have a similar range of variation as those of the Philippines and the Great Barrier Reef. Coralla from mainland localities are plate-like and lightly calcified. Pale brown or grey in colour. Illustrated in colour: Uchida and Fukuda (1988a).

\section{Records:}

This study: Yaeyama, Okinawa and Amami Is., Tanegashima, Tosashimizu, Amakusa Is., Kushimoto, Shirahama.

Previous studies: Eguchi (1968): Sagami Bay; Ooishi (1970): Ogasawara and Volcano Is.; ?Hamada (1963b) and Eguchi and Mori (1973): Tateyama; Eguchi (1974): Kerama Is.; Chou and Yamazato (1990): Okinawa.

\section{Montipora informis}

Bernard, 1897

Sometimes common, has a similar range of variation on the Great Barrier Reef. Massive colonies are frequently $>500 \mathrm{~mm}$ diameter at Tanegashima. Has an especially wide colour range at Tanegashima. Illustrated in colour: Nishihira (1988, Uchida and Fukuda (1988a)).

\section{Records:}

This study: Yaeyama and Okinawa Is., Tanegashima, Tosashimizu, Amakusa Is., Kushimoto, Shirahama.

Previous studies: Kikuchi (1968) (as M. cactus): Amakusa Is.; Eguchi and Miyawaki (1975) and Anonymous (1977) (as M. cactus): Kushimoto.

\section{Montipora efflorescens}

\author{
Bernard, 1897
}

Common, especially at Amitori Bay, where colonies have a similar range of variation in the Philippines, but tend to develop branch-like up-growths more than is usual on the Great Barrier Reef. Illustrated in colour: Uchida and Fukuda (1988a). 


\title{
Records:
}

This study: Yaeyama and Okinawa Is., Izu.

Previous studies: Kawaguti (1983): Yaeyama Is.; Tachikawa (in prep., 1991): Ogasawara Is.

\section{Montipora grisea}

\author{
Bernard, 1897
}

Common, especially at stations 2 and 41 , where colonies have a similar range of variation in the Philippines and the Great Barrier Reef. Colonies may be colourful, but are often a uniform dark brown.

\section{Records:}

This study: Yaeyama and Okinawa Is.

Previous studies: Not recorded.

\section{Montipora hirsuta \\ Nemenzo, 1967}

Generally common, especially in shallow water. As noted by Veron and Hodgson (1989), this species is distinguished from $M$. stellata by having smaller branches and finer corallites. It also tends to have longer reticulum papillae giving an 'hirsute' appearance in situ. Colonies are cream in colour and have a similar range of variation in the Philippines.

\section{Records:}

This study: Yaeyama and Okinawa Is.

Previous studies: Not recorded.

\section{Montipora stellata}

Bernard, 1897

Common in Amitori Bay and several stations at Ishigaki I., but probably uncommon elsewhere. Colonies are generally finely branched. Coralla show no differences from those of the Philippines. Illustrated in colour: Uchida and Fukuda (1988a).

\section{Records:}

This study: Yaeyama, Okinawa and Amami Is.

Previous studies: Kawaguti (1983): Yaeyama Is.; Tachikawa (in prep., 1991): Ogasawara Is. 


\section{Montipora malampaya}

Nemenzo, 1967

Generally rare, common at station 4 where colonies have compacted branches. Colonies show no differences from those of the Philippines. The growth form is similar to that of $M$. cactus but reticulum papillae are longer, especially at branch tips.

\section{Records:}

This study: Yaeyama Is.

Previous studies: Not recorded.

\section{Montipora sp.}

Common in Amitori Bay and Sekisei Lagoon over a wide range of environments (including stations 11, 12, 13 and 15), probably less common elsewhere. Colonies consist of thin plates like those of $M$. foliosa with irregular coenostial ridges and elongate papillae. Corallites are minute and widely spaced. Usually dark brown in colour.

Coralla are very similar to those of the Philippines (Montipora sp. 2 of Veron and Hodgson, 1989). Further study of type specimens is required before this species can be described as a new species.

Records:

This study: Yaeyama, Okinawa and Amami Is.

Previous studies: Not recorded.

\section{Montipora foliosa \\ (Pallas, 1766)}

Generally uncommon or rare. Coralla are very similar to those of the Philippines and the Great Barrier Reef. Colonies are pale or dark grey-brown with paler reticulum ridges. Illustrated in colour: Masuda and Hayashi (1989), Nishihira (1988), Uchida and Fukuda (1988a).

\section{Records:}

This study: Yaeyama, Okinawa and Amami Is.

Previous studies: Ooishi (1970): Ogasawara and Volcano Is.; Eguchi (1974) (as M. foliosa and M. pulcherrima): Yaeyama Is. and Kerama Is.; Yamazato et al. (1978) (as M. foliosa, M. prolifera and M. pulcherrima): Okinawa; Kawaguti (1983) (as M. 
prolifera and M. pulcherrima): Okinawa; Habe (1989): Iriomote I. ; Chou and Yamazato (1990): Okinawa; Tachikawa (in prep., 1991): Ogasawara Is.

\section{Montipora cebuensis}

Nemenzo, 1976

Generally uncommon except station 3 where colonies are pale brown with yellowish coenostial ridges.

Records:

This study: Yaeyama Is.

Previous studies: Not recorded.

\section{Montipora aequituberculata}

Bernard, 1897

Generally uncommon throughout the distribution range and seldom forms large plates. Coralla are very similar to those of the Philippines and the Great Barrier Reef. Illustrated in colour: Nishihira (1988), Uchida and Fukuda (1988a).

\section{Records:}

This study: Yaeyama, Okinawa and Amami Is., Tanegashima.

Previous studies: ?Eguchi (1974) (as M. challengeri and ?M. verrilli): Yaeyama Is.; Habe (1989): Iriomote I.; Tachikawa (in prep., 1991): Ogasawara Is.

\section{Montipora friabilis}

Bernard, 1897

Uncommon and little studied. Colonies from flat whorls. Veron and Hodgson (1989) note that this species and M. florida may be synonyms.

\section{Records:}

This study: Yaeyama and Okinawa Is., Tanegashima.

Previous studies: Not recorded. 


\title{
Genus Anacropora
}

\author{
Ridley, 1884
}

\section{Anacropora forbesi \\ Ridley, 1884}

Generally uncommon but may be a dominant species on soft substrates. Often a dominant species in deeper water (eg. in Ago and Amitori Bays) and forms extensive stands in shallow water of Sekisei Lagoon. Colonies are usually pale brown with white branch tips.

This is a very polymorphic species, the full variation of which has probably not been seen. Coralla from Japan are very similar to those from Vanuatu in having prominent, conical shaped corallites, but differ in having blunt, rather than pointed branch tips.

Records:

This study: Yaeyama and Okinawa Is.

Previous studies: Not recorded.

\section{Anacropora puertogalerae}

Nemenzo, 1964

Generally uncommon but forms extensive stands on soft substrates in shallow-water of Sekisei Lagoon (eg. station 15) and in deeper water (eg. in Ago and Amitori Bays). Colonies are very similar to those of the Philippines and other equatorial western Pacific countries, but differ substantially from those of the Great Barrier Reef in having finer branches and relatively prominent coenosteum styles. Possible species- level differences are under study. Pale brown in colour. Illustrated in colour: Masuda and Hayashi (1986), Nishihira (1988), Uchida and Fukuda (1988a).

\section{Records:}

This study: Yaeyama and Okinawa Is.

Previous studies: Not recorded except in the abovementioned publications. 


\section{Anacropora spinosa \\ Rehberg, 1892}

Common in Amitori Bay where it may form extensive stands (eg. station 15, along with other Anacropora spp.). Branches may be up to $600 \mathrm{~mm}$ long in very protected habitats, but become short and compact in partly exposed ones. Either cream or pale blue in colour. Illustrated in colour: Uchida and Fukuda (1988a).

\section{Records:}

This study: Yaeyama Is.

Previous studies: Not recorded except in the abovementioned publication.

\section{Anacropora matthai}

Pillai, 1973

Rare, but forms some extensive colonies in Amitori Bay (station 2) consisting of compact branches up to $300 \mathrm{~mm}$ high; also common in Ago Bay (station 45, at $25 \mathrm{~m}$ depth) where it forms small dark brown colonies. Was not found in Sekisei Lagoon. Has a similar range of variation in the Philippines and the Great Barrier Reef.

\section{Records:}

This study: Yaeyama and Okinawa Is.

Previous studies: Not recorded.

\section{Anacropora reticulata \\ Veron and Wallace, 1984}

As in the Philippines, branches are very robust; up to $12 \mathrm{~mm}$ diameter $20 \mathrm{~mm}$ from the tip. This species has been found only at station 13, where it is scattered over an area of approximately $50 \mathrm{~m}^{2}$. Is pale to dark brown on upper and lower branch surfaces (respectively), with pale branch tips. Coralla from the Philippines are very similar, those from the Great Barrier Reef have a relatively fine coenosteum and elaborated coenosteum spinules.

\section{Records:}

This study: Yaeyama Is.

Previous studies: Not recorded. 


\section{Anacropora sp.}

This is a rare, undescribed species, previously recorded from a single specimen from the Philippines. As indicated by Veron and Hodgson (1988), branches are like those of $A$. forbesi; the single corallum from Japan has more compact branches than the corallum from the Philippines. The species is primarily characterised by having numerous small corallites with small thecal spines, giving a rasp-like appearance. Pale brown in colour.

Records:

This study: Yaeyama Is.

Previous studies: Not recorded.

\section{Genus Acropora}

Oken, 1815

More than in most other genera, there is a marked distinction between the Acropora of Japanese coral reefs and those of higher latitude non-reefal areas. In both regions, Acropora remains the overwhelmingly dominant genus; the differences being (a) in skeletal structure, colour and general appearance in situ, (b) in the relative abundance of dominant species and (c), in total species composition. Skeletal structures of mainland Acropora are relatively thick, solid and highly calcified. Colour patterns may be the same or be completely different; they are usually darker and more intense. Relative abundance of species is generally uniform between adjacent localities of relatively high diversity (eg. between Shirahama and Kushimoto), but may vary greatly between distant mainland localities (eg. between the Amakusa Is. and Kushimoto). In general, for any given species, there is less geographic variation within the Ryukyu Is, than there is within mainland localities. This may be genetic or it may be the result of more critical environmental gradations.

\section{Acropora palifera}

(Lamarck, 1816)

A dominant species of the Ryukyu Is. on very exposed upper reef slopes where it may form flat plates covering the whole surface (notably stations 8 and 16). Generally uncommon in other habitats, but may form large branching colonies (eg. stations 41 and 48 ) with branches up to $150 \mathrm{~mm}$ diameter. Has a similar range of variation in the Philippines and the Great Barrier Reef. Colonies are pale pinkishbrown. Illustrated in colour: Masuda and Hayashi (1986), Nishihira (1988), Uchida and Fukuda (1988a). 


\section{Records:}

This study: Yaeyama, Okinawa and Amami Is.

Previous studies: Eguchi (1974): Yaeyama Is.; Kawaguti (1983): Yaeyama Is.; Habe (1989): Iriomote I.; Tachikawa (in prep., 1991): Ogasawara Is.

\section{Acropora cuneata}

(Dana, 1846)

Uncommon. As in the Philippines, corallites tend to be smaller than normal for Great Barrier Reef colonies. At Tanegashima, encrusting colonies occur in exposed habitats. These have irregular corallites with some tendency to form incipient axial corallites. Grey or pale to dark brown in colour. Illustrated in colour: Uchida and Fukuda (1988a).

\section{Records:}

This study: Yaeyama and Okinawa Is., Tanegashima

Previous studies: Kawaguti (1983) (as A. securis): Okinawa.

\section{Acropora brueggemanni}

(Brook, 1893)

Very common on reef flats and upper reef slopes and may be a dominant species in both exposed and protected habitats. Has a similar range of variation in the Philippines and the Great Barrier Reef. Dark brown greyish-white in colour. Illustrated in colour: Masuda and Hayashi (1986), Nishihira (1988), Uchida and Fukuda (1988a).

\section{Records:}

This study: Yaeyama and Okinawa Is.

Previous studies: Kawaguti (1983): Yaeyama Is.; Habe (1989): Iriomote I. ; Chou and Yamazato (1990): Okinawa.

\section{Acropora humilis}

(Dana, 1846)

Restricted to exposed biotopes where it is generally uncommon to rare (common, station 18). Illustrated in colour: Nishihira (1988), Uchida and Fukuda (1988a).

\section{Records:}

This study: Yaeyama and Okinawa Is. 
Previous studies: Eguchi (1974): Kerama Is.; Yamazato et al. (1978): Okinawa; Kawaguti (1983): Yaeyama Is.; Habe (1989): Iriomote I. ; Chou and Yamazato (1990): Okinawa; Tachikawa (in prep., 1991): Ogasawara Is.

\section{Acropora gemmifera}

(Brook, 1892)

Restricted to exposed biotopes where it is usually much more abundant than A. humilis. Usually yellowish-brown in colour with pale axial corallites. Illustrated in colour: Nishihira (1988), Uchida and Fukuda (1988a).

\section{Records:}

This study: Yaeyama, Okinawa and Amami Is.

Previous studies: ?Utinomi (1956, 1965b (as A. humilus): Tokara Is. and south-west Shikoku; Ooishi (1970): Ogasawara and Volcano Is.; Eguchi (1974): Yaeyama Is.; Kawaguti (1983): (as A. pyramidalis): Okinawa; Tachikawa (in prep., 1991): Ogasawara Is.

\section{Acropora monticulosa}

(Brüggemann, 1897)

Restricted to exposed biotopes where it is generally uncommon. Has a similar range of variation on the Great Barrier Reef. Usually dark blue in colour. Illustrated in colour: Nishihira (1988), Uchida and Fukuda (1988a).

Records:

This study: Yaeyama and Okinawa Is.

Previous studies: Not recorded except in the abovementioned publications.

\section{Acropora samoensis}

(Brook, 1891)

Rare, except at station 11, and not studied in detail. Collected coralla are similar to those from the Philippines.

\section{Records:}

This study: Yaeyama, Okinawa and Amami Is., Tanegashima.

Previous studies: Chou and Yamazato (1990): Okinawa. 


\section{Acropora digitifera}

(Dana, 1846)

Restricted to exposed upper reef slopes of the Ryukyu Is. where it may be very common (eg. station 8). Also common in some exposed biotopes of Tanegashima. Polyps are often extended during the day. Illustrated in colour: Nishihira (1988), Uchida and Fukuda (1988a, p.86 only).

\section{Records:}

This study: Yaeyama, Okinawa and Amami Is., Tanegashima, Amakusa Is.

Previous studies: ?Yagi (1970): south-west Shikoku; Utinomi (1971): northeast Kyushu; Eguchi (1974) (as A. leptocyathus): Yaeyama Is. and Kerama Is.; Chou and Yamazato (1990): Okinawa; Tachikawa (in prep., 1991): Ogasawara Is.

\section{Acropora verweyi}

Veron and Wallace, 1984

Generally uncommon, but may be found in both protected and exposed biotopes. Uniform pale brown with yellow axial corallites as with Great Barrier Reef colonies. Shows no geographic variation in growth form or colour.

\section{Records:}

This study: Yaeyama, Okinawa and Amami Is., Tanegashima.

Previous studies: Not recorded.

\section{Acropora glauca}

(Brook, 1893)

Generally uncommon at Tanegashima, becoming common in mainland locations. Colonies consist of irregularly anastomosing horizontal branches and short upward-curving branchlets forming large corymbose plates. Coralla are similar to those from high latitudes of eastern Australia, except that radial corallites tend to have thinner outer lips giving a rasp-like appearance and axial corallites tend to be smaller.

\section{Records:}

This study: Tanegashima, Tosashimizu, Amakusa Is. and Kushimoto.

Previous studies: Anonymous (1977) (as A. symmetrica: Kushimoto; Shirai (1986): Kii coast. 


\section{Acropora robusta}

(Dana, 1846)

Uncommon. Has a similar range of variation and habitat preference on the Great Barrier Reef and elsewhere and a similar appearance in situ. Radial corallites are finer than usual in Great Barrier Reef coralla. Usually dark brown in colour. Illustrated in colour: Nishihira (1988), Uchida and Fukuda (1988a).

Records:

This study: Yaeyama, Okinawa and Amami Is.

Previous studies: Anonymous (1970) (as A. humilis): Ehime coast; Eguchi (1974) (as A. smithi): Kerama Is.; Kawaguti (1983) (as A. smithi): Okinawa; Chou and Yamazato (1990): Okinawa; Tachikawa (in prep., 1991): Ogasawara Is.

\section{Acropora danai}

(Edwards and Haime, 1816)

Uncommon. Colonies generally have finer, more highly fused branches than on the Great Barrier Reef and may form very large (up to $2 \mathrm{~m}$ diameter at station 43 ) corymbose plates. Colonies are usually uniform brown in colour. Illustrated in colour: Shirai (1980), Nishihira (1988), Uchida and Fukuda (1988a).

\section{Records:}

This study: Yaeyama, Okinawa and Amami Is.

Previous studies: Eguchi (1974) (as A abrotanoides): Yaeyama Is.; Yamazato et al. (1978) (as A. irregularis and A. rotumana): Okinawa; Chou and Yamazato (1990): Okinawa; Tachikawa (in prep., 1991): Ogasawara Is.

\section{Acropora nobilis}

(Dana, 1846)

Common, may from extensive monospecific stands in a wide range of environments (notably stations 8 and 15). Has a similar range of variation on the Great Barrier Reef. May be green, blue or brown in colour. Illustrated in colour: Uchida and Fukuda (1988a).

Records:

This study: Yaeyama, Okinawa and Amami Is.

Previous studies: Eguchi (1974): Kerama Is.; Habe (1989): Iriomote I. ; Chou and Yamazato (1990): Okinawa; Tachikawa (in prep., 1991): Ogasawara Is. 


\section{Acropora listeri}

(Brook, 1893)

Rare in the Yaeyama Is. to generally uncommon in the Kerama Is. Restricted to exposed fringing reefs. Coralla are very similar to those on the Great Barrier Reef. Colonies are a uniform pale yellow. Uchida and Fukuda (1988a)

\section{Records:}

This study: Yaeyama and Okinawa Is., Tanegashima.

Previous studies: Not recorded except in the abovementioned publications.

\section{Acropora grandis}

(Brook, 1892)

Common, sometimes forms very extensive stands in protected biotopes (eg. stations 2, 12, 13 and 15). Commonly forms open thickets, but has a similar range of variation in the Philippines and on the Great Barrier Reef. Has a wide range of colours, the most common being pale brown with blue branch tips.

\section{Records:}

This study: Yaeyama, Okinawa and Amami Is.

Previous studies: Chou and Yamazato (1990): Okinawa; Tachikawa (in prep., 1991): Ogasawara Is.

\section{Acropora formosa}

(Dana, 1846)

Very common, sometimes forms very extensive stands in protected biotopes (eg. station 15). Has a similar range of variation in the Philippines and the Great Barrier Reef. Usually brown of blue with pale branch tips. Illustrated in colour: Shirai (1980), Nishihira (1988), Uchida and Fukuda (1988a).

\section{Records:}

This study: Yaeyama, Okinawa and Amami Is.

Previous studies: Utinomi (1965b): south-west Shikoku; Ooishi (1970): Ogasawara and Volcano Is.; Eguchi (1974): Kerama Is.; Kawaguti (1983): Yaeyama Is.; Habe (1989): Iriomote I. ; Chou and Yamazato (1990): Okinawa; Tachikawa (in prep., 1991): Ogasawara Is. 


\section{Acropora abrolhosensis}

Veron, 1985

Generally uncommon except in Sekisei Lagoon and some reef flat lagoons. Forms extensive thickets with straight branches. These resemble those of $A$. grandis, but have large axial corallites, usually blue in colour. Coralla are similar to those of Western Australia.

Records:

This study: Yaeyama and Okinawa Is.

Previous studies: Not recorded.

\section{Acropora teres}

(Verrill, 1866)

This is an arborescent species, primarily characterised by very straight branches and immersed radial corallites. It has been recorded from the Philippines (Ross and Hodgson, 1982 and Veron and Hodgson, 1989) but not Japan during the present study. The type locality is the Amami Is.

\section{Records:}

This study: Not recorded.

Previous studies: ?Kawaguti (1983): Yaeyama Is.

\section{Acropora acuminata}

(Verrill, 1864)

Uncommon, except on high diversity reef flats of the Kerama Is. where the species forms large, circular, pale to dark brown, corymbose plates. Branches are finer and closer, and corallites smaller, than in most coralla from the Great Barrier Reef, but are similar in these respects to coralla from Thailand. The skeleton bleaches white, whereas in all other Indo-west Pacific countries (where studied), it retains dark pigments after bleaching. The present identification must be considered doubtful and the species warrants further study.

\section{Records:}

This study: Yaeyama and Okinawa Is.

Previous studies: Tachikawa (in prep., 1991): Ogasawara Is. 


\section{Acropora valenciennesi}

(Edwards and Haime, 1860)

Rare (Yaeyama Is.) to uncommon (Kerama Is.). Restricted to exposed reef slopes. Coralla are very similar to those of the Great Barrier Reef. Colonies are a uniform brown with pale branch tips.

\section{Records:}

This study: Yaeyama and Okinawa Is.

Previous studies: Habe (1989): Iriomote I.

\section{Acropora parilis}

Quelch, 1816

Common in some lagoon biotopes and may form extensive stands (station 15); rare elsewhere. Colonies are bushy, caespitose, finely branched, with fine exsert labellate radial corallites. These are very similar to those from the Philippines. Bright or pale blue or pale brown (with or without blue branch tips) in colour.

\section{Records:}

This study: Yaeyama, Okinawa and Amami Is.

Previous studies: Not recorded.

\section{Acropora exquisita}

Nemenzo, 1971

Common, stations 13 and 17, uncommon elsewhere. Colonies display very wide environment-correlated, and possibly age-related, variation, analogous to that of A. pulchra. Colonies from very protected shallow biotopes may have long straight branches with fine, widely spaced radial corallites. These appear to be undergoing rapid growth with relatively little calcification. In deeper water, branches become much more sturdy and have more elongate, more calcified corallites. In exposed biotopes, colonies have shorter branches and finer corallites. Coralla are similar to those of other Indo-west Pacific countries. Colonies have a wide range of colours, always with white branch tips.

\section{Records:}

This study: Yaeyama, Okinawa and Amami Is.

Previous studies: Not recorded. 


\title{
Acropora akajimensis
}

\author{
Veron, 1990
}

Colonies are irregularly arborescent with proliferous, occasionally anastomosing, primarily horizontal branches, giving a sprawling growth form. Axial corallites are moderately exsert; incipient axial corallites are abundant on the upper surface of horizontal branches. Radial corallites are exsert, tubular, fluted towards branch ends. The coenosteum is costate and coarse and the skeleton lightly calcified. This species is closest to A. exquisita, which differs in having an upright growth form, non-anastomosed branches and more uniform radial corallites. Common on high diversity reef flats of the Kerama Is. Living colonies have a range of colours, predominantly blue and yellow. Also recorded from the Philippines.

\section{Records:}

This study: Yaeyama and Okinawa Is.

Previous studies: Veron (1990): Yaeyama and Okinawa Is.

\section{Acropora sp. 1}

Colonies form small compact clumps with proliferous, tapering branches and very small axial corallites. Radial corallites are likewise very small, tubular, outward projecting, with circular openings on main branches, becoming dimidiate towards branch tips. The skeleton is hard; the species has the general appearance of a diminutive A. microphthalma. The only recorded colour is blue.

\section{Records:}

This study: Yaeyama Is.

Previous studies: Not recorded.

\section{Acropora microphthalma}

(Verrill, 1869)

Forms extensive stands, stations 13 and 17 and may be common in a wide range of biotopes. Colonies are very similar to those of the Philippines and Great Barrier Reef. They are mostly pale grey in colour. Illustrated in colour: Uchida and Fukuda (1988a).

\section{Records:}

This study: Yaeyama, Okinawa and Amami Is.

Previous studies: Kawaguti (1983): Yaeyama Is.; Chou and Yamazato (1990): Okinawa. 


\section{Acropora copiosa \\ Nemenzo, 1967}

An ill-defined species recorded from Japan only from collected coralla. Growth forms range from compact thickets to sprawling horizontal branches. The only recorded colour is dark brown.

\section{Records:}

This study: Yaeyama and Okinawa Is., Tanegashima.

Previous studies: Not recorded.

\section{Acropora kirstyae}

Veron and Wallace, 1984

Forms very extensive stands at station 15, common in protected parts of Amitori Bay, rare elsewhere. Branches are open, lax, forming dense thickets. Corallites are very similar to those of Great Barrier Reef coralla, but have less flared lips than those from the Philippines. Colonies are pale brown or occasionally blue and may have pale blue or whitish branch tips.

\section{Records:}

This study: Yaeyama and Okinawa Is.

Previous studies: Tachikawa (in prep., 1991): Ogasawara Is.

\section{Acropora sekiseiensis}

Veron, 1990

Common over a wide range of environments, including reef flats and lagoons. Colonies are composed of irregular branches, usually forming upright bushy, sometimes subcorymbose, thickets. Coralla are primarily characterised by very irregular radial corallites, which readily form incipient axial corallites, and a very coarse coenosteum (visible in situ). In several respects, this species is like a diminutive $A$. horrida; it also has resemblances to $A$. insignis. Colonies are brown in colour. Illustrated in colour: Veron (1990b).

\section{Records:}

This study: Yaeyama, Okinawa and Amami Is.

Previous studies: Veron (1990): Yaeyama, Okinawa and Amami Is. 


\section{Acropora horrida}

(Dana, 1846)

Uncommon and not studied in detail. Forms compact bushes or has a sprawling growth form. There remains some doubt about the present identification; only two coralla were collected, both from station 41 , and these have a more compact branching pattern and slightly smaller corallites than is usual for the species. Generally yellowish in colour; the characteristically blue-coloured colonies of the Philippines and Great Barrier Reef have not been observed.

\section{Records:}

This study: Okinawa Is.

Previous studies: Habe (1989): Iriomote I.; Tachikawa (in prep., 1991): Ogasawara Is.

\section{Acropora vaughani}

Wells, 1954

Common, Kerama Is., rare elsewhere. Coralla are similar to those of the Great Barrier Reef, but environment-correlated variation has not been studied. Grey or yellow-grey in colour. Illustrated in colour: Uchida and Fukuda (1988a).

\section{Records:}

This study: Yaeyama and Okinawa Is.

Previous studies: Chou and Yamazato (1990): Okinawa; Tachikawa (in prep., 1991): Ogasawara Is.

\section{Acropora austera}

(Dana, 1846)

Found in a wide range of environments. Sometimes common in areas of high diversity. Coralla are very similar to those of the Philippines and Great Barrier Reef with peripheral branches curving away from main branches and radial corallites having open, almost square, calices. Forms large pale brown, greenishbrown or dark blue stands (notably at station 8). Axial corallites are usually yellow, as they are in Great Barrier Reef colonies. Illustrated in colour: Nishihira (1988), Uchida and Fukuda (1988a).

\section{Records:}

This study: Yaeyama and Okinawa Is.

Previous studies: Eguchi (1974) (as A. scherzeriana): Yaeyama Is.; Chou and Yamazato (1990): Okinawa; Tachikawa (in prep., 1991): Ogasawara Is. 


\section{Acropora aspera}

(Dana, 1846)

Generally common in a wide range of biotopes. Colonies from reef flats are characteristically corymbose. Those from mainland localities are highly anastomosed, becoming plate-like or forming solid plates; these are usually dark colours. Usually cream coloured at Amitori Bay, but may be bright blue or green in shallow biotopes. Acropora yaeyamaensis Eguchi and Shirai, 1977 is a junior synonym of this species. Illustrated in colour: Nishihira (1988), Uchida and Fukuda (1988a).

Several Japanese references to A. studeri Brook, 1893 (Eguchi, 1968; Hamada, 1963a; Utinomi, 1971; Yabe and Sugiyama, 1932a, 1935a) may be this species, but this has not been confirmed by re-examination of specimens.

\section{Records:}

This study: Yaeyama, Okinawa and Amami Is., Tosashimizu, Amakusa Is., Kushimoto, Shirahama.

Previous studies: Eguchi (1974) (as A. hebes): Yaeyama Is. and Kerama Is.; Yamazato et al. (1978) (as A. aspera and A. hebes): Okinawa; Chou and Yamazato (1990): Okinawa.

\section{Acropora pulchra}

(Brook, 1891)

May form very extensive stands in shallow, protected environments of Sekisei Lagoon (notably stations 12, 13 and 15) and Ishigaki I., but is generally uncommon elsewhere. Has a similar (wide) range of variation in the Philippines and the Great Barrier Reef. Usually blue or cream. Illustrated in colour: Nishihira (1988), Uchida and Fukuda (1988a).

\section{Records:}

This study: Yaeyama, Okinawa and Amami Is.

Previous studies: Yamazato et al. (1978): Okinawa; Habe (1989): Iriomote I.; Chou and Yamazato (1990): Okinawa; Tachikawa (in prep., 1991): Ogasawara Is.

\section{Acropora millepora}

(Ehrenberg, 1834)

Sometimes common and found in a wide range of biotopes in the Yaeyama Is., generally uncommon elsewhere. Has a similar range of variation in the Philippines and the Great Barrier Reef. May be the same distinctive salmon-pink colour as it often is on the Great Barrier Reef and has a wide range of other colours. Illustrated in colour: Masuda and Hayashi (1986), Nishihira (1988). 


\section{Records:}

This study: Yaeyama, Okinawa and Amami Is.

Previous studies: Yamazato et al. (1978) (as A. squamosa): Okinawa.

\section{Acropora tenuis}

(Dana, 1846)

Uncommon, except in some reef flats, notably of the Kerama Is. Has a similar appearance in situ in the Philippines: colonies have a sprawling growth form and large, distinctive corallites with wide flaring lips. Usually the same cream colour in the Philippines and the Great Barrier Reef. Illustrated in colour: Nishihira (1988), Uchida and Fukuda (1988a).

\section{Records:}

This study: Yaeyama, Okinawa and Amami Is.

Previous studies: Not recorded except in the abovementioned publications.

\section{Acropora selago}

(Studer, 1878)

Very common in protected biotopes and on reef flats. Collected coralla have fine branches and fine corallites; it is not known if the full range of variation determined on the Great Barrier Reef occurs in Japan. Radial corallites of collected coralla are slightly more appressed than usual in Great Barrier Reef coralla. Has a wide colour range, including grey-brown, cream, blue and yellow. Illustrated in colour: Nishihira (1988).

\section{Records:}

This study: Yaeyama, Okinawa and Amami Is.

Previous studies: Chou and Yamazato (1990): Okinawa; Tachikawa (in prep., 1991): Ogasawara Is.

\section{Acropora sp. 2}

A single corallum from Tanegashima appears to be a distinct species. It is a corymbose plate with an open branching pattern and is primarily characterised by flaring radial corallites (similar to, but smaller than, those of $A$. selago) and a very coarse lace-like skeleton. 


\section{Records:}

This study: Tanegashima.

Previous studies: Not recorded.

\section{Acropora dendrum}

(Bassett-Smith, 1890)

A rare, ill-defined species, readily confused, in mainland localities, with mainland A. valida (see below). Forms corymbose plates with tapering branchlets and thick-lipped immersed corallites. This identification of mainland coralla is tentative as the species was not clearly recognised in situ.

\section{Records:}

This study: Yaeyama Is., Tosashimizu, Amakusa Is., Kushimoto, Shirahama.

Previous studies: Tachikawa (in prep., 1991): Ogasawara Is.

\section{Acropora yongei}

Veron and Wallace, 1984

Common in high diversity areas of upper reef slopes and flats, especially in the Kerama Is. and Sekisei Lagoon where it characteristically forms large subcorymbose colonies. Can be readily confused with A. tenuis in situ, the latter having more regular and more flared radial corallites. Always pale colours, usually brown or cream.

\section{Records:}

This study: Yaeyama and Okinawa Is.

Previous studies: Eguchi (1974) (as A. haimei): Yaeyama Is. and Kerama Is.; Chou and Yamazato (1990) (as A. haimei): Okinawa; Tachikawa (in prep., 1991): Ogasawara Is.

\section{Acropora cytherea}

(Dana, 1846)

Forms extensive stands in shallow water in some localities, uncommon in others. Has a similar range of variation in the Philippines and the Great Barrier Reef. Mostly pale greys and browns in colour. Illustrated in colour: Nishihira (1988), Uchida and Fukuda (1988a).

\section{Records:}

This study: Yaeyama, Okinawa and Amami Is. 
Previous studies: Kawaguti (1983)(as A. reticulata): Okinawa; Habe (1989): Iriomote I. ; Chou and Yamazato (1990): Okinawa; Tachikawa (in prep., 1991): Ogasawara Is.

\section{Acropora microclados}

(Ehrenberg, 1834)

Common, Yaeyama Is., uncommon elsewhere. Occurs in a wide range of biotopes and has a similar range of variation on the Great Barrier Reef and Philippines, which includes the presence of proliferous, elongate, incipient axial corallites in coralla from protected biotopes. Those from exposed, or partly exposed reef slopes have compact, almost $A$. nasuta-like axial and radial corallites. Colonies are pale brown, not the distinctive pinky-brown of Great Barrier Reef colonies.

Records:

This study: Yaeyama and Okinawa Is.

Previous studies: Tachikawa (in prep., 1991): Ogasawara Is.

\section{Acropora tenella}

(Brook, 1892)

Recorded from a single specimen from the Amitori Research Center, Iriomote I., recovered from deep water attached to a boat anchor.

Records:

This study: Yaeyama Is.

Previous studies: Not recorded.

\section{Acropora elegans}

Edwards and Haime, 1860

Recorded only from laboratory specimens only. Colonies are all flat interlocking branches with corallites on the upper side only.

\section{Records:}

This study: Yaeyama and Okinawa Is.

Previous studies: Not recorded. 


\section{Acropora insignis}

Nemenzo, 1967

Uncommon. Colonies form compact, irregular clumps, with distal branches much finer than proximal ones. Corallites are primarily immersed on main branches, but have fine, labellate lips distally. Environment-correlated variation has not been studied. Philippines coralla have similar skeletal detail.

This species is similar to A. pruinosa, but branches and corallites are both finer.

\section{Records:}

This study: Yaeyama, Okinawa and Amami Is., Tosashimizu.

Previous studies: Not recorded.

\section{Acropora paniculata}

\section{Verrill, 1902}

Rare, Has a similar range of variation in the Philippines and the Great Barrier Reef. Pale brown in colour.

\section{Records:}

This study: Yaeyama and Okinawa Is.

Previous studies: Not recorded.

\section{Acropora hyacinthus}

(Dana, 1846)

Usually common on shallow upper reef slopes (especially of the Yaeyama Is.) and is the overwhelmingly dominant species of shallow-water coral communities of Tanegashima. Has a similar range of variation in the Philippines and the Great Barrier Reef. Shows little geographic variations except that, in mainland localities, branchlets tend to be thick and radial corallites immersed (except those near the corallum margins). Recorded in most studies north to Shirahama. Usually pinkishbrown. Illustrated in colour: Masuda and Hayashi (1986), Nishihira (1988), Uchida and Fukuda (1988a).

\section{Records:}

This study: Yaeyama, Okinawa and Amami Is., Tanegashima, Tosashimizu, Amakusa Is., Kushimoto, Shirahama.

Previous studies: Utinomi $(1956,1966,1971)$ (as A. pectinata and A. spicifera): Tokara Is., south-west Shikoku, north-east Kyushu; Eguchi (1974) (as $A$. hyacinthus, A pectinata and A. spicifera): Yaeyama Is. and Kerama Is.; Anonymous 
(1977) (as A. pectinata): Kushimoto; Yamazato et al. (1978) (as A. hyacinthus and $A$. spicifera): Okinawa; Kawaguti (1983) (as A. hyacinthus, A. pectinata and A. surculosa): Okinawa; Shirai (1986): Kii coast; Habe (1989): Iriomote I. ; Chou and Yamazato (1990): Okinawa; Tachikawa (in prep., 1991): Ogasawara Is.

\section{Acropora tanegashimensis \\ Veron, 1990}

Colonies are flat corymbose plates similar to those of $A$. hyacinthus. Branches are uniform in size, $9-11 \mathrm{~mm}$ diameter and branchlets are short, terete, and uniform. Axial and radial corallites are of similar size, the latter being uniformly crowded over the upper surface of the colony. What little coenosteum there is between corallites is very coarse. Living colonies are greenish-grey in colour. Readily distinguished from $A$. hyacinthus by having crowded radial corallites, indistinct axial corallites, and, in situ, by its greenish-grey colour. Illustrated in colour: Veron (1990b).

\section{Records:}

This study: Tanegashima.

Previous studies: Veron (1990): Tanegashima.

\section{Acropora striata}

(Verrill, 1866)

Uncommon except at Tanegashima, station 58, where it forms monospecific stands many hundreds $\mathrm{m}^{2}$. Colonies are bushy or form sub-corymbose plates. Radial corallites are irregular, with flaring lips. Colonies are greyish-brown with white branch tips and white exsert radial corallites.

Coralla are similar to Verrill's (type?) specimens from the Amami Is.: \#5808, Museum of Comparative Zoology, Harvard and, to a lesser extent, \#371, United States National Museum.

\section{Records:}

This study: Okinawa and Amami Is., Tanegashima.

Previous studies: ?Anonymous (1977) (as A. quelchi): Kushimoto. 


\section{Acropora anthocercis}

(Brook, 1893)

Sometimes common on exposed upper reef slopes (notably station 11). Has a similar range of variation and the same colour as Great Barrier Reef colonies. Colonies at Tanegashima have almost solid plate-like bases. Illustrated in colour: Nishihira (1988), Uchida and Fukuda (1988a).

\section{Records:}

This study: Yaeyama, Okinawa and Amami Is., Tanegashima.

Previous studies: Tachikawa (in prep., 1991): Ogasawara Is.

\section{Acropora tumida}

Verrill, 1866

Common around Kushimoto and Shirahama. Colonies have irregular to submassive bases and irregular, digitate branches. Radial corallites are aligned along branches, are appressed, with thick lips and wide calices. Mottled yellowishgrey and dark green in colour. Recorded elsewhere only from the South China Sea (Brook, 1893) (a doubtful record) and Hong Kong (Verrill, 1866 (type locality) and Veron 1980). Verrill's type specimen (\#5811, Museum of Comparative Zoology, Harvard University) is very close to specimens in the present series.

\section{Records:}

This study: Tosashimizu, Kushimoto, Shirahama.

Previous studies: ?Eguchi (1971) (as Acropora squarrosa): Goto I.; ?Eguchi (1972a) (as A. squarrosa): Izu; Anonymous (1977) (as A. squarrosa): Kushimoto .

\section{Acropora latistella}

(Brook, 1892)

Common on most upper reef slopes where it has a wide colour range. The range of variation in the Ryukyu Is. is similar to that in the Philippines and the Great Barrier Reef, mainland coralla are relatively heavily calcified, sturdy, with relatively solid bases. Colonies are often bright green at mainland islands.

\section{Records:}

This study: Yaeyama, Okinawa and Amami Is., Tanegashima, Amakusa Is.

Previous studies: Eguchi (1974) (as A. latistella and A. loricata): Kerama Is.; Anonymous (1977) (as A. surculosa): Kushimoto; Tachikawa (in prep., 1991): Ogasawara Is. 


\section{Acropora subulata}

(Dana, 1846)

Usually common in the Ryukyu Is. and occurs in a wide range of biotopes. Uncommon at Tanegashima. Colonies are very similar to those of the Philippines and the Great Barrier Reef. Has a wide colour range including blue, pink and mauve.

\section{Records:}

This study: Yaeyama, Okinawa and Amami Is., Tanegashima, Tosashimizu.

Previous studies: Tachikawa (in prep., 1991): Ogasawara Is.

\section{Acropora nana}

(Studer, 1878)

Restricted to exposed upper reef slopes. Has a similar range of variation in the Philippines and the Great Barrier Reef. Commonly bright blue at the Ryukyu Is., brown, blue-grey or cream at Tanegashima. Illustrated in colour: Uchida and Fukuda (1988a).

\section{Records:}

This study: Yaeyama, Okinawa and Amami Is.

Previous studies: Tachikawa (in prep., 1991): Ogasawara Is.

\section{Acropora pruinosa}

(Brook, 1893)

A distinctive species restricted to the environmental extremes of Acropora distribution. Colonies are irregularly arborescent with immersed radial corallites, except towards branch ends, where they become appressed with slightly flaring margins, similar to those of $A$. aculeus. Is the dominant species at Tomioka Point (station 72) where it has two colour morphs: greenish and brown. It is also a dominant species in a small area at Hirido, Izu (station 93), where colonies are green.

Non-Japanese occurrences of the species include the Straits of Korea and 'China' (type localities) and Hong Kong (Veron, 1980). Nemenzo (1967) records this species from the Philippines, a record accepted by Veron and Hodgson (1989), but now believed to be $A$. insignis, which it resembles.

\section{Records:}

This study: Tosashimizu, Amakusa Is., Izu.

Previous studies: ?Anonymous (1977) (as A. prostrata (Dana, 1846). 


\section{Acropora aculeus}

(Dana, 1846)

Uncommon, except in Amitori Bay (eg. station 10). Colonies are pillowshaped with outwardly curving horizontal branches as on the Great Barrier Reef. Mostly blue in situ (becoming purple at the water surface) or else brown or cream.

Records:

This study: Yaeyama and Okinawa Is.

Previous studies: Habe (1989): Iriomote I. ; Chou and Yamazato (1990): Okinawa; Tachikawa (in prep., 1991): Ogasawara Is.

\section{Acropora cerealis}

(Dana, 1846)

Uncommon, has a similar range of variation in the Philippines and on the Great Barrier Reef. Illustrated in colour: Uchida and Fukuda (1988a).

\section{Records:}

This study: Yaeyama, Okinawa and Amami Is.

Previous studies: Utinomi (1966, 1971): Kii coast and north-east Kyushu; Eguchi (1974): Kerama Is.; Yamazato et al. (1978) (as A. cerealis and A. tizardi): Okinawa; Kawaguti (1983) (as A. hystrix): Okinawa; Chou and Yamazato (1990): Okinawa; Tachikawa (in prep., 1991): Ogasawara Is.

\section{Acropora nasuta}

(Dana, 1846)

Common. Has a similar range of variation on the Great Barrier Reef. Has a wide colour range. Illustrated in colour: Masuda and Hayashi (1986), Nishihira (1988), Uchida and Fukuda (1988a).

\section{Records:}

This study: Yaeyama, Okinawa and Amami Is.

Previous studies: Eguchi (1974) (as A. quelchi): Yaeyama Is.; Yamazato et al. (1978) (as A. nasuta and A. quelchi): Okinawa; Kawaguti (1983): Yaeyama Is.; Habe (1989): Iriomote I. ; Chou and Yamazato (1990): Okinawa. 


\section{Acropora valida}

(Dana, 1846)

Common on upper reef slopes. May be a dominant Acropora species in some mainland localities where there is a distinct geographic subspecies primarily characterised by having radial corallites with thick rounded lips. These are similar to mainland $A$. dendrum. Ryukyu Is. coralla have a similar range of variation as Great Barrier Reef coralla. May have the same distinctive colours (see Nishihira (1988) and Uchida and Fukuda (1988a) as Great Barrier Reef colonies.

\section{Records:}

This study: Yaeyama, Okinawa and Amami Is., Tanegashima, Tosashimizu, Amakusa Is., Kushimoto, Shirahama.

Previous studies: Anonymous (1970) (as A. syringodes): Ehime coast; Eguchi (1974) (as A. variabilis): Yaeyama Is.; Anonymous (1977) (as A. digitifera): Kushimoto.

\section{Acropora secale}

(Studer, 1878)

Sometimes common on exposed upper reef slopes. Has a similar range of variation on the Great Barrier Reef. Usually brown or bright blue in colour (as on the Great Barrier Reef). Illustrated in colour: Nishihira (1988).

\section{Records:}

This study: Yaeyama, Okinawa and Amami Is.

Previous studies: Yamazato et al. (1978): Okinawa; Chou and Yamazato (1990): Okinawa; Tachikawa (in prep., 1991): Ogasawara Is.

\section{Acropora clathrata}

(Brook, 1891)

Uncommon in the Yaeyama Is., common in some other regions (eg. Kerama Is.). Forms horizontal plates composed of anastomosed branches without significant development of upright branchlets. Has a similar range of variation in the Philippines and the Great Barrier Reef. Pale to dark brown. Illustrated in colour: Nishihira (1988).

\section{Records:}

This study: Yaeyama and Okinawa Is.

Previous studies: Not recorded except in the abovementioned publication. 


\section{Acropora divaricata}

(Dana, 1846)

Uncommon throughout range. Has a similar, very wide, range of variation on the Great Barrier Reef. Illustrated in colour: Masuda and Hayashi (1986), Nishihira (1988), Uchida and Fukuda (1988a).

\section{Records:}

This study: Yaeyama, Okinawa and Amami Is., Tanegashima, Tosashimizu, Amakusa Is.

Previous studies: Chou and Yamazato (1990): Okinawa; Tachikawa (in prep., 1991): Ogasawara Is.

\section{Acropora solitaryensis}

Veron and Wallace, 1984

Uncommon in the Ryukyu Is., where colonies are found on upper reef slopes. Becomes common at Tanegashima and may be a dominant species in some biotopes. One of the most common species of the Amakusa Is. Colonies are very similar in colour, structure and abundance to those from both eastern and western Australia. In all cases, this species shows a wide range of growth form variation; it is relatively rare in tropical localities and becomes abundant at higher latitudes. There remains a possibility that colonies forming a solid plate (as illustrated, Veron, 1986) are a separate species rather than an ecomorph of this species. Usually blue or green in colour, usually with pale margins. Probably recorded by most authors from mainland localities under different names, few of which have been verified by the present author. Illustrated in colour: Uchida and Fukuda (1988a).

\section{Records:}

This study: Yaeyama, Okinawa and Amami Is., Tanegashima, Tosashimizu, Amakusa Is., Kushimoto, Shirahama, Izu.

Previous studies: Anonymous (1977) (as A. abrotanoides and A. sp.): Kushimoto; Tribble and Randall (1986) (as Acropora sp. 1): Miyaki I.; Tachikawa (in prep., 1991): Ogasawara Is.

\section{Acropora stoddarti}

Pillai and Scheer, 1976

The most common Acropora of many localities of Tanegashima; not recorded elsewhere. At Tanegashima, colonies in partly protected biotopes form corymbose plates with irregularly fused basal branches; in very exposed biotopes (eg. station 65), they form compact thickets. Radial corallites are strongly appressed (as they are 
throughout the geographic range of the species) but are smaller than those of coralla from other Indo-west Pacific countries. This species requires further study; the conclusion of this study is that it forms a distinct geographic subspecies, but may prove to be a separate species. Colonies are brown with pale axial corallites.

Records:

This study: Tanegashima.

Previous studies: Not recorded.

\section{Acropora echinata}

(Dana, 1846)

Common in some protected habitats with soft substrates (eg. stations 2 and 45), rare elsewhere. Colonies are a uniform brown or are brown with pale branch or corallite tips, not blue as elsewhere in the Indo-west Pacific. Recorded north to the Ehime coast, but not found further north than Okinawa by the author. Illustrated in colour: Nishihira (1988), Uchida and Fukuda (1988a).

\section{Records:}

This study: Yaeyama and Okinawa Is.

Previous studies: Anonymous (1970): Ehime coast; Eguchi (1974): Yaeyama Is. and Kerama Is.; Yamazato et al. (1978); Okinawa; Kawaguti (1983); Yaeyama Is.

\section{Acropora subglabra}

(Brook, 1891)

Very common in some protected deeper biotopes (eg. stations 2, 34 and 45) and may form extensive stands in shallow lagoons (eg. station 15). Colonies may be up to $1 \mathrm{~m}$ high. Usually cream and/or pale brown, sometimes blue, in colour. Acropora spiniformis Eguchi and Shirai, 1977, is a junior synonym of this species. Illustrated in colour: Nishihira (1988), Uchida and Fukuda (1988a).

\section{Records:}

This study: Yaeyama and Okinawa Is.

Previous studies: Eguchi and Shirai (1977); Eguchi (1974): Kerama Is.; Kawaguti (1983): Yaeyama Is. 


\section{Acropora carduus}

(Dana, 1846)

Sometimes common in protected biotopes. Has a similar range of variation in the Philippines and the Great Barrier Reef. Usually uniform brown colour, sometimes with blue branch tips. Illustrated in colour: Nishihira (1988), Uchida and Fukuda (1988a).

\section{Records:}

This study: Yaeyama, Okinawa and Amami Is.

Previous studies: Kawaguti (1983): Yaeyama Is.; Habe (1989): Iriomote I.; Tachikawa (in prep., 1991): Ogasawara Is.

\section{Acropora elseyi}

(Brook, 1892)

Generally uncommon to rare except at station 12, where it forms extensive stands. Colonies are very similar to those of the Great Barrier Reef and Philippines. Pale cream or off-white, occasionally blue in colour. Illustrated in colour: Uchida and Fukuda (1988a).

\section{Records:}

This study: Yaeyama Is.

Previous studies: Not recorded except in the abovementioned publication.

\section{Acropora longicyathus}

(Edwards and Haime, 1860)

Common. Has a similar range of variation in the Philippines and the Great Barrier Reef, with bushy colonies being relatively common. Coralla are very similar to those of the Great Barrier Reef and Philippines. Brown in colour. Illustrated in colour: Uchida and Fukuda (1988a).

\section{Records:}

This study: Yaeyama and Okinawa Is.

Previous studies: Yamazato et al. (1978) (as A. syringodes): Okinawa; Habe (1989): Iriomote I.; Tachikawa (in prep., 1991): Ogasawara Is. 


\section{Acropora rosaria}

(Dana, 1846)

Generally uncommon. This species has not been sufficiently studied for detailed comparisons with other countries to be made. Colonies are pale brown or pinkish-cream, not deep blue as they usually are on the Great Barrier Reef.

\section{Records:}

This study: Yaeyama, Okinawa and Amami Is.

Previous studies: Yamazato et al. (1978); Okinawa.

\section{Acropora loripes}

(Brook, 1892)

Only colonies from the Ryukyu Is. are readily identified as this species. These are very similar to those of the Philippines and Great Barrier Reef except that only corymbose growth forms have been recorded. Coralla from Tanegashima and the Amakusa Is. are corymbose plates with highly fused bases and relatively small corallites. These are only tentatively placed in this species. Fawn or dark green in colour.

\section{Records:}

This study: Yaeyama, Okinawa and Amami Is., Tanegashima, Tosashimizu, Amakusa Is.

Previous studies: ?Utinomi (1965b) (as A. squarrosa): south-west Shikoku; Anonymous (1970) (as A. squarrosa): Ehime coast; Yamazato et al. (1978) (as A. squarrosa): Okinawa; ?Shirai (1986): Kii coast; Chou and Yamazato (1990): Okinawa.

\section{Acropora granulosa}

(Edwards and Haime, 1860)

Uncommon throughout range except in some shallow, exposed biotopes (station 11). Forms plates similar to those of Great Barrier Reef colonies. Pale greybrown in colour.

\section{Records:}

This study: Yaeyama, Okinawa and Amami Is.

Previous studies: Kawaguti (1983) (as A. rayneri): Okinawa; Tachikawa (pers. comm., 1991): Ogasawara Is. 


\section{Acropora willisae}

Veron and Wallace, 1984

Uncommon, colonies are very similar to those of the Great Barrier Reef.

\section{Records:}

This study: Yaeyama, Okinawa and Amami Is., Tosashimizu.

Previous studies: Tachikawa (pers. comm., 1991): Ogasawara Is.

\section{Acropora florida}

(Dana, 1846)

Generally uncommon in the Yaeyama Is. where it is pale brown in colour but common on exposed fringing reefs of the Kerama Is. where it is usually pinkishbrown (the common colour of Great Barrier Reef colonies), occasionally dark brown with orange axial corallites. May also be bottle-green as are Western Australian colonies. Very large colonies such as are found on the Great Barrier Reef were not found in Japan but extensive grey-brown plates occur at Tanegashima. Illustrated in colour: Masuda and Hayashi (1989), Nishihira (1988), Uchida and Fukuda (1988a).

\section{Records:}

This study: Yaeyama, Okinawa and Amami Is., Tanegashima, Tosashimizu, Amakusa Is., Kushimoto, Shirahama.

Previous studies: Eguchi (1974) (as A. affinis and ?A. compressa): Yaeyama Is. and Kerama Is.; Chou and Yamazato (1990): Okinawa; Tachikawa (pers. comm., 1991): Ogasawara Is.

\section{Acropora wallaceae}

Veron, 1990

Uncommon, restricted to upper reef slopes. Fully developed colonies are composed of upright branches which decrease in size in a regular pattern, each generation of sub-branches growing from the preceding generation in a regular manner and remaining distinct. Branches taper in a regular manner to small axial corallites. Living colonies are brown with yellowish radial corallites. Illustrated in colour: Veron (1990b).

This species has previously been collected on the Great Barrier Reef (Veron and Wallace, 1984), the Philippines (Veron and Hodgson, 1989) and Thailand. It shows very little variation over this range and is readily recognised in situ. 
Records:

This study: Yaeyama and Okinawa Is.

Previous studies: Veron (1990): Yaeyama and Okinawa Is.

\section{Acropora sarmentosa}

(Brook, 1892)

Uncommon and little studied. Coralla are very similar to corymbose platelike coralla from the Philippines and Great Barrier Reef. Usually mustard coloured.

Records:

This study: Yaeyama and Okinawa Is.

Previous studies: Not recorded.

\section{Acropora mirabilis}

(Quelch, 1886)

Uncommon; forms corymbose plates with tapering branchlets. Axial corallites are small. Radial corallites are similar to those of $A$. millepora, only much smaller and less exsert. Radial corallites have very well developed septa, including distinct directive septa and an abortive third cycle (as discussed, Quelch, 1886 and Veron and Wallace, 1984).

Records:

This study: Yaeyama and Okinawa Is., Tanegashima.

Previous studies: Not recorded.

\section{Genus Astreopora}

de Blainville, 1830

\section{Astreopora myriophthalma}

(Lamarck, 1816)

Generally common throughout the distribution range. Has a similar range of variation on the Great Barrier Reef. Usually purple or pinkish-brown colours. Illustrated in colour: Masuda and Hayashi (1989), Nishihira (1988), Uchida and Fukuda (1988b). 


\section{Records:}

This study: Yaeyama, Okinawa and Amami Is., Tanegashima.

Previous studies: Yabe et al. (1936) and Yabe and Sugiyama (1941): north to Amakusa Is.; Utinomi (1965b): south-west Shikoku; Kawaguti (1983): Yaeyama Is.; Habe (1989): Iriomote I. ; Chou and Yamazato (1990): Okinawa; Tachikawa (pers. comm., 1991): Ogasawara Is.

\section{Astreopora gracilis}

Bernard, 1896

Less common than A. myriophthalma. Has a similar range of variation in the Philippines and the Great Barrier Reef. Usually cream in colour. Illustrated in colour: Nishihira (1988), Uchida and Fukuda (1988b).

\section{Records:}

This study: Yaeyama, Okinawa and Amami Is., Kushimoto.

Previous studies: Yabe et al. (1936) and Yabe and Sugiyama (1941): north to south-west Shikoku; Eguchi (1974): Kerama Is.; Yamazato et al. (1978): Okinawa; Habe (1989): Iriomote I.; Tachikawa (pers. comm., 1991): Ogasawara Is.

\section{Astreopora incrustans}

Bernard, 1896

Second to A. myriophthalma in abundance in the Ryukyu Is. but is the most common Astreopora of mainland localities. Well-developed colonies are characterised by an encrusting growth form with short contorted upgrowths which are frequently associated with polychaete worm tubes.

\section{Records:}

This study: Yaeyama, Okinawa and Amami Is., Tanegashima, Tosashimizu, Kushimoto, Shirahama.

Previous studies: Yabe et al. (1936) and Yabe and Sugiyama (1941): Ogasawara Is. and Amami Is., Kawaguti (1983): Yaeyama Is. Of Yabe and Sugiyama's collection, specimens \#44848 and \#44849 from the Ogasawara Is. are incrusting coralla with small irregular corallites. A second specimen numbered \#44849 is A. myriophthalma; Anonymous (1977) (as A. gracilis): Kushimoto. 


\section{Astreopora explanata}

Veron, 1985

An uncommon but distinctive species at Tanegashima forming thin tiers of pale brown plates, usually on vertical rock surfaces. Recorded in the Yaeyama Is. (Iriomote I.) from a single dark orange-brown colony. Illustrated in colour: Nishihira (1988).

Records:

This study: Yaeyama Is., Tanegashima.

Previous studies: Tachikawa (pers. comm., 1991): Ogasawara Is.

\section{Astreopora ocellata}

Bernard, 1896

Rare; corallites are usually inclined on the corallum surface and have wide, open calices. Illustrated in colour: Nishihira (1988).

Records:

This study: Yaeyama Is.

Previous studies: Tachikawa (pers. comm., 1991): Ogasawara Is.

\section{Astreopora suggesta}

Wells, 1954

Very rare, recorded from a single specimen collected from Kayama I., Sekisei Lagoon. Corallites are very small, as are those of the holotype (United States National Museum); they differ in having better developed septa. The present identification is tentative.

\section{Records:}

This study: Yaeyama Is.

Previous studies: Not recorded.

\section{Astreopora listeri}

Bernard, 1896

Rare and little studied. Coralla are similar to those of the Great Barrier Reef.

\section{Records:}

This study: Yaeyama, Okinawa and Amami Is.

Previous studies: Not recorded. 


\section{Astreopora macrostoma}

Veron and Wallace, 1984

Rare except at some stations at Tanegashima (notably 61) where colonies form large flat plates. The species is readily recognised by its large irregular corallites; coralla are very similar to those from the Great Barrier Reef. Various shades of brown in colour.

\section{Records:}

This study: Okinawa Is., Tanegashima.

Previous studies: Not recorded. 



\section{9 \\ Family \\ Poritidae \\ Gray, 1842}

\section{Genus Porites}

Link, 1807

Non-massive Porites (as with all other species) were studied in situ as well as from collections. Sample specimens of massive colonies were collected only if distinguishing characters were observed in situ. One hundred and eighty-six coralla were thus obtained, which, together with coralla from other collections, give some insight into intraspecific variation, but little into the relative abundance or habitat preferences of species. Fourteen of these coralla have not been identified are not included in the following account.

Porites remains the least satisfactorily studied of the major coral genera of Japan, partly because massive species are usually difficult to identify in situ, partly because a wide variety of taxonomic problems remain unresolved.

Most Porites species are restricted to the Ryukyu Is., especially the Yaeyama and Okinawa groups. In this respect they are most similar to Fungia.

\section{Porites solida}

(Forskål, 1775)

Probably rare. The species is recognisable in situ by the neat, regular appearance of the septa which lack pali. Illustrated in colour: Nishihira (1988), Uchida and Fukuda (1988a).

\section{Records:}

This study: Yaeyama and Okinawa Is.

Previous studies: Not recorded except in the abovementioned publications. 


\section{Porites lobata}

Dana, 1846

Probably the most common Porites of the Ryukyu Is. Distinguishing characters, notably corallite walls having three concentric rows of denticles (illustrated, Veron 1986), are the same in coralla from the Philippines and the Great Barrier Reef.

\section{Records:}

This study: Yaeyama, Okinawa and Amami Is.

Previous studies: Anonymous (1970): Ehime coast; Eguchi (1974): Yaeyama Is.; Kawaguti (1983): Yaeyama Is.; Habe (1989): Iriomote I.

\section{Porites murrayensis \\ Vaughan, 1918}

Probably common. Distinguishing characters, notably small corallites with a conspicuous central fossa and usually four well-developed pali (illustrated, Veron 1986), are the same in coralla from the Philippines and the Great Barrier Reef.

\section{Records:}

This study: Yaeyama and Okinawa Is.

Previous studies: Tachikawa (pers. comm., 1991): Ogasawara Is.

\section{Porites australiensis}

\section{Vaughan, 1918}

Probably uncommon. Coralla have corallite structures similar to those from the Great Barrier Reef except that in some, there is little tendency to have three pali on the septal triplets.

\section{Records:}

This study: Yaeyama and Okinawa Is.

Previous studies: Yamazato et al. (1978): Okinawa; Kawaguti (1983) (?as P. australiensis and $P$. fragosa): Okinawa.

\section{Porites lutea}

Edwards and Haime, 1860

Probably common. Some coralla of the present series have the same corallite characters (notably the septal triplet fused into a trident and five tall pali associated 
with the lateral pairs of septa and the triplet) as Great Barrier Reef coralla, but several specimens are attributed to this species with doubt. The holotype of $P$. tenuis Verrill, 1866 (USNM \#407), with the Ryukyu Is. as type locality, has been reexamined. It is a spherical corallith $62 \mathrm{~mm}$ maximum dimension with small corallites $(0.8-1.1 \mathrm{~mm}$ diameter). The corallites have well-developed columellae, thin walls and thin septa with fused triplets sometimes forming a trident, usually five weakly developed pali and two denticles. The inner synapticular ring is welldeveloped and five radii are usually present. Despite the wide useage of this species in the taxonomic literature of Japan (Eguchi (1972a): Izu; Eguchi (1974): Yaeyama Is. and Kerama Is.; Eguchi and Miyawaki (1975) and Anonymous (1977): Kushimoto; Kawaguti (1983): Yaeyama Is.; Shirai (1986): Kii coast; Habe (1989): Iriomote I.) and other countries including the Philippines (Veron and Hodgson, 1988), the conclusion of the present study is that it is a likely synonym of $P$. lutea, but that this remains to be further studied.

\section{Records:}

This study: Yaeyama, Okinawa and Amami Is., Tosashimizu.

Previous studies: (It is probable that most references to $P$. tenuis (see above) are also this species.) ?Utinomi (1956, 1966, 1971): Tokara Is., Kii coast and northeast Kyushu; ?Yagi (1970): S. Kyushu; Eguchi (1974) (as P. lutea and P. haddoni): Yaeyama Is.; Kawaguti (1983): Yaeyama Is.; Habe (1989): Iriomote I. ; Chou and Yamazato (1990): Okinawa; Tachikawa (pers. comm., 1991): Ogasawara Is.

\section{Porites heronensis}

Veron, 1985

Common in mainland localities, uncommon in the Ryukyu Is. Skeletal detail is similar to that of $P$. lutea, especially as septal triplets are fused in corallites where they can be distinguished. Septa are usually not as disarranged as those from extratropical Australian localities; otherwise there is little difference. Has the same general appearance, and is usually greenish-brown, in all mainland localities.

Records:

This study: Okinawa and Amami Is., Tanegashima, Tosashimizu, Amakusa Is., Kushimoto, Shirahama, Izu, Tateyama.

Previous studies: Tachikawa (pers. comm., 1991): Ogasawara Is. 


\section{Porites stephensoni \\ Crossland, 1952}

Probably uncommon; little studied. Corallites of some coralla collected show no differences from those Great Barrier Reef coralla.

\section{Records:}

This study: Yaeyama and Okinawa Is.

Previous studies: Chou and Yamazato (1990): Okinawa.

\section{Porites mayeri \\ Vaughan, 1918}

Probably rare; recorded in the present study from a single corallum from Ishigaki I. This is indistinguishable from Great Barrier Reef coralla.

\section{Records:}

This study: Yaeyama Is.

Previous studies: Not recorded.

\section{Porites evermanni}

Vaughan, 1907

Uncommon but very distinctive. Colonies are massive or columnar. Corallites are large and shallow and have long septa. Lateral pairs of septa have tall pali; shorter pali usually occur on the directive septum and also on each septum of the triplet. The latter are sometimes fused or partly fused, in which case they have one or two pali. As elsewhere in the Indo-west Pacific, polyps are usually extended during the day and are yellow-brown in colour.

\section{Records:}

This study: Yaeyama and Okinawa Is.

Previous studies: Not recorded.

\section{Porites okinawensis}

\section{Veron, 1990}

Colonies are massive or encrusting. Corallites are superficial, unevenly distributed, up to $1.7 \mathrm{~mm}$ diameter. Wall thicknesses between adjacent corallites vary from less than the thickness of a septum, to over $2 \mathrm{~mm}$. Septa vary in number according to the size of the corallite, both small and large corallites with below and 
above normal numbers of septa (respectively) are common. The Porites pattern of fusion is obscure in most corallites, due to a very high degree of fusion. The triplet is fused and frequently the directive septum is fused to one of the lateral pairs. The directive septum and the triplet are usually both fused to the columella. There are two weakly developed denticles per septum. Columellae are small or absent; highly fused radii link the septa to the corallite centre.

\section{Records:}

This study: Okinawa Is., Izu.

Previous studies: Veron (1990): Okinawa Is.

\section{Porites cylindrica}

Dana, 1846

Forms extensive monospecific stands in a wide variety of environments. Usually a uniform yellow in colour. Has a similar range of variation in the Philippines and the Great Barrier Reef. Illustrated in colour: Nishihira (1988), Uchida and Fukuda (1988a)).

\section{Records:}

This study: Yaeyama and Okinawa Is.

Previous studies: Utinomi (1971) (as P. andrewsi): north-east Kyushu; Eguchi (1974): Yaeyama Is. and Kerama Is.; Kawaguti (1983) (as P. andrewsi): Okinawa; Habe (1989): Iriomote I.; Chou and Yamazato (1990) (as P. andrewsi): Okinawa.

\section{Porites nigrescens \\ Dana, 1848}

Generally common in a wide range of environments. Usually pale to dark brown or yellow-brown in colour. Has a similar range of variation in the Philippines and the Great Barrier Reef. Illustrated in colour: Nishihira (1988), Uchida and Fukuda (1988a).

\section{Records:}

This study: Yaeyama, Okinawa and Amami Is.

Previous studies: Eguchi (1974): Yaeyama Is. and Kerama Is.; Kawaguti (1983): Yaeyama Is.; Habe (1989): Iriomote I. ; Chou and Yamazato (1990): Okinawa. 


\section{Porites sillimaniani}

Nemenzo, 1976

Common. Coralla show differences from those of the Philippines. Commonly forms thickets, usually yellow in colour.

\section{Records:}

This study: Yaeyama and Okinawa Is.

Previous studies: Not recorded.

\section{Porites latistella}

Quelch, 1886

Uncommon. Coralla show no differences from those of the Philippines.

\section{Records:}

This study: Yaeyama and Okinawa Is.

Previous studies: Eguchi (1974): Yaeyama Is.

\section{Porites attenuata}

Nemenzo, 1955

Common, but less so than in the Philippines. Colonies have the same appearance in situ, with branches of irregular size and shape and corallites more excavated than those of $P$. cylindrica. Holes in the centre of many corallites, presumably made by parasites, which expose the inner synapticular ring and remove the columella, are common. Usually greenish-yellow. Illustrated in colour: Shirai (1980).

\section{Records:}

This study: Yaeyama, Okinawa and Amami Is.

Previous studies: Not recorded except in the abovementioned publication.

\section{Porites deformis}

Nemenzo, 1955

Generally uncommon. Readily recognised in situ by having irregular, highly anastomosed branches. Corallites are shallow, giving the corallum a smooth appearance. 


\section{Records:}

This study: Yaeyama Is.

Previous studies: Not recorded.

\section{Porites negrosensis}

Veron, 1990

Rare. Colonies are irregularly arborescent with contorted anastomosing branches with flattened tips. Corallites are separated by approximately one corallite diameter; corallites on smaller branches may be aligned length-wise. Septa are neatly and regularly spaced. The triplet is usually, but not always fused. The columella and inner synapticular ring are well-developed. Calicular structures and the coenosteum are uniformly covered with fine spinules. The coenosteum is coarse. Colonies are usually pale brownish-grey. Illustrated in colour: Veron (1990b).

\section{Records:}

This study: Yaeyama Is.

Previous studies: Veron (1990): Yaeyama Is.

\section{Porites lichen}

Dana, 1846

Generally common. Has a similar range of variation in the Philippines and the Great Barrier Reef. Usually yellow or mustard in colour, but may be other colours eg. dark pink. Illustrated in colour: Nishihira (1988), Uchida and Fukuda (1988a, p. 219).

\section{Records:}

This study: Yaeyama, Okinawa and Amami Is., Tanegashima.

Previous studies: Eguchi (1968): Sagami Bay; Ooishi (1970): Ogasawara and Volcano Is.; Eguchi (1973): Tsushima; Kawaguti (1983): Yaeyama Is.; Tachikawa (pers. comm., 1991): Ogasawara Is.

\section{Porites vaughani \\ Crossland, 1952}

Probably uncommon. Collected coralla are similar to those from the Philippines and Great Barrier Reef.

\section{Records:}

This study: Yaeyama and Okinawa Is.

Previous studies: Not recorded. 


\section{Porites annae}

Crossland, 1952

Generally uncommon, usually grey, yellowish-grey or brown in colour. Has a similar range of variation in the Philippines and the Great Barrier Reef. Illustrated in colour: Nishihira (1988), Uchida and Fukuda (1988a).

\section{Records:}

This study: Yaeyama and Okinawa Is.

Previous studies: Not recorded except in the abovementioned publications. Eguchi (1974) records two varieties of $P$. compressa Vaughan from the Yaeyama and Kerama Is.; these possibly refer to the present species which has an undefined relationship with P. compressa; Tachikawa (pers. comm., 1991): Ogasawara Is.

\section{Porites eridani}

Umbgrove, 1940

This species has not been recorded during the present study. It is likely that the following records refer to P. sillimaniani, which may have a similar growth form but which is primarily distinguished by having relatively excavated corallites.

\section{Records:}

This study: Not recorded.

Previous studies: Yamazato et al. (1978): Okinawa; Chou and Yamazato (1990): Okinawa.

\section{Porites aranetai}

Nemenzo, 1955

Probably rare. Coralla are similar to $P$. lichen, but corallites are smaller and septal structures are reduced so that the Porites pattern seldom distinguishable.

\section{Records:}

This study: Yaeyama and Okinawa Is.

Previous studies: Not recorded.

\section{Porites horizontalata}

Hoffmeister, 1925

Generally uncommon, except on some upper reef slopes but may form extensive monospecific stands, notably at station 2 at $10 \mathrm{~m}$ depth, where colonies 
form large tiered plates. Grey, cream, brown or grey-brown in colour. Has a similar range of variation in the Philippines.

\title{
Records:
}

This study: Yaeyama and Okinawa Is.

Previous studies: Kawaguti (1983): Yaeyama Is.

\section{Porites rus}

(Forskål, 1775)

May be common and may form very large colonies (up to $5 \mathrm{~m}$ diameter). Usually grey, brown or blue in colour. Illustrated in colour: Nishihira (1988), Uchida and Fukuda (1988a).

\section{Records:}

This study: Yaeyama, Okinawa Is. and Amami Is.

Previous studies: Eguchi (1974) (as P. convexa): Yaeyama Is.; Kawaguti (1983) (as P. irregularis and P. iwayamaensis): Okinawa; Habe (1989): Iriomote I.

\section{Genus Goniopora}

\author{
de Blainville, 1830
}

No specimens of G. sagamiensis Eguchi (from Sagami Bay) have been found during this study. Eguchi and Miyawaki's (1975) and Utinomi's (1965b) records of G. planulata Ehrenberg have not been traced; the type specimen is lost and existing descriptions are inadequate for recognition. As this species has been recorded from Tateyama, it is likely to be a synonym of G. lobata, the only Goniopora now extant there.

It is likely that the following account of Gonipora is incomplete as the present study is primarily based on collected coralla, not detailed field work.

\section{Goniopora djiboutiensis}

Vaughan, 1907

Generally uncommon. Colonies are submassive or massive and show no differences from those of the Great Barrier Reef and the Philippines. Illustrated in colour: Nishihira (1988), Uchida and Fukuda (1988b). 
Records:

This study: Yaeyama and Amami Is., Tanegashima.

Previous studies: Tribble and Randall (1986): Miyake I.; Tachikawa (pers. comm., 1991): Ogasawara Is.

\section{Goniopora stokesi}

Edwards and Haime, 1851

Uncommon, but may form extensive clones through the production of daughter colonies (e.g. at station 45 at $20 \mathrm{~m}$ depth). Has a similar range of variation in the Philippines and the Great Barrier Reef. Usually pale green, yellow, or brown in colour.

\section{Records:}

This study: Yaeyama and Okinawa Is., Tanegashima, Tosashimizu and Amakusa Is.

Previous studies: Tribble and Randall (1986); Miyake I.

\section{Goniopora lobata}

Edwards and Haime, 1860

Generally common throughout the distribution range and frequently forms large colonies. Has a similar range of variation in the Philippines and the Great Barrier Reef. Usually grey-brown with cream oral cones and pink mouths. Probably recorded in most studies of mainland corals under a variety of names that have not been verified. Illustrated in colour: Nishihira (1988), Uchida and Fukuda (1988b).

\section{Records:}

This study: Yaeyama and Okinawa Is., Tanegashima, Tosashimizu, Amakusa Is., Kushimoto, Shirahama.

Previous studies: Eguchi (1973): Tsushima; Shirai (1986): Kii coast; Tachikawa (pers. comm., 1991): Ogasawara Is.

\section{Goniopora pendulus \\ Veron, 1985}

Uncommon, has long, tapering, pale to dark brown tentacles. Has the same appearance in situ as colonies from Western Australia and coralla are also very similar.

\section{Records:}

This study: Tanegashima, Amakusa Is., Kushimoto.

Previous studies: Anonymous (1977) (as Goniopora sp.): Kushimoto; Tachikawa (pers, comm., 1991): Ogasawara Is. 


\section{Goniopora columna}

Dana, 1846

Common, may form large colonies. Has a similar range of variation in the Philippines and the Great Barrier Reef except at mainland localities where colonies are encrusting. Usually brown in colour, with or without a white oral cone. Illustrated in colour: Nishihira (1988).

\section{Records:}

This study: Yaeyama, Okinawa and Amami Is., Izu, Tateyama.

Previous studies: Not recorded except in the abovementioned publication.

\section{Goniopora somaliensis}

Vaughan, 1907

Generally uncommon in the Ryukyu Is., becoming common at Tanegashima. Forms large flat plates with even surfaces. Polyps are extended during the day and have short tentacles of even length. Colonies are dark, uniform colours.

Records:

This study: Yaeyama, Okinawa and Amami Is., Tanegashima.

Previous studies: Tribble and Randall (1986): Miyake I.; Habe (1989): Iriomote I.

\section{Goniopora tenuidens}

Quelch, 1886

Particularly common in shallow water of Sekisei Lagoon (station 13) and may be common elsewhere. Has a similar range of variation in the Philippines and the Great Barrier Reef. Commonly brown in colour. Illustrated in colour: Nishihira (1988).

\section{Records:}

This study: Yaeyama and Okinawa Is.

Previous studies:

\section{Goniopora burgosi \\ Nemenzo, 1955}

Uncommon. An encrusting species with very small corallites. These are similar to those of G. minor, except that the columella is less developed and septa fewer. Has not been studied in detail, but has the same appearance in situ Philippine colonies and is commonly dark red or brown in colour. 
Records:

This study: Yaeyama and Okinawa Is.

Previous studies: Not recorded.

\section{Goniopora minor}

Crossland, 1952

Common. Has similar colours and range of variation in the Philippines and the Great Barrier Reef.

\section{Records:}

This study: Yaeyama, Okinawa and Amami Is.

Previous studies: Kawaguti (1983): Yaeyama Is.; Habe (1989): Iriomote I.

\section{Goniopora cellulosa}

Veron, 1990

Colonies are massive. Mature corallites are six sided, or rounded, 2.4-3.3mm diameter. Walls are thin and highly perforated. Calices of the same corallum show very great variation. Most are deep; some have irregularly developed septa which fuse to form a columella tangle, while others have no distinctive septa, the floor of the corallite consisting of irregularly fused skeletal rods and a rudimentary columella. This species has not been studied in situ.

\section{Records:}

This study: Amami Is., Tanegashima, Tosashimizu.

Previous studies: Veron (1990): Amami Is. and Tanegashima.

\section{Goniopora fruticosa}

Saville-Kent, 1891

Rare. Colonies are composed of encrusting bases with short, irregular upgrowths. Corallites are irregular in shape, especially those on the upgrowths. Calices are $2.8-3.2 \mathrm{~mm}$ diameter. The present series shows wide variation in septal development, encrusting coralla having fine irregular septa. Colonies are brown in colour.

\section{Records:}

This study: Yaeyama and Okinawa Is.

Previous studies: Tachikawa (pers. comm., 1991): Ogasawara Is. 


\title{
Goniopora polyformis
}

\author{
Zou, 1980
}

This species has previously been referred to by the author as Goniopora sp. of the Philippines (Veron and Hodgson, 1989).

Rare. Colonies are encrusting, with contorted bases and irregular upgrowths. Corallites are irregular in shape, especially those on upgrowths, and have thin walls. Calices $3.5-4.2 \mathrm{~mm}$ diameter. Septa are numerous and even. The appearance of this species in situ is not known. It is primarily distinguished from $G$. fruticosa by its larger corallites and more numerous and regular septa. Brown or grey in colour.

\section{Records:}

This study: Amakusa Is.

Previous studies: Not recorded.

\section{Goniopora pandoraensis}

Veron and Pichon, 1982

Generally uncommon but may form stands over $10 \mathrm{~m}$ diameter in some localities, notably station 5. Mostly brown in colour, with some branches being bleached, as is common on the Great Barrier Reef (as illustrated, Nishihira (1988)).

\section{Records:}

This study: Yaeyama Is.

Previous studies: First recorded from Japan, Nishihira (1988).

\section{Goniopora sp.}

This is very likely the same species are Goniopora sp. 1 of Eastern Australia (Veron and Pichon, 1982).

Colonies are massive or submassive. Corallites are shallow, rounded to polygonal, with calices $3.5-4 \mathrm{~mm}$ diameter. The walls are thin and highly perforated. Septa are in three orders although the gonioporoid pattern of fusion is less obvious in Japanese coralla than in Australian coralla. The columella is weakly developed. This species has not been studied in situ.

\section{Records:}

This study: Yaeyama and Okinawa Is., Shirahama.

Previous studies: Not recorded. 


\section{Goniopora stutchburyi}

Wells, 1955

Generally uncommon. Has a similar range of variation in the Philippines and the Great Barrier Reef. Usually uniform dark colours, especially rust red, brown or green, sometimes pale pink. Illustrated in colour: Nishihira (1988).

\section{Records:}

This study: Yaeyama and Okinawa Is., Tosashimizu, Shirahama.

Previous studies: Habe (1989): Iriomote I.

\section{Genus Alveopora}

de Blainville, 1830

\section{Alveopora catalai}

Wells, 1968

Forms very extensive stands in Amitori Bay (station 2), also found in Kabira Bay (station 18), but has not been found elsewhere. Has a similar range of variation in the Philippines and the Great Barrier Reef. Creamy-yellow in colour, with white centres.

Records:

This study: Yaeyama Is.

Previous studies: Habe (1989): Iriomote I.

\section{Alveopora allingi}

Hoffmeister, 1925

Generally uncommon but may form large colonies in protected environments. Has a similar range of variation in the Philippines and the Great Barrier Reef. Pale brown in colour. Illustrated in colour: Shirai (1980).

Records:

This study: Yaeyama and Okinawa Is.

Previous studies: Habe (1989): Iriomote I. 


\section{Alveopora verrilliana}

Dana, 1872

Generally uncommon but conspicuous. Colonies are typically composed of a complex of nodular branches. Skeletal characters are very similar to those of Great Barrier Reef and Philippines coralla, with corallites having well-developed septal spines and a palisade of trabecular rods on the walls. Colonies are usually greybrown in colour, with or without white tentacle tips, but are occasionally other colours such as pale brown or pink. Illustrated in colour: Uchida and Fukuda (1988b).

Records:

This study: Yaeyama, Okinawa and Amami Is.

Previous studies: Eguchi (1974): Kerama Is.; Eguchi (1973): Tsushima; Anonymous (1977): Kushimoto; Kawaguti (1983): Yaeyama Is.; Tachikawa (pers. comm., 1991): Ogasawara Is.

\section{Alveopora spongiosa \\ Dana, 1846}

Common. Found in a wide range of environments, including moderately exposed ones. Colonies are usually pillow-shaped. Has a similar range of variation in the Philippines and the Great Barrier Reef. Usually chocolate brown, often green, sometimes other colours. Illustrated in colour: Nishihira (1988), Uchida and Fukuda (1988b).

\section{Records:}

This study: Yaeyama, Okinawa and Amami Is., Amakusa Is., Shirahama.

Previous studies: Tachikawa (pers. comm., 1991): Ogasawara Is.

\section{Alveopora excelsa}

Verrill, 1863

Generally uncommon but conspicuous. Usually found in exposed environments. Coralla are similar to those from the Philippines. Usually grey or brown in colour.

\section{Records:}

This study: Yaeyama, Okinawa and Amami Is., Tanegashima, Kushimoto, Shirahama.

Previous studies: Not recorded. 


\section{Alveopora tizardi \\ Bassett-Smith,1890}

Rare. Similar to colonies from the Philippines. Pale brown to pinkish brown in colour. This species requires further study.

\section{Records:}

This study: Yaeyama Is.

Previous studies: Not recorded.

\section{Alveopora japonica}

\section{Eguchi,1968}

Restricted to shallow water of high latitude localities where it occupies habitats where other corals are seldom found. Usually rare, but relatively common at station 70. Appears to be endemic to Japan and Korea (Song, 1982). Polyps have green tentacles with pale cream tips. Recorded in most studies north to Tateyama Peninsula. Illustrated: Shirai (1980), Eguchi, (1968).

\section{Records:}

This study: Tanegashima, Amakusa Is., Kushimoto, Shirahama, Izu, Tateyama.

Previous studies: Yabe and Sugiyama (1935c) (as A. cf. verrilliana): Sagami Bay; Hamada (1963b) (as A. verrilliana): Tateyama; Eguchi $(1965,1968)$ : Kii coast and Sagami Bay; Utinomi (1966, 1971): north-east Kyushu and Kii coast; Eguchi (1968): Sagami Bay; Kikuchi (1968): Amakusa Is.; Eguchi (1972a): Izu; Eguchi (1973): Tsushima; Eguchi and Miyawaki (1975) and Anonymous (1977): Kushimoto; Kawaguti (1983): Yaeyama Is.; Kikuchi (1985): Tsuji-shima; Shirai (1986): Kii coast. 


\section{0 \\ Family \\ Siderastreidae \\ Vaughan and Wells, 1943}

\section{Genus Pseudosiderastrea}

Yabe and Sugiyama, 1935

\section{Pseudosiderastrea tayamai}

Yabe and Sugiyama, 1935

Uncommon but very distinctive and restricted to shallow, usually non-reefal substrates where other corals are seldom found. Forms small brownish-grey colonies with white corallite walls. Has a similar range of variation in the Philippines and the Great Barrier Reef.

\section{Records:}

This study: Yaeyama and Okinawa Is.

Previous studies: Not recorded.

\section{Genus Psammocora}

Dana, 1846

A single specimen collected from Kushimoto, not listed below, could be an abnormal $P$. vaughani, but may be a distinct species.

\section{Psammocora digitata}

Edwards and Haime, 1851

Uncommon or rare but may form large, columnar colonies up to $800 \mathrm{~mm}$ high. Has a similar range of variation in the Philippines and the Great Barrier Reef. Usually blue-grey in colour, but may be bright green. Illustrated in colour: Shirai (1980) (as P. togianensis), Masuda and Hayashi (1989), Nishihira (1988). 
Records:

This study: Yaeyama, Okinawa and Amami Is.

Previous studies: Yabe et al. (1936) (as P. exesa): Ogasawara Is.; Kawaguti (1983) (as P. togianensis): Okinawa; Habe (1989): Iriomote I.; Tachikawa (pers. comm., 1991): Ogasawara Is.

\section{Psammocora contigua}

(Esper, 1797)

Generally common, may form colonies $>1 \mathrm{~m}$ diameter and often forms coralliths. Has a similar range of variation in the Philippines and the Great Barrier Reef. Usually grey in colour. Illustrated in colour: Shirai (1980), Masuda and Hayashi (1986), Nishihira (1988), Uchida and Fukuda (1988a).

\section{Records:}

This study: Yaeyama, Okinawa and Amami Is., Tanegashima.

Previous studies: Yabe et al. (1936): Ogasawara and Daito Is.; Ooishi (1970): Ogasawara and Volcano Is.; Yamazato et al. (1978): Okinawa; Kawaguti (1983): Okinawa; Tachikawa (pers. comm., 1991): Ogasawara Is.

\section{Psammocora decussata}

Yabe and Sugiyama, 1937

A rare and little known species. Colonies have irregularly flattened to subcylindrical branches. Corallites are superficial although larger and more deeply excavated than those of $P$. contigua. Septa are coarsly beaded and petaliod septa are conspicuous. The in situ appearance is not known.

\section{Records:}

This study: Okinawa and Amami Is.

Previous studies: Yabe and Sugiyama (1937): Amami Is. and south Kyushu.

\section{Psammocora superficialis}

Gardiner, 1898

Generally common throughout the Ryukyu Is. where it may form large, brightly coloured colonies. Common in mainland localities, where colonies are usually dark green or brown but may be other colours, eg. brick red. Calices of mainland colonies are relatively large with distinct septa and this is observable in situ 
Coralla from the Ryukyu Is. have a similar range of variation to those from the Philippines. Illustrated in colour: Nishihira (1988), Uchida and Fukuda (1988a).

\section{Records:}

This study: Yaeyama, Okinawa and Amami Is., Tanegashima, Tosashimizu, Amakusa Is., Kushimoto, Shirahama, Izu, Tateyama.

Previous studies: Eguchi (1971): Goto I.; Eguchi (1973): Tsushima; Kawaguti (1983): Yaeyama Is.; Tribble and Randall (1986): Miyake I.; Chou and Yamazato (1990): Okinawa; Tachikawa (pers. comm., 1991): Ogasawara Is.

\section{Psammocora haimeana}

Edwards and Haime, 1851

Rare, not studied in detail. Coralla show no significant differences from those of the Great Barrier Reef.

\section{Records:}

This study: Yaeyama and Okinawa Is.

Previous studies: Tachikawa (pers. comm., 1991): Ogasawara Is.

\section{Psammocora profundacella}

Gardiner, 1898

Common over the full distribution range. Does not form large colonies; occasionally forms coralliths. Illustrated in colour: Shirai (1980), Masuda and Hayashi (1989), Nishihira (1989).

\section{Records:}

This study: Yaeyama, Okinawa and Amami Is., Tanegashima, Tosashimizu, Amakusa Is., Kushimoto, Shirahama, Izu, Tateyama.

Previous studies: Eguchi (1968): Sagami Bay; Eguchi and Miyawaki (1975) and Anonymous (1977): Kushimoto; Kawaguti (1983): Yaeyama Is.; Tribble and Randall (1986): Miyake I.; Shirai (1986): Kii coast; Habe (1989): Iriomote I. ; Chou and Yamazato (1990): Okinawa; Tachikawa (pers. comm., 1991): Ogasawara Is.

\section{Psammocora nierstraszi}

van der Horst, 1921

Uncommon; not studied in detail. Colonies have a wide range of valley shapes, from short to sinuous; they show no significant differences from those of the Great Barrier Reef. 
Records:

This study: Yaeyama and Okinawa Is., Tanegashima.

Previous studies: Yamazato et al. (1978): Okinawa.

\section{Psammocora vaughani}

Yabe and Sugiyama, 1936

Common at Ishigaki I. (station 17); probably uncommon elsewhere, but has not been studied in detail. The species is retained in the genus Psammocora primarily because the corallites are the same size as other species of the genus; most skeletal characters, however, are Coscinaraea-like. It is unlikely that this is the Psammocora sp. of Vaughan (1918) from the Cocos (Keeling) Is., as recorded by Yabe and Sugiyama (Veron, 1990a)

\section{Records:}

This study: Yaeyama and Okinawa Is.

Previous studies: Yabe and Sugiyama: Ogasawara Is.; Tribble and Randall (1986): Miyake I.; Tachikawa (pers. comm., 1991): Ogasawara Is.

\section{Genus Coscinaraea}

Edwards and Haime, 1848

Type specimens of C. kusimotoensis Yabe and Sugiyama, 1936 have not been located. It has not been identified from the original description and illustrations.

\section{Coscinaraea exesa}

(Dana, 1846)

Rare, recorded form a few coralla only and not studied in detail.

\section{Records:}

This study: Okinawa Is.

Previous studies: ?Kawaguti (1983): Yaeyama Is.

\section{Coscinaraea columna}

(Dana, 1846)

Usually uncommon but may be common in some localities (eg. station 11). Forms colonies plate-like colonies up to $3 \mathrm{~m}$ diameter at Kushimoto. Has a similar range of variation in the Philippines and the Great Barrier Reef. Usually yellow or 
grey (as on the Great Barrier Reef). Illustrated in colour: Masuda and Hayashi (1986), Nishihira (1988), Uchida and Fukuda (1988b, p. 67).

\section{Records:}

This study: Yaeyama, Okinawa and Amami Is., Tanegashima, Tosashimizu, Amakusa Is., Kushimoto, Shirahama, Izu.

Previous studies: Eguchi (1974): Kerama Is.; Eguchi and Miyawaki (1975) and Anonymous (1977) (as C. columna and possibly C. kusimotoensis: Kushimoto; Yamazato et al. (1978): Okinawa; Shirai (1986): Kii coast; Habe (1989): Iriomote I.; Tachikawa (pers. comm., 1991): Ogasawara Is.

\section{Coscinaraea wellsi}

Veron and Pichon, 1980

Rare. Has the same structure as coralla from the Philippines and the Great Barrier Reef.

\section{Records:}

This study: Okinawa Is., Tosashimizu.

Previous studies: Kawaguti (1983): Yaeyama Is.

\section{Coscinaraea crassa}

Veron and Pichon, 1980

Rare but conspicuous, forming large, flat plates; not studied in situ. Coralla show no significant differences from those of the Great Barrier Reef.

\section{Records:}

This study: Okinawa and Amami Is., Tanegashima, Shirahama.

Previous studies: Not recorded.

\section{Coscinaraea monile}

(Forskål, 1775)

Generally rare except at Tanegashima, where it is very common; usually grey in colour.

\section{Records:}

This study: Okinawa Is., Tanegashima, Tosashimizu.

Previous studies: ?Eguchi (1972a): Izu. 


\section{Coscinaraea hahazimaensis}

Yabe and Sugiyama, 1936

Uncommon, recorded from single specimens from each of the localities below. The holotype of Yabe and Sugiyama (1936) (\#44691) has been re-examined. The species is a likely high latitude endemic of Japan. It is morphologically close to C. columna, but has much smaller corallites and valleys, but relatively coarse septal elements. The appearance of living colonies has not been recorded.

\section{Records:}

This study: Tanegashima, Tosashimizu, Kushimoto, Izu.

Previous studies: Yabe and Sugiyama (1936): eastern Kii coast. 


\section{1 \\ Family
Agariciidae \\ Gray, 1847}

\section{Genus Pavona}

Lamarck, 1801

Pseudocolumnastrea Yabe and Sugiyama, 1933 was created for P. yamanarii Yabe and Sugiyama, 1933, a single corallum from the Daito Is. This has not been reexamined during the present study. The genus was used as a sub-genus of Pavona by Wells (1954) and others; the species may a synonym of Pavona maldivensis.

\section{Pavona cactus}

(Forskål, 1775)

Common in protected habitats, especially on soft substrates where it may form extensive stands. Has a similar range of variation in the Philippines and the Great Barrier Reef. Pale cream in colour at the Ryukyu Is., but may be grey-brown at Tanegashima (stations 58 and 60). Illustrated in colour: Masuda and Hayashi (1989), Nishihira (1988), Uchida and Fukuda (1988b).

\section{Records:}

This study: Yaeyama, Okinawa and Amami Is., Tanegashima.

Previous studies: Yamazato et al. (1978) (as P. cactus and P. praetorta): Okinawa; Kawaguti (1983) (as P. cactus and P. praetorta): Yaeyama Is.; Tachikawa (pers. comm., 1991): Ogasawara Is.

\section{Pavona decussata}

(Dana, 1846)

Common, Amakusa Is., sometimes common, Yaeyama Is., uncommon elsewhere. May form very large colonies at the Ryukyu Is., Tanegashima and Amakusa Is., with vertical plates up to $600 \mathrm{~mm}$ high. Has a similar range of variation in the Philippines and the Great Barrier Reef. Yellowish-brown in colour at the Ryukyu Is. and Tanegashima, chocolate brown, sometimes with green tentacles 
at mainland localities. Tentacles are normally extended the day at mainland localities, not in the Ryukyu Is. Illustrated in colour: Shirai (1980), Masuda and Hayashi (1989), Nishihira (1988), Uchida and Fukuda (1988b).

\title{
Records:
}

This study: Yaeyama, Okinawa and Amami Is., Tanegashima, Tosashimizu, Amakusa Is., Kushimoto.

Previous studies: Yabe et al. (1936): north to Suruga Bay; Utinomi (1965b, 1966, 1971): south-west Shikoku, Ehime coast, Kii coast and north-east Kyushu; Kikuchi (1968): Amakusa Is.; Anonymous (1970): Ehime coast; Yagi (1970): Ehime coast; Eguchi and Miyawaki (1975) and Anonymous (1977): Kushimoto; Tribble and Randall (1986): Miyake I., Kawaguti (1983) (as P. decussata, P. lata): Okinawa; Shirai (1986): Kii coast; Habe (1989): Iriomote I.; Tachikawa (pers. comm., 1991): Ogasawara Is.

\section{Pavona explanata}

\author{
Veron, 1985
}

Sometimes common (eg. Amitori Bay and Tanegashima). Usually restricted to steeply sloping substrates. Has a similar, very wide range of variation in the Philippines and the Great Barrier Reef. Corallites vary in size, shape and orientation both within and between colonies, especially those from differing depths. Increased variation occurs in coralla from different localities, with those from Tanegashima having recognisably smaller corallites than those from the Ryukyu Is. from similarly exposed biotopes. Coralla with similar corallites have, however, been found elsewhere, eg. Thailand. Colonies are usually uniform in colour, browns, greys and greens being the most common, often with calices of distinct colours. Illustrated in colour: Masuda and Hayashi (1989), Nishihira (1988), Uchida and Fukuda (1988b).

\section{Records:}

This study: Yaeyama, Okinawa and Amami Is., Tanegashima, Tosashimizu, Amakusa Is., Izu.

Previous studies: Kawaguti (1983): Yaeyama Is.; Tachikawa (pers. comm., 1991): Ogasawara Is.

\section{Pavona danai}

Edwards and Haime, 1860

Rare and restricted to shallow water. Has not been studied in situ, but coralla have a similar range of variation as those from the Philippines.

\section{Records:}

This study: Yaeyama and Okinawa Is.

Previous studies: Not recorded. 


\section{Pavona frondifera}

(Lamarck, 1816)

Generally uncommon at the Ryukyu Is., but may be common in some localities (from Iriomote I. and Tanegashima). Has a similar wide range of variation in the Philippines. Usually pale orange-brown in colour.

\section{Records:}

This study: Yaeyama, Okinawa and Amami Is., Tanegashima.

Previous studies: Yabe et al. (1936): north to south-west Shikoku; Utinomi (1965b): south-west Shikoku; Tokioka (1968): south-west Shikoku; Eguchi (1974): Kerama Is.; Kawaguti (1983): Yaeyama Is.

\section{Pavona maldivensis}

(Gardiner, 1905)

Rare and restricted to wave washed habitats with steep substrates. Colonies at Tokunoshima (station 56) and the only colony observed in the Okinawa Is. (Kuba I., station 47), had well-developed columnar growth forms and thin explanate bases. At Tanegashima, large, thin, explanate colonies were found on steep rock substrates (stations 60 and 62). Explanate growth forms are much more common in Japan than observed elsewhere; there is no discernable geographic variation in the structure of the corallites. All colonies observed were grey or had grey columns and margins and greenish central parts.

Records:

This study: Okinawa and Amami Is., Tanegashima.

Previous studies: Tachikawa (pers. comm., 1991): Ogasawara Is.

\section{Pavona clavus}

(Dana, 1846)

Uncommon to rare, but may form large colonies. Colonies may be either columnar or have flattened branches. They have a similar range of variation in the Philippines and the Great Barrier Reef. Usually pale pinkish-cream or orange brown in colour, with or without green calices. Illustrated in colour: Shirai (1980), Nishihira (1988).

\section{Records:}

This study: Yaeyama and Okinawa Is.

Previous studies: Kawaguti (1983) (as P. lilacea): Okinawa; Habe (1989): Iriomote I.; Tachikawa (pers. comm., 1991): Ogasawara Is. 


\section{Pavona minuta}

Wells, 1954

Uncommon to rare and does not form large colonies. Corallites are similar to those of the Great Barrier Reef and Philippines. Uniform grey or grey-brown in colour except at Tanegashima where it is cream. Illustrated in colour: Uchida and Fukuda (1988b).

\section{Records:}

This study: Yaeyama, Okinawa and Amami Is., Tanegashima, Amakusa Is.

Previous studies: Yabe et al. (1936) (as P. maldivensis): Daito Is.; Habe (1989): Iriomote I.; Tachikawa (pers. comm., 1991): Ogasawara Is.

\section{Pavona bipartita}

Nemenzo, 1980

Rare, usually restricted to the same biotopes as $P$. minuta, which it closely resembles. Has not been studied in detail in situ.

\section{Records:}

This study: Yaeyama and Okinawa Is.

Previous studies: Not recorded.

\section{Pavona varians}

Verrill, 1864

Common throughout the distribution range. Has a similar range of variation in the Philippines and the Great Barrier Reef. Usually dark or pale greenish-cream in colour. Illustrated in colour: Shirai (1980), Nishihira (1988), Uchida and Fukuda (1988b).

\section{Records:}

This study: Yaeyama, Okinawa and Amami Is., Tanegashima, Tateyama.

Previous studies: Yabe et al. (1936): Ogasawara and Daito Is.; Yamazato et al. (1978): Okinawa; Kawaguti (1983): Yaeyama Is.; Habe (1989): Iriomote I. ; Chou and Yamazato (1990): Okinawa; Tachikawa (pers. comm., 1991): Ogasawara Is. 


\section{Pavona venosa}

(Ehrenberg, 1834)

Uncommon. Valleys are usually short. Usually bright greenish-yellow in colour. Illustrated in colour: Masuda and Hayashi (1989), Nishihira (1988), Uchida and Fukuda (1988b).

\section{Records:}

This study: Yaeyama, Okinawa and Amami Is.

Previous studies: Habe (1989): Iriomote I.; Tachikawa (pers. comm., 1991): Ogasawara Is.

\section{Genus Leptoseris}

Edwards and Haime, 1849

\section{Leptoseris papyracea \\ (Dana, 1846)}

Found only on soft substrated in deeper water at Amitori Bay (stations 2 and 4 and with L. amitoriensis), Kabira Bay and Ago Bay (station 42). Colonies form continuous pale pink mats composed of fine, tightly compacted fronds.

\section{Records:}

This study: Yaeyama and Okinawa Is.

Previous studies: Not recorded.

\section{Leptoseris gardineri}

van der Horst, 1921

Generally rare, but forms extensive stands in deeper water of Amitori Bay (station 2). Has a similar range of variation in the Philippines and the Great Barrier Reef.

\section{Records:}

This study: Yaeyama Is.

Previous studies: Not recorded. 


\section{Leptoseris amitoriensis}

Veron, 1990

Colonies form extensive stands in situ in Amitori Bay, Iriomote I. at a depth of approximately $50 \mathrm{~m}$ (Yokochi, pers. comm.), where it is intermixed with $L$. gardineri. Coralla are very thin and delicate, foliose, unifacial laminae, with subentire to irregularly bifurcated margins and upward curving sides. Laminae vary in width; those of collected specimens are up to $67 \mathrm{~mm}$ wide but in situ photographs show that they may be several times this width. Septocostae are in neat, straight rows. Corallites are elongate and very superficial. Living colonies are brown in colour, becoming pale towards the margins, which have whitish borders. Illustrated in colour: Veron (1990b).

\section{Records:}

This study: Yaeyama Is.

Previous studies: Veron (1990): Yaeyama Is.

\section{Leptoseris explanata}

Yabe and Sugiyama, 1941

Uncommon; colonies are pale cream in colour, often with a white border. They have a similar range of variation to those of the Philippines and Great Barrier Reef. Illustrated in colour: Uchida and Fukuda (1988b).

\section{Records:}

This study: Yaeyama, Okinawa and Amami Is.

Previous studies: Tribble and Randall (1986): Miyake I.; Tachikawa (pers. comm., 1991): Ogasawara Is.

\section{Leptoseris scabra}

Vaughan, 1907

Generally uncommon and restricted to steeply sloping substrates. Has a similar range of variation in the Philippines and the Great Barrier Reef. Usually yellowish brown in colour with whitish margins. Illustrated in colour: Masuda and Hayashi (1989), Nishihira (1988).

\section{Records:}

This study: Yaeyama, Okinawa and Amami Is., Tosashimizu.

Previous studies: Tribble and Randall (1986): Miyake I.; Kawaguti (1983): Yaeyama Is.; Tachikawa (pers. comm., 1991): Ogasawara Is. 


\section{Leptoseris hawaiiensis}

Vaughan, 1907

Rare throughout the distribution range and restricted to steeply sloping substrates. Has a similar range of variation in the Philippines and the Great Barrier Reef. Colonies are dark coloured with pale costae and white colony margins.

Records:

This study: Yaeyama, Okinawa and Amami Is., Tanegashima.

Previous studies: Tribble and Randall (1986): Miyake I.; Kawaguti (1983): Yaeyama Is.; Tachikawa (pers. comm., 1991): Ogasawara Is.

\section{Leptoseris mycetoseroides \\ Wells, 1954}

Common, Ryukyu Is. and Amakusa Is., uncommon elsewhere. Usually found on steeply sloping substrates and has a wide range of variation on the Great Barrier Reef and in the Philippines. Has a similar range of variation in the Philippines and the Great Barrier Reef. Usually uniform dark colours, most commonly green. Illustrated in colour: Nishihira (1988), Uchida and Fukuda (1988b).

\section{Records:}

This study: Yaeyama, Okinawa and Amami Is., Tanegashima, Tosashimizu, Amakusa Is., Kushimoto, Shirahama, Izu, Tateyama.

Previous studies: Yabe et al. (1936) (as Agaricia minikoiensis): north to Suruga Bay; Kikuchi (1968) (as Agaricia minikoiensis); Amakusa Is.; Tribble and Randall (1986): Miyake I.; Tachikawa (pers. comm., 1991): Ogasawara Is.

\section{Leptoseris incrustans}

(Quelch, 1886)

Rare, recorded from three coralla; not studied in situ.

\section{Records:}

This study: Yaeyama Is.

Previous studies: Not recorded. 


\section{Leptoseris yabei \\ (Pillai and Scheer, 1976)}

Sometimes common on upper reef slopes of the Ryukyu Is.; rare, Tanegashima. Coralla from the Ryukyu Is. may be very similar to those from the Great Barrier Reef but some have less well defined radiating ridges. Coralla from Tanegashima are relatively finely structured. Colonies are uniform brown in colour with white margins. Illustrated in colour: Nishihira (1988).

\section{Records:}

This study: Yaeyama, Okinawa and Amami Is., Tanegashima.

Previous studies: Tachikawa (pers. comm., 1991): Ogasawara Is.

\section{Leptoseris foliosa}

Dineson, 1980

Rare. Has a similar range of variation in the Philippines and the Great Barrier Reef. Colonies usually have very dark calices.

\section{Records:}

This study: Yaeyama, Okinawa and Amami Is.

Previous studies: Not recorded.

\section{Leptoseris solida}

(Quelch, 1886)

Rare. Coralla are similar to those of Western Australia, but this remains a poorly known species; not studied in situ.

Records:

This study: Yaeyama and Okinawa Is., Tanegashima.

Previous studies: Not recorded. 


\section{Genus Gardineroseris}

Scheer and Pillai, 1974

\section{Gardineroseris planulata}

(Dana, 1846)

Generally uncommon but may form conspicuous, large, massive colonies in Amitori Bay. Has a similar range of variation in the Philippines and the Great Barrier Reef. Is a uniform purple-grey to fawn in colour. Illustrated in colour: Nishihira (1988), Uchida and Fukuda (1988b).

\section{Records:}

This study: Yaeyama, Okinawa and Amami Is., Tanegashima.

Previous studies: Yabe et al. (1936) (as Agaricia ponderosa): Ogasawara and Daito Is.; Yamazato et al. (1978): Okinawa; Habe (1989): Iriomote I.; Tachikawa (pers. comm., 1991): Ogasawara Is.

\section{Genus Coeloseris}

Vaughan, 1918

\section{Coeloseris mayeri}

Vaughan, 1918

Common, especially on exposed upper reef slopes, Yaeyama Is. and also in some shallow lagoons. Has a similar range of variation in the Philippines and the Great Barrier Reef. Most commonly a uniform green, brown or blue in colour. Illustrated in colour: Masuda and Hayashi (1989), Nishihira (1988), Uchida and Fukuda (1988b).

\section{Records:}

This study: Yaeyama and Okinawa Is.

Previous studies: Yabe et al. (1936): Yaeyama Is.; Eguchi (1974): Yaeyama Is. and Kerama Is.; Kawaguti (1983): Yaeyama Is.; Habe (1989): Iriomote I. 


\section{Genus Pachyseris}

Edwards and Haime, 1849

\section{Pachyseris rugosa}

(Lamarck, 1801)

Uncommon throughout the distribution range. Has a similar range of variation in the Philippines and the Great Barrier Reef. Blue-grey in colour. Illustrated in colour: Shirai (1980), Masuda and Hayashi (1989), Nishihira (1988), Uchida and Fukuda (1988b) (p. 97 as $P$ speciosa and p. 98).

\section{Records:}

This study: Yaeyama, Okinawa and Amami Is.

Previous studies: Yabe et al. (1936): Daito Is. and Okinawa Is.; Eguchi (1974): Yaeyama Is.; Yamazato et al. (1978): Okinawa; Kawaguti (1983): Yaeyama Is.; Tachikawa (pers. comm., 1991): Ogasawara Is.

\section{Pachyseris speciosa \\ (Dana, 1846)}

Generally common, Yaeyama Is., becoming uncommon at higher latitudes. Colonies at Tanegashima are fine plates up to $1 \mathrm{~m}$ diameter growing on vertical surfaces. Has a similar range of variation in the Philippines and the Great Barrier Reef. Pale brown in colour. Recorded in most studies north to Tateyama Peninsula. Illustrated in colour: Shirai (1980), Masuda and Hayashi (1989), Nishihira (1988), Uchida and Fukuda (1988b) (p. 96).

\section{Records:}

This study: Yaeyama, Okinawa and Amami Is., Tanegashima, Tosashimizu.

Previous studies: Eguchi (1974): Kerama Is.; Kawaguti (1983): Yaeyama Is.; Tribble and Randall (1986): Miyake I.; Chou and Yamazato (1990): Okinawa; Tachikawa (pers. comm., 1991): Ogasawara Is. 


\section{Pachyseris gemmae \\ Nemenzo, 1955}

Common in exposed environments where colonies are frequently $>1 \mathrm{~m}$ diameter. This is an ill-defined species, similar to plate-like P. rugosa. Colonies are dark grey-brown, becoming pale on the sides of collines. Illustrated in colour: Shirai (1980).

\section{Records:}

This study: Yaeyama and Okinawa Is.

Previous studies: Kawaguti (1983): Yaeyama Is. 


\section{2 \\ Family
Fungiidae \\ Dana, 1846}

As on both east and west Australian coasts, Japanese fungiids, more than any other major family, are restricted to the lower latitudes of the Ryukyu Is. (with the notable exceptions of one species of Lithophyllon, which thrives in mainland latitudes and Cycloseris, which are mostly non-reefal).

This account of the Fungiidae has been modified from earlier accounts of Veron and his colleagues to incorporate the recent revision of Hoeksema (1989) who made a substantial series of subgeneric changes within Fungia. Of these, the raising of Ctenactis to generic status is supported by the present author; the incorporation of Cycloseris and Diaseris into Fungia is not considered justified.

\section{Genus Cycloseris}

Edwards and Haime, 1849

In great contrast to the Philippines, all species of Cycloseris are rare in Japan. All specimens observed in situ throughout this study (with the exception of $C$. costulata from site 42) were collected.

As noted above, Hoeksema (1989), as have most earlier museum taxonomists, places Cycloseris as a subgenus of Fungia in contrast to the treatments of Wells (1966b) and Veron and Pichon (1980). Both Cycloseris and Fungia have few species (none in Japan) of doubtful affinity: they are as distinct morphologically as most faviid genera. Ecologically they are very distinct, Cycloseris being typically non-reefal, often mobile, and having high latitude distribution ranges, Fungia being reef dwelling, mostly non-mobile and restricted more than any other major genus to tropical latitudes. Wells (1966b) also records the fossil record of Cycloseris as being approximately twice that of other free-living fungiids.

Most records of Cycloseris in Japan are likely to be dredged specimens from non-reefal biotopes. These were seldom visited by the author and this is likely to be the reason why many records (below) have not been confirmed by the author. 


\section{Cycloseris cyclolites}

(Lamarck, 1801)

Rare, restricted to non-reefal biotopes. Specimens from Okinawa are similar to those from the Philippines but are larger, more irregular, and have coarser septa than those from the Great Barrier Reef. This trend is greatly extended in mainland localities where there is either a high latitude ecomorph of cyclolites or, possibly, a high latitude endemic.

\section{Records:}

This study: Okinawa Is.

Previous studies: (including mainland records, see above): Hamada (1963b) (as Fungia cyclolites): Tateyama; Eguchi (1968): Amami Is. to Sagami Bay; Kikuchi (1968): Amakusa Is.; Kawaguti (1983): Yaeyama Is.; Shirai (1986): Kii coast; Tachikawa (pers. comm., 1991): Ogasawara Is.

\section{Cycloseris hexagonalis}

(Edwards and Haime, 1848)

Rare, known only from a series of specimens collected from deep water, Amitori Bay, Iriomote I.

\section{Records:}

This study: Yaeyama Is.

Previous studies: Not recorded.

\section{Cycloseris sinensis}

Edwards and Haime, 1851

Specimens of the present series are similar to $C$. sinensis (Edwards and Haime) of Veron and Hodgson (1989) from the Philippines but have distinctively higher septa than those from lower latitudes.

\section{Records:}

This study: Yaeyama and Okinawa Is.

Previous studies: ?Hoeksema (1989) (as Fungia (Cycloseris) sinensis): Yaeyama Is. 


\section{Cycloseris somervillei}

(Gardiner, 1909)

No specimens of this species has been observed in Japan by the author.

\section{Records:}

This study: Not recorded.

Previous studies: Tribble and Randall (1986): Miyake I.

\section{Cycloseris sp.}

Known in Japan from a single specimen from Tanegashima (station 61). As in the Philippines, the corallum is 'strongly arched, and has the septal characters of $C$. vaughani. Costae are markedly cyclical and well developed.' (Veron and Hodgson, 1989 as Cycloseris sp. 2).

\section{Records:}

This study: Tanegashima.

Previous studies: Not recorded.

\section{Cycloseris erosa}

(Doderlein, 1901)

No specimens of this species has been observed in Japan by the author.

\section{Records:}

This study: Not recorded.

Previous studies: Yabe et al. (1936) (as Fungia erosa): Ogasawara Is.; Tachikawa (pers. comm., 1991): Ogasawara Is.

\section{Cycloseris patelliformis}

(Boschma, 1923)

Rare; only six specimens have been observed. Those from the Ryukyu Is. are similar to those from the Philippines; those from Tanegashima and the Shirahama (Tanabe Bay) are doubtful.

\section{Records:}

This study: Yaeyama and Okinawa Is., Tanegashima, Shirahama.

Previous studies: Tachikawa (pers. comm., 1991): Ogasawara Is. 


\section{Cycloseris vaughani}

(Boschma, 1923)

Rare, only four specimens have been observed during this study. The single specimen from the Amakusa Is. is lightly calcified and is included here with doubt.

Records:

This study: Yaeyama, Okinawa, Amami and Amakusa Is.

Previous studies: Kawaguti (1983): Yaeyama Is.; Tachikawa (pers. comm., 1991): Ogasawara Is.

\section{Cycloseris marginata}

(Boschma, 1923)

No specimens of this species has been observed in Japan by the author.

\section{Records:}

This study: Not recorded.

Previous studies: Kawaguti (1983): Yaeyama Is.

\section{Cycloseris costulata}

(Ortmann, 1889)

Rare, except at site 42 where a group of specimens were found together. Collected with $C$. vaughani (Nishihira, pers. comm.) from shallow sandy biotope, Okinawa. Illustrated in colour: Uchida and Fukuda (1988a).

\section{Records:}

This study: Yaeyama and Okinawa Is.

Previous studies: Not recorded.

\section{Cycloseris curvata}

(Hoeksema, 1989)

This is a new name for Cycloseris elegans Verrill which is pre-occupied (Hoeksema, 1989). It is a distinctive species with wavy margins and prominent septocostae. The colour ranges from brown to a distinctive pale pink.

Records:

This study: Yaeyama and Okinawa Is.

Previous studies: Not recorded. 


\section{Genus Diaseris}

Edwards and Haime, 1849

Hoeksema (1989) includes Diaseris in subgenus Cycloseris of Fungia. The key to this is a confusion (well illustrated by Hoeksema) between Cycloseris sinensis, $C$. hexagonalis and the following two species of Diaseris. The former Cycloseris is one of the most common and distinctive of all Cycloseris in equatorial countries, the latter is very rare and (as far as the author knows) remains little studied. Neither are known to occur on the Great Barrier Reef and are not, in any situation, field or laboratory, similar to Diaseris.

Diaseris typically occurs in isolated pockets of non-reefal habitats, which is probably why they are seldom found in museum collections. Their distinctive mode of asexual reproduction by autotomy is not environment-correlated, nor is it an abnormality: it is always the principal means of reproduction and makes the genus morphologically and ecologically distinct from both Cycloseris and (by any standards within the Scleractinia), Fungia. Cycloseris, like most Fungia species, rarely develops multiple centres, let alone lines of autotomy and seldom, if ever, reproduces by autotomy. The fine structure of Diaseris septocostae is not genusspecific, but, as originally noted by Wells (1966b), neither is that of Fungia.

Diaseris is a useful, distinctive genus, which would only include sinensis if the latter were shown to undergo reproduction by autotomy and have a corresponding septal configuration. Recent unpublished studies of Nishihira and others in Thailand indicate that there is likely to be more than two species of Diaseris in the Indo-west Pacific.

\section{Diaseris distorta}

(Michelin, 1843)

Rare, except in isolated biotopes. Tentacles are normally extended during the day at Okinawa, not at Iriomote I. (Nishihira pers. comm.). Illustrated in colour: Uchida and Fukuda (1988a).

\section{Records:}

This study: Yaeyama and Okinawa Is.

Previous studies: Verrill (1866) (as Diaseris pulchella): Yaeyama and Okinawa Is.; Tachikawa (pers, comm, 1991): Ogasawara Is. 


\section{Diaseris fragilis}

Alcock, 1893

Recorded only from Ishigaki I. and Amitori Bay at approximately 40m depth. Has a similar range of variation in the Philippines and the Great Barrier Reef.

Records:

This study: Yaeyama Is.

Previous studies: Hoeksema (1989) (as Fungia (Cycloseris) fragilis): Okinawa.

\section{Genus Heliofungia}

Wells, 1966

\section{Heliofungia actiniformis}

(Quoy and Gaimard, 1833)

Usually uncommon and restricted to protected biotopes (eg. station 15). Has a similar range of variation in the Philippines and the Great Barrier Reef. Polyps are pale to dark blue-grey with white tips to the tentacles. Illustrated in colour: Shirai (1980) (as Fungia actiniformis), Masuda and Hayashi (1989), Nishihira (1988), Uchida and Fukuda (1988a, 1988b).

\section{Records:}

This study: Yaeyama Is.

Previous studies: Kawaguti (1983): Yaeyama Is.; Habe (1989): Iriomote I.

\section{Genus Fungia}

\section{Lamarck, 1801}

For the identification purposes, Fungia have historically been divided into subgeneric groups, which have been variously changed according to different authors eg. Wells (1966), Veron and Pichon (1980) and Hoeksema (1989). They are not used here as this confusion has not yet been resolved, and also to give consistency of treatment with other genera. The raising of Ctenactis from subgenus to genus after Hoeksema (1989), is an appropriate solution to instability in this subgenus, which formally included Herpetoglossa.

Fungia are very common throughout the Ryukyu Is., show little geographic variation within this range, and are readily identifiable in situ. There also appears to 
be little variation in relative abundance within the three major groups of the Ryukyu Is., yet only one species, F. scutaria, has been recorded further north (Tanegashima) during the present study. A similar pattern occurs on both the east and west coasts of Australia. There is little difference between the Fungia of the Philippines and that of Japan.

In these several respects there is a great difference between Fungia and Cycloseris. The basis of this may be physiological, ecological, or involve some aspect of reproductive biology, but, when combined with consistently distinct morphological characters, provides sound grounds for retaining Cycloseris as a separate genus (after Wells, 1966 and Veron and Pichon, 1980) as opposed to combining them (after Hoeksema, 1989).

Nishihira (pers. comm.) has shown the author a fungites-like species, common at a single locality at Okinawa I., which remains permanently attached to the substratum. This appears to be an undescribed species; it has not been observed by the author and is not included in the present account.

\section{Fungia fungites}

(Linnaeus, 1758)

Very common. Has a similar range of variation in the Philippines and the Great Barrier Reef. Illustrated in colour: Shirai (1980), Nishihira (1988), Uchida and Fukuda (1988a).

\section{Records:}

This study: Yaeyama, Okinawa and Amami Is.

Previous studies: Yabe and Sugiyama (1941): Amami and Miyako Is.; Anonymous (1970): Ehime coast; Eguchi (1974): Yaeyama Is. and Kerama Is.; amazato et al. (1978): Okinawa; Kawaguti (1983): Yaeyama Is.; Chou and Yamazato (1990): Okinawa; Hoeksema (1989): Okinawa.

\section{Fungia danai}

(Edwards and Haime, 1851a)

Common. Has a similar range of variation in the Philippines and the Great Barrier Reef.

\section{Records:}

This study: Yaeyama and Okinawa Is.

Previous studies: Yamazato et al. (1978): Okinawa. 


\title{
Fungia scabra \\ Doderlein, 1901
}

Generally uncommon; not studied in detail. Coralla observed were similar to those of the Great Barrier Reef.

\section{Records:}

This study: Yaeyama and Okinawa Is.

Previous studies: Eguchi (1974): Kerama Is.

\section{Fungia scruposa \\ Klunzinger, 1879}

Generally common over a wide range of biotopes; not studied in detail. Coralla are similar to those of the Philippines and the Great Barrier Reef. Illustrated in colour: Uchida and Fukuda (1988a).

\section{Records:}

This study: Yaeyama and Okinawa Is.

Previous studies: Yabe and Sugiyama (1941): Amami Is.

\section{Fungia valida}

\author{
Verrill, 1864
}

Probably rare. Coralla are similar to those from the Great Barrier Reef. Illustrated in colour: Nishihira (1988).

\section{Records:}

This study: Yaeyama (laboratory specimen only), Okinawa and Amami Is.

Previous studies: Chou and Yamazato (1990): Okinawa.

\section{Fungia repanda \\ Dana, 1846}

Very common. Has a similar range of variation in the Philippines and the Great Barrier Reef. Illustrated in colour: Nishihira (1988).

Records:

This study: Yaeyama, Okinawa and Amami Is.

Previous studies: Yabe and Sugiyama (1941): Yaeyama, Okinawa and Amami Is., Ogasawara Is., south Kyushu; Yamazato et al. (1978): Okinawa; 
Kawaguti (1983): Yaeyama Is.; Chou and Yamazato (1990): Okinawa; ?Hoeksema (1989): Okinawa, south-east Honsyu.

\section{Fungia concinna}

Verrill, 1864

Very common. Has a similar range of variation in the Philippines and the Great Barrier Reef. Illustrated in colour: Shirai (1980), Nishihira (1988), Uchida and Fukuda (1988a).

\section{Records:}

This study: Yaeyama, Okinawa and Amami Is.

Previous studies: Yabe and Sugiyama (1941): Amami and Okinawa Is.;?Anonymous (1970): Ehime coast; Kawaguti (1983): Yaeyama Is.; Chou and Yamazato (1990): Okinawa.

\section{Fungia granulosa}

Klunzinger, 1879

Common. Has a similar range of variation in the Philippines and the Great Barrier Reef. Illustrated in colour: Nishihira (1988).

\section{Records:}

This study: Yaeyama, Okinawa and Amami Is.

Previous studies: Eguchi (1974): Yaeyama Is.; Habe (1989): Iriomote I.

\section{Fungia spinifer}

Claereboudt and Hoeksema, 1987

Recorded from a single corallum which is similar to Philippines coralla.

\section{Records:}

This study: Okinawa Is.

Previous studies: Not recorded. 


\section{Fungia scutaria}

Lamarck, 1801

Common in the Ryukyu Is., becoming rare at Tanegashima (station 61). Has a similar range of variation in the Philippines and the Great Barrier Reef. Commonly bright green in colour; uniform pale brown at Tanegashima. Illustrated in colour: Shirai (1980), Masuda and Hayashi (1989), Nishihira (1988), Uchida and Fukuda (1988a).

\section{Records:}

This study: Yaeyama, Okinawa and Amami Is., Tanegashima.

Previous studies: Yabe and Sugiyama (1941): Yaeyama and Amami Is. and Ogasawara and Daito Is.; Ooishi (1970): Ogasawara and Volcano Is.; Eguchi (1974) (as F. scutaria and F. scutaria placunaria: Yaeyama Is. and Kerama Is.; Yamazato et al. (1978): Okinawa; Kawaguti (1983): Yaeyama Is.; Habe (1989): Iriomote I.; Tachikawa (pers. comm., 1991): Ogasawara Is.

\section{Fungia paumotensis}

Stutchbury, 1833

Common. Has a similar range of variation in the Philippines and the Great Barrier Reef. Pale grey-brown in colour. Illustrated in colour: Shirai (1980), Masuda and Hayashi (1989), Nishihira (1988), Uchida and Fukuda (1988a).

\section{Records:}

This study: Yaeyama, Okinawa and Amami Is.

Previous studies: Yabe and Sugiyama (1941): Amami Is.; Eguchi (1974): Kerama Is.; Yamazato et al. (1978): Okinawa; Kawaguti (1983): Yaeyama Is.; Habe (1989): Iriomote I.

\section{Fungia moluccensis}

van der Horst, 1919

Sometimes common. Has a similar range of variation in the Philippines and the Great Barrier Reef. Illustrated in colour: Nishihira (1988), Uchida and Fukuda (1988a).

\section{Records:}

This study: Yaeyama and Okinawa Is.

Previous studies: Chou and Yamazato (1990): Okinawa. 


\section{Genus Ctenactis}

Verrill, 1864

A specimen with the colouration of Ctenactis albitentaculata Hoeksema, 1989 (the primary diagnostic character of the species) has been collected and photographed at Okinawa by Nishihira. It differs from Hoeksema's description of this species in having septal dentations indistinguishable from those of C. echinata, in being elongate $(227 \mathrm{~mm}$ long and $69 \mathrm{~mm}$ wide at the centre) rather than rounded, and in having three mouths. It is concluded that this specimen is a colour morph of C. echinata, of which species C. albitentaculata is a probable synonym (a conclusion which applies in the Great Barrier Reef where, contrary to Hoeksema, C. echinata as illustrated by Veron et al. (1980), is not divisable into two species on any grounds).

\section{Ctenactis echinata}

(Pallas, 1766)

Very common. Has a similar range of variation in the Philippines and the Great Barrier Reef. Illustrated in colour (as Fungia echinata): Shirai (1980), Masuda and Hayashi (1989), Nishihira (1988), Uchida and Fukuda (1988a).

\section{Records:}

This study: Yaeyama, Okinawa and Amami Is.

Previous studies: (as Fungia echinata) Yabe and Sugiyama (1941): Yaeyama and Okinawa Is.; Anonymous (1970): Ehime coast; Kawaguti (1983): Yaeyama Is.; Habe (1989): Iriomote I. ; Chou and Yamazato (1990): Okinawa.

\section{Ctenactis crassa}

(Dana, 1846)

The name simplex has been changed to crassa by Hoeksema (1989) because Dana's type, recorded by Veron and Pichon (1980) as lost, was found.

Uncommon (stations 6 and 7) or rare. Has a similar range of variation in the Philippines and the Great Barrier Reef. Illustrated in colour: Masuda and Hayashi (1989), Nishihira (1988), Uchida and Fukuda (1988a) (as Fungia (Ctenactis) simplex).

\section{Records:}

This study: Yaeyama, Okinawa and Amami Is.

Previous studies: Not recorded except in the abovementioned publications. 


\section{Genus Herpolitha}

Eschscholtz, 1825

\section{Herpolitha limax}

(Esper, 1797)

Very common. Has a similar range of variation in the Philippines and Great Barrier Reef. A uniform brown or grey-brown in colour. Illustrated in colour: Shirai (1980) (as H. limax and H. stricta (Dana), Nishihira (1988), Uchida and Fukuda (1988a).

\section{Records:}

This study: Yaeyama, Okinawa and Amami Is.

Previous studies: Yabe and Sugiyama (1941) Amami Is.; Kawaguti (1983) (as H. limax and H. stricta); Okinawa.

\section{Herpolitha weberi \\ (van der Horst, 1921)}

Rare, recorded from a single corallum which is very similar to the syntypes.

\section{Records:}

This study: Yaeyama Is.

Previous studies: Not recorded.

\section{Genus Polyphyllia \\ Quoy and Gaimard, 1833 \\ Polyphyllia talpina}

(Lamarck, 1801)

Generally uncommon. Polyps are extended during the day to give colonies a mop-like appearance. Has a similar range of variation in the Philippines and the Great Barrier Reef. Illustrated in colour: Shirai (1980), Masuda and Hayashi (1989), Nishihira (1988), Uchida and Fukuda (1988a).

\section{Records:}

This study: Yaeyama, Okinawa and Amami Is.

Previous studies: Yabe and Sugiyama (1941): Amami Is. 


\section{Genus Sandalolitha}

Quelch, 1884

Hoeksema (1989) records two species of Sandalolitha, both from the Australia to Japan. However, the only likely occurrence of a second species in the Indo-west Pacific, excluding Indonesia, is at the Cocos (Keeling) Is. (Veron 1990).

\section{Sandalolitha robusta}

(Quelch, 1886)

Very common in a wide range of environments. Has a similar range of variation in the Philippines and the Great Barrier Reef. Illustrated in colour: Shirai (1980) (as Parahalomitra robusta and P. irregularis Gardiner), Masuda and Hayashi (1989), Nishihira (1988), Uchida and Fukuda (1988a).

\section{Records:}

This study: Yaeyama, Okinawa and Amami Is.

Previous studies: Eguchi (1974) (as Halomitra robusta): Kerama Is.; Yamazato et al. (1978): Okinawa; Kawaguti (1983): Yaeyama Is.; Chou and Yamazato (1990): Okinawa; Hoeksema (1989) (as S. dentata and S. robusta): Okinawa.

\section{Genus Halomitra}

Dana, 1846

\section{Halomitra pileus}

(Linnaeus, 1758)

Rare. Has a similar range of variation in the Philippines and the Great Barrier Reef. Colonies are grey-brown with pale septo-costae and calices and usually with blue (in situ, pink when photographed with artificial light) margins. Illustrated in colour: Nishihira (1988).

\section{Records:}

This study: Yaeyama and Okinawa Is.

Previous studies: Not recorded except in the abovementioned publication. 


\section{Genus Zoopilus}

Dana, 1846

\section{Zoopilus echinatus}

Dana, 1846

Rare, recorded only from Sakieda Bay (station 35), Ishigaki I. at $18 \mathrm{~m}$ depth, where there are numerous large colonies. Coralla show no significant differences from this species in equatorial regions. Uniform dark brown in colour. Illustrated in colour: Veron (1986b), Nishihira (1988).

\section{Records:}

This study: Yaeyama Is.

Previous studies: Not recorded except in the abovementioned publications.

\section{Genus Lithophyllon}

Rehberg, 1892

In his recent revision, Hoeksema (1989) records two species of Lithophyllon in total, as concluded by Veron (1986b). One species occurs on the Great Barrier Reef: L. mokai Hoeksema, an appropriate new name for the L. cf. edwardsi of Veron and Pichon, 1980 and subsequent uses of that name by Veron from Australian localities, but not Japan. Lithophyllon undulatum sensu Hoeksema (1989), occurs in north-west Australia but has not, to this author's knowledge, been found on the Great Barrier Reef. There are probably no species of Lithophyllon in common between the Great Barrier Reef and Japan. Three species of Lithophyllon have been observed by the author in situ in the Philippines and two in Japan: the latter two (which are common to the Philippines) are illustrated by Hoeksema (1989), Figs. 567 and 568, referred to below as $L$. lobata and 570 and 571 , referred to below as $L$. undulatum.

Specimens of Yabe et al. (1936) have been re-examined during this study. The names Podabacia formosa and $P$. varians are confused on several. Podabacia elegans plicata (\#36905) has a large central corallite and coarse septo-costae; peripheral corallites are similar to those of $P$. elegans varians (\#39098); both are from Tanabe Bay. All specimens of $P$. elegans lobata and $P$. elegans formosa are very similar. 


\title{
Lithophyllon undulatum
}

\author{
Rehberg, 1892
}

Uncommon, but very conspicuous, especially in high latitudes where colonies may be $>1 \mathrm{~m}$ diameter and have a wide range of growth forms. Yellowishbrown or greenish-brown in colour. Illustrated in colour: Nishihira (1988) (as $L$. eleggans), Uchida and Fukuda (1988b) (as L. edwardsi).

\section{Records:}

This study: Yaeyama and Okinawa Is., Tanegashima, Amakusa Is., Kushimoto, Shirahama.

Previous studies: The following records may include some $L$. lobata: Yabe et al. (1936) (as Podabacia elegans varians, P. elegans plicata, P. elegans lobata nomanensis, $P$. elegans lobata and P. elegans formosa): north to Tanabe Bay; Utinomi (1965b, 1966, 1971) (as L. lobata and L. elegans): south-west Shikoku, Kii coast, north-east Kyushu; Kikuchi (1968) (as Podabacia elegans lobata): Amakusa Is.; Anonymous (1970) (as $L$. lobata): Ehime coast: Yagi (1970) (as L. lobata): Ehime coast; Eguchi (1971) (as L. lobata): Goto I.; Eguchi (1973) (as L. lobata): Tsushima; Eguchi (1974): Kerama Is.; Eguchi and Miyawaki (1975) and Anonymous (1977) (as L. elegans): Kushimoto; Yamazato et al. (1978) (as L. elegans): Okinawa; Shirai (1986): Kii coast.

\section{Lithophyllon lobata}

van der Horst, 1921

Rare, especially in the Ryukyu Is., but very conspicuous throughout its range. Skeletal detail is similar to those of $L$. undulatum. The most distinguishing character is that coralla are almost always monocentric: only very large colonies from mainland localities (including the holotype if this is applicable) have peripheral corallites. Small, free-living colonies have been found in shallow lagoons. The usual colour is pale yellowish-brown.

\section{Records:}

This study: Yaeyama, Okinawa and Amami Is.

Previous studies: See previous species. 


\section{Genus Podabacia}

Edwards and Haime, 1849

\section{Podabacia crustacea}

(Pallas, 1766)

Generally uncommon throughout the distribution range. Has a similar range of variation in the Philippines and the Great Barrier Reef. Usually amberbrown in colour. Illustrated in colour: Shirai (1980), Nishihira (1988), Uchida and Fukuda (1988b).

\section{Records:}

This study: Yaeyama, Okinawa and Amami Is.

Previous studies: Kawaguti (1983): Yaeyama Is.; Habe (1989): Iriomote I.

\section{Podabacia motuporensis}

Veron, 1990

A single corallum of this species has been recorded from Iriomote I.; it has not been seen in situ. Colonies are thin, unifacial plates attached at or near one edge. Corallites are irregularly but equidistantly arranged; there is no central corallite. Mature corallites are less than $5 \mathrm{~mm}$ diameter; calices are less than $2.5 \mathrm{~mm}$. This species is similar to P. crustacea, but much is finer and is readily distinguished in situ. Illustrated in colour: Veron (1990b).

\section{Records:}

This study: Yaeyama Is.

Previous studies: Veron (1990): Yaeyama Is. 


\section{3 \\ Family
Oculinidae \\ Gray, 1847}

\section{Genus Galaxea}

Oken, 1815

\section{Galaxea astreata}

(Lamarck, 1816)

Generally uncommon, but common at station 13 , where colonies are mostly pillow-like, less than $150 \mathrm{~mm}$ diameter. Forms an extensive monospecific stand at station 2, which (if regarded as a single colony), is one of the largest coral colonies seen by the author. The colony is dark brown in colour with whitish calices and consist of tiers of unifacial plates. Otherwise the species has a similar range of variation (including a range of abnormalities associated with mud) in the Philippines and the Great Barrier Reef. Usually grey-brown in colour. Illustrated in colour: Nishihira (1988), Uchida and Fukuda (1988b).

\section{Records:}

This study: Yaeyama and Okinawa Is., Tosashimizu.

Previous studies: Yabe et al. (1936) (as G. musicalis): Yaeyama and Miyako Is. and Ogasawara Is.; Ooishi (1970) (as G. clavus): Ogasawara and Volcano Is.; Eguchi (1974) (as G. musicalis): Yaeyama Is. and Kerama Is.; Kawaguti (1983) (as G. astreata, G. musicalis and G. clavus): Okinawa; Tachikawa (pers. comm., 1991): Ogasawara Is.

\section{Galaxea fascicularis}

(Linnaeus, 1767)

Common throughout the Ryukyu Is. where colonies are frequently of large size. Large numbers of what appear to be daughter colonies of the same colour are often found in close proximity to parent colonies. Uncommon at Tanegashima where colonies are small, dark green in colour, and occur in a wide range of biotopes. Otherwise, the species has a similar range of variation as colonies from the Philippines and the Great Barrier Reef. Galaxea columnaris Eguchi and Shirai, 1977 is a junior synonym of this species. Has a wide range of colours (illustrated, Nishihira 
(1988)), green being the most common. Also illustrated: Shirai (1980) (as G. columnaris and G. fascicularis, Masuda and Hayashi (1989), Uchida and Fukuda (1988b).

\section{Records:}

This study: Yaeyama, Okinawa and Amami Is., Tanegashima, Tosashimizu.

Previous studies: Yabe et al. (1936): Yaeyama, Miyako, Okinawa and Amami Is.; Anonymous (1970): Ehime coast; Eguchi (1974): Yaeyama Is. and Kerama Is.; Yamazato et al. (1978): Okinawa; Habe (1989): Iriomote I. ; Chou and Yamazato (1990): Okinawa; Tachikawa (pers. comm., 1991): Ogasawara Is.

\section{Genus Acrhelia}

Edwards and Haime, 1849

Kawaguti (1983) records Simplastrea Umbgrove, 1939 from Okinawa..

\section{Acrhelia horrescens}

(Dana, 1846)

Generally uncommon except in some exposed biotopes. As in the Philippines, but not the Great Barrier Reef, colonies frequently occur in turbid environments where they have lax growth forms. Usually yellowish-brown in colour. Illustrated in colour: Nishihira (1988), Uchida and Fukuda (1988b).

\section{Records:}

This study: Yaeyama Is.

Previous studies: Kawaguti (1983): Yaeyama Is.; Habe (1989): Iriomote I. 


\section{4 \\ Family \\ Pectiniidae \\ Vaughan and Wells, 1943}

The genus Oxyphyllia Yabe and Eguchi, 1935a, an invalid genus, was created for two varieties of Echinophyllia aspera (tosaensis and sugiyamai). Yabe and Eguchi (1935b) compare the skeletal characters of this and related genera.

\section{Genus Echinophyllia}

Klunzinger, 1879

\section{Echinophyllia aspera}

(Ellis and Solander, 1786)

Generally common in a wide range of habitats and is especially common at Tanegashima and the Amakusa Is. Uncommon at Shirahama and Kushimoto. Has a similar range of corallite variation on the Great Barrier Reef. Colonies are distinctive dark reds and greens at higher latitudes. Recorded in most studies north to Tateyama Peninsula. Illustrated in colour: Shirai (1980), Masuda and Hayashi (1989), Nishihira (1988), Uchida and Fukuda (1988b).

\section{Records:}

This study: Yaeyama, Okinawa and Amami Is., Tanegashima, Tosashimizu, Amakusa Is., Kushimoto, Shirahama, Izu, Tateyama.

Previous studies: Yabe et al. (1936) (as Oxyphyllia aspera, Oxyphyllia aspera tosaensis and Oxyphyllia aspera sugiyamai): north to Suruga Bay, Ogasawara and Daito Is.; Utinomi (1965b, 1971): south-west Shikoku, Kochi, north-east Kyushu; Kikuchi (1968): Amakusa Is.; Eguchi (1971): Goto I.; Eguchi (1972a): Izu; Eguchi (1973): Tsushima; Eguchi (1974): Kerama Is.; Eguchi and Miyawaki (1975) and Anonymous (1977): Kushimoto; Kawaguti (1983): Yaeyama Is.; Yamazato et al. (1978): Okinawa; Tribble and Randall (1986): Miyake I.; Tachikawa (pers. comm., 1991): Ogasawara Is. 


\section{Echinophyllia orpheensis}

Veron and Pichon, 1980

Generally uncommon throughout the distribution range. Colonies are usually mottled orange, or have dark yellow-brown septo-costae.

\section{Records:}

This study: Yaeyama and Okinawa Is.

Previous studies: Tachikawa (pers. comm. 1991): Ogasawara Is.

\section{Echinophyllia echinata}

(Saville-Kent, 1871)

Uncommon but very distinctive and colourful, mottled browns and greens being the most common colours. The central corallite of most colonies is often very large. Illustrated in colour: Uchida and Fukuda (1988b).

\section{Records:}

This study: Yaeyama, Okinawa and Amami Is., Tosashimizu, Amakusa Is.

Previous studies: Kawaguti (1983): Yaeyama Is.; Tachikawa (pers. comm., 1991): Ogasawara Is.

\section{Echinophyllia nishihirai \\ Veron, 1990}

Rare, but very conspicuous. Coralla have a very large central corallite with a compact, circular or elongate columella up to $20 \mathrm{~mm}$ diameter. Septo-costae radiate from the central corallite to the corallum perimeter. There are no clearly formed secondary corallites. Colonies are dark, usually mottled, greens and browns. Illustrated in colour: Uchida and Fukuda (1988a) (as Scolymia vitiensis); Veron (1990b).

\section{Records:}

This study: Yaeyama and Okinawa Is., Tosashimizu.

Previous studies: Veron (1990b): Yaeyama and Okinawa Is. 


\title{
Echinophyllia echinoporoides
}

Veron and Pichon, 1980

Rare except in some protected biotopes. Has a similar range of variation in the Philippines. Mostly rust red in colour, often with mottled green or white calices, occasionally grey with green or red calices.

\section{Records:}

This study: Yaeyama, Okinawa and Amami Is.

Previous studies: Not recorded.

\section{Echinophyllia patula}

(Hodgson and Ross, 1982)

Rare, except at Tanegashima where it has the same grey-green colour and appearance as Philippines colonies. This species is primarily distinguished from $E$. aspera by having smaller corallites and finer septo-costae.

\section{Records:}

This study: Yaeyama and Okinawa Is., Tanegashima.

Previous studies: Not recorded.

\section{Genus Oxypora}

\author{
Saville-Kent, 1871
}

\section{Oxypora lacera}

(Verrill, 1864)

Common throughout the Ryukyu Is. to Tanegashima, uncommon in mainland localities. Has a similar range of variation in the Philippines and the Great Barrier Reef. Colonies are usually pale grey or brown at the Ryukyu Is., or yellowish-brown to creamy grey at Tanegashima or bright green (sometimes red) at mainland localities. Illustrated in colour: Shirai (1980), Nishihira (1988), Uchida and Fukuda (1988b).

Paratype 44872 of Oxypora titizimaensis Yabe and Sugiyama, 1935 from Tohoku University was re-examined during the present study and shows no distinguishing characters from O. lacera. 
Records:

This study: Yaeyama, Okinawa and Amami Is., Tanegashima, Tosashimizu, Amakusa Is., Kushimoto, Shirahama, Izu.

Previous studies: Yabe et al. (1936) (as O. titizimaensis): Ogasawara Is.; Kawaguti (1983): Yaeyama Is.; Tachikawa (pers. comm., 1991): Ogasawara Is.

\section{Oxypora glabra \\ Nemenzo, 1959}

Uncommon, frequently thin, brittle sheets. Has a similar range of variation in the Philippines and the Great Barrier Reef. Almost white in colour. Illustrated in colour: Nishihira (1988), Uchida and Fukuda (1988b).

\section{Records:}

This study: Yaeyama Is.

Previous studies: Not recorded except in the abovementioned publications.

\section{Genus Mycedium}

Oken, 1815

\section{Mycedium elephantotus}

(Pallas, 1766)

Common at the Ryukyu Is. and Kushimoto, where it has a very wide colour range. Uncommon at Tanegashima and other mainland localities, but forms large colonies with a wide range of dark colours (predominantly green) and a wide variation in corallite structure. Illustrated in colour: Shirai (1980) (as M. elephantotus and M. tubifex), Nishihira (1988), Uchida and Fukuda (1988b).

\section{Records:}

This study: Yaeyama, Okinawa and Amami Is., Tanegashima, Tosashimizu, Amakusa Is., Kushimoto, Shirahama, Izu.

Previous studies: Eguchi (1974) (as M. elephantotus and M. tubifex): Kerama Is.; Tribble and Randall (1986): Miyake I.; Kawaguti (1983) (as M. elephantotus and $M$. tubifex:): Yaeyama Is.; Tachikawa (pers. comm., 1991): Ogasawara Is. 


\section{Mycedium robokaki \\ Moll and Borel Best, 1984}

Rare, recorded only from Ishigaki I. and not studied in situ. Coralla are similar to those from several equatorial Indo-Pacific countries.

Records:

This study: Yaeyama Is.

Previous studies: Tachikawa (pers. comm., 1991): Ogasawara Is.

\section{Genus Physophyllia}

Duncan, 1884

This is a poorly defined genus with one species. Further study is likely to indicate that $P$. ayleni can be placed in Pectinia.

\section{Physophyllia ayleni}

Wells, 1934

Rare throughout the distribution range. Dark grey in colour. Illustrated in colour: Shirai (1980), Nishihira (1988), Uchida and Fukuda (1988b).

\section{Records:}

This study: Yaeyama and Amakusa Is., Kushimoto, Shirahama.

Previous studies: Yabe et al. (1936): Ogasawara Is., north to Suruga Bay; Kikuchi (1968): Amakusa Is.; Anonymous (1970): Ehime coast; Anonymous (1977): Kushimoto.

\section{Genus Pectinia}

Oken, 1815

\section{Pectinia lactuca}

(Pallas, 1766)

Generally uncommon. Usually found in partly protected biotopes but sometimes found on partly exposed upper reef slopes. Has a similar range of variation in the Philippines and the Great Barrier Reef. Always battleship grey. Illustrated in colour: Shirai (1980) (as P. laciniata), Nishihira (1988), Uchida and Fukuda (1988b). 


\section{Records:}

This study: Yaeyama, Okinawa, Amami and Amakusa Is., Kushimoto

Previous studies: Yabe et al. (1936) (as Tridacophyllia lactuca japonica): north to Tanabe Bay; Utinomi (1965b, 1971): south-west Shikoku, north-east Kyushu; Kikuchi (1968): Amakusa Is.; Anonymous (1970): Ehime coast; Eguchi (1971): Goto I.; Eguchi (1973): Tsushima; Eguchi and Miyawaki (1975) and Anonymous (1977): Kushimoto; Kawaguti (1983): Yaeyama Is.; Shirai (1986): Kii coast; Chou and Yamazato (1990): Okinawa.

\section{Pectinia paeonia}

(Dana, 1846)

Uncommon. Usually restricted to partly protected biotopes. Has a similar range of variation in the Philippines and the Great Barrier Reef. Usually pale orange, yellow or cream. Illustrated in colour: Nishihira (1988), Uchida and Fukuda (1988b).

\section{Records:}

This study: Yaeyama, Okinawa, Amami and Amakusa Is. (laboratory specimen only), Kushimoto, Shirahama (laboratory specimen only).

Previous studies: Yabe et al. (1936) (as Tridacophyllia lactuca tanabensis): north to Tanabe Bay.

\section{Pectinia alcicornis}

(Saville-Kent, 1871)

Uncommon and restricted to protected lagoons. Has a similar range of variation in the Philippines and the Great Barrier Reef. Illustrated in colour: Nishihira (1988), Uchida and Fukuda (1988b).

\section{Records:}

This study: Yaeyama and Okinawa Is.

Previous studies: Kawaguti (1983) (as P. alcicornis and P. plicata): Yaeyama Is.

\section{Pectinia teres}

Nemenzo and Montecillo, 1981

Rare, usually restricted to lower reef slopes. Not studied in situ. Illustrated in colour: Uchida and Fukuda (1988b).

\section{Records:}

This study: Yaeyama Is.

Previous studies: Not recorded except in the abovementioned publication. 


\section{5 \\ Family \\ Mussidae \\ Ortmann, 1890}

\section{Genus Blastomussa}

Wells, 1961

\section{Blastomussa wellsi}

Wijsman-Best, 1973

Rare throughout the distribution range. Usually sub-plocoid but may be completely cereoid, especially in mainland localities. Greenish or red in colour. Illustrated in colour: Nishihira (1988).

\section{Records:}

This study: Okinawa and Amami Is., Tanegashima, Tosashimizu, Amakusa Is., Kushimoto, Tateyama.

Previous studies: Kawaguti (1983): Yaeyama Is.

\section{Blastomussa merleti}

(Wells, 1961)

Very rare, red (station 37), green (station 43) or brownish (stations 2 and 4) in colour. Described in detail by Eguchi (1975a) as Cladocora kabiraensis with Kabira Bay as the type locality and noting that the living polyps have a 'dark green oral disk with purplish brown tentacles'. Has a similar range of variation in the Philippines and the Great Barrier Reef. Illustrated in colour: Shirai (1980) (as Cladocora kabiraensis), Masuda and Hayashi (1989), Nishihira (1988), Uchida and Fukuda (1988b).

\section{Records:}

This study: Yaeyama, Okinawa and Amami Is.

Previous studies: Eguchi (1975) (as Cladocora kabiraensis): Eguchi (1975); Kawaguti (1983) (as Cladocora kabiraensis): Yaeyama Is. 


\section{Genus Cynarina}

Brüggemann, 1877

Yabe and Sugiyama $(1931,1936)$ combined Cynarina with Trachyphyllia in the genus Antillia Yabe and Sugiyama, 1931, and then Antillophyllia Vaughan, 1932. Protolobophyllia Yabe and Sugiyama, 1935 was created for Antillia japonica Yabe and Sugiyama, 1931, a confusion of Cynarina lacrymalis and Scolymia vitiensis Brüggemann, 1877.

\section{Cynarina lacrymalis}

(Edwards and Haime, 1848c)

Very rare, but conspicuous. Three specimens only were observed at Okinawa (Nishihira, pers. comm.) and Tanegashima, two at Shirahama, but not found in situ at Kushimoto. Cream, brown or grey in colour. Illustrated in colour: Masuda and Hayashi (1989), Nishihira (1988), Uchida and Fukuda (1988a).

\section{Records:}

This study: Yaeyama and Okinawa Is., Tanegashima, Tosashimizu, Amakusa Is., Kushimoto, Shirahama.

Previous studies: Yabe and Sugiyama (1931) (as Antillia japonica and $A$. nomaensis): Sima and Suruga Bay; Utinomi (1966, 1971): north-east Kyushu and Kii coast; Eguchi (1971): Goto I.; Eguchi and Miyawaki and Anonymous (1977): Kushimoto; Tribble and Randall (1986) (as Acanthophyllia deshayesiana): Miyake I.; Kawaguti (1983) (as Acanthophyllia sp.): Okinawa; Masuda (1986); Iriomote I.

\section{Genus Scolymia}

Haime, 1852

\section{Scolymia australis}

Edwards and Haime, 1849b

Tribble and Randall's specimen from Miyake I. has been re-examined during the present study and shows no differences from coralla of this species from southern Australia.

\section{Records:}

This study: Not recorded.

Previous studies: Tribble and Randall (1986): Miyake I.; Tachikawa (pers. comm. 1991): Ogasawara Is. 


\section{Scolymia vitiensis}

Brüggemann, 1877

Very rare; observed in the Okinawa Is. by Nishihira (pers, comm.).

Records:

This study: Yaeyama and Okinawa Is.

Previous studies: Tachikawa (pers. comm., 1991); Ogasawara Is.

\section{Genus Australomussa}

Veron, 1985

\section{Australomussa rowleyensis}

Veron, 1985

Rare throughout distribution range and known in the Okinawa Is. from a single lab. specimen. Colonies are dark grey in colour. Illustrated in colour: Uchida and Fukuda (1988b).

\section{Records:}

This study: Yaeyama, Okinawa and Amami Is.

Previous studies: Not recorded except in the abovementioned publication.

\section{Genus Acanthastrea}

Edwards and Haime, 1848

\section{Acanthastrea echinata}

(Dana, 1846)

Generally common throughout the Ryukyu Is., especially on exposed upper reef slopes. Less common in higher latitudes. Colonies are frequently $>100 \mathrm{~mm}$ diameter throughout the distribution range. They have a similar range of variation in the Philippines and the Great Barrier Reef. Usually red, grey or mottled yellow in colour. Illustrated in colour: Uchida and Fukuda (1988b).

\section{Records:}

This study: Yaeyama, Okinawa and Amami Is., Tanegashima, Tosashimizu, Amakusa Is., Kushimoto, Shirahama.

Previous studies: Yabe et al. (1936): north to south-west Shikoku; Kikuchi 
(1968) (as A. cf. echinata): Amakusa Is.; Eguchi (1974): Kerama Is.; Eguchi and Miyawaki (1975) and Anonymous (1977): Kushimoto; Tribble and Randall (1986): Miyake I.; Kawaguti (1983): Yaeyama Is.; Habe (1989): Iriomote I.; Tachikawa (pers. comm., 1991): Ogasawara Is.

\section{Acanthastrea rotundoflora}

Chevalier, 1975

Rare, except as station 11, where colonies were various dark colours. Has a similar appearance in situ as colonies from the Philippines.

Records:

This study: Yaeyama, Okinawa and Amami Is., Tanegashima.

Previous studies: Tribble and Randall (1986): Miyake I.; Kawaguti (1983): Yaeyama Is,

\section{Acanthastrea hillae}

Wells, 1955

Rare, especially in the Ryukyu Is., where colonies are mostly grey, brown or mottled green in colour. At Tanegashima and mainland localities, colonies are also commonly red. Has a similar range of variation on the Great Barrier Reef. Illustrated in colour: Nishihira (1988), Uchida and Fukuda (1988b).

\section{Acanthastrea bowerbanki}

Edwards and Haime, 1857

Rare. As in eastern Australia, living colonies do not have the fleshy appearance of other Acanthastrea species. Coralla are similar to those from eastern Australia.

Records:

This study: Yaeyama and Okinawa Is.,Tosashimizu, Amakusa Is.

Previous studies: Not recorded.

\section{Acanthastrea hemprichii}

(Ehrenberg, 1934)

Generally uncommon, but may form conspicuous orange-yellow colonies over 1m diameter in the Ryukyu Is. and uniform brownish-grey to dark green or red colonies at mainland localities. Has a similar range of variation in the Philippines. Illustrated in colour: Nishihira (1988), Uchida and Fukuda (1988b). 


\section{Records:}

This study: Yaeyama, Okinawa and Amami Is., Tanegashima, Tosashimizu, Amakusa Is., Kushimoto, Shirahama.

Previous studies: Eguchi (1971); Goto I.; Eguchi and Miyawaki (1975) and Anonymous (1977): Kushimoto; Tachikawa (pers. comm., 1991): Ogasawara Is.

\section{Acanthastrea ishigakiensis}

Veron, 1990

Uncommon to rare, but very conspicuous. Colonies massive, usually hemispherical, often $>300 \mathrm{~mm}$ diameter. Corallites are cereoid, becoming plocoid on the colony sides, with angular calices up to $24 \mathrm{~mm}$ diameter. Several colonies were observed at stations $8,10,11,16,17$ and 50 . Colonies have the same appearance and the same structure as those from the Philippines. They are blue-grey in colour, with occasional exceptions. Illustrated in colour: Veron (1990b).

\section{Records:}

This study: Yaeyama, Okinawa and Amami Is., Tanegashima.

Previous studies: Veron (1990): Yaeyama, Okinawa and Amami Is.; Tachikawa (pers. comm. 1991): Ogasawara Is.

\section{Acanthastrea lordhowensis}

Veron and Pichon, 1982

Very rare except in higher latitudes. Has a similar range of variation in the Philippines and the Great Barrier Reef. Colonies have a very wide range of colours (as illustrated, Veron, 1986), most commonly red, less commonly green.

Records:

This study: Okinawa, Amami Is., Tanegashima, Tosashimizu, Amakusa Is., Kushimoto, Izu.

Previous studies: Tachikawa (pers. comm., 1991): Ogasawara Is.

\section{Acanthastrea amakusensis}

Veron, 1990

Rare. Colonies are cerioid, with neat, angular corallites with calices up to $7.5 \mathrm{~mm}$ diameter. The nearest species structurally (and with a similar in situ appearance) is $A$. lordhowensis which has larger, less regular corallites. Colonies are fleshy, brightly coloured, green or red. Illustrated in colour: Veron (1990b). 
Records:

This study: Yaeyama Is., Tanegashima, Tosashimizu, Amakusa Is., Kushimoto, Shirahama, Izu.

Previous studies: Veron (1990): Tanegashima, Amakusa Is., Kushimoto, Shirahama; Tachikawa (pers. comm. 1991): Ogasawara Is.

\section{Genus Lobophyllia}

de Blainville, 1830

\section{Lobophyllia hemprichii}

(Ehrenberg, 1834)

The most common Lobophyllia. Colonies from the Ryukyu Is. have a similar range of variation as those from the Philippines and the Great Barrier Reef but at the Amakusa Is. they are extremely fleshy. Illustrated in colour: Shirai (1980), Nishihira (1988), Uchida and Fukuda (1988b).

\section{Records:}

This study: Yaeyama, Okinawa and Amami Is., Tanegashima, Amakusa Is., Kushimoto, Shirahama.

Previous studies: Yabe et al. (1936) (as L. costata, L. hemprichii and L. robusta): Ogasawara and Daito Is. and Okinawa and Amami Is.; Kikuchi (1968) (as Lobophyllia costata): Amakusa Is.; Eguchi (1971): Goto I.; Eguchi (1974) (as L. costata and L. hemprichii): Yaeyama Is. and Kerama Is.; Anonymous (1977): Kushimoto; Yamazato et al. (1978) (as L. costata): Okinawa;; Kawaguti (1983) (as L. hemprichii and L. costata); Okinawa; Tribble and Randall (1986): Miyake I.; Shirai (1986): Kii coast; Habe (1989): Iriomote I. ; Chou and Yamazato (1990): Okinawa; Tachikawa (pers. comm., 1991): Ogasawara Is.

\section{Lobophyllia corymbosa}

(Forskål, 1775)

Uncommon in the Ryukyu Is., rare at Tanegashima. Has the same appearance in situ in the Philippines and the Great Barrier Reef where it exhibits little growth form variation. Usually blue-grey in colour, but may be creamy-yellow. Illustrated in colour: Shirai (1980), (as L. costata), Nishihira (1988), Uchida and Fukuda (1988b). 


\section{Records:}

This study: Yaeyama, Okinawa and Amami Is., Tanegashima.

Previous studies: Yabe et al. (1936): Ogasawara Is.; ?Eguchi (1971): Goto I.; Yamazato et al. (1978): Okinawa; Kawaguti (1983): Yaeyama Is.; Habe (1989): Iriomote I.; Tachikawa (pers. comm., 1991): Ogasawara Is.

\section{Lobophyllia pachysepta \\ Chevalier, 1975}

Uncommon throughout the distribution range and seldom forms colonies over $300 \mathrm{~mm}$ diameter. Exsert septo-costae are the same yellow colour in the Philippines and the Great Barrier Reef. Mlustrated in colour: Nishihira (1988).

\section{Records:}

This study: Yaeyama and Okinawa Is.

Previous studies: Not recorded except in the abovementioned publication.

\section{Lobophyllia hataii}

Yabe, Sugiyama and Eguchi, 1936

Rare throughout the distribution range, but very distinctive. Similar to Great Barrier Reef colonies. Usually mottled dark bluish-grey and cream in colour. Illustrated in colour: Uchida and Fukuda (1988b).

\section{Records:}

This study: Yaeyama, Okinawa and Amami Is., Tanegashima, Amakusa Is., Kushimoto.

Previous studies: Ooishi (1970) (as Lobophylia (Palauphyllia) hataii): Ogasawara and Volcano Is.; Eguchi (1971) (as Palauphyllia hataii): Goto I.; Eguchi (1974) (as Lobophyllia (Palauphyllia) hataii): Yaeyama Is.; Tribble and Randall (1986): Miyake I.; Kawaguti (1983): Yaeyama Is.; Tachikawa (pers. comm., 1991): Ogasawara Is.

\section{Lobophyllia robusta}

\section{Yabe, Sugiyama and Eguchi}

Uncommon, but sometimes forms conspicuous colonies over $2 \mathrm{~m}$ diameter. Has the same appearance in situ and a similar range of variation as colonies from the Philippines. Very large colonies have not been found on the Great Barrier Reef, but Lobophyllia sp. from east Australia of Veron et al. (1980) is probably this species. Usually dark blue-grey in colour. 


\section{Records:}

This study: Yaeyama, Okinawa and Amami Is., Tanegashima, Amakusa Is.

Previous studies: Yabe et al. (1936): north to Suruga Bay; Kikuchi (1968): Amakusa Is.; Anonymous (1977): Kushimoto.

\section{Genus Symphyllia}

Edwards and Haime, 1848

\section{Symphyllia recta}

(Dana, 1846)

Sometimes common. Has a similar range of variation in the Philippines and the Great Barrier Reef. Has a wide colour range. Illustrated in colour: Shirai (1980), Nishihira (1988), Uchida and Fukuda (1988b).

\section{Records:}

This study: Yaeyama, Okinawa and Amami Is.

Previous studies: Yabe et al. (1936): Ogasawara, Daito, Okinawa and Amami Is.; Anonymous (1970): Ehime coast; Eguchi (1974): Kerama Is.; Yamazato et al. (1978) (as S. nobilis); Kawaguti (1983): Yaeyama Is.; Habe (1989): Iriomote I. ; Chou and Yamazato (1990): Okinawa; Tachikawa (pers. comm., 1991): Ogasawara Is.

\section{Symphyllia radians}

\section{Edwards and Haime, 1849}

Probably less common than S. recta. In the Ryukyu Is., this species has a similar range of variation and the same appearance in situ as colonies from the Philippines and Great Barrier Reef, but at Tanegashima, where it is rare, colonies are small, encrusting, and brick- or bright red in colour. Illustrated in colour: Shirai (1980), Uchida and Fukuda (1988b).

\section{Records:}

This study: Yaeyama, Okinawa and Amami Is., Tanegashima, Tosashimizu.

Previous studies: Yabe et al. (1936): north to south-west Shikoku; Anonymous (1970): Ehime coast; Tribble and Randall (1986): Miyake I.; Kawaguti (1983): Yaeyama Is.; ?Shirai (1986): Kii coast; Chou and Yamazato (1990): Okinawa; Tachikawa (pers. comm., 1991): Ogasawara Is. 


\section{Symphyllia agaricia}

Edwards and Haime, 1849

Uncommon throughout the distribution range, except in isolated locations (notably station 11). Rare at Tanegashima, but forms large blue-grey colonies. Has a similar range of variation in the Philippines and the Great Barrier Reef. Illustrated in colour: Nishihira (1988),Uchida and Fukuda (1988b).

\section{Records:}

This study: Yaeyama, Okinawa and Amami Is., Tanegashima, Tosashimizu

Previous studies: Yabe et al. (1936): Ogasawara Is. and Yaeyama, Okinawa and Amami Is.; Anonymous (1970) (as Lobophyllia hemprichii): Ehime coast; Tachikawa (pers. comm., 1991): Ogasawara Is.

\section{Symphyllia valenciennesii}

Edwards and Haime, 1849

Rare throughout the distribution range. Colonies at the Ryukyu Is. are mostly grey and have a similar range of variation in the Philippines and the Great Barrier Reef. Colonies at mainland localities are distinctive, with thick, fleshy polyps of a wide range of colours, including brown, red, blue, grey and green. There is some doubt that Ryukyu Is. and mainland colonies are the same species. The latter are distinguished, at least, as a geographic sub-species. Illustrated in colour: Nishihira (1988), Uchida and Fukuda (1988b).

\section{Records:}

This study: Yaeyama, Okinawa and Amami Is., Tosashimizu, Amakusa Is., Kushimoto, Shirahama.

Previous studies: Yabe et al. (1936): south-west Shikoku; Tachikawa (pers. comm., 1991): Ogasawara Is. 



\section{6

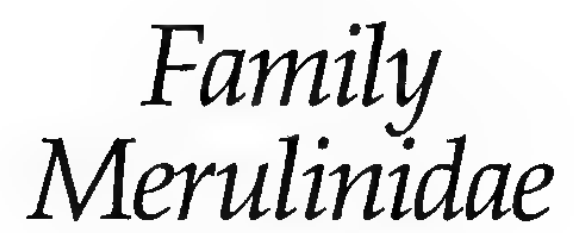 \\ Verrill, 1866}

\section{Genus Boninastrea}

Yabe and Sugiyama, 1935

This genus has not been found in the Ryukyu Is. or mainland Japan.

\section{Boninastrea boninensis}

Yabe and Sugiyama, 1935

This species superficially resembles Platygyra contorta and, as the holotype was believed lost, was confused with this species by Veron (1986,) and Nishihira (1988).

Records:

This study: Not found.

Previous studies: Yabe et al. (1936): Ogasawara Is.; Tachikawa (pers. comm., 1991): Ogasawara Is.

\section{Genus Hydnophora}

Fischer de Waldheim, 1807

\section{Hydnophora rigida}

(Dana, 1846)

Common throughout the distribution range where it frequently forms extensive monospecific stands in shallow water of both exposed (eg. stations 8, 11 and 41) and protected (eg. stations 9 and 18) biotopes. Has a similar range of variation in the Philippines and the Great Barrier Reef. Uniform pale grey-brown in colour. Illustrated in colour: Masuda and Hayashi (1989), Nishihira (1988), Uchida and Fukuda (1988b). 


\title{
Records:
}

This study: Yaeyama, Okinawa and Amami Is,

Previous studies: Yabe et al. (1936) (as Merulina laxa): Yaeyama and Okinawa Is.; Eguchi (1974) (as Merulina laxa): Yaeyama Is.; Yamazato et al. (1978) (as Merulina laxa): Okinawa; Kawaguti (1983) (as H. laxa and Merulina laxa): Okinawa; Habe (1989): Iriomote I.

\section{Hydnophora bonsai}

\author{
Veron, 1990
}

Uncommon. Colonies are encrusting, plate-like, with short irregular branchlike upgrowths. Colonies are mostly pale colours; tentacles are not extended during the day. This species is apparently a high-latitude Japanese endemic. The growth form is similar to $\mathrm{H}_{4}$ exesa but is finer, with relatively stunted branches.

\section{Records:}

This study: Tosashimizu, Amakusa Is., Kushimoto, Shirahama, Izu.

Previous studies: Veron (1990): Amakusa Is., Kushimoto, Shirahama.

\section{Hydnophora exesa}

(Pallas, 1766)

Uncommon throughout the Ryukyu Is. but common in mainland localities. Usually plate-like. Tentacles are usually retracted during the day in the Ryukyu Is., but are usually extended in mainland localities. Usually pale coloured, but may be green, red or brown at Shirahama. Recorded in most studies north to Tateyama Peninsula. Illustrated in colour: Shirai (1980), Nishihira (1988), Uchida and Fukuda (1988b).

\section{Records:}

This study: Yaeyama, Okinawa and Amami Is., Tanegashima, Tosashimizu, Amakusa Is., Kushimoto, Shirahama, Izu, Tateyama.

Previous studies: Yabe et al. (1936) (as H. grandis): north to Sagami Bay; Hamada (1963b): Tateyama; Eguchi (1968): Sagami Bay; Utinomi (1965b, 1971): south-west Shikoku, north-east Kyushu; Kikuchi (1968): Amakusa Is.; Anonymous (1970): Ehime coast; Eguchi (1973): Tsushima; Ooishi (1970): Ogasawara and Volcano Is.; Eguchi (1971): Goto I.; Eguchi (1972a): Izu; Eguchi and Miyawaki (1975) and Anonymous (1977): Kushimoto; Tribble and Randall (1986): Miyake I., Kawaguti (1983): Yaeyama Is.; Kikuchi (1985): Tsuji-shima; Shirai (1986): Kiĩ coast; Habe (1989); Iriomote I. ; Chou and Yamazato (1990): Okinawa; Tachikawa (pers. comm., 1991): Ogasawara Is. 


\section{Hydnophora microconos}

(Lamarck, 1816)

Generally rare throughout the distribution range. Has a similar range of variation in the Philippines and the Great Barrier Reef. Usually mottled or uniform yellowish-brown in colour. Illustrated in colour: Shirai (1980), Nishihira (1988), Uchida and Fukuda (1988b).

\section{Records:}

This study: Yaeyama, Okinawa and Amami Is.

Previous studies: Yabe et al. (1936): Daito Is.; Eguchi (1974): Yaeyama Is. and Kerama Is.; Yamazato et al. (1978): Okinawa; Kawaguti (1983): Yaeyama Is.; Chou and Yamazato (1990): Okinawa.

\section{Genus Merulina}

Ehrenberg, 1834

\section{Merulina ampliata}

(Ellis and Solander, 1786)

Common, colonies frequently form flat plates, with or without nodular upgrowths in the Ryukyu Is. and are almost always without nodular upgrowths in mainland localities. Always yellowish-orange in colour. Illustrated in colour: Shirai (1980), Nishihira (1988), Uchida and Fukuda (1988b, not p. 47).

\section{Records:}

This study: Yaeyama, Okinawa and Amami Is., Tanegashima.

Previous studies: Yabe et al. (1936): Ogasawara and Daito Is, north to east Kyushu; Ooishi (1970): Ogasawara and Volcano Is.; Eguchi (1974): Yaeyama Is. and Kerama Is.; Yamazato et al. (1978): Okinawa; Kawaguti (1983): Yaeyama Is.; Habe (1989): Iriomote I. ; Chou and Yamazato (1990); Okinawa; Tachikawa (pers. comm., 1991): Ogasawara Is.

\section{Merulina scabricula}

Dana, 1846

Common in the Ryukyu Is. where colonies usually have bluish extremities, and a similar range of variation in the Philippines and the Great Barrier Reef. Rare at Tanegashima where colonies consist only of flat sheets which are a dark yellowish-orange. Illustrated in colour: Nishihira (1988), Uchida and Fukuda(1988b). 


\section{Records:}

This study: Yaeyama, Okinawa and Amami Is., Tanegashima.

Previous studies: Not recorded except in the abovementioned publication.

\section{Genus Scapophyllia}

Edwards and Haime, 1848

\section{Scapophyllia cylindrica}

(Edwards and Haime, 1848)

Uncommon, especially on upper exposed reef slopes. Colonies are are usually plate like, rarely columnar. Skeletal detail is similar to that of Great Barrier Reef coralla. Usually very pale brown.

\section{Records:}

This study: Yaeyama, Okinawa and Amami Is.

Previous studies: Yabe et al. (1936): Ogasawara Is.; Tachikawa (pers. comm., 1991): Ogasawara Is. 


\section{7 \\ Family \\ Faviidae \\ Gregory, 1900}

\section{Genus Caulastrea}

Dana, 1846

\section{Caulastrea echinulata}

(Edwards and Haime, 1949)

Rare throughout the distribution range.

\section{Records:}

This study: Yaeyama, Okinawa and Amami Is.

Previous studies: Probably not recorded.

\section{Caulastrea furcata \\ Dana, 1846}

Generally common, forming extensive compact colonies in exposed biotopes. Some coralla, especially those from shallow biotopes, are strongly costate and have irregular corallite walls and irregularly exsert septa. Usually phaceloid but may become completely plocoid. Brown with yellow exsert septa. Illustrated in colour: Masuda and Hayashi (1989), Nishihira (1988), Uchida and Fukuda (1988b).

\section{Records:}

This study: Yaeyama, Okinawa and Amami Is.

Previous studies: ?Yabe et al. (1936) (as C. furcata and C. aiharai: north to Suruga Bay; Ooishi (1970): Ogasawara and Volcano Is.; ?Eguchi (1971): Goto I.; Kawaguti (1983): Yaeyama Is.; Veron's (1988) records of E. echinulata from Ishigaki I. are the present species. 


\section{Caulastrea tumida}

Matthai, 1928

Generally uncommon in the Ryukyu Is., becoming relatively common in mainland localities. As in the Philippines, colonies may be sub-plocoid, even plocoid. Yellow-brown to grey-green in colour. Recorded in most studies north to Shirahama. Illustrated in colour: Shirai (1980), Masuda and Hayashi (1989), Nishihira (1988), Uchida and Fukuda (1988b).

Records:

This study: Yaeyama, Okinawa and Amami Is., Tanegashima, Amakusa Is., Kushimoto, Shirahama.

Previous studies: Yabe et al. (1936) (as C. tumida, C. tumida multiseptata and C. tumida conglobata): north to Tanabe Bay; Utinomi (1965b, 1966, 1971): south-west Shikoku, Kii coast and north-east Kyushu; Kikuchi (1968): Amakusa Is.; Anonymous (1970): Ehime coast; Yagi (1970): Ehime coast; Eguchi (1973): Tsushima; Eguchi and Miyawaki (1975) and Anonymous (1977): Kushimoto; Tribble and Randall (1986): Miyake I.; Kawaguti (1983): Yaeyama Is.; Shirai (1986): Kii coast; Habe (1989): Iriomote I.; Tachikawa (pers. comm., 1991): Ogasawara Is.

Yabe's collections of the three subspecies listed above were re-examined during the present study; they fall within the normal variation of the species.

\section{Caulastrea curvata}

Wijsman-Best, 1972

Rare, recorded from a single outcrop at station 45. The corallum shows no significant differences from those from the Great Barrier Reef.

Records:

This study: Okinawa Is.

Previous studies: Not recorded.

\section{Genus Favia}

Oken, 1815

It is likely that there are more species of Favia in Japan than are included in the present account. Illustrated specimens, presumably holotypes, of Favia rariseptata Eguchi and Shirai, 1977; F. elongata Eguchi and Shirai, 1977; and F. deformis Eguchi and Shirai, 1977 have been re-examined by the author and are believed unlikely to be valid species. Favia sp. nov., illustrated Shirai (1980, top of p. 551), has 
been recognised in situ as possibly a distinct species which, as yet, remains unstudied. A single corallum of what is likely to be Favia sp.2 of Veron et al. (1977), from Okinawa, remains to be verified.

\section{Favia stelligera}

(Dana, 1846)

Generally common in some localities. Restricted to exposed biotopes where columnar colonies may be large and conspicuous. Has a similar range of variation in the Philippines and the Great Barrier Reef. Illustrated in colour: Masuda and Hayashi (1989), Nishihira (1988), Uchida and Fukuda (1988b).

\section{Records:}

This study: Yaeyama, Okinawa and Amami Is.

Previous studies: Yabe et al. (1936): Daito Is.; Habe (1989): Iriomote I.

\section{Favia laxa}

(Klunzinger, 1879)

Uncommon throughout distribution range and not studied in detail. There appears to be no significant difference between Ryukyu I. and mainland coralla. Colonies are mostly dark brown or dark red-brown.

\section{Records:}

This study: Yaeyama and Okinawa Is., Tanegashima, Tosashimizu, Amakusa Is., Kushimoto.

Previous studies: Kawaguti (1983): Yaeyama Is.

\section{Favia helianthoides}

Wells, 1954

Rare throughout distribution range. Coralla from the Ryukyu Is. and the mainland show no significant differences and are similar to those from the Philippines and the Great Barrier Reef. Pale orange-brown in colour at the Ryukyu Is., dark colours at mainland localities. Illustrated in colour: Uchida and Fukuda (1988b).

\section{Records:}

This study: Yaeyama and Okinawa Is., Tosashimizu, Amakusa Is., Kushimoto.

Previous studies: Not recorded except in the abovementioned publication. 


\section{Favia pallida}

(Dana, 1846)

Common throughout the Ryukyu Is. and Tanegashima, uncommon further north. Corallites of Ryukyu Is. colonies usually have dark calices as do those of the Philippines and the Great Barrier Reef. Colonies in mainland localities have a wider range of colours. Illustrated in colour: Nishihira (1988), Uchida and Fukuda (1988b).

\section{Records:}

This study: Yaeyama, Okinawa and Amami Is., Tanegashima, Tosashimizu, Amakusa Is., Kushimoto.

Previous studies: Yabe et al. (1936) (as F. speciosa): north to Suruga Bay; Ooishi (1970): Ogasawara and Volcano Is.; Kikuchi (1968): Amakusa Is.; Eguchi (1973): Tsushima; Eguchi (1974) (? as F. speciosa): Yaeyama Is. and Kerama Is.; Utinomi (1971) (as F. speciosa): north-east Kyushu; Kawaguti (1983): Yaeyama Is.; Chou and Yamazato (1990): Okinawa; Tachikawa (pers. comm., 1991): Ogasawara Is.

\section{Favia speciosa}

(Dana, 1846)

Relatively common, especially in mainland localities, but readily confused with $F$. pallida. Ryukyu Is, colonies have uniform colours, usually pale brown. Mainland colonies are often more colourful. Has a similar range of variation in the Philippines and the Great Barrier Reef except that corallites tend to be relatively small. Illustrated in colour: Nishihira (1988), Uchida and Fukuda (1988b).

\section{Records:}

This study: Yaeyama, Okinawa and Amami Is., Tanegashima, Tosashimizu, Amakusa Is., Kushimoto, Shirahama, Izu, Tateyama.

Previous studies: Kikuchi (1968): Amakusa Is,; Eguchi (1971): Goto I.; Eguchi (1972a): Izu; Eguchi (1973): Tsushima; Eguchi and Miyawaki (1975) and Anonymous (1977): Kushimoto: Tribble and Randall (1986): Miyake I.; Kawaguti (1983): Yaeyama Is.; Kikuchi (1985): Tsuji-shima; Habe (1989): Iriomote I. ; Chou and Yamazato (1990): Okinawa; Tachikawa (pers. comm., 1991): Ogasawara Is.

\section{Favia lizardensis}

\section{Veron, Pichon and Wijsman-Best, 1977}

Generally uncommon throughout the distribution range except at Tanegashima where it is common. Has a similar range of variation in the Philippines and the Great Barrier Reef. As on the Great Barrier Reef, colonies are 
characteristically pinkish-brown with cream or greenish oral discs. Illustrated in colour: Nishihira (1988).

\section{Records:}

This study: Yaeyama, Okinawa and Amami Is., Tanegashima, Tosashimizu, Amakusa Is., Kushimoto, Izu?

Previous studies: Tachikawa (pers. comm., 1991): Ogasawara Is.

\section{Favia danae}

Verrill, 1872

Common in some Ryukyu I. localities where colonies are usually mottled green, yellow-green and brown. Uncommon at Tanegashima where colonies are mostly dark colours.

\section{Records:}

This study: Yaeyama and Okinawa Is., Tanegashima, Tosashimizu.

Previous studies: Not recorded.

\section{Favia favus}

(Forskål, 1775)

Generally uncommon throughout the Ryukyu Is.; generally common in mainland localities. Has a similar range of variation in the Philippines and the Great Barrier Reef. Has a wide range of colours, either uniform colours, or with oral discs and walls of different colours. Is darker in high latitude localities. Illustrated in colour: Nishihira (1988), Uchida and Fukuda (1988b).

\section{Records:}

This study: Yaeyama, Okinawa and Amami Is., Tanegashima, Tosashimizu, Amakusa Is., Kushimoto, Shirahama.

Previous studies: Tribble and Randall (1986): Miyake I.; Habe (1989): Iriomote I. ; Chou and Yamazato (1990): Okinawa; Tachikawa (pers. comm., 1991): Ogasawara Is.

\section{Favia matthaii}

Vaughan, 1918

Common throughout the distribution range. Has a similar range of variation in the Philippines and the Great Barrier Reef. and a similarly wide colour range. Illustrated in colour: Nishihira (1988). 


\section{Records:}

This study: Yaeyama, Okinawa and Amami Is.

Previous studies: Tribble and Randall (1986): Miyake I.; Habe (1989): Iriomote I.; Tachikawa (pers. comm. 1991): Ogasawara Is.

\section{Favia rotumana}

(Gardiner, 1899)

Rare and not studied in situ where it is readily confused with several Platygyra species. The colour of colonies has not been recorded.

Records:

This study: Yaeyama, Okinawa and Amami Is., Tanegashima.

Previous studies: Kawaguti (1983): Yaeyama Is.; Chou and Yamazato (1990): Okinawa; Tachikawa (pers. comm. 1991): Ogasawara Is.

\section{Favia maxima}

Veron, Pichon and Wijsman-Best, 1977

Rare, usually pale colours, in the Philippines.

\section{Records:}

This study: Yaeyama, Okinawa and Amami Is., Tanegashima, Tosashimizu, Shirahama.

Previous studies: Tachikawa (pers. comm., 1991): Ogasawara Is.

\section{Favia rotundata}

(Veron, Pichon and Wijsman-Best, 1977)

Rare throughout the distribution range. Corallites are slightly smaller than usual in Great Barrier Reef coralla. The distinctive grey and orange colouration of Great Barrier Reef colonies is not always found in Japanese colonies, which are sometimes greenish-yellow. Illustrated in colour: Nishihira (1988).

Records:

This study: Yaeyama Is., Okinawa Is., Tanegashima, Kushimoto.

Previous studies: Tachikawa (pers. comm., 1991): Ogasawara Is. 


\section{Favia veroni}

Moll and Borel Best, 1984

Uncommon throughout the distribution range. Has a similar range of variation as colonies from the Philippines and the Great Barrier Reef. Pale coloured in the Ryukyu Is., usually dark in mainland localities. Illustrated in colour: Nishihira (1988), Uchida and Fukuda (1988b).

\section{Records:}

This study: Yaeyama, Okinawa and Amami Is., Tanegashima, Tosashimizu, Amakusa Is., Kushimoto, Shirahama.

Previous studies: Tachikawa (pers. comm., 1991): Ogasawara Is.

\section{Favia maritima}

(Nemenzo, 1971)

Uncommon throughout the distribution range. Usually dark colours.

\section{Records:}

This study: Yaeyama, Okinawa and Amami Is.

Previous studies: Tachikawa (pers, comm., 1991): Ogasawara Is.

\section{Favia sp.}

Rare; known in Japan from two coralla only. This may be the same species as Favia sp. of Veron and Hodgson (1989), known from Thailand and the Philippines. These coralla are primarily characterised by small corallites $(4-5.5 \mathrm{~mm}$ diameter) with neat septa and a well-developed paliform crown. They are close to F. laxa, differing primarily in having corallites with thinner, (Barabattoia-like) walls.

\section{Records:}

This study: Okinawa Is.

Previous studies: Not recorded. 


\section{Genus Barabattoia}

Yabe and Sugiyama, 1941

\section{Barabattoia amicorum}

(Edwards and Haime, 1850)

Generally uncommon throughout the distribution range. Has a similar range of variation in the Philippines and the Great Barrier Reef. Has a wide colour range, commonly uniform dark brown. Illustrated in colour: Shirai (1980) (as $B$. mirabilis), Nishihira (1988), Uchida and Fukuda (1988b).

\section{Records:}

This study: Yaeyama, Okinawa and Amami Is., Tanegashima, Tosashimizu, Amakusa Is., Kushimoto, Shirahama.

Previous studies: Ooishi (1970) (as Barabattoia mirabilis): Ogasawara and Volcano Is.; Kawaguti (1983) (as B. mirabilis): Okinawa; Tachikawa (pers. comm., 1991): Ogasawara Is.

\section{Genus Favites}

Link, 1807

\section{Favites abdita}

(Ellis and Solander, 1786)

Common over a wide range of habitats. Has a similar range of variation in the Philippines and the Great Barrier Reef. Usually honey or cream coloured; colonies from mainland localities have a wider range of darker (grey, green and brown) colours. Recorded in most studies north to Izu Peninsula. Illustrated in colour: Shirai (1980), Masuda and Hayashi (1989), Nishihira (1988), Uchida and Fukuda (1988b).

\section{Records:}

This study: Yaeyama, Okinawa and Amami Is., Tanegashima, Tosashimizu, Amakusa Is.; Kushimoto, Shirahama, Izu.

Previous studies: Yabe et al. (1936): Ogasawara and Daito Is. and north to Suruga Bay; Hamada (1963b) (as F. favosa): south-west Shikoku; Utinomi (1965b, 1971): south-west Shikoku, north-east Kyushu; Kikuchi (1968): Amakusa Is.; Anonymous (1970): Ehime coast; Yagi (1970): Ehime coast; Eguchi (1972a) (as F. favosa): Izu; Eguchi (1974): Yaeyama Is. and Kerama Is.; Eguchi and Miyawaki (1975) and Anonymous (1977): Kushimoto: Ooishi (1970): Ogasawara and Volcano Is.; Kawaguti (1983): Yaeyama Is.; Kikuchi (1985): Tsuji-shima; Shirai (1986): Kii coast; Habe (1989): Iriomote I. ; Chou and Yamazato (1990): Okinawa. 


\section{Favites halicora}

(Ehrenberg, 1834)

Usually uncommon. Has a similar range of variation in the Philippines and the Great Barrier Reef. Usually cream or yellowish-brown in colour. Illustrated in colour: Nishihira (1988), Uchida and Fukuda (1988b) (p. 210).

\section{Records:}

This study: Yaeyama and Okinawa Is.

Previous studies: Eguchi (1974): Kerama Is.; Tribble and Randall (1986): Miyake I.; Kawaguti (1983): Yaeyama Is.; Chou and Yamazato (1990): Okinawa; Tachikawa (pers. comm., 1991): Ogasawara Is.

\section{Favites flexuosa \\ (Dana, 1846)}

Generally uncommon throughout the distribution range. Has a similar range of variation in the Philippines and the Great Barrier Reef. Illustrated in colour: Nishihira (1988), Uchida and Fukuda (1988b).

\section{Records:}

This study: Yaeyama, Okinawa and Amami Is., Tanegashima, Tosashimizu, Amakusa Is., Kushimoto, Shirahama, Izu.

Previous studies: Yabe et al. (1936) (as F. favosa and F. virens, (pars)): north to between Shirahama and Kushimoto; Kikuchi (1968) (as F. virens): Amakusa Is.; Utinomi (1971) (as F. virens): north-east Kyushu (Utinomi, 1971 places 'Gen. et sp. nov.?' of Yabe et al., 1936 in synonomy with F. virens); Eguchi (1971) (as F. cf. virens): Goto I.; Eguchi (1974) (as F. virens): Yaeyama Is. and Kerama Is.; Eguchi and Miyawaki (1975) (as F. favosa and F.flexuosa) and Anonymous (1977): (as F. favosa and ?F. virens): Kushimoto; Tribble and Randall (1986): Miyake I.; Kawaguti (1983): Yaeyama Is.; Shirai (1986): Kii coast; Tachikawa (pers. comm., 1991): Ogasawara Is.

\section{Favites chinensis}

(Verrill, 1866)

Sometimes common, especially at Tanegashima where it forms large colonies which are dark coloured, often with pale grey rings around mouths. Has a similar range of variation in the Philippines and the Great Barrier Reef. Illustrated in colour: Masuda and Hayashi (1989), Nishihira (1988). 


\section{Records:}

This study: Yaeyama, Okinawa and Amami Is., Tanegashima, Tosashimizu, Amakusa Is.

Previous studies: Habe (1989); Iriomote I.

\section{Favites complanata}

(Ehrenberg, 1834)

Generally uncommon. Usually uniform pale grey, brown or cream in colour, except at Tanegashima where it is generally common and has a wide colour range. Has a similar range of variation in the Philippines and the Great Barrier Reef. Probably recorded in most studies of mainland corals under several names, most of which have not been verified.

\section{Records:}

This study: Yaeyama, Okinawa and Amami Is., Tanegashima, Tosashimizu, Amakusa Is., Kushimoto, Shirahama, Izu.

Previous studies: Yabe et al. (1936) (as F. virens (pars)): north to south-west Shikoku; Kawaguti (1983): Yaeyama Is.; Tachikawa (pers. comm., 1991): Ogasawara Is.

\section{Favites pentagona}

(Esper, 1794)

Common throughout the Ryukyu Is. and at Tanegashima, where it has a wide range of uniform or mottled colours, pale brown or cream being the most common. Generally uncommon in mainland localities where colonies are usually encrusting and have a very wide range of pale or bright colour combinations. Has a similar range of variation in the Philippines and the Great Barrier Reef. Illustrated in colour: Nishihira (1988), Uchida and Fukuda (1988b).

\section{Records:}

This study: Yaeyama, Okinawa and Amami Is., Tanegashima, Tosashimizu, Amakusa Is., Kushimoto, Shirahama, Izu.

Previous studies: Yabe et al. (1936); north to between Shirahama and Kushimoto; Kikuchi (1968): Amakusa Is.; Utinomi (1971): north-east Kyushu; Eguchi (1974): Yaeyama Is. and Kerama Is.; Tribble and Randall (1986): Miyake I; Kawaguti (1983): Yaeyama Is.; Shirai (1986): Kii coast; Tachikawa (pers. comm., 1991): Ogasawara Is. 


\section{Favites stylifera \\ Yabe and Sugiyama, 1937}

Probably rare. Like $F$. pentagona but with smaller corallites. Corallites are angular, septa are few and irregular, with irregular dentations. A paliform crown is weakly developed. The only recorded colour is cream with dark colony sides.

\section{Records:}

This study: Yaeyama and Okinawa Is.

Previous studies: Yabe and Sugiyama (1937): Amami Is. and south Kyushu.

\section{Favites russelli}

(Wells, 1954)

Rare throughout the Ryukyu Is, but common in mainland localities. Has a similar range of variation in the Philippines and the Great Barrier Reef. Colonies have a wide range of colours, commonly green or pale grey. Illustrated in colour: Nishihira (1988).

\section{Records:}

This study: Yaeyama, Okinawa and Amami Is., Tanegashima, Tosashimizu, Amakusa Is., Kushimoto, Shirahama.

Previous studies: Tachikawa (pers. comm., 1991): Ogasawara Is.

\section{Genus Goniastrea}

Edwards and Haime, 1848

Four specimens, all from Tanegashima, are close to G. favulus, but differ in having very granulated septa with a high degree of septal fusion. These specimens may represent a separate species.

\section{Goniastrea retiformis}

(Lamarck, 1816)

Generally common in shallow, exposed biotopes except at Tanegashima, where it is rare. Has a similar range of variation in the Philippines and the Great Barrier Reef. Usually pale orange-brown throughout the distribution range, but may be bright green where light is limiting (eg. station 8), Illustrated in colour: Nishihira (1988), Uchida and Fukuda (1988b). 


\section{Records:}

This study: Yaeyama, Okinawa and Amami Is., Tanegashima, Tosashimizu.

Previous studies: Yabe et al. (1936): Ogasawara and Daito Is. and north to south-west Shikoku; Kikuchi (1968): Amakusa Is.; Anonymous (1970) (as G. pectinata): Ehime coast; Eguchi (1974): Yaeyama Is. and Kerama Is.; Miyawaki (1978): Kushimoto; Yamazato et al. (1978): Okinawa; Kawaguti (1983): Yaeyama Is.; Habe (1989): Iriomote I. ; Chou and Yamazato (1990): Okinawa; Tachikawa (pers. comm., 1991): Ogasawara Is.

\section{Goniastrea edwardsi}

Chevalier, 1971

Occupies the same biotopes as G. retiformis, where it is probably more common and is the same pale orange-brown colour. Has a similar range of variation in the Philippines and the Great Barrier Reef. Illustrated in colour: Uchida and Fukuda (1988b).

\section{Records:}

This study: Yaeyama, Okinawa and Amami Is., Tosashimizu.

Previous studies: Yabe et al. (1936) (as G. parvistella): Yaeyama and Miyako Is.; Eguchi (1974) (as G. parvistella): Yaeyama Is.; Habe (1989): Iriomote I.

\section{Goniastrea favulus}

(Dana, 1846)

Uncommon to rare, except at stations 13 and 73 where honey-coloured colonies are relatively common. These have the same appearance in situ as Great Barrier Reef colonies.

\section{Records:}

This study: Yaeyama, Okinawa and Amami Is., Tanegashima, Tosashimizu, Amakusa Is., Kushimoto, Shirahama, Izu.

Previous studies: Tribble and Randall (1986): Miyake I.

\section{Goniastrea aspera}

Verrill, 1905

Uncommon in most localities but may be common in some (eg.stations 11, 13 and 16). Appears to have very localised dispersal in some sub-tidal biotopes. Coralla are similar to those from the Philippines and the Great Barrier Reef. Usually 
a uniform pale to dark orange-brown throughout the distribution range. Illustrated in colour: Shirai (1980) (as G. pectinata), Nishihira (1988), Uchida and Fukuda (1988b).

\title{
Records:
}

This study: Yaeyama, Okinawa and Amami Is., Tanegashima, Tosashimizu, Izu.

Previous studies: Yabe et al. (1936) (as G. aspera (pars) and G. yamanarii): Ogasawara Is. and north to south Kyushu; Eguchi (1974): Yaeyama Is. and Kerama Is.; Eguchi and Miyake (1975) and Anonymous (1977) (as G. pectinata): Kushimoto; Yamazato et al. (1978) (as G. aspera and G. incrustans): Okinawa; Kawaguti (1983) (as G. spectabilis): Okinawa; Habe (1989): Iriomote I.; Tachikawa (pers. comm., 1991): Ogasawara Is.

\section{Goniastrea deformis}

\author{
Veron, 1990
}

Uncommon and probably largely confined to high latitude localities. Coralla are massive, cerioid, with angular to irregular corallites up to $8.8 \mathrm{~mm}$ diameter. Septa are equal or slightly alternate and usually have strong, almost Acanthastrealike dentations and granulated sides. Most coralla have a high degree of septal fusion. Paliform lobes are usually well developed, but this, as with other Goniastrea species, is variable and some coralla, especially those from Kushimoto, have only weakly formed paliform lobes and hence a Favites-like appearance. Some coralla from Kushimoto have some development of a 'groove and tubercle' formation. Colonies are usually dark colours, usually deep red. Illustrated in colour: Veron (1990b).

\section{Records:}

This study: Tanegashima, Tosashimizu, Amakusa Is., Kushimoto, Shirahama, Izu, Tateyama.

Previous studies: Veron (1990b): Tanegashima, Amakusa Is., Kushimoto, Shirahama.

\section{Goniastrea pectinata}

(Ehrenberg, 1834)

Generally uncommon throughout the distribution range. Has a similar range of variation in the Philippines and the Great Barrier Reef. Usually the same pale pinkish-brown as are Great Barrier Reef colonies, but may be dark colours, especially in mainland localities. Illustrated in colour: Masuda and Hayashi (1986), Nishihira (1988), Uchida and Fukuda (1988b) (not p. 223).

\section{Records:}

This study: Yaeyama, Okinawa and Amami Is., Tanegashima, Tosashimizu.

Previous studies: Yabe et al. (1936) (as G. pectinata and G. aspera (pars)): 
Ogasawara and Daito Is. and north to Suruga Bay; Utinomi (1965b): south-west Shikoku; Hamada (1963b): Tateyama; Anonymous (1970) (as Platygyra lamellina): Ehime coast; Ooishi (1970): Ogasawara and Volcano Is.; Eguchi (1974): Yaeyama Is. and Kerama Is.; Yamazato et al. (1978): Okinawa; Kawaguti (1983) (as G. pectinata, G. and planulata): Okinawa; Habe (1989): Iriomote I. ; Chou and Yamazato (1990); Okinawa; Tachikawa (pers. comm., 1991): Ogasawara Is.

\section{Goniastrea australensis}

(Edwards and Haime, 1857)

Rare throughout the Ryukyu Is. and at the Amakusa Is., common at Shirahama and Kushimoto. Usually uniform grey or brown in colour, but sometimes has green valleys. Illustrated in colour: Uchida and Fukuda (1988b).

\section{Records:}

This study: Yaeyama, Okinawa and Amami Is., Tanegashima, Tosashimizu, Amakusa Is., Kushimoto, Shirahama, Izu.

Previous studies: Kawaguti (1983): Yaeyama Is.; Tribble and Randall (1986): Miyake I.; Shirai (1986): Kii coast; Tachikawa (pers. comm., 1991): Ogasawara Is.

\section{Genus Platygyra}

Ehrenberg, 1834

\section{Platygyra daedalea}

(Ellis and Solander, 1786)

Generally uncommon throughout most of the distribution range. Has a similar range of variation in the Philippines and the Great Barrier Reef. Illustrated in colour: Nishihira (1988), Uchida and Fukuda (1988b) (p. 75).

Records:

This study: Yaeyama, Okinawa and Amami Is., Tanegashima, Tosashimizu, Amakusa Is.

Previous studies; Yabe et al. (1936) (as Coeloria rustica (pars) and Coeloria lamellina (pars)): Ogasawara and Daito Is. and north to Tanabe Bay; Kikuchi (1968) (as Platygyra rustica): Amakusa Is.; Eguchi (1971): Goto I.; ?Eguchi (1972a) (as P. rustica): Izu; Eguchi (1974): Anonymous (1977) (as P. lamellina): Kushimoto; Yaeyama Is.; Tribble and Randall (1986): Miyake I.; Chou and Yamazato (1990): Okinawa. Other records of $P$. lamellina and $P$. rustica are likely to be primarily this species: Utinomi (1965b, 1971): Ehime coast, north-east Kyushu, south-west Shikoku; Eguchi 
(1968): Sagami Bay; Ooishi (1970): Ogasawara and Volcano Is.; Yagi (1970): Ehime coast; Eguchi (1974): Kerama Is.; Eguchi and Miyawaki (1975): Kushimoto; Yamazato et al. (1978): Okinawa; Kawaguti (1983): Yaeyama Is.; Kikuchi (1985) (as $P$. lamellina): Tsuiji-shima; Shirai (1986): Kii coast; Tachikawa (pers. comm., 1991): Ogasawara Is.

\section{Platygyra contorta}

Veron, 1990

Rare in the Ryukyu Is., becoming common in mainland Japan. Colonies are massive or encrusting, usually with explanate margins, rarely with contorted upgrowths. Valleys are $3.5-5 \mathrm{~mm}$ wide, usually long and relatively straight and radiating on the margins, becoming short and/or sinuous and contorted towards the colony centre. Walls are thin and acute. Septa are irregular in all respects giving walls a ragged appearance similar to those of $P$. daedalea. Colours are uniform, commonly red, grey, pale yellow or green. Illustrated in colour: Veron (1990b).

\section{Records:}

This study: Yaeyama, Okinawa and Amami Is., Tanegashima, Tosashimizu, Amakusa Is., Kushimoto, Shirahama, Izu.

Previous studies: Anonymous (1977) (as P. rustica): Kushimoto; Veron (1990): Yaeyama, Okinawa and Amami Is., Tanegashima, Amakusa Is., Kushimoto, Shirahama.

\section{Platygyra lamellina}

(Ehrenberg, 1834)

Uncommon throughout the distribution range. Has a similar range of variation in the Philippines and the Great Barrier Reef. Uniform brown or pale brown with pale grey valleys. Illustrated in colour: Masuda and Hayashi (1989), Nishihira (1988), Uchida and Fukuda (1988b).

\section{Records:}

This study: Yaeyama and Okinawa Is.

Previous studies: ?Eguchi (1971): Goto I.; ?Eguchi (1974): Yaeyama Is.; Habe (1989): Iriomote I. ; ?Chou and Yamazato (1990): Okinawa. 


\section{Platygyra sinensis}

(Edward and Haime, 1849)

Generally uncommon throughout the distribution range. Generally uniform brown in colour but may be a range of bright colours.

\section{Records:}

This study: Yaeyama, Okinawa and Amami Is., Tanegashima.

Previous studies: Anonymous (1977); Kushimoto; Yamazato et al. (1978): Okinawa; Kawaguti (1983): Yaeyama Is.; Chou and Yamazato (1990); Okinawa.

\section{Platygyra ryukyuensis \\ Yabe and Sugiyama, 1936}

Uncommon in most localities throughout the distribution range. Has a similar range of variation in the Philippines. Usually dark brown or grey in colour. Illustrated in colour: Shirai (1980), Masuda and Hayashi (1989), Nishihira (1988), Uchida and Fukuda (1988b).

\section{Records:}

This study: Yaeyama, Okinawa and Amami Is.

Previous studies: Yabe et al. (1936): Okinawa and Amami Is. and Ogasawara Is.; Eguchi (1974): Kerama Is.; Yamazato et al. (1978) (as Leptoria ryukyuensis): Okinawa.

\section{Platygyra pini}

Chevalier, 1975

Probably the most common Platygyra of Japan. Has a similar range of variation in the Philippines. Has a wide range of colours, most commonly brown with green valleys. Illustrated in colour: Nishihira (1988), Uchida and Fukuda (1988b).

\section{Records:}

This study: Yaeyama, Okinawa and Amami Is., Tosashimizu, Amakusa Is.

Previous studies: Yabe et al. (1936) (as Coeloria astreiformis): Daito Is.; Kawaguti (1983): Yaeyama Is.; Tachikawa (pers. comm., 1991): Ogasawara Is. 


\section{Platygyra verweyi \\ Wijsman-Best, 1976}

Uncommon or rare. Colonies are similar to those from the Philippines but skeletal variations have not been studied. Usually honey-coloured.

\section{Records:}

This study: Yaeyama, Okinawa and Amami Is., Tanegashima.

Previous studies: Not recorded.

\section{Platygyra yaeyamaensis \\ (Eguchi and Shirai, 1977)}

Rare. Colonies are encrusting or submassive. Coralla are monocentric, especially towards the colony centre, or form short valleys at the margins. Coralla are primarily characterised by exsert septa which have irregular dentations and a ragged appearance. Columellae are mostly continuous, with centres indistinguishable. Paliform lobes are weakly developed. Illustrated in colour: Shirai (1980).

\section{Records:}

This study: Yaeyama and Okinawa Is.

Previous studies: Shirai (1980) (as Goniastrea yaeyamaensis): Yaeyama Is.

\section{Genus Leptoria}

Edwards and Haime, 1848

\section{Leptoria phrygia}

(Ellis and Solander, 1786)

Common throughout the distribution range. Usually restricted to upper reef slopes. Has a similar range of variation in the Philippines and the Great Barrier Reef. Uniform blue-grey in colour. Illustrated in colour: Shirai (1980) (as L. gracilis), Masuda and Hayashi (1989), Nishihira (1988), Uchida and Fukuda (1988b).

\section{Records:}

This study: Yaeyama, Okinawa and Amami Is.

Previous studies: (It is possible that some records of L. gracilis are L. irregularis (see below). Yabe et al. (1936) (as L. phrygia and L.gracilis): Okinawa, Miyako and Okinawa Is. and Ogasawara and Daito Is.); ?Hamada (1963b) (as Platygyra phrygia): 
Tateyama; Eguchi (1968) (as Platygyra phrygia): Sagami Bay; Eguchi (1974) (as L. phrygia and L. gracilis): Yaeyama Is. and Kerama Is.; Yamazato et al. (1978) (as $L$. gracilis): Okinawa; Kawaguti (1983) (as L. phrygia and L. gracilis): Yaeyama Is.; Tachikawa (pers. comm., 1991): Ogasawara Is.

\title{
Leptoria irregularis
}

Veron, 1990

Colonies are submassive or plate-like, up to $1.5 \mathrm{~m}$ diameter. Valleys are 2.8 $3.9 \mathrm{~mm}$ wide, mostly straight and parallel at the corallum margins, becoming sinuous towards the corallum centre. Septa are equal, with strong dentations. Columellae do not form centres; they are not plate-like. Living colonies are pale blue-grey. Illustrated in colour: Veron (1990b).

\section{Records:}

This study: Yaeyama, Okinawa and Amami Is.

Previous studies: Veron (1990): Yaeyama, Okinawa and Amami Is.

\section{Genus Oulophyllia}

\author{
Edwards and Haime, 1848
}

\section{Oulophyllia crispa}

(Lamarck, 1816)

Generally uncommon to rare throughout the distribution range. At the Amakusa Is., colonies become hemispherical and develop larger valleys than found in Great Barrier Reef colonies. A similar range of variation is found in the Philippines where Veron and Hodgson (1989) note that the possible validity of Coelogyra laevis Nemenzo (as a third species of Oulophyllia) requires further study. Usually pale brown in colour. Illustrated in colour: Shirai (1980), Nishihira (1988), Uchida and Fukuda (1988b).

\section{Records:}

This study: Yaeyama, Okinawa and Amami Is., Tanegashima, Amakusa Is., Kushimoto, Shirahama.

Previous studies: Yabe et al, (1936) (as Coeloria gigantea); north to south-west Shikoku; Kikuchi (1968) (as Platygyra gigantea): Amakusa Is.; Anonymous (1970) (as Platygyra gigantea: Ehime coast; Eguchi and Miyawaki (1975) and Anonymous (1977) (as Platygyra gigantea): Kushimoto; Tribble and Randall (1986) (as O. aspera): Miyake I.; Chou and Yamazato (1990): Okinawa; Tachikawa (pers. comm., 1991): Ogasawara Is. 


\section{Oulophyllia bennettae}

(Veron, Pichon and Wijsman-Best, 1977)

Rare. Has the similar colours as colonies from the Philippines and Great Barrier Reef.

Records:

This study: Yaeyama, Okinawa and Amami Is.

Previous studies: Not recorded.

\section{Genus Montastrea}

de Blainville, 1830

\section{Montastrea curta}

(Dana, 1846)

Common throughout the Ryukyu Is., especially on exposed upper reef slopes. Corallites are relatively large in coralla from mainland localities. Otherwise the species shows no differences from coralla from the Philippines and the Great Barrier Reef. Usually orange-brown in the Ryukyu Is. and in deeper water of mainland localities and dark brown in shallow water of mainland localities. Illustrated in colour: Nishihira (1988), Uchida and Fukuda (1988b).

Records:

This study: Yaeyama, Okinawa and Amami Is., Tanegashima, Tosashimizu, Amakusa Is., Kushimoto, Shirahama.

Previous studies: Yabe et al. (1936) (as Orbicella curta): Ogasawara and Daito Is. and north to between Shirahama and Kushimoto; Hamada (1963b): Tateyama; Eguchi (1974) (as Plesiastrea curta): Yaeyama Is. and Kerama Is.; Yamazato et al. (1978): Okinawa; Tribble and Randall (1986): Miyake I.; Chou and Yamazato (1990): Okinawa; Tachikawa (pers. comm., 1991): Ogasawara Is.

\section{Montastrea annuligera}

(Edwards and Haime, 1849)

Rare in Japan in the Philippines. Japanese coralla have more exsert and more dentate septa than those from the Great Barrier Reef. Usually mottled dark greens and browns in colour. Illustrated in colour: Nishihira (1988).

\section{Records:}

This study: Yaeyama and Okinawa Is.

Previous studies: Not recorded except in the abovementioned publication. 


\title{
Montastrea multipunctata
}

\author{
Hodgson, 1985
}

Rare; not studied in detail. Corallites have thick walls with conspicuous groove and tubercle formation. Colonies are similar to those from the Philippines. The only recorded colours are mottled yellow or green with dark calices.

\section{Records:}

This study: Yaeyama and Okinawa Is., Tanegashima.

Previous studies: Not recorded.

\section{Montastrea magnistellata}

\author{
Chevalier, 1971
}

Generally uncommon and not studied in detail. Has a similar range of variation in the Philippines. Usually a uniform creamy-brown to orange-brown in colour, dark grey-brown at Tanegashima. Illustrated in colour: Shirai (1980) (as M. curta), Nishihira (1988), Uchida and Fukuda (1988b).

\section{Records:}

This study: Yaeyama, Okinawa and Amami Is., Tanegashima, Tosashimizu.

Previous studies: Anonymous (1970) (as Favia speciosa): Ehime coast; Eguchi (1974) (as Favia magnistellata): Kerama Is.; Yamazato et al. (1978): Okinawa; Tachikawa (pers. comm. 1991): Ogasawara Is.

\section{Montastrea valenciennesi}

(Edwards and Haime, 1848)

Generally uncommon in the Ryukyu Is., common at mainland localities. Usually found on exposed upper reef slopes (Ryukyu Is.) or on partly exposed rock faces (mainland localities). Has a similar range of variation in the Philippines. Corallites are much smaller than usual in Great Barrier Reef coralla, indicating the presence of geographic subspecies. Usually mottled colours. Illustrated in colour: Masuda and Hayashi (1989), Nishihira (1988), Uchida and Fukuda (1988b).

\section{Records:}

This study: Yaeyama, Okinawa and Amami Is., Tanegashima, Tosashimizu.

Previous studies: Yabe et al. (1936) (as Phymastrea valenciennesi): north to Kushimoto; Utinomi (1965b) (as Favia valenciennesi): south-west Shikoku; Kikuchi (1968) (as Phymastrea valenciennesi): Amakusa Is.; Eguchi (1971) (as Phymastrea valenciennesi): Goto I.; Eguchi (1974) (as Phymastrea valenciennesi): Kerama Is.; Kawaguti (1983): Yaeyama Is. 


\section{Genus Oulastrea}

Edwards and Haime, 1848

\section{Oulastrea crispata}

(Lamarck, 1816)

Rare except in isolated sub-tidal biotopes (very rarely $>12 \mathrm{~m}$ depth) where other corals are seldom found. Has a similar range of variation in the Philippines. Nearly black with pale septo-costae above the corallite walls. Recorded in most studies north to Tateyama and north to the Noto Peninsula on the west coast of Honsyu where it tolerates near freezing temperatures in shallow water (Yajima et al., 1986). It thus has the northernmost distribution on any normally hermatypic species. Illustrated in colour: Shirai (1980), Masuda and Hayashi (1989), Nishihira (1988), Uchida and Fukuda (1988b).

\section{Records:}

This study: Yaeyama, Okinawa and Amami Is., Tanegashima, Tosashimizu, Amakusa Is., Kushimoto, Shirahama, Izu, Tateyama.

Previous studies: Yabe et al. (1936): north to Sagami Bay; Hamada et al. (1963): Tateyama; Eguchi (1968): Sagami Bay; Kawaguti (1983): Yaeyama Is.; Chou and Yamazato (1990): Okinawa; Shirai (1986): Kii coast; Kikuchi (1985): Tsuji-shima; Yajima et al. (1986): north to Noto Pen.; Tachikawa (pers. comm., 1991): Ogasawara Is.

\section{Genus Plesiastrea}

Edwards and Haime, 1848

\section{Plesiastrea versipora}

(Lamarck, 1816)

Uncommon throughout the Ryukyu Is. and Tanegashima, common at mainland localities. Has a similar range of variation in the Philippines and the Great Barrier Reef. In the Ryukyu Is., colonies are a uniform fawn or brown colour. In mainland localities they are occasionally other colours including pale green and grey with pink tentacles. Polyps are often partly extended during the day. Recorded in most studies north to Tateyama Peninsula. Illustrated in colour: Nishihira (1988), Uchida and Fukuda (1988b).

\section{Records:}

This study: Yaeyama, Okinawa and Amami Is., Tanegashima, Tosashimizu, Amakusa Is., Kushimoto, Shirahama, Izu, Tateyama. 
Previous studies: Yabe et al. (1936): Daito Is.; Eguchi (1968): Sagami Bay; Eguchi (1971): Goto I.; Eguchi (1972a): Izu; Eguchi (1973): Tsushima; Eguchi (1974): Yaeyama Is. and Kerama Is.; Ooishi (1970): Ogasawara and Volcano Is.; Kikuchi (1968): Amakusa Is.; Eguchi and Miyawaki (1975) and Anonymous (1977): Kushimoto; Tribble and Randall (1986): Miyake I.; Shirai (1986): Kii coast; Habe (1989): Iriomote I.; Tachikawa (pers. comm., 1991): Ogasawara Is.

\section{Genus Diploastrea Matthai, 1914}

\section{Diploastrea heliopora}

(Lamarck, 1816)

Generally common and shows no colour, structural or ecological differences from colonies elsewhere in the Indo-west Pacific. Illustrated in colour: Shirai (1980), Masuda and Hayashi (1989), Nishihira (1988), Uchida and Fukuda (1988b).

\section{Records:}

This study: Yaeyama and Okinawa Is.

Previous studies: Eguchi (1974): Kerama Is.; Kawaguti (1983): Yaeyama Is.; Habe (1989): Iriomote I.

\section{Genus Leptastrea}

Edwards and Haime, 1848

\section{Leptastrea inaequalis}

Klunzinger, 1879

Uncommon; cream or yellow with black calices. Has a similar range of variation in the Philippines and the Great Barrier Reef.

\section{Records:}

This study: Yaeyama and Okinawa Is.

Previous studies: Kawaguti (1983) (as L. bottae): Okinawa; Tachikawa (pers. comm., 1991): Ogasawara Is. 


\section{Leptastrea purpurea}

(Dana, 1846)

Common throughout the distribution range. Corallites are more uniform in size than usual for Great Barrier Reef colonies and some may form a short, indistinct series. Colonies are usually a uniform or mottled greenish-yellow with cream walls. Recorded in most studies north to Tateyama. Illustrated in colour: Masuda and Hayashi (1989), Nishihira (1988), Uchida and Fukuda (1988b).

\section{Records:}

This study: Yaeyama, Okinawa and Amami Is., Tanegashima, Tosashimizu, Amakusa Is., Kushimoto, Shirahama, Izu.

Previous studies: Yabe et al. (1936): Ogasawara and Daito Is. and north to Sagami Bay; Hamada (1963b): Tateyama; Eguchi (1968): Sagami Bay; Kikuchi (1968): Amakusa Is.; Eguchi (1973): Tsushima; Eguchi and Miyawaki (1975) and Anonymous (1977): Kushimoto; Yamazato et al. (1978): Okinawa; Tribble and Randall (1986): Miyake I.; Kawaguti (1983): Yaeyama Is.; Shirai (1986): Kii coast; Tachikawa (pers. comm., 1991): Ogasawara Is.

\section{Leptastrea transversa}

Klunzinger, 1879

Generally uncommon or rare. Colonies are usually mottled pale yellowishbrown and white. Illustrated in colour: Masuda and Hayashi (1989), Nishihira (1988).

\section{Records:}

This study: Yaeyama, Okinawa and Amami Is.

Previous studies: Yamazato et al. (1978): Okinawa; Chou and Yamazato (1990): Okinawa; Tachikawa (pers. comm., 1991): Ogasawara Is.

\section{Leptastrea pruinosa \\ Crossland, 1952}

Uncommon. Colonies are similar to those from the Philippines but with smaller corallites ( 3 - $4 \mathrm{~mm}$ diameter). Often purple with white oral discs (as illustrated, Veron, 1986) but may be a wide range of other colours, notably green or greenish-yellow calices and brown coenosarc.

\section{Records:}

This study: Yaeyama, Okinawa and Amami Is., Tosashimizu, Izu.

Previous studies: Tribble and Randall (1986): Miyake I.; Shirai (1986): Kii coast; Tachikawa (pers. comm., 1991); Ogasawara Is. 


\section{Leptastrea bewickensis}

Veron, Pichon and Wijsman-Best, 1977

Rare throughout the Ryukyu Is., but common at Tanegashima (station 63). Coralla from the Great Barrier Reef, the Ryukyu Is. and Tanegashima all show geographic variations, especially in the development of the columella and the size of the calices, with Great Barrier Reef coralla having the least well-developed columellae and the largest corallites. Coralla from Tanegashima have primary septa fused at the corallite centre; these show no essential differences from Parasimplastrea simplicitexta (Umbgrove, 1939) collected my Sheppard from Oman and deposited in the BM(NH). Further study may indicate that Parasimplastrea Sheppard, 1985 is a junior synonym of Leptastrea. The holotype of simplicitexta, a fossil from Indonesia, also recorded from the Pliocene of Papua New Guinea by Veron and Kelley (1988), has not been re-examined.

\section{Records:}

This study: Yaeyama, Okinawa and Amami Is., Tanegashima.

Previous studies: Kawaguti (1983): Yaeyama Is.; Tachikawa (pers. comm., 1991): Ogasawara Is.

\section{Genus Cyphastrea}

Edwards and Haime, 1848

The series of Cyphastrea in the present collection contains six specimens of two species from the Ryukyu Is. that are likely to be additional to those listed below. One of these may be Cyphastrea zhongjianensis Zou, 1980.

\section{Cyphastrea serailia}

(Forskål, 1775)

Very common throughout the distribution range and varies greatly in colour, especially in shallow water and in higher latitudes where colonies, or the sides of colonies, may be dark. Otherwise, colonies are uniform in colour, commonly red, green or grey. Has a wide range of corallite characters. Recorded in most studies north to Tateyama Peninsula. Illustrated in colour: Nishihira (1988), Uchida and Fukuda (1988b).

\section{Records:}

This study: Yaeyama, Okinawa and Amami Is., Tanegashima, Tosashimizu, Amakusa Is., Kushimoto, Shirahama, Izu, Tateyama.

Previous studies: Yabe et al. (1936): north to Sagami Bay; Eguchi (1971): Goto 
I.; Eguchi (1973): Tsushima; Eguchi (1974): Kerama Is.; Anonymous (1977): Kushimoto; Yamazato et al. (1978): Okinawa; Kawaguti (1983): Yaeyama Is.; Tribble and Randall (1986): Miyake I.; Chou and Yamazato (1990): Okinawa; Tachikawa (pers. comm., 1991): Ogasawara Is.

\section{Cyphastrea chalcidicum}

(Forskål, 1775)

Common throughout distribution range, except Shirahama where it is uncommon. Has a similar range of variation in the Philippines and the Great Barrier Reef. Colonies usually have uniform colours. Recorded in most studies north to Shirahama. Illustrated in colour: Nishihira (1988), Uchida and Fukuda (1988b).

Records:

This study: Yaeyama, Okinawa and Amami Is., Tanegashima, Tosashimizu, Amakusa Is., Kushimoto, Shirahama, Izu.

Previous studies: Yabe et al. (1936): Ogasawara Is. and north to Sagami Bay; Utinomi (1965b): south-west Shikoku; Kikuchi (1968): Amakusa Is.; Eguchi (1971): Goto I.; Eguchi (1974): Kerama Is.; ?Eguchi and Miyawaki (1975) and Anonymous (1977) (as C. serailia in part): Kushimoto; Yamazato et al. (1978): Okinawa; Kawaguti (1983): Yaeyama Is.; Habe (1989): Iriomote I. ; Chou and Yamazato (1990): Okinawa; Tachikawa (pers. comm., 1991): Ogasawara Is.

\section{Cyphastrea ocellina}

(Dana, 1864)

Rare and little studied. Corallites are small, neatly arranged, usually exsert. The only recorded colour is dark green.

Records:

This study: Yaeyama Is.

Previous studies: Not recorded.

\section{Cyphastrea japonica}

Yabe and Sugiyama, 1932

The name japonica has been incorrectly used for C. decadia by Veron et al. (1977) and all subsequent taxonomic accounts of Cyphastrea. Cyphastrea chalcidicum tanabensis Yabe and Sugiyama, 1932 appears to be a synomnym of this species. 
Holotypes of both nominal species have been re-examined during the present study: substatial differences in corallite structure appear to be environmen-correlated. The holotype is submassive but very porous due to a heavy infestation of polychaete worms and barnacles.

Common in shallow exposed biotopes throughout the distribution range. Coenosteum spinules are prominent; corallites are small, often crowded and have two very unequal orders of septa, first order septa being very exsert and irregularly dentate. 'Groove and tubercle' formations are often present. Colonies are often infested with parasitic barnacles. Coralla have the same range of variation as those from the Philippines. Colonies are usually mottled colours, commonly cream or yellowish-green, but may be mottled grey.

Records:

This study: Yaeyama, Okinawa and Amami Is., Tanegashima, Tosashimizu, Kushimoto, Shirahama, Izu.

Previous studies: Yabe et al. (1936): north to between Shirahama and Kushimoto; Utinomi (1971): north-east Kyushu; ?Yabe et al. (as C. chalcidicum tanabensis): north to Tanabe Bay (type locality); Tachikawa (pers. comm. 1991): Ogasawara Is.

\section{Cyphastrea microphthalma}

(Lamarck, 1816)

Common, especially in exposed biotopes of the Ryukyu Is., generally uncommon in mainland localities. Has a similar range of variation in the Philippines and the Great Barrier Reef. Has a wide range of colours which are uniform over the colony surface or are relatively pale on upper surfaces. Illustrated in colour: Shirai (1980), Nishihira (1988), Uchida and Fukuda (1988b).

\section{Records:}

This study: Yaeyama, Okinawa and Amami Is., Tanegashima, Tosashimizu, Amakusa Is., Kushimoto.

Previous studies: Yabe et al. (1936); north to east of Kushimoto; Utinomi (1966): Kii coast; Kikuchi (1968): Amakusa Is.; Ooishi ?: Ogasawara Is.; Eguchi and Miyawaki (1975) and Anonymous (1977): Kushimoto; Ooishi (1970); Ogasawara and Volcano Is.; Kawaguti (1983): Yaeyama Is.; Habe (1989): Iriomote I, ; Chou and Yamazato (1990): Okinawa; Tachikawa (pers. comm., 1991): Ogasawara Is. 


\section{Cyphastrea agassizi}

(Vaughan, 1907)

Rare, but distinctive. 'Primarily characterised by large, widely spaced corallites, separated by a smooth coenosteum and exsert, irregular primary septa. Irregular 'groove and tubercle' formation may be present' (Veron and Hodgson (1989). The species is further characterised by the septa, which are arranged in three distinct orders. Mottled cream, pale brown or white in colour, sometimes with orange septa. Illustrated in colour: Uchida and Fukuda (1988b, as Leptastrea inaequalis).

\section{Records:}

This study: Yaeyama, Okinawa and Amami Is.

Previous studies: Not recorded except in the abovementioned publication.

\section{Cyphastrea decadia}

Moll and Borel Best, 1984

This species has been mistakenly called Cyphastrea japonica by Veron et al. (1977) and all subsequent taxonomic accounts of Cyphastrea. Holoytpe (\#40327) and paratype (\#40588) of C. japonica from Tohoku University have been re-examined during the present study, and as these are a different species, a name change is obligatory.

Generally uncommon or rare on upper reef slopes, where colonies usually have tightly compacted branches. May form large colonies with an open growth form on soft substrates in deeper water. Is uniform cream in colour.

There may be substantial differences between Great Barrier Reef, Indonesian, Philippines and Japanese coralla. The former and latter are similar in having $\mathbf{1 0}$ to 12 (most commonly 12) primary septa in axial corallites and well-developed, granular costae. Indonesian and Philippine coralla typically have 10 primary septa and relatively weakly developed, smooth costae. This latter form was re-named $C$. decadia by Moll and Borel-Best (1984). The present study indicates that only one species is involved, and thus the name decadia is applicable to it. Illustrated in colour (as C. japonica): Masuda and Hayashi (1989), Nishihira (1988), Uchida and Fukuda (1988b).

\section{Records:}

This study: Yaeyama and Okinawa Is.

Previous studies: Not recorded except as illustrated in the abovementioned publications. 


\section{Genus Echinopora}

Lamarck, 1816

\section{Echinopora lamellosa}

(Esper, 1795)

Generally common throughout the distribution range and especially common at station 46 where many colonies are over $5 \mathrm{~m}$ diameter and consist of overlapping tiers of plates (intermixed with plates of E. gemmacea). Also forms very big colonies at Tanegashima (station 60) which have contorted centres. Uniform pale brown or honey-coloured. Has a similar range of variation in the Philippines and the Great Barrier Reef. Illustrated in colour: Shirai (1980), Masuda and Hayashi (1989), Nishihira (1988), Uchida and Fukuda (1988b).

Records:

This study: Yaeyama, Okinawa and Amami Is., Tanegashima, Tosashimizu.

Previous studies: Yabe et al. (1936): Okinawa Is. and Ogasawara Is.; Eguchi (1974): Yaeyama Is. and Kerama Is.; Yamazato et al. (1978): Okinawa; Kawaguti (1983): Yaeyama Is.; Habe (1989): Iriomote I. ; Chou and Yamazato (1990): Okinawa; Tachikawa (pers. comm., 1991): Ogasawara Is,

\section{Echinopora gemmacea}

(Lamarck, 1816)

Common throughout the distribution range. Colonies are mostly plate-like, but may have irregular, contorted branches, which is the same range of variation in the Philippines and Great Barrier Reef. Usually a uniform grey or grey-brown to grey-green in colour, with pale branch ends. Illustrated in colour: Nishihira (1988).

\section{Records:}

This study: Yaeyama, Okinawa and Amami Is.

Previous studies: Kawaguti (1983): Yaeyama Is.; Tachikawa (pers. comm., 1991): Ogasawara Is.

\section{Echinopora pacificus \\ Veron, 1990}

Generally uncommon throughout the distribution range. Colonies are unifacial (rarely bifacial) plates, usually with free margins and thick, encrusting or attached, centres. Corallites are similar to those of $E$. lamellosa, but are much larger, with calices up to $9.8 \mathrm{~mm}$ diameter. Costae are beaded, the beads integrating with 
the coenosteum spinules which are very numerous and equi-distant, giving both coralla and living colonies a velvet-like appearance. Colonies are green to greybrown in colour. Illustrated in colour: Veron (1990b).

\title{
Records:
}

This study: Yaeyama, Okinawa and Amami Is.

Previous studies: Veron (1990): Yaeyama, Okinawa and Amami Is.

\section{Echinopora hirsutissima}

(Edwards and Haime, 1849)

This species has not been observed by the author in Japan.

\section{Records:}

This study: Not recorded.

Previous studies: ?Tribble and Randall (1986): Miyake I.; ?Kawaguti(1983): Yaeyama Is.

\section{Echinopora mammiformis}

(Nemenzo, 1959)

Rare, but occasionally forms large colonies in protected lagoons (notably site 12). Has a similar range of variation in the Philippines and the Great Barrier Reef. Illustrated in colour: Masuda and Hayashi (1989), Nishihira (1988), Uchida and Fukuda (1988b).

\section{Records:}

This study: Yaeyama Is.

Previous studies: Kawaguti (1983): Yaeyama Is.; Habe (1989): Iriomote I.

\section{Echinopora horrida}

\author{
Dana, 1846
}

This species has not been observed by the author in Japan.

\section{Records:}

This study: Not recorded.

Previous studies: ?Eguchi (1974): Yaeyama Is.; ?Kawaguti (1983): Yaeyama Is. 



\section{8 \\ Family \\ Trachyphylliidae \\ Verrill, 1901}

\section{Genus Trachyphyllia}

Audouin, 1826

Wellsophyllia radiata Pichon, 1980 was renamed Trachyphyllia radiata by Borel Best and Hoeksema (1987) and made a junior synonym of Trachyphyllia geoffroyi by Veron and Hodgson (1988).

\section{Trachyphyllia geoffroyi}

(Audouin, 1826)

Rare. All coralla collected fall within the range of variation of Great Barrier Reef and Philippine coralla. All are monocentric and $<50 \mathrm{~mm}$ diameter. A pale green or brown mantle is extended during the day. Illustrated in colour: Masuda and Hayashi (1989), Nishihira (1988), Uchida and Fukuda (1988a).

\section{Records:}

This study: Yaeyama and Okinawa Is., Tosashimizu, Kushimoto, Shirahama.

Previous studies: Yabe and Sugiyama (1931) (as Antillia flabelliformis and Antillia duncani) and Yabe et al. (1936) (as Antillophyllia constricta kuensis, Antillophyllia flabiformis and Trachyphyllia amarantum): south-west Shikoku to Suruga Bay; Utinomi (1965b, 1966, 1971): south-west Shikoku, Kii coast, north-east Kyushu; Kikuchi (1968): Amakusa Is.; Anonymous (1970): Ehime coast; Ooshi (1970) (as Antillia constricta): Ogasawara Is.; Yagi (1970): Ehime coast; Kawaguti (1983): Yaeyama Is.; Shirai (1986): Kii coast; Masuda (1986): Shirahama; Tachikawa (pers. comm., 1991): Ogasawara Is. 



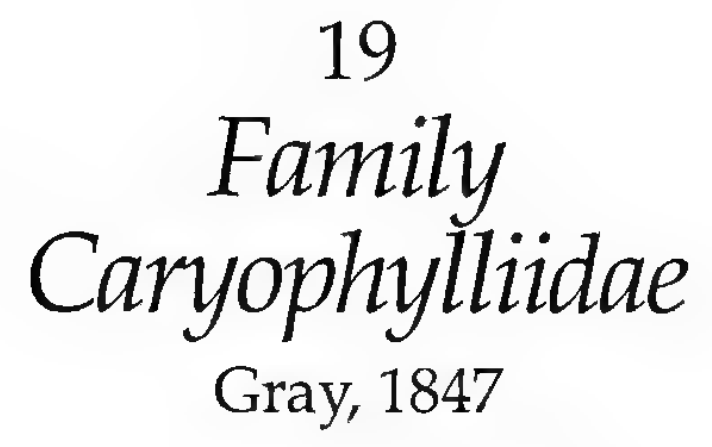

Heterocyathus japonicus (Verrill) (Eguchi, 1968) appears to be an ahermatypic species. Recorded only from Okinawa.

\title{
Genus Euphyllia
}

\author{
Dana, 1846
}

Catalaphyllia okinawaensis Eguchi and Shirai, 1977 is a large colony of E. glabrescens.

\section{Euphyllia glabrescens}

(Chamisso and Eysenhardt, 1821)

Euphyllia paraglabrescens has essentially the same skeleton as E. glabrescens. Uncommon throughout the distribution range. Has a similar range of variation in the Philippines and the Great Barrier Reef "As in the Philippines and Australia, colonies have long grey or greenish-grey tentacles with white tips: other colours recorded in the Philippines were not observed in Japan. Illustrated in colour: Shirai (1980) (as E. glabrescens and Catalaphyllia okinawaensis Eguchi and Shirai), Nishihira (1988) and Uchida and Fukuda (1988b).

\section{Records:}

This study: Yaeyama, Okinawa and Amami Is.

Previous studies: Yabe et al. (1936): Yaeyama Is. and Ogasawara Is.; Eguchi (1974): Yaeyama Is. and Kerama Is; Yamazato et al. (1978): Okinawa; Kawaguti (1983): Yaeyama Is.; Tribble and Randall (1986): Miyake I. (A specimen in the Seto Marine Biological Laboratory, is likely to be from the Shirahama).

\section{Euphyllia paraglabrescens \\ Veron, 1990}

Euphyllia glabrescens has essentially the same skeleton as E. paraglabrescens. Coralla are phaceloid, branches being $30-37 \mathrm{~mm}$ diameter near the calices. Branches 
are costate, without epithecae. Tentacles are short and bubble-like and are extended day and night, retracting only if disturbed. They are a uniform grey, or varied greens, or combinations of both grey and green. In general appearance they resemble the vesicles of Plerogyra and thus colonies look much like Plerogyra simplex Rehberg, 1892 in situ.

Known only from Ojioya Port, Tanegashima, Japan where this is one of the dominant species. The diversity of this area is low. Colonies are attached to sandstone. Illustrated in colour: Veron (1990b).

Records:

This study: Tanegashima.

Previous studies: Veron (1990): Tanegashima.

\section{Euphyllia cristata}

Chevalier, 1971

Rare, recorded only from Iriomote I. and Sekisei Lagoon. Colonies were small, monocentric, with brown tentacles with white tips. Coralla are similar to those from the Great Barrier Reef.

Records:

This study: Yaeyama and Okinawa Is.

Previous studies: Not recorded.

\section{Euphyllia ancora}

Veron and Pichon, 1980

Generally uncommon throughout the distribution range. They are often over $1 \mathrm{~m}$ diameter. They have a similar range of variation in the Philippines and the Great Barrier Reef. Colonies are usually brown or greenish-brown with cream margins to tentacle tips, but, as in the Philippines, colonies are sometimes green, pink or grey. Recorded from many mainland localities as E. fimbriata or Catalaphyllia. Euphyllia kabiraensis Eguchi and Shirai, 1977 appears to be this species with widely spread tentacle tips. Illustrated in colour: Shirai (1980) (as E. kabiraensis and E. fimbriata), Masuda and Hayashi (1989), Nishihira (1988), Uchida and Fukuda (1988b).

\section{Records:}

This study: Yaeyama, Okinawa and Amami Is., Tanegashima, Tosashimizu, Amakusa Is., Kushimoto, Tateyama. 
Previous studies: (all records as E. fimbriata); Yabe et al. (1936): Ogasawara Is. and north to Tanabe Bay; Utinomi (1965b, 1966, 1971): south-west Shikoku, Kii coast north-east Kyusyu; Anonymous (1970) (as Euphyllia fimbriata): Ehime coast; Yagi (1970): Ehime coast; Eguchi (1974) (as E. fimbriata:) Yaeyama Is. and Kerama Is.; Eguchi and Miyawaki (1975) and Anonymous (1977) (as E. fimbriata); Kushimoto; Ooishi (1970): Ogasawara and Volcano Is.; Yamazato et al. (1978): Okinawa; Kawaguti (1983): Yaeyama Is.; Habe (1989): Iriomote I. ; Chou and Yamazato (1990): Okinawa; Tachikawa (pers. comm., 1991); Ogasawara Is.

\section{Euphyllia divisa}

Veron and Pichon, 1980

Rare; observed only in Amitori Bay, Iriomote I. Has a similar range of variation in the Philippines and the Great Barrier Reef. Illustrated in colour: Nishihira (1988) (lower illustration), Uchida and Fukuda (1988b).

Records:

This study: Yaeyama Is.

Previous studies: May have been recorded as E. fimbriata (see above).

\section{Euphyllia yaeyamaensis}

(Shirai, 1980)

Uncommon, colonies have the same colour and appearance as those from the Philippines. Illustrated in colour: Shirai (1980) (as Botryphyllia yaeyamaensis), Uchida and Fukuda (1988b).

\section{Records:}

This study: Yaeyama, Okinawa and Amami Is.

Previous studies: Not recorded except as illustrated in the abovementioned publications.

\section{Genus Catalaphyllia}

Wells, 1971

\section{Catalaphyllia jardinei}

(Saville-Kent, 1893)

Common at station 81 and also found at Shirahama. Colonies have the same general appearance as those from the Philippines and the Great Barrier Reef. They have the same grey-green tentacles with pink tips, but minor colour and ecological 
differences suggest the presence of distinct geographic sub-species. Catalaphyllia sabiuraensis is a junior synonym of this species. Illustrated in colour: Masuda and Hayashi (1989), Nishihira (1988), Uchida and Fukuda (1988b).

\section{Records:}

This study: Kushimoto, Shirahama.

Previous studies: Eguchi and Miyawaki (1975) and Anonymous (1977) (as C. sabiuraensis: Kushimoto.

\section{Genus Plerogyra}

Edwards and Haime, 1848

\section{Plerogyra eurysepta}

Nemenzo, 1960

Rare, found only at Tokunoshima (stations 55 and 56) where it is conspicuous, with very large vesicles. It is readily distinguished from $P$. sinuosa in situ when both species co-occur in the same biotope, but difficult to identify with certainty otherwise.

\section{Records:}

This study: Amami Is.

Previous studies: Not recorded.

\section{Plerogyra sinuosa \\ (Dana, 1846)}

Generally rare throughout the distribution range. Has a similar range of variation in the Philippines and the Great Barrier Reef. Grey in colour. Illustrated in colour: Shirai (1980), Nishihira (1988), Uchida and Fukuda (1988a, 1988b).

\section{Records:}

This study: Yaeyama, Okinawa and Amami Is.

Previous studies: Eguchi (1974): Yaeyama Is.; Habe (1989): Iriomote I. 


\section{Genus Physogyra}

Quelch, 1884

\section{Physogyra lichtensteini}

(Edwards and Haime, 1851)

Generally uncommon. Colonies have a similar range of variation on the Great Barrier Reef except that, as in the Philippines, vesicles are often tapered or tubular rather than spherical or ovoid. Has a similar range of variation in the Philippines and the Great Barrier Reef. Grey or greyish-brown in colour. Illustrated in colour: Shirai (1980), Nishihira (1988), Uchida and Fukuda (1988b).

\section{Records:}

This study: Yaeyama and Okinawa Is.

Previous studies: Kawaguti (1983): Yaeyama Is.; Habe (1989): Iriomote I.

\section{Genus Gyrosmilia}

Edwards and Haime, 1851

\section{Gyrosmilia interrupta}

(Ehrenberg, 1834)

A single specimen corallum collected by an unknown person at Ishigaki I. (at or near station 17) is the only presently existing record of this genus in the western Pacific.

\section{Records:}

This study: Yaeyama Is.

Previous studies: Not recorded. 



\section{0 \\ Family \\ Dendrophylliidae \\ Gray, 1847}

\section{Genus Turbinaria}

Oken, 1815

Turbinaria is much less abundant in Japan than on either the eastern or western coasts of Australia. As in Australia it is relatively common in the higher latitudes.

Yabe and Sugiyama's (1941) account of Turbinaria is based on Bernard (1896) which, in turn, is based entirely on museum specimens. As species distinctions bear little relation to natural variation, Yabe and Sugiyama's account of Turbinaria has not been further studied except where noted below.

The identity of T. immersa Yabe and Sugiyama (1941) has not been determined. The holotype (\#4484c) is an encrusting colony,

\section{Turbinaria peltata}

(Esper, 1794)

Not found in the Yaeyama Is., rare in the Okinawa and Amami Is., generally uncommon at Tanegashima where it may form large flat plates, grey in colour, with polyps extended during the day. Has a similar range of variation in the Philippines and the Great Barrier Reef. Recorded in most studies north to Kushimoto. Illustrated in colour: Shirai (1980), Masuda and Hayashi (1989), Nishihira (1988), Uchida and Fukuda (1988b).

\section{Records:}

This study: Okinawa and Amami Is., Tanegashima, Tosashimizu, Amakusa Is., Kushimoto.

Previous studies: Yabe et al. (1936): from west Kyushu to Suruga Bay; Utinomi (1965b, 1966, 1971): south-west Shikoku, Kii coast, north-east Kyushu; Anonymous (1970): Ehime coast; Kikuchi (1968): Amakusa Is.; Yagi (1970): Ehime coast; Eguchi (1971): Goto I.; Eguchi (1973): Tsushima; Eguchi and Miyawaki (1975) and Anonymous (1977): Kushimoto; Kawaguti (1983): Yaeyama Is.; Shirai (1986): Kii coast; Habe (1989): Iriomote I.; Tachikawa (pers. comm., 1991): Ogasawara Is. 


\section{Turbinaria frondens \\ (Dana, 1846)}

Rare, except at Tanegashima, where it is generally uncommon. As in the I'hilippines, highly convoluted colonies which occur in very shallow waters of the Great Barrier Reef, have not been observed. Otherwise, coralla are similar to those of the Great Barrier Reef. Colonies are grey to brown in colour. Illustrated in colour: Uchida and Fukuda (1988b).

\section{Records:}

This study: Yaeyama, Okinawa and Amami Is., Tanegashima, Tosashimizu, Amakusa Is., Shirahama.

Previous studies: Yabe and Sugiyama (1941) (as T. rugosa, ?T. auricularis, $T$. tubifera (pars), T. contorta and T. mollis): north to Tanabe Bay; Eguchi (1968) (as T. contorta and T. rugosa): Sagami Bay; Kikuchi (1968) (as T. contorta): Amakusa Is.; Utinomi (1971): north-east Kyushu; Kawaguti (1983): Yaeyama Is.; Chou and Yamazato (1990): Okinawa; Tachikawa (pers. comm., 1991): Ogasawara Is.

The specimens of Yabe and Sugiyama (1941) were re-examined during this study. A wide range of specimens labeled $T$. rugosa fall clearly within the range of the species. Turbinaria tubifera (\#40203) and T. contorta (\#40205 and \#40209) are both plate-like, the former having strongly convoluted margins; T. tubifera \# 40212 is upright. Some specimens of T. auricularis (\#64502) and T. contorta (\#40210) are less clearly $T$. frondens.

\section{Turbinaria mesenterina}

(Lamarck, 1816)

Uncommon throughout the distribution range. As in the Philippines, the growth form range observed is similar to that of $T$. frondens. Colonies are brown in colour. Illustrated in colour: Nishihira (1988) Uchida and Fukuda (1988b).

\section{Records:}

This study: Yaeyama, Okinawa and Amami Is., Tanegashima, Tosashimizu.

Previous studies: ?Yabe et al. (1936) (as T. crater and T. undata): south Kyushu to Tanabe Bay; Tribble and Randall (1986) (as T. undata): Miyake I.; Kawaguti (1983): Yaeyama Is.; Tachikawa (pers. comm., 1991): Ogasawara Is. 


\section{Turbinaria reniformis}

Bernard, 1896

Uncommon throughout the distribution range, but may form extensive monospecific stands in deeper, protected biotopes (notably Amitori Bay). Has the same yellow-green colour and a similar range of variation in the Philippines and the Great Barrier Reef. Illustrated in colour: Nishihira (1988), Uchida and Fukuda (1988b).

\section{Records:}

This study: Yaeyama, Okinawa and Amami Is., Tanegashima, Tosashimizu.

Previous studies: ?Yabe et al. (1936) (as T. brueggemanni, T. elegans and T. reniformis): north to Tanabe Bay; ?Hamada et al. (1963): Tateyama; Eguchi (1968) (as T. brueggemanni): Sagami Bay; Kawaguti (1983): Yaeyama Is.; Tachikawa (pers. comm., 1991): Ogasawara Is.

\section{Turbinaria irregularis}

Bernard, 1896

Generally common. Colonies consist of contorted free or encrusting fronds and irregular, exsert corallites. Colonies are usually uniform or mottled, dark colours. Illustrated in colour: Uchida and Fukuda (1988b) (as T, ramosa).

Records:

This study: Yaeyama, Okinawa and Amami Is., Tanegashima, Tosashimizu, Amakusa Is., Kushimoto.

Previous studies: Yabe et al. (1936) (as T, tubifera): Ogasawara Is. and north to Tanabe Bay; Shirai (1986): Kii coast.

\section{Turbinaria stellulata}

(Lamarck, 1816)

Usually uncommon. Usually a uniform brown, pink or purple in colour. Has a similar range of variation in the Philippines and the Great Barrier Reef. Illustrated in colour: Masuda and Hayashi (1989), Nishihira (1988), Uchida and Fukuda (1988b).

Records:

This study: Yaeyama, Okinawa and Amami Is., Tanegashima, Tosashimizu, Kushimoto, Shirahama.

Previous studies: Yabe and Sugiyama (1941): (as T. titizimaensis): Ogasawara Is.; Kawaguti (1983): Yaeyama Is. 


\section{Turbinaria bifrons \\ Brüggemann, 1877}

This species has not been recorded by the author from Japan.

Records:

This study: Not recorded.

Previous studies: ?Yabe and Sugiyama (1941): south-west Shikoku, ?Utinomi (1965b, 1966, 1971): south-west Shikoku, Kochi, Kii coast, north-east Kyushu; ?Yagi (1970): Ehime coast; ?Shirai (1986): Kii coast; ?Habe (1989): Iriomote I.

\section{Genus Heteropsammia}

Edwards and Haime, 1848

\section{Heteropsammia cochlea}

(Spengler, 1781)

Has a similar range of variation in the Philippines and the Great Barrier Reef. nlustrated in colour: Nishihira (1988).

\section{Records:}

This study: Okinawa Is.

Previous studies: Not recorded except in the abovementioned publication. 


\section{西 Acknowledgements}

The author is very grateful for the personal assistance of Prof. Moritaka Nishihira of the Department of Biology, University of the Ryukyus, who made this work possible by unfailingly guiding him through the logistic nightmare of SCUBA diving in remote areas of Japan as well as managing the labyrinth of permits and permissions required to do so. Prof. Masashi Yamaguchi of the Department of Marine Sciences, University of the Ryukyus, Dr Toru Nakamori of the Institute of Geology and Paleontology, Tohoku University and Mr Ken Okaji of the University of the Ryukyus also gave substantial personal assistance in these areas.

Field work was greatly assisted by many people with particular thanks (in geographic order) to Mr Hiroyuki Yokochi of the Iriomote Marine Research Centre of Tokai University (Iriomote I.); Mr Fumihito Iwase of the Yaeyama Marine Park Research Station, Kuroshima; Mr Yoshiyasu Sano of Ishigaki I.; Mr Kazuhiko Sakai, of the Sesoko Marine Science Centre, University of the Ryukyus; Prof. Makoto Omori, Mr Saburo Hosaka, Mr Takeshi Hayashibara and Mr Kazuyuki Shimoike of the Establishment of Tropical Marine Ecological Research (ETMER), Akajima; Mr Yusuke Itagaki and Mr Ken-Ichi Kikutani of Tokunoshima I., Mr Kenji Shimizu of Kagoshima and Mr Sueo Nagahama of Tanegashima; Dr Satoshi Nojima and Mr Thamasak Yeemin of the Amakusa Marine Biological Laboratory; Mr Hideaki Imanishi of Tosashimizu; Mr Taiji Yamamoto and Dr Keiji Wada of the Seto Marine Biological Laboratory, Shirahama; Mr Teruo Fukuda and Dr Hiro'omi Uchida of the Sabiura Marine Park Research Station, Kushimoto; Prof. Yasutsugu Yokohama of the Shimoda Research Center; Mr Shigeki Kubota of Hamamatsu; Prof. Yasuyuki Koike of the Banda Marine Laboratory; and Mr Hiroyuki Arakawa and Mr Hitoshi Narita of Banda.

Many Japanese colleagues helped with the acquisition and translation of Japanese literature, with particular thanks to Prof. Nishihira, Prof. Yamaguchi, Mr Hayashibara, Dr Nojima, Mr Hiroyuki Tachikawa of the Ogasawara Marine Center, Mr Shuichi Fujiwara of the Marine Parks Center of Japan and Dr Tenshi Ayukai of Australian Institute of Marine Science. Ms Christine Cansfield-Smith, Mr Steve Clarke, Ms Frances Conn and Mr Kim Navin, all of AIMS, helped with various aspects of manuscript preparation. Several volunteers also helped, with particular thanks to Ms Lisa Saxby, Mr Duncan Smith and Ms Margot Warnett.

Institutional support was provided by the Amitori Research Centre, Iriomote I.; the Yaeyama Marine Park Research Station, Kuroshima; the Sesoko Marine Science Centre; ETMER, Akajima; the Amakusa Marine Biological Laboratory; the Seto Marine Biological Laboratory; the Sabiura Marine Park Research Station, Kushimoto; 
Shimoda Marine Research Centre, University of Tsukuba and the Banda Marine Laboratory, Tokyo University of Fisheries.

Prof. Kei Mori and Dr Toru Nakamori of the Institute of Geology and Paleontology, Tohoku University, and Mr Shohei Shirai of Ishigaki I. provided access to the collections of Prof. Yabe and his colleagues. Mr Richard Randall provided specimens from Miyake I. Many other research collections were examined during the course of the study at most of the abovementioned institutions.

Financial support was provided by Australian Institute of Marine Science, the Australia-Japan Bilateral Science and Technology Program, private Japanese foundations and the Regional Office for Science and Technology, UNESCO, Jakarta. 


\section{I \\ Literature Cited}

ALCOCK, A. (1893). 'On some newly-recorded corals from the Indian Seas'. J. Asiat. Soc. Bengal (Nat. Hist.), 62(2): 138-49.

ANONYMOUS (1977). Madreporarian corals in Kushimoto (in Japanese). Kushimoto Mar. Park Cent. (Ed, and Publ.).

AUDOUIN, V. (1826). 'IV. Explication sommaire des planches de Polypes', in SAVIGNY, J.C. Description de l'Egypte, 1: 225-44.

BABA, K. (1954). 'Coral Reef animals', in TSUTSUI, Y. (ed.) 'Tokara Island' (in Japanese). Asaki Syasin, 2: 44-55.

BASSETT-SMITH, P.W. (1890). Report on the corals from the Lizard and Macclesfield Banks, China Sea. Ann. Mag. Nat. Hist., 6: 353-374.

BELBIN, L. (1987). PATN Pattern analysis package reference manual. CSIRO Division of Wildlife and Rangelands Research.

BERNARD, H.M. (1896). 'The genus Tubrinaria. The Genus Astraeopora'. Cat. Madreporarian Corals Br. Mus. (Nat. Hist.), 2: 1-166.

BERNARD, H.M. (1897). The Genus Montipora. The Genus Anacropora'. Cat. Madreporarian Corals Br. Mus. (Nat. Hist.), 3: 1-192.

BERNARD, H.M. (1903). 'The family Poritidae: I. The Genus Goniopora'. Cat. Madreporarian Corals Br. Mus. (Nat. Hist.), 4: 1-206.

BERNARD, H.M. (1905). 'The family Poritidae: II. The genus Porites. Pt. I. Porites of the Indo-Pacific region'. Cat. Madreporarian Corals Br. Mus. (Nat. Hist.), 5: 1-303.

BERNARD, H.M. (1906). The family Poritidae: II. The genus Porites. Pt. II. Porites of the Atlantic and West Indies with the European fossil forms. The genus Goniopora'. A supplement to Vol. 4. Cat. Madreporarian Corals Br. Mus. (Nat. Hist.), 6: 1-173.

BINGXIAN, G. (1986). 'A sketch of the current structures and eddy characteristics in the East China Sea', (in Chinese). Studia Marina Sinica, 27: 2-21.

BOREL BEST, M. \& HOEKSEMA, B. (1987). New observation on scleractinian corals from Indonesia: 1. Free-living species belonging to the Faviina', Zoologische Mededelingen, 61(27): 387-403.

BLAINVILLE, H.M. de (1830). 'Zoophytes', in Dict. des Sci. Nat., Paris, 60; 295-364.

BOSCHMA, H. (1923). 'Knospung und Verwandte Erscheinungen bei Fungia fungites und Fungia actiniformis'. Treubia, 3: 149-79. BROOK, G. (1891). 'Descriptions of new species of Madrepora in the collections of the British Museum'. Ann. Mag. Nat. Hist., 8(6); 458-71.

BROOK, G. (1892). Preliminary descriptions of new species of Madrepora in the collections of the British Museum. Pt. II'. Ann. Mag. Nat. Hist., 10(6): 451-65.

BROOK, G. (1893). 'The genus Madrepora'. Cat. Madreporarian Corals Br. Mus. (Nat. Hist.), 1\$1-212. 
BRÜGGEMANN, F. (1877a). 'Neue Korallen-Arten aus dem Rotten Meer und von Mauritius'. Abh. Naturwiss. Ver. Bremen, 5: 395-400.

BRÜGGEMANN, F, (1877b). Notes on stony corals in the British Museum. Pt. III. A revision of recent solitary Mussaceae'. Ann. Mag. Nat. Hist., ser. 4, 20: 300-12.

CHAMISSO, A. de \& EYSENHARDT, C.G. (1821). 'De animalibus quibusdam e classe Vermium linneana, in circumnavigatione terrae, auspicante Comite $\mathrm{N}$. Romanzoff, duce Ottone de Kotzebue, annuis 1815-1818'. Nova Acta Leopold., 10(2): 343-74.

CHEVALIER, J.P. (1971). Les scléractiniaires de la mélanésie Française (NouvelleCalédonie, Iles Chesterfield, Mes Loyauté, Nouvelles- Hébrides). 1ere Partie'. Expéd. Récifs Coralliens Nouvelle-Calédonie, Fond. Singer-Polignac, Paris, 5: 5-307.

CHEVALIER, J.P. (1975). Les scléractiniaires de la mélanésie Française (NouvelleCalédonie, Iles Chesterfield, Iles Loyauté, Nouvelles- Hébrides). 2eme Partie'. Expéd. Récifs Coralliens Nouvelle-Calédonie, Fond. Singer-Polignac, Paris, 7: 5-407

CHOU, L.M. \& YAMAZATO, K. (1990), 'Community structure of coral reefs within the vicinity of Motobu and Sesoko, Okinawa, and the effects of human and natural influences'. Galaxea, 9: 9-75.

CLAEREBOUDT, M. \& HOEKSEMA, B.W. (1987). 'Fungia (Verrillofungia) spinifer spec. nov., a new scleractinian coral (Fungiidae) from the Indo-Malayan region'. Zool. Meded. (Leiden), 61:303-309.

CROSSLAND, C. (1952). 'Madreporaria, Hydrocorallinae, Heliopora and Tubipora'. Sci. Rep. Great Barrier Reef Exped. 1928-29. Br. Mus. (Nat. Hist.), 6(3): 85-257.

DANA, J.D. (1846-1849). United States Exploring Expedition during the years 18381842'. Zoophytes, 7: 1-740. Lea \& Blanchard, Philadelphia.

DANA, J.D. (1872). Coral and coral islands. List of species of corals by Verrill, A.E.

DINESEN, Z. (1980). 'A revision of the coral genus Leptoseris (Scleractinia: Fungina: Agricỉdae)'. Mem. Qld. Mus., 20(1): 181-235.

DODERLEIN, L. (1901). 'Die Korallengattung Fungia'. Zool. Anz., 24: 351-60.

DUNCAN, M.P. (1884). 'A Revision of the Families and Genera of the Sclerodermic Zoantharia, ED. \& H., or Madreoporaria'. Linn. Soc. J. Zool., 18: 118.

EDWARDS, H., MILNE \& HAIME, J. (1848a). 'Recherches sur les polypiers. Mem. 1 Observations sur la structure et le developpement des polypiers en général'. Ann. Sci. Nat. Zool., 3e ser., 9: 37-89.

EDWARDS, H., MILNE \& HAIME, J. (1848b). 'Recherches sur les polypiers. Mem. 3 Monographie des Eupsammides'. Ann. Sci. Nat. Zool., 3e. ser., 10: 65-114.

EDWARDS, H., MILNE \& HAIME, J. (1848c). 'Recherches sur les polypiers. Mem. 4 Monographie des Astreides'. Ann. Sci. Nat. Zool., 3e. ser., 10: 209-320.

EDWARDS, H., MILNE \& HAIME, J. (1848d). 'Note sur la classification de la deuxième tribu de la famille des Astreides'. C.R. Hebd. Séances Acad. Sci., 27(20): 490-7.

EDWARDS, H., MILNE \& HAIME, J. (1849a). 'Mémoire sur les polypiers appartenant à la famille des Oculinides, au groupe intermédiaire des Oculinides, au groupe intermediaire des Pseudastreides et a la famille des Fongides'. C.R. Hebd. Séances Acad. Sci., 29: 67-73. 
EDWARDS, H., MILNE \& HAIME, J. (1849b). 'Recherches sur les polypiers. Mem. 4 Monographie des Astreides", Ann. Sci. Nat, Zool., 3e. ser., 11: 233-312.

EDWARDS, H., MILNE \& HAIME, J. (1850). 'Recherches sur les polypiers. Monographie des Astreides'. Ann. Sci. Nat. Zool., 3e ser., 12: 95- 107.

EDWARDS, H., MILNE \& HAIME, J. (1851a). 'Recherches sur les polypiers. Mem. 6 Monographie des Fongides'. Ann. Sci. Nat. Zool., 3e, ser., 15: 73-144.

EDWARDS, H., MILNE \& HAIME, J. (1851b). 'Recherches sur les polypiers. Mem. 7 Monographie des Poritides'. Ann. Sci. Nat. Zool., 3e. ser., 16: 21-70.

EDWARDS, H., MILNE \& HAIME, J. (1851c). 'Monographie des polypiers fossiles des terrains paléozoiques précédée d'un tableau général de la classifications des polypes ${ }^{*}$, Arch. Mus. Nat Hist. Nat. (Paris), 5: 1-505.

EDWARDS, H., MILNE \& HAIME, J. (1857-1860). Histoire naturelle des Coralliaires. Parìs, 1, 2 \& 3: 1-326, 1-632, 1-560.

EGUCHI, M. (1935a). 'Stony corals of Tokyo Bay' (in Japanese). Plant and Animal, 4(2): 66-74. EGUCHI, M. (1935b). 'On the Madreporarian corals from the Sagaimi Bay and Tokyo Bay' (in Japanese). Zool. Mag., 47.

EGUCHI, M. (1968). 'II. The scleractinian corals of Sagami Bay', in Biological Laboratory, Imperial Household (ed.) The hydrocorals and scleractinian corals of Sagami Bay collected by H.M. The Emperor of Japan, Maruzen Co. Ltd., Tokyo, C1C74, pl. C1-33.

EGUCHI, M. (1970a). 'On geology and corals of marine park area of Saga Prefecture' (in Japanese). Rep. Mar. Park Cent, Saga Prefect.: 25-34.

EGUCHI, M. (1970b). 'On geology and corals of marine park site of Tottori Prefecture' (in Japanese). Rep. Mar. Park Cent., Tottori Prefect.: 11-16.

EGUCHI, M. (1971). 'Scleractinia of Goto Island' (in Japanese). Rep. Mar. Park Cent., Nagasaki Prefect.; 19-31.

EGUCHI, M. (1972a), 'Corals of the coast of south Izu, Shizuoka Prefecture' (in Japanese). Rep. Mar. Park Cent., Shizuoka Prefect.: 19-25.

EGUCHI, M. (1972b). 'On coral fauna of Kushimoto and nearby' (in Japanese). Mar. Parks. J., 21:7-9.

EGUCHI, M. (1973). 'Coral fauna of the Tsushima Islands, Nagasaki Prefecture' (in Japanese). Rep. Mar. Park Cent., Nagasaki Prefect.: 45-56.

EGUCHI, M. (1974). Scleractinian corals from sites proposed for the Marine Park at Kerama and Yaujama Islands (in Japanese). Mar. Parks Cent. (ed.). Mar. Park Survey, Okinawa Reef: 37-48.

EGUCHI, M. (1975a). 'Notes on coral genera of the Yaeyama Islands Group, with description of a new species, Cladocora kabiraensis n.sp'. Proc. Jpn. Soc. Syst. Zool., 11: 1-4.

EGUCHI, M. (1975b). 'Coral fauna of Nagasaki Prefecture' (in Japanese). Rep. Mar. Park Cent, Nagasaki Prefect, 56: 39-46.

EGUCHI, M. \& Fukuda, T. (1972). 'Invertebrata (chiefly coral fauna) of Marine Park of Iki Island, Nagasaki Prefecture' (in Japanese). Rep. Mar. Park Cent., Nagasaki Prefect:: 45-48. 
EGUCHI, M. \& MIYAWAKI, T. (1975). 'Systematic study of the scleractinian corals of Kushimoto and its vicinity'. Bull. Mar. Park. Res. Stns., 1: 47-62.

EGUCHI, M. \& MORI, R. (1973). 'A study of fossil corals from Tateyama city and its environs and recent coral fauna of Chiba Prefecture, Central Japan' (in Japanese). Bull. Tokyo Coll. Domest. Sci, 13; 41-57.

EGUCHI, M. \& SHIRAI, S. (1977). In SHIRAI, S. (1980) Ecological encyclopedia of the marine animals of the Ryukyu Islands (in Japanese), Okinawa Kyoiku Shuppan, Japan.

EHRENBERG, C.G. (1834). 'Beiträge zur physiologischen Kenntniss der Corallenthiere im Allgemeinen und besonders des Rothen Meeres'. Abh. Akad. Wiss. D.D.R.: 250-380.

ELLIS, J. \& SOLANDER, D. (1786). The natural history of many curious and uncommon zoophytes, London, 1*1-208.

ESPER, E.J.C. (1788-1830). Die Pflanzenthiere 1-3, Fortsetzungen 1-2, Nurnberg.

FISCHER de WALDHEIM (1807). Description du Museum Demidoff, Moscow, 3: 295-6.

FORSKÅL, P. (1775). 'Descriptiones Animalium, Avium, Amphibiorum, Piscium, Insectorum, Vermium que in intinere orientali observavit Petrus Forskål. IV. Corallia'. Hauniae: 131-9.

FUJIWARA, S. (1979), Distribution of reef-building corals in Japanese waters (in Japanese). Undergraduate thesis, Univ. Ryukyus.

FUJIWARA, S. (1985). 'Marine Park in Ogasawara Islands'. Mar. Parks J., 68: 11-14. Fukuda, T. \& IWASE, F. (1984). 'Hermatypic corals in Danjo Islands' (in Japanese). Mar. Parks J., 61: 3-6.

GARDINER, J.S. (1898). 'On the fungid corals collected by the author in the South Pacific'. Proc. Zool. Soc. Lond.: 525-539.

GARDINER, J.S. (1899). 'On the astraeid corals collected by the author in the south Pacific'. Proc. Zool. Soc. Lond.: 734-764.

GARDINER, J.S. (1905). 'Madreporaria. III. Fungida. IV. Turbinolidae'. Fauna Geog. Maldive Laccadive Arch., 2: 933-957.

GARDINER, J.S. (1909). 'The Madreporarian corals. I. The family Fungiidae, with a revision of its genera and species and an account of their geographical distribution'. Trans. Linn. Soc. Lond., 12(2): 257-290.

GRAY, J.E. (1842). Pocilloporidae in Synopsis British Museum, 44th edn.

GRAY, J.E. (1847). 'An outline of an arrangement of stony corals'. Ann. Mag. Nat. Hist., 19: 120-8.

GREGORY, J.W. (1900). 'The fossil Corals of Christmas Island', in ANDREWS (ed.) British Museum (Natural History) A Monograph of Christmas Island: 206-225.

HABE, T. (1989). 'Corals of Amitori Bay and Sakiyama Bay'. Studies on the protection and growth of coral reefs and removal of the Crown- of-Thorns starfish. Dept. Education, Japan, (3): 1-266.

HAIME, J. (1852). In BELLARDI, L. (ed.) 'Catalogue raisonné des fossiles nummulitiques du comte de Nice'. Bull. Soc. Geol. Fr, ser. 2, 7: 249.

HAMADA, T. (1963a). In [Scleractinia] Geological figures of Chiba-ken (in Japanese). Geological Education Research Group in Chiba Prefecture, 4: 94-119. 
HAMADA, T. (1963b). 'Some problems on the Numa Coral Bed in Chiba Prefecture' (in Japanese with English Abstract). Geol. Soc. Jpn. (Special Bull.): 94-119.

HIRATA, K. \& OOSAKO, N. (1968a). 'Corals of northern Amami-oshima' (in Japanese). Rep. Underwater Mar. Parks Cent.: 209-215.

HIRATA, K. \& OOSAKO, N. (1968b). ' Corals of onshore bays in Yamato-mura' (in Japanese), Rep. Underwater Mar, Parks Cent.: 223-224.

HIRATA, K., ZAISHO, T. \& OOSAKO, N. (1969). Possible locations of Kagoshima Marine Park and lists of marine invertebrates. Kagoshima Prefect. (Publ.)

HODGSON, G. (1985). 'A new species of Montastrea (Cnidaia, Scleractinia) from the Philippines', Pac. Sci, 39(3): 283-290.

HODGSON, G. \& ROSS, M.A. (1982). Unreported scleractinian corals from the Philippines'. Proc. Fourth Int. Coral Reef Symp. 2: 171-175.

HOEKSEMA, B.W. (1989). Taxonomy, phylogeny and biogeography of mushroom corals (Scleractinia: Fungiidae)'. Zool. Verh. (Leiden), 254: 1- 678.

HOFFMEISTER, J.E. (1925). 'Some corals from American Somoa and the Fiji Islands'. Pap. Dep. Mar. Biol. Carnegie Inst. Wash., (Publ. 343), 22: 1-90.

HORI, N. (1977). 'A morphometrical study on the geographical distribution of coral reef'. Geogr, Rep. Tokyo Metropl. Univ, 5: 1-75

HORIKOSHI, M. (1979). Regional ecosystems in the tropical coastal region - Kabira Cove, Ishigaki Island as a model of the physiographic unit of regional ecosystems (in Japanese), in HORIBE, Y. (ed.) Environ. Mar. Sci., 3: 145-170. Tokyo Press.

HORIKOSHI, K., KITANO, Y., YAMAZATO, K. \& NISHIHIRA, M. (1975). Ecosystems of the coral sea in Okinawa - Preliminary survey of Kabira Bay in Ishigaki Island (in Japanese). Environ, and Hum. Survival: 230-247.

HORST, C.J. (1919). 'A new species of Fungia'. Zool. Meded. (Leiden), 5: 65-6.

HORST, C.J. VAN DER (1821). The Madreporaria of the Siboga Expedition, Pt. II. Madreporaria Fungida. Siboga Exped. 16b, 1-46.

IMAJIMA, M. (1969). Report on the natural view of the Bonin Islands' (in Japanese), Marine fauna of the Bonin Islands ser. 2,: 145-177. Tokyo Metropolitan Government.

IMAJIMA, M. (1970a). Report on the natural view of the Bonin Islands' (in Japanese), Marine fauna of the Bonin Islands Tokyo Metropolitan Government, ser. 2,: 225-251.

IMAJMA, M. (1970b). Nature in the Bonin Islands, TUYAMA, T. \& ASAMI, S. (eds.) (in Japanese) Chapter 6 'Marine fauna': 179-186.

ISHINO, M. \& OTSUKA, K. (1970). 'On the coastal "Kyucho", a catastrophic influx of offshore water from the Kuroshio', in MARR, J.C., (ed.) The Kuroshio. EastWest Center Press: 61-67.

IWASE, H. \& NOMURA, K. (1988). 'Distribution of stony and soft corals and crownof-thorns starfish in Sekisei Lagoon' (in Japanese). Mar. Parks J., 80: 8-12.

KAMEZAKI, N., NOMURA, K. \& UI, S. (1987). 'Population dynamics of stony corals and Acanthaster planci in Sekisei lagoon, Okiniawa (1983-1986)' (in Japanese). Mar. Parks J., 74: 12-19. 
KAWABE, M. (1980). 'Sea level variations around the Nansei Islands and the large meander in the Kuroshio south of central Japan'. J. Oceanogr. Soc. Jpn., 36: 227-235.

KAWABE, M. (1985). 'El Niño effects in the Kuroshio and western north Pacific', in WOOSTER, W.S. \& FLUHARDY, D.L. (eds.) El Niño North: Nino effects in the eastern subartic Pacific Ocean., Washington: 31-43.

KAWABE, M. (1986). Transition process between the three typical paths of the Kuroshio'. J. Oceanogr. Soc. Jpn., 42(3): 174-191.

KAWABE, M. \& YONENO, M. (1987). Water and flow variations in Sagami Bay under the influence of the Kuroshio Path'. J. Oceanogr. Soc. Jpn., 43(5): 283-294.

KAWAGUTI, S. (1983). 'Stony corals of Kabira Bay Ishigaki Is'. Rep. Okinawa Prefect. Fish. Exp. Stn., Yaeyama Branch: 9-16.

KIKUCHI, T. (1968). Fauna and flora of the seas around the Amakusa Marine Biological Laboratory (in Japanese). Pt. VII. Amakusa Marine Laboratory, Kyushu Univ.

KIKUCHI, T, (1985). Checklist of the shore fauna in Tsuji-shima islet, Amakusa, West Kyushu. Publ. Amakusa Mar, Biol. Lab., 8(1): 65-88.

KIKUCHI, T. \& ARAGA T. (1980). 'Underwater views in offshore of Amakusa Islands' (in Japanese). Rep. Mar. Park Cent., Kumamoto Prefect.: 43-47.

KLUNZINGER, C.B. (1879). Die Korallentheire des Rothern Meeres, II. Die Madreporaceen und Oculinaceen. III. Die Astraceen und Fungiaceen. Berlin, Verlag der Gutmann'schen Buchandlung. II: 85 pp., III: 100 pp.

KONAGA, S., NISHIYAMA, ' K., ISHIZAKI, H. and HANZAWA, Y. (1980). 'Geostrophic current south-east of Yakushima Island'. La Mer 18: 1- 16.

KURATA, Y., MIMURA, T., TAKAHASHI, K. SHIOYA, T. \& HIROSE, I. (1969), Report on the basic research for development of fisheries in the Bonin Islands (in Japanese), Tokyo Fisheries Experimental Station Chapter 5 'A general view of the coral reefs of the Bonin Islands: 130-160.

LAMARCK, J.B.P. de (1801). Système des animaux sans vertèbres. Paris: 1-432.

LAMARCK, J.B.P. de (1816). Histoire naturelle des animaux sans vertebres. Paris, 2: 1-568.

LINK, H.T. (1807). Beischreibung der Naturalien-Sammlungen der Universitat zu Rostock., 3: $161-65$.

LINNAEUS, C. (1758). Systema naturae. I Regnum animale. Ed. X.

LINNAEUS, C. (1767). Systema naturae. I Regnum animale. Ed. XII.

MASUDA, K. \& HAYASHI, K. (1989). Marine Invertebrates (in Japanese). Tokai Univ.: 1-255.

MASUDA K. (1986). Teef-building corals, seaweeds and sediments of the reef flat and moat off Shiraho' (in Japanese). Sci. Rep. Shiraho Coral Reef, Ishijaki Island World Wildlife Fund.

MATTHAI, G. (1914). 'Revision of the recent colonial asrraeidae possessing distinct corallites'. Trans. Linn. Soc. Lond. Zool., ser. 2, 17: 1-140.

MATTHAI, G. (1928). Cat. Madreporarian Corals Brit. Mus. (Nat. Hist.). Pt. VII. A monograph of the recent meandroid Astraeidae. London, Trustees of the British Museum (Natural History): 288. 
MICHELIN, H. (1843). 'Description d'une nouvelle espece du genre fongie'. Mag. de Zool., Paris, 5

MIYAWAKI, T. (1978). 'The additional scleractinian corals of Kushimoto'. Bull. Mar. Park Res. Stn., 2: 99-104.

MOLL, H. \& BEST, M.B. (1984). 'New Scleractinian from the Spermonde Archipelago, South Sulawesi, Indonesia'. Zoologische Mededelingen, 58(4): 47-58.

MORIYASU, S. (1972). 'The Tsushima Current', in STOMMEL, H. \& YOSHIDA, K. (eds.) Kuroshio, Physical aspects of the Japan Current: 353-369.

MUZIK, K. (1984a). Ishigaki lagoon coral survey. I. Research on Environmental disruption. Towards Interdisciplinary Cooperation, 13(4): 68-70.

MUZIK, K. (1984b). Ishigaki lagoon coral survey. II. Research on Environmental distuption. Towards Interdisciplinary Cooperation, 14(1):70-72.

NAKAMORI, T. (1986). 'Community structures of Recent and Pleistocene hermatypic corals in the Ryukyu Islands, Japan'. Sci. Rep. Tohoku Univ. ser. 2, (Geol.), 56(2):71-133.

NAKASONE, Y., YAMAZATO, K., NISHIHIRA, M., KAMURA, S. \& ARAMOTO, Y. (1974). Preliminary report on the ecological distribution of benthic animals on the coral reefs of Sesoko Island, Okinawar (in Japanese with English summary). Ecol. Stud. Nat. Con. Ryukyu Is., 1: 213-236.

NEMENZO, F. (1955), 'Systematic study on Philippine shallow water Scleractinians: I. Suborder Fungiidar', Nat. App. Sci. Bull. Philipp., 15(1):3-83

NEMENZO, F. (1959). 'Systematic study on Philippine shallow water Scleractinians: II. Suborder Faviida'. Nat. App. Sci. Bull. Philipp., 16(1-4): 73-135.

NEMENZO, F. (1960). 'Systematic studies on Philippine shallow water Scleractinians: III. Suborder Caryophillida'. Nat. App. Sci. Bull. Philipp., 17(3, 4): 207-213.

NEMENZO, F. (1964). 'Systematic studies on Philippine shallow water Scleractinians: V. Suborder Astrocoenida'. Nat. App. Sci. Bull. Philipp., 18(3, 4): 193-223.

NEMENZO, F. (1967). 'Systematic studies on Philippine shallow water Scleractinians: VI. Suborder Astrocoeniida (Montipora and Acropora)'. Nat. Appl. Sci. Bull. Philipp., 20(1): 1-141.

NEMENZO, F. (1967). 'Systematic studies on Philippine shallow-water Scleractinians: VI. Suborder Astrocoeniida (Montipora and Acropora)'. Nat. Appl. Sci. Bull. Philipp., 20(2): 1-224.

NEMENZO, F. (1971). 'Systematic studies on Philippine shallow water Scleractinians: VII. Additional forms', Nat. App. Sci. Bull. Philipp., 23(3): 142-185.

NEMENZO, F. (1976). 'New species and new records of corals from the Philippines'. Nat. App. Sci. Bull. Philipp., 28: 229-276.

NEMENZO, F. (1979). New species and new records of stony corals from west central Philippines'. Philipp. J. Sci., 108(1-2): 1-25.

NEMENZO, F. (1980). 'Fungiid corals from central Philippines'. Kalikasan, Philipp. J. Biol, 9(2-3): 283-302.

NEMENZO, F. \& MONECILLO, E. (1981). Four new scleractinian species from Arangasa Inlet (Surigao del sur Province, Philippines)'. Philip. J. Sci., 18: 120-128. 
NISHIHIRA, M. (1988). Field guide to hermatypic corals of Japan. Tokai Univ. Press: 241 pp. NISHIHIRA, M., YAMAZATO, K., NAKAZONE, Y., KAMURA, S. \& ARAMOTO, Y. (1974). 'Notes on the Acanthaster infestation on the coral reefs around Sesoko Island, Okinawa' (in Japanese with English summary). Ecol. Stud. Nat. Cons. Ryukyu Is., 1: 237-254.

NISHIHIRA, M., YANAGIYA, K. \& SAKAI, K. (1987). 'A preliminary list of hermatypic corals collected around Kudaka Island, Okinawa'. Galaxea, 6: 53-60.

NISHIHIRA, M. \& YOKOCHI, H. (1990). 'A tenative list of hermatypic corals of Sakiyama Bay Nature Conservation Area, Iriomate Island, Okinawa' (in Japanese). Nature Conservation Bureau Environment Agency: 95-105.

NITANI, H. (1972). 'Beginning of the Kuroshio', in STOMMEL, H. \& YOSHIDA, K. (eds.). Kuroshio, Physical aspects of the Japan Current: 129-163.

NOMURA, K. \& KAMEZAKI, N. (1987). 'The present condition of crown-of-thorns starfish and corals of Haterama Island, Yaegama Group' (in Japanese). Mar. Parks J. 73: 16-19.

OKEN, L. (1815). 'Lehrbuch der Naturgeschichte. III Zoologie'. Schmid, Leipzig, Jena., 1: $59-74$.

OOISHI, S. (1970). 'Marine invertebrate fauna of the Ogasawara and Volcano Islands', collected by OOISHI, S., TOMIDA, Y., IZAWA, K. \&

MANABE, S. (eds) in Report of the marine biological expedition to the Ogasawara (Bonin) Islands. Toba Aquarium and the Asahi Shimbun Publ. Co., Nagoya, 1968, 75-104.

OOISHI, S. \& YAGI, S. (1964). 'Invertebrate fauna of Amami-osima' (in Japanese). Rep. Mar. Biol. Exp. Amami-osima, Asahi Shinbun Publ. Co., Tokyo: 43-46.

ORTMANN, A. (1889). 'Beobachtungen an Steinkorallen von der Südküste Ceylons'. Zool. Jahrb. Abt. Syst. Oekol. Geogr. Biol. Tiere, 4: 493-590.

ORTMANN, A. (1890). 'Die Morphologie des Skeletts der Steinkorallen in Beziehung zur Koloniebildung', Z. Wiss. Zool,, 50: 278-316.

OTSUKA, K. (1985). Characteristics of the Kuroshio in the vicinity of the Izu Ridge. J. Oceanogr. Soc. Japan 41(6): 441-451.

OTSUKA. K. \& ISHINO, M. (1988). 'Investigation of current systems with drift-bottle in the subtropical region of the northwestern Pacific Ocean'. J. Tokyo Univ. Fisheries, 75(2): 275-294.

PALLAS, P.S. (1766). Elenchus Zoophytorum. Den Haag: 1-451.

PILLAI, C.S. (1973). 'A review of the genus Anacropora Ridely (Scleractinia, Acroporidae) with the description of a new species'. J. Mar. Biol. Assoc. India, 15(1): 296-301.

PILLAI, C.S.G. \& SCHEER, G. (1974). 'On a collection of Scleractinia from the Strait of Malacca'. Proc. 2nd Int. Coral Reef Symp., 1: 445-464.

PILLAI, C.S.G. \& SCHEER, G. (1976). 'Report on the stony corals from the Maldive Archipelago" ${ }^{\prime}$ Zoologica, 126: 1-83.

QUELCH, J.J. (1884). Preliminary notice of new genera and species of Challenger reef-corals', Ann. Mag. Hist. Zool. Bot. Geol. Ser., 5(13): 292-7. 
QUELCH, J.J. (1886). 'Report on the reef-corals collected by H.M.S. Challenger during the years 1873-76'. Rep. Sci. Results Voyage H.M.S. Challenger Zool., 16(3): 1-203. QUOY, J.R.C. \& GAIMARD, J.P. (1833). 'Zoophytes', in DUMONT D'URVILLE, J.S.C. (ed.) 'Voyage de découvertes de l'Astrolabe, exécuté parordre du Roi, pendant les annees 1826-29, sous le commandement de M.J. Dumont d'Urville'. Zoologie, 4: 175-254.

REHBERG, H. (1892). 'Neue und wenig bekannte Korallen'. Abh. Naturwiss. Ver. Hambg, 12(1): 1-50.

RIDLEY, S.O. (1884). 'On the classificatory value of growth and budding in the Madreporaria and on a new genus illustrating this point'. Ann. Mag. Nat. Hist., 13: 284-291.

ROSS, M.A. \& HODGSON, G. (1982). 'A quantitative study of hermatypic coral diversity and zonation of Apo Reef, Mindoro, Philippines'. Proc. Fourth Int. Coral Reef Symp ., 2: 281-291.

SAKAGUCHI, Y. (1954). 'On some Anthozoa from Kii, Japan'. J. Zool. Bot. Soc. Kishu Biol., 1: 123-124.

SAKAI, K. \& YAMAZATO, K. (1987). 'Preliminary list of hermatypic corals around Sesoko Island, Okinawa with a note on the decrease of the species richness from 1980 to 1986 . Galaxea, 6: 43-51.

SAVILLE-KENT, W. (1871). 'New madrepores'. Proc. Zool. Soc. Lond., 1871.

SAVILLE-KENT, W. (1891). Notes on new and little known Australian Madreporaceae', Rec. Aust. Mus., 1: 123-4.

SAVILLE-KENT, W. (1893). The Great Barrier Reef of Australia. Its products and potentialities. W.H. Allen and Co., London, 1-387.

SCHWEIGGER, A.F. (1819), Beobachtungen auf naturhistorischen Reisen-Anat. physiol. Untersuchungen ueber Corallen. Berlin.

SHIN, Y. (1979). 'Stony corals of Nikijima' (in Japanese). Mar. Parks Cent. Rep., 68.

SHIRAI, S. (1963). Report of the Investigation for Marine Resources in NigistimaBay' (in Japanese). The Pacific: 1-71.

SHIRAI, S. (1980). Ecological encyclopedia of the marine animals of the Ryukyu Islands (in Japanese), Okinawa Kyoiku Shuppan: Japan 636 pp.

SHIRAI, S. (1986). 'Scleractinia of Mie Prefecture', in Mie Ken, Nature and its Animals (in Japanese). Mie-ryosho-shippamkai: 572-593.

SHIRAI, S., SASAKI, A. \& KATAYAMA, Y. (1965). 'Report of the Investigations for Kumano-nada Marine Park, Suzushima Area in Mie Prefecture' (in Japanese). The Pacific: 1-50.

SHIRAI, S \& SANO, Y. (1985). The Report of the coral reefs around the sea of Ishigaki Island, Okinawa, Japan. Inst. Development Pacific Nat. Res.

SONG, J.T. (1982). A study on the classification of the Korean Anthozoa 7. Scleractinia (Hexacorallia). Natural History Museum, Ewha Womont University, 25(3): 131-140. SPENGLER, L. (1781). 'Beskrivelse over et ganske besonderliat Corall prodeskt'. K. Dan. Vidensk. Selsk. Biol. Skr., 1: 240. 
STUDER, T. (1878). Übersicht der steinkorallen aus der Familie der Madreporaria aporosa Eupsammia und Turbinaria, welche auf der Reise S.M.S. Gazelle um die Erde gesammelt wurden', K. Akad. Wissen, Berlin Monatsber, 42: 625-655.

STUTCHBURY, S. (1833). 'An account of the mode of growth of young corals of the genus Fungia'. Trans. Linn. Soc. Lond., 16: 493-7.

SUGIYAMA, T. (1937). 'On the recent reef-building corals found in the Japanese seas' (in Japanese). Contrib. Inst. Geol. and Paleontol. Tohoku Univ., 22: 1-60.

SUZUKI, K. (1972). 'A study of the coral fauna of Irimote Island', in Rep. Investigation of Irimote Islands (in Japanese). Tokai Univ.: 92-99.

TACHIKAWA, H. (1990). 'Study of the corals of the Ogasawara Is.', (in Japanese). Rep. Ogasawara Mar. Res. Cent., 89(8).

TAKAHASHI, K. (1983). Shallow water scleractinian corals around Hachizyo Is. Mar. Parks J., 60: 7-10.

TAKAHASHI, K. \& KOBA, M. (1978). 'A preliminary investigation of the coral reef at the southern coast of Ishigaki Island, Ryukyus' (in Japanese). Sci. Rep. Tohoku Univ., Ser. 7 (Geog.), 28(1): 49-60.

TOKIOKA, T. (1953). Invertebrate fauna of the intertidal zone and the Tokara Islands, I. Introductory notes, with the outline of the shore and the fauna'. Publ. Seto. Mar. Biol. Lab., 3(2).

TOKIOKA, T. (1968). Preliminary observations made by Mr S. Hamahir on the growth of the giant colony of the madreporarian coral Pavona frondifera Lamarck, found in a core on the southwestern coast of Sikoku Island'. Publ. Seto Mar. Biol. Lab., XVI(I): 55-59.

TRIBBLE, G.W. \& RANDALL, R.H. (1986). 'A description of the high-latitude shallow water coral communities of Miyake-jima, Japan'. Coral Reefs, 4: 151-159.

UCHIDA, H. \& FUKUDA, T. (1988a). Coral guide. 1 (in Japanese). Southern Press Pty. Ltd.: 240 pp.

UCHIDA, H. \& FUKUDA, T. (1988b). Coral guide. 2 (in Japanese). Southern Press Pty. Ltd.: $246 \mathrm{pp}$.

UDA, M. (1953). The Kuroshio and its branch currents in the seas adjacent to Itachijo Island in relation to fisheries (Report 1)'. Rec, Oceanog. Works Jpn., new ser., 1(1):1-10.

UDA, M. (1953). 'On the stormy current ("Kyucho") and its prediction in the Sagami Bay' (in Japanese). J. Oceanogr. Soc Jpn. $^{\prime}$ 9: 15-22.

UI, S. (1985). 'Past and current distribution of crown-of-thorns starfish and hermatypic corals in Sekisei lagoon, Yaeyama Is., Okinawa' (in Japanese). Mar. Parks J., 64: 13-17.

UMBGROVE, J.H.F. (1939). Madrepora from the Bay of Batavia'. Zool. Meded., 22(12): 1-64.

UMBGROVE, J.H.F. (1940). Madreporaria from the Togian reefs (Gulf of Tomini, North Celebes)'. Rijksmuseum natuurlijke Historie Leiden Zool. Meded., 22: 265-310. 
UTINOMI, H. (1956). 'Invertebrate fauna of the intertidal zone of the Tokara Islands. XVI. Stony corals and hydrocorals'. Publ. Seto Mar. Biol. Lab. 5(3): 339-346.

UTINOMI, H. (1965a). Preliminary list of the corals of south-west Shikoku (in Japanese). Zool. Taxonomy Assoc. (Publ.): 1-6.

UTINOMI, H. (1965b). Revised catalogue of scleractinian corals from the southwest coast of Sikoku in the collections of the Ehime University and the Ehime Prefectural Museum, Matsuyama. Publ. Seto Mar. Biol. Lab., 13(3): 245-61.

UTINOMI, H. (1966). 'Outline of shallow-water coral fauna on the coasts of Kii Peninsula' (in Japanese). Surv. Rep. on Jap. Assoc. Nature Prot., 27: 97-102.

UTINOMI, H. (1970). Corals of Ehime Prefecture (in Japanese). Nat. Mus. Ehime Prefect. Yagi, S. (Publ.): 61 pp.

UTINOMI, H. (1971). Scleractinian corals from Kamae Bay, Oita Prefecture, north-east of Kyushu, Japan. Publ. Seto Mar. Biol. Lab., 19(4); 203-29.

UTINOMI, H. (1972). 'On coral fauna of Kushimoto and nearby' (in Japanese). Mar. Parks J., 21: 6-7.

VAUGHAN, T.W. (1907). 'Recent Madreporaria of the Hawaiian Islands and Laysan'. U.S. Natl. Mus. Bull., 59(9): 1-427.

VAUGHAN, T.W. (1918). 'Some shoal-water corals from Murray Islands, CocosKeeling Islands and Fanning Island'. Pap. Dep. Mar. Biol. Carnegie Inst. Wash., 9 (Publ. 213): 51-234.

VAUGHAN, T.W. (1932). 'A new coral generic name'. J. Washington Acad. Sci., 22(1819): 506.

VAUGHAN, T.W. \& WELLS, J.W. (1943). 'Revision of the suborders, families and genera of the Scleractinia'. Geol. Soc. Am. Spec. Pap., 44: 1-363

VERON, J.E.N. (1980). 'Hermatypic Scleractinia of Hong-Kong - an annotated list of species', in Proc. First Intern. Mar. Biol. Workshop: The Marine Flora and Fauna of Hong Kong and Southern China, MORTON, B.S. \& TSENG, C.K. (eds). Hong Kong Univ. Press: 111-125.

VERON, J.E.N. (1986a). New Scleractinia from Australian coral reefs', Rec. West. Aust. Mus., 12(1): 147-183.

VERON, J.E.N. (1986b). Corals of Australia and the Indo-Pacific. Angus \& Robertson: 644 pp.

VERON, J.E.N. (1988). 'Comparisons between the hermatypic corals of the southern Ryukyu Islands of Japan and the Great Barrier Reef of Australia'. Galaxea, 7: 211-231.

VERON, J.E.N. (1990a), 'Re-examination of the reef corals of Cocos (Keeling) Atoll'. Rec. West, Austr. Mus., 14(4): 553-581.

VERON, J.E.N. (1990b). New Scleractinia from Japan and other Indo-west Pacific countries'. Galaxea, 9: 95-173.

VERON, J.E.N. (in press a). Conservation of biodiversity: a critical time for the hermatypic corals of Japan. Coral Reefs. 
VERON, J.E.N. (in press b). 'Environmental control of Holocene change in the world's most northern hermatypic coral outcrop'. Pac Sci.

VERON, J.E.N. \& HODGSON, G.A. (1989). 'Annotated checklist of the hermatypic corals of the Philippines', Pac. Sci., 43(3): 234-287.

VERON, J.E.N. \& MINCHIN, P.R. (in press) Correlations between sea surface temperature and the distribution of hermatypic corals of Japan. Continental Shelf Res.

VERON, J.E.N. \& PICHON, M. (1980). 'Scleractinia of Eastern Australia. III. Families Agariciidae, Siderastreidae, Fungiidae, Oculinidae, Merulinidae, Mussidae, Pectiniidae, Caryophylliidae, Dendrophylliidae'. Aust. Inst. Mar. Sci. Monogr., vol. 4: $422 \mathrm{pp}$.

VERON, J.E.N. \& PICHON, M. (1982). 'Scleractinia of Eastern Australia. IV. Family Portidae'. Aust. Inst. Mar. Sci. Monogr., vol. 5: 159 pp.

VERON, J.E.N. PICHON, M. \& WIJSMAN-BEST, M. (1977). 'Scleractinia of Eastern Australia. II. Families Faviidae, Trachyphylliidae'. Aust. Inst. Mar. Sci. Monogr, vol. 3: 233 pp.

VERON, J.E.N. \& WALLACE, C. (1984). 'Scleractinia of eastern Australia. V. Family Acroporidae'. Aust. Inst. Mar. Sci. Monogr, pol. 6: 485 pp.

VERRILL, A.E. (1864). 'List of the polyps and corals sent by the Museum of Comparative Zoology to other institutions in exchange, with annotations'. Bull. Mus. Comp. Zool. (Harv. Univ.), 1: 29-60.

VERRILL, A.E. (1866). 'Synopsis of the polyps and corals of the North Pacific Exploring Expedition: 1853-1856, with descriptions of some additional species from the West Coast of North America. III. Madreporaria', Comm. Essex Inst. Salem., 5: 6.

VERRILL, A.E. (1869a). 'Polyps and corals of the North Exploring Expedition. Additions and corrections'. Comm. Essex Inst. Salem., 6: 51-70.

VERRILL, A.E. (1901). 'Variations and nomenclature of Bermudian, West Indian and Brazilian reef corals, with notes on various Indo-Pacific corals'. Trans. Connecticut Acad. Arts Sci., 11:163-68.

VERRILL, A.E. (1902). Notes on corals of the genus Acropora (Madrepora Lam.) with new descriptions and figures of types, and of several new species'. Trans. Connecticut Acad. Arts Sci., 11: 207-66.

WELLS, J.W. (1934). 'Some fossil corals from the West Indies'. Proc. U.S. Natl. Mus., 83: $71-110$.

WELLS, J.W. (1954). 'Recent corals of the Marshall Islands'. Prof. Pap. U.S. Geol. Surv., 260-I: 385-486.

WELLS, J.W. (1955). 'Recent and subfossil corals of Moreton Bay, Queensland'. Univ. Qd. Pap. Dept. Geol, n.s., 4(10): 1-18.

WELLS, J.W. (1961). 'Notes on Indo-Pacific scleractinian corals. III. A new reef coral from New Caledonia'. Pac. Sci., 15(2): 189-91.

WELLS, J.W. (1966a). 'Notes on Indo-Pacific scleractinian corals. IV. A second species of Stylocoeniella'. Pac. Sci., 20(2): 203-205.

WELLS, J.W. (1966b). Evolutionary development in the scleractinian family Fungiidae'. Symp. Zool. Soc. Lon, 16: 223-46. 
WELLS, J.W. (1968). 'Notes on Indo-Pacific scleractinian corals. V. A new species of Alveopora from New Caledonia. VI. Further notes on Bantamia merletti Wells'. Pac. Sci. 22(2);274-6.

WELLS, J.W. (1971a). 'Notes on Indo-Pacific Bscleractinian corals. VII Catalaphyllia, a new genus of reef corals'. Pac, Sci., 25(3): 368-71.

WIJSMAN-BEST, M. (1972). 'Systematics and ecology of New Caledonian Faviinae (Coelenterata, Scleractinia)'. Bijdr. Dierkd., 42(1): 1- 76.

WIJSMAN-BEST, M. (1973). 'A new species of the Pacific coral genus Blastomussa from New Caledonia'. Pac. Sci., 27(2): 154-55.

WIJSMAN-BEST, M. (1976). Biological results of the Snellius Expedition. XXVII. Faviidae collected by the Snellius Expedition. II. The genera Favites, Goniastrea, Platygyra, Ouphyllia, Leptoria, Hydnophora and Caulastrea'. Zool. Med., 50(4): 45-63.

YABE, H. \& EGUCHI, M. (1935b). Revision of the reef coral genera Echinopora, Oxyphyllia, Mycedium, Oxypora and Physophyllia'. Proc. Imp. Acad. Ipn., 11(10): 429-31.

YABE, H. \& SUGIYAMA, T. (1931). 'A study of recent and semi-fossil corals of Japan'. Sci. Rep. Tohoku Imperial Univ, (Geol.), ser. 2, 14: 119-133.

YABE, H. \& SUGIYAMA, T. (1932a), 'Reef corals found in Japanese seas', Sci. Rep. Tohoku Imp, Univ., Ser. 2, (Geol.), 15(2): 143-168.

YABE, H. \& SUGIYAMA, T. (1932b). 'A living species of Stylocoenia recently found in Japan'. Jpn.J. Geol. Geogr., IX (3-4).

YABE, H. \& SUGIYAMA, T. (1932c). 'Notes on three new corals from Japan'. Jpn. J. Geol. Geogr. IX (1-2).

YABE, H. \& SUGIYAMA, T. (1933a). 'Geographical distribution of reef corals in Japan, Past and Present' (in Japanese). Proc. Jpn. Assoc. Advan. Sci., 8(3): 335-341.

XABE, H. \& SUGIYAMA, T. (1935a). 'Revised lists of the reef corals from the Japanese seas and of the fossil reef corals of the raised reefs and the Ryukyu Limestone of Japan ${ }^{*}$ J. Geol. Soc. Jpn + 42(502): 279-403.

YABE, H. \& SUGIYAMA, T. (1935b). 'Stylocoeniella, a new coral genus allied to Stylocoenia and Astrocoenia', Jpn. 1. Geol. Geogr., 12(3-4): 103-105.

YABE, H. \& SUGIYAMA, T. (1935c). 'Geological and geographical distribution of Reef Corals in Japan'. J. Paleontol, 9(3): 183-217.

YABE, H. \& SUGIYAMA, T. (1935d). 'A new living coral, Pseudosiderastrea tayamai, from Dobo in Wamar, Aru Island'. Proc. Ipn. Acad, 11(9): 373-378.

YABE, H. \& SUGIYAMA, T. (1936). 'Some deep-water corals from the Palau Islands'. Proc. Imp. Academic Tokyo, 12.

YABE, H. \& SUGIYAMA, T. (1937). 'Two new species of reef-building corals from Yoron-zima and Amami-O-sima'. Proc. Imp. Acad. Tokyo, 13(10): 425-429.

YABE, H. \& SUGIYAMA, T. (1941). 'Recent reef building corals from Japan and the south sea islands under the Japanese mandate. II'. Sci. Rep. Tohoku Univ. Geol., ser. 2, spec. vol. 2: 67-91. 
YABE, H., SUGIYAMA, T. \& EGUCHI, M. (1936). Recent reef-building corals from Japan and the south sea islands under the Japanese mandate. I'. Sci. Rep. Tohoku Univ. Geol, ser. 2, spec. vol. 1: 1-66.

YAGI, S. (ed.)(1970). Illustrated catalogue of scleractinian corals etc. stored in the Ehime Prefectural Museum. (Scleractinia identified by UTINOMI, H.). Prefectural Museum, Matsuyama. (Publ.): 61 pp.

YAMAGUCHI, M. (1986). 'Acanthaster planci infestations or reefs and coral assemblages in Japan: a retrospective analysis of control efforts'. Coral Reefs, 5: 23-30.

YAMAZATO, K. (1971). 'Benthic organisms of the Ryukyu Islands', in Problems of marine geology of the area around Kyushu by Geological Society of Japan and 4 other societies (in Japanese): 111-119.

YAMAZATO, K. (1978), 'Tentative list of corals found at a reef near the Sesoko Marine Science Laboratory', in Studies on fauna, flora and main organisms for experiments around marine and inland water biological stations in Japan.

YAMAZATO, K. (1985). In KOKUSHI, H. (ed.) Coastal oceanography offapanese Islands. Tokai Univ. Press: 1078-1090.

YAMAZATO, K., KAMURA, S. \& HIDAKA, M. (1980). 'The sheltered coral reef communities of Kume Island' (in Japanese). Rep. Sesoko Sci. Cent., 49: 133-144.

YAMAZATO, K., KAMURA, S., NAKASONE, Y., ARAMOTO, Y. \& NISHIHIRA, M. (1976). 'Ecological distribution of the reef associated organisms in the BiseShinzato coast of Okinawa'. Ecol, Stud. Nat, Cons. Ryukyu Is., 2; 1-30.

YAMAZATO, K., NISHIHIRA, M., NISHIIMA, S., KAMURA, S., NAKASONE, S., SHOKITA, S. \& YOSHINO, T. (1978). 'Studies on the biota and on the ecology of some important experimental organisms around Sesoko Island, Okinawa', in Studies on the biota and on the ecology of some important experimental organisms around the marine and freshwater laboratories of the Japanese national universities (in Japanese). Assoc. Directors Mar. Freshwater Lab. Jpn. National. Univ. (eds): 223-233.

YAMAZATO, K., NISHIHIRA, M., NAKASONE, Y., KAMURA, S. \& ARAMOTO, Y. (1974). 'Biogeomorphical notes on the Sesoko Island reefs, Okinawa' (in Japanese with English summary). Ecol. Stud. Nat. Cons, Ryukyu Is., 1: 201-212.

YAMAZATO, K., SHIMABUKRO, S. \& SAKAI, K. (1982). 'Corals of Uotsuri- shima' (in Japanese). Publ. Tropical Mar. Sci. Cent., Ryukyu Islands: 36-55.

YASUMOTO, M. (1986). 'Coral community of Shirako coral reef areas correlating ecological problems with geographic advantage' (in Japanese). Sci. Rep. Shiraho Coral Reef, Ishijaki Island World Wildlife Fund.

YAJIMA, T., OSAMU, S., OKAMOTO, T., SHIRAI, Y., SHINYA, T. \& MATADA, M. (1986). 'Ecological distribution of the reef coral, Oulastrea crispata (Lamarck) at the shore region in the vicinity of Tsukumo Bay' (in Japanese with English abstract). Bull. Jpn. Sea Res., 18: 21-26.

YOON, J. \& YASUDA, I. (1987). 'Dynamics of the Kuroshio large meander: two-layer model'. J. Phys. Oceanogr., 17(1): 66-81.

ZOU, R. (1980). 'Studies on the corals of the Xisha Islands. IV. Two new hermatypic scleractinian corals' (in Chinese). Nanhai Studia Marina Sinica, 1: 117-118. 


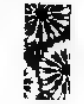 \\ Index}

A

abdita, Favites 168

abrolhosensis, Acropora 64

abrotanoides, Acropora $\quad 62,79$

Acanthaster planci $17,26,39$

Acanthastrea 27, 149

Acanthastrea amakusensis 151

Acanthastrea bowerbanki 150

Acanthastrea echinata 149

Acanthastrea hemprichii 150

Acanthastrea hillae 150

Acanthastrea ishigakiensis 151

Acanthastrea lordhowensis $\quad 17,151$

Acanthastrea rotundoflora 150

Acanthophyllia deshayesiana 148

Acrhelia 140

Acrhelia horrescens 140

Acropora 58

Acropora abrolhosensis 64

Acropora abrotanoides $\quad 62,79$

Acropora aculeus $\quad 76,77$

Acropora acuminata 64

Acropora affinis 83

Acropora akajimensis 66

Acropora anthocercis 75

Acropora aspera 69

Acropora austera 68

Acropora brueggemanni 59

Acropora carduus 81

Acropora cerealis 77

Acropora clathrata 78

Acropora compressa 83

Acropora copiosa 67

Acropora cuneata 59

Acropora cytherea 71

Acropora danai 62
Acropora dendrum $\quad 71,77$

Acropora digitifera $\quad 61,78$

Acropora divaricata 79

Acropora echinata $\quad 9,80$

Acropora elegans 72

Acropora elseyi 81

Acropora exquisita $\quad 65,66$

Acropora florida 83

Acropora formosa 63

Acropora gemmifera 60

Acropora glauca 10,61

Acropora grandis 63,64

Acropora granulosa 82

Acropora haimei 71

Acropora hebes 69

Acropora horrida 68

Acropora humilis $\quad 59,60$

Acropora hyacinthus 73,74

Acropora hystrix 77

Acropora insignis $\quad 67,73,76$

Acropora irregularis 62

Acropora kirstyae 67

Acropora latistella 75

Acropora leptocyathus 61

Acropora listeri 63

Acropora longicyathus 81

Acropora loricata 75

Acropora loripes 9, 69, 10, 82

Acropora microclados 72

Acropora microphthalma 66

Acropora millepora $\quad 69,84$

Acropora mirabilis 84

Acropora monticulosa 60

Acropora nana 76

Acropora nasuta 72,77

Acropora nobilis 62 
Acropora palifera 58

Acropora paniculata 73,74

Acropora parilis 65

Acropora pectinata $\quad 73,74$

Acropora prostrata 76

Acropora pruinosa $\quad 73,76$

Acropora pulchra $\quad 65,69$

Acropora pyramidalis 60

Acropora quelchi $\quad 74,77$

Acropora rayneri 82

Acropora reticulata 72

Acropora robusta 62

Acropora rosaria 82

Acropora rotumana 62

Acropora samoensis 60

Acropora sarmentosa 84

Acropora scherzeriana 68

Acropora secale 78

Acropora securis 59

Acropora sekiseiensis 67

Acropora selago 70

Acropora smithi 62

Acropora solitaryensis

Acropora sp, $1 \quad 1,66,79$

Acropora sp. 270

Acropora spicifera $\quad 73,74$

Acropora spiniformis 80

Acropora squamosa 70

Acropora squarrosa $\quad 75,82$

Acropora stoddarti $\quad 18,79$

Acropora striata 74

Acropora studeri 69

Acropora subglabra 80

Acropora subulata 76

Acropora surculosa 75

Acropora symmetrica 61

Acropora syringodes $\quad 78,81$

Acropora tanegashimensis $\quad 74$

Acropora tenella 72

Acroporatenuis 70,71

Acroporateres 64

Acropora tizardi 77
Acropora tumida 75

Acropora valenciennesi 65

Acropora valida $\quad 71,78$

Acropora variabilis $\quad 78$

Acropora vaughani 68

Acropora verweyi 61

Acropora wallaceae 83

Acropora willisae 83

Acropora yaeyamaensis 69

Acropora yongei 71

Acroporidae 43

actiniformis, Fungia 128

actiniformis, Heliofungia 128

aculeus, Acropora 77

acuminata, Acropora 64

aequituberculata, Montipora 55

affinis, Acropora 83

Agaricia minikoiensis 117

Agaricia ponderosa 119

agaricia, Symphyllia 155

Agariciidae 111

agassizi, Cyphastrea 187

aiharai, Caulastrea 161

akajimensis, Acropora 66

albitentaculata, Ctenactis 133

alcicornis, Pectinia 146

allingi, Alveopora 102

altasepta, Montipora $\quad 50,51$

Alveopora 102

Alveopora allingi 102

Alveopora catalai 102

Alveopora excelsa 103

Alveopora japonica $\quad 18,29,104$

Alveopora spongiosa 103

Alveopora tizardi 104

Alveopora verrilliana 103,104

amakusensis, Acanthastrea 151

amarantum, Trachyphyllia 191

amicorum, Barabattoia 168

amitoriensis, Leptoseris $\quad 18,115,116$

ampliata, Merulina 159

Anacropora 56 
Anacropora forbesi $\quad 56,57$

Anacropora matthai 57

Anacropora puertogalerae 56

Anacropora reticulata 57

Anacropora sp. 57,58

Anacropora spinosa 57

ancora, Euphyllia 17, 194

andrewsi, Porites 96

angulata, Montipora 49

angulata, Seriatopora 39

annae, Porites 96

annuligera, Montastrea 179

anthocercis, Acropora 75

Antillia constricta 191

Antillia duncani 191

Antillia flabelliformis 191

Antillia japonica 148

Antillia nomaensis 148

Antillophyllia 148

Antillophyllia constricta kuensis

Antillophyllia flabiformis 191

aranetai, Porites 96

armata, Stylocoeniella 33, 34

asanoi, Madracis 42

aspera sugiyamai, Oxyphyllia 141

aspera tosaensis, Oxyphyllia 141

aspera, Acropora 69

aspera, Echinophyllia $29,141,143$

aspera, Goniastrea $\quad 168,169$

aspera, Oulophyllia 178

aspera, Oxyphyllia 141

astreata, Galaxea 139

astreiformis, Coeloria 176

Astreopora 84,185

Astreopora explanata 86

Astreopora gracilis 85

Astreopora incrustans 85

Astreopora listeri 86

Astreopora macrostoma 87

Astreopora myriophthalma $\quad 84,85$

Astreopora ocellata 86

Astreopora suggesta 86
Astrocoenia 33

Astrocoeniidae 33

attenuata, Porites 94

auricularis, Turbinaria 200

austera, Acropora 68

australensis, Goniastrea 174

australiensis, Porites 90

australis, Scolymia 148

Australomussa 148

Australomussa rowleyensis

149

ayleni, Physophyllia 145

B

Barabattoia 168

Barabattoía amicorum 168

Barabattoia mirabilis 168

bennettae, Oulophyllia 179

bewickensis, Leptastrea 184

bifrons, Turbinaria 202

bipartita, Pavona 114

Blastomussa 147

Blastomussa merleti 147

Blastomussa wellsi 17, 30, 147

Boninastrea 157

Boninastrea boninensis 157

boninensis, Boninastrea 157

bonsai, Hydnophora $17,18,158$

Botryphyllia yaeyamaensis 195

bottae, Leptastrea 182

bowerbanki, Acanthastrea 150

brueggemanni, Acropora 59

brueggemanni, Turbinaria 201

burgosi, Goniopora 99

cactus, Montipora $\quad 50,52,54$

cactus, Pavona 111

caliculata, Montipora 49

caliendrum, Seriatopora 39,40

capitata, Montipora 48

carduus, Acropora 81

Caryophylliidae 193

catalai, Alveopora 102 
Catalaphyllia 194, 195

Catalaphyllia jardinei $\quad 18,195$

Catalaphyllia okinawaensis 193

Catalaphyllia sabiuraensis 196

Caulastrea 161

Caulastrea aiharai 161

Caulastrea curvata 162

Caulastrea echinulata 161

Caulastrea furcata 161

Caulastrea tumida $\quad 9,162$

Caulastrea tumida conglobata 162

Caulastrea tumida multiseptata 162

cebuensis, Montipora $\mathbf{5 5}$

cellulosa, Goniopora 100

cerealis, Acropora 77

chalcidicum tanabensis, Cyphastrea 185, 186

chalcidicum, Cyphastrea 185

challengeri, Montipora 55

chinensis, Favites 169

Cladocora kabiraensis 147

clathrata, Acropora 78

clavus, Galaxea 139

clavus, Pavona 113

cochlea, Heteropsammia 202

cocosensis, Stylocoeniella 35

Coelogyra laevis 178

Coeloria astreiformis 176

Coeloria gigantea 178

Coeloria lamellina 174

Coeloria rustica 174

Coeloseris 119

Coeloseris mayeri 119

columna, Coscinaraea 108, 109, 110

columna, Goniopora 99

columnaris, Galaxea 140

complanata, Favites 170

compressa, Acropora 83

compressa, Montipora 51

compressa, Porites 96

concinna, Fungia $\quad 9,131$

conferta, Montipora 48

constricta kuensis, Antillophyllia constricta, Antillia 191

contigua, $P_{\text {sammocora }} 106$

contorta, Platygyra 157,175

contorta, Turbinaria 200

convexa, Porites 97

copiosa, Acropora 67

corymbosa, Lobophyllia 152

Coscinaraea 108

Coscinaraea columna $108,109,110$

Coscinaraea crassa 109

Coscinaraea exesa 108

Coscinaraea hahazimaensis 110

Coscinaraea kusimotoensis 108, 109

Coscinaraea monile 109

Coscinaraea wellsi 109

costata, Lobophyllia 152

costulata, Cycloseris 124

crassa, Coscinaraea 109

crassa, Ctenactis 133

crassa, Seriatopora 39

crater, Turbinaria 200

crispa, Oulophyllia 178

crispata, Oulastrea $\quad 9,29,181$

crista-galli, Montipora 45

cristata, Euphyllia 194

crustacea, Podabacia 138

Ctenactis 123,133

Ctenactis albitentaculata 133

Ctenactis crassa 133

Ctenactis echinata 9,133

cuneata, Acropora 59

curta, Montastrea 179, 180

curta, Orbicella 179

curta, Plesiastrea 179

curvata, Caulastrea 162

curvata, Cycloseris 126

cyclolites, Cycloseris 124

cyclolites, Fungia 124

Cycloseris $123,127,129$

Cycloseris costulata $\quad 123,126$

Cycloseris curvata 126

Cycloseris cyclolites 124 
Cycloseris elegans 126

Cycloseris erosa 125

Cycloseris hexagonalis 124,127

Cycloseris marginata 126

Cycloseris patelliformis 125

Cycloseris, fragilis, Fungia 124

Cycloseris sinensis 124,127

Cycloseris, sinensis, Fungia 124

Cycloseris somervillei 17, 125

Cycloseris sp. 125

Cycloseris vaughani 125,126

cylindrica, Porites $\quad 27,93,94$

cylindrica, Scapophyllia 160

Cynarina 148

Cynarina lacrymalis 148

Cyphastrea 184,185

Cyphastrea agassizi 187

Cyphastrea chalcidicum 185

Cyphastrea chalcidicum tanabensis 185,186

Cyphastrea decadia $\quad 185,187$

Cyphastrea japonica 185,187

Cyphastrea microphthalma 10,186

Cyphastrea ocellina 185

Cyphastrea serailia $\quad 29,184,185$

Cyphastrea zhongjianensis 184

cytherea, Acropora 71

D

daedalea, Platygyra $\quad 174,175$

damicornis, Pocillopora 37

danae, Favia 165

danae, Montipora 47

danai, Acropora 62

danai, Fungia 129

danai, Pavona 112

decadia, Cyphastrea $\quad 185,187$

decussata, Pavona $\quad 9,10,111,112$

decussata, Psammocora 106

deformis, Favia 162

deformis, Goniastrea 18, 173

deformis, Porites 94

dendritica, Stylophora 40

Dendrophylliidae 199 dendrum, Acropora $\quad 71,77$

dentata, Sandalolitha 135

deshayesiana, Acanthophyllia 148

Diaseris 123, 127

Diaseris distorta 127

Diaseris fragilis 128

Diaseris pulchella 127

digitata, Montipora $\quad 9,50,51$

digitata, Psammocora 105

digitifera, Acropora $\quad 61,78$

Diploastrea 182

Diploastrea heliopora 182

distorta, Diaseris 127

divaricata, Acropora 79

divaricata, Montipora 51

divisa, Euphyllia 195

djiboutiensis, Goniopora 97

duncani, Antillia 191

E

echinata, Acanthastrea 149

echinata, Acropora $\quad 9,80$

echinata, Ctenactis 9,133

echinata, Echinophyllia 142

echinata, Fungia 133

echinatus, Zoopilus 18, 136

Echinophyllia 141

Echinophyllia aspera $\quad 29,141,143$

Echinophyllia echinata 142

Echinophyllia echinoporoides 143

Echinophyllia nishihirai 142

Echinophyllia orpheensis 142

Echinophyllia patula 143

Echinopora 188

Echinopora gemmacea 188

Echinopora hirsutissima 189

Echinopora horrida 189

Echinopora lamellosa 188

Echinopora mammiformis 189

Echinopora pacificus 188

echinoporoides, Echinophyllia 143

echinulata, Caulastrea 161

edwardsi, Goniastrea 172 


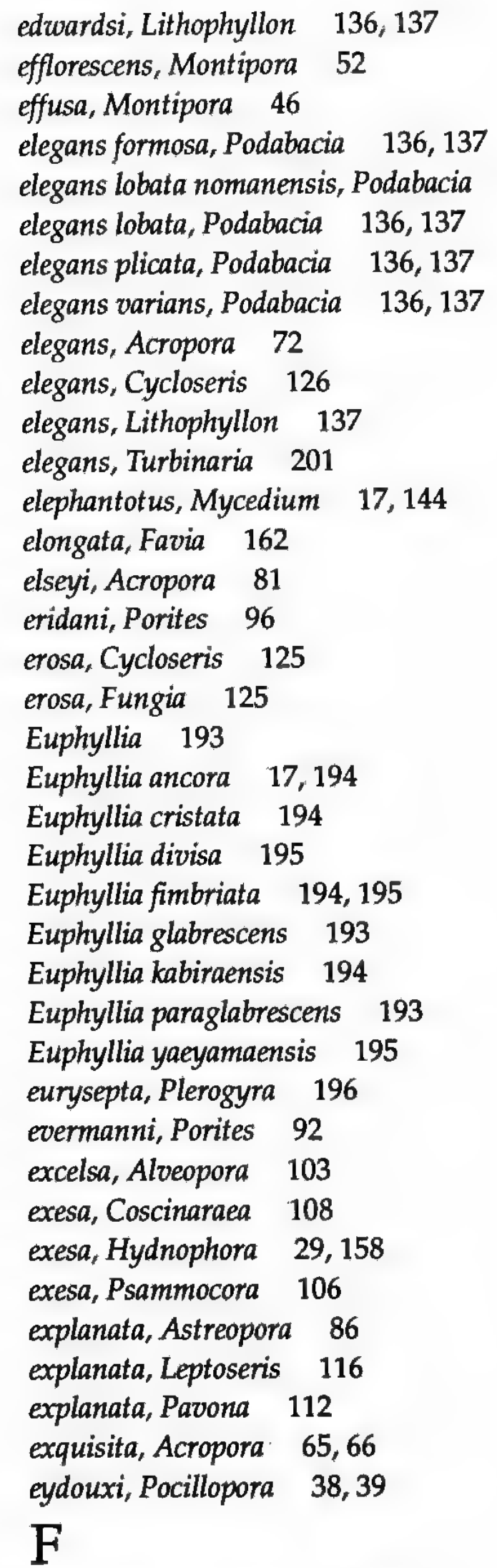

fascicularis, Galaxea 139,140

Favia 162

Favia danae 165

Favia deformis 162
Favia elongata 162

Favia favus 165

Favia helianthoides 163

Favia laxa 163, 167

137 Favia lizardensis 164

Favia magnistellata 180

Favia maritima 167

Favia matthaii 165

Favia maxima 166

Favia pallida 164

Favia rariseptata 162

Favia rotumana 166

Favia rotundata $\mathbf{1 6 6}$

Favia sp. 167

Favia speciosa 164,180

Favia stelligera 163

Favia valenciennesi 180

Favia veroni 167

Faviidae 161

Favites 168

Favites abdita 168

Favites chinensis 169

Favites complanata 170

Favites favosa $\quad 168,169$

Favites flexuosa 169

Favites halicora 169

Favites pentagona 170,171

Favites russelli 171

Favites stylifera 171

Favites virens 169,170

favosa, Favites 168,169

favulus, Goniastrea 171, 172

favus, Favia 165

fimbriata, Euphyllia 194, 195

flabellata, Stylophora 41

flabelliformis, Antillia 191

flabiformis, Antillophyllia 191

flexuosa, Favites 169

florida, Acropora 83

florida, Montipora 55

foliosa, Leptoseris 118

foliosa, Montipora $\quad 54,55$ 
forbesi, Anacropora $\quad 56,57$

formosa, Acropora 63

formosa, Podabacia 136

foveolata, Montipora 48

fragilis, Diaseris 128

fragilis, Fungia (Cycloseris)

128

fragosa, Porites 90

friabilis, Montipora 55

frondens, Turbinaria 200

frondifera, Pavona $\quad 9,113$

fruticosa, Goniopora 100,101

fruticosa, Montipora 51

Fungia $\quad 89,123,124,127,128$

Fungia actiniformis 128

Fungia concinna 9,131

Fungia (Ctenactis) simplex

133

Fungia cyclolites 124

Fungia (Cycloseris) fragilis 128

Fungia (Cycloseris) sinensis 124

Fungia danai 129

Fungia echinata 133

Fungia erosa 125

Fungia fungites $\quad 9,129$

Fungia granulosa 131

Fungia moluccensis 132

Fungia paumotensis 132

Fungia repanda 130

Fungia scabra 130

Fungia scruposa 130

Fungia scutaria 129, 132

Fungia scutaria placunaria 132

Fungia spinifer 131

Fungia valida 130

Fungidae 123

fungites, Fungia $\quad 9,129$

furcata, Caulastrea 161

gaimardi, Montipora 51

Galaxea 139

Galaxea astreata 139

Galaxea clavus 139

Galaxea columnaris 140
Galaxea fascicularis $\quad 139,140$

Galaxea musicalis 139

gardineri, Leptoseris 115,116

Gardineroseris 119

Gardineroseris planulata 119

gemmacea, Echinopora 188

gemmae, Pachyseris 121

gemmifera, Acropora 60

geoffroyi, Trachyphyllia 191

gigantea, Coeloria 178

gigantea, Platygyra 178

glabra, Oxypora 144

glabrescens, Euphyllia 193

glauca, Acropora $\quad 10,61$

Goniastrea 171

Goniastrea aspera $\quad 172,173$

Goniastrea australensis $\quad 174$

Goniastrea deformis 18,173

Goniastrea edwardsi 172

Goniastrea favulus 171,172

Goniastrea incrustans 173

Goniastrea parvistella 172

Goniastrea pectinata $172,173,174$

Goniastrea planulata 174

Goniastrea retiformis $\quad 10,171$

Goniastrea spectabilis 173

Goniastrea yaeyamaensis 177

Goniastrea yamanarii 173

Goniopora 97, 101

Goniopora burgosi 99

Goniopora cellulosa 100

Goniopora columna 99

Goniopora djiboutiensis 97

Goniopora fruticosa 100, 101

Goniopora lobata $\quad 97,98$

Goniopora minor 100

Goniopora pandoraensis 101

Goniopora pendulus 98

Goniopora planulata 97

Goniopora polyformis 101

Goniopora sagamiensis 97

Goniopora somaliensis 99 
Goniopora sp. 101

Goniopora stokesi 98

Goniopora stutchburyi 102

Goniopora tenuidens 99

gracilis, Astreopora 85

gracilis, Leptoria 177,178

grandis, Acropora 63,64

grandis, Hydnophora 158

granulosa, Acropora 82

granulosa, Fungia 131

grisea, Montipora 53

guentheri, Stylocoeniella 33, 34

Gyrosmilia 197

Gyrosmilia interrupta 197

$\mathrm{H}$

haddoni, Porites 91

hahazimaensis, Coscinaraea 110

haimeana, Psammocora 107

haimei, Acropora 71

halicora, Favites 169

Halomitra 135

Halomitra pileus 135

Halomitra robusta 135

hanzawai, Stylocoenia 33, 34

hanzawai, Stylocoeniella 34

hataii, Lobophyllia 153

hataii, Lobophyllia (Palauphyllia) 153

hataii, Palauphyllia 153

hawaiiensis, Leptoseris 117

hebes, Acropora 69

helianthoides, Favia 163

Heliofungia 128

Heliofungia actiniformis 128

heliopora, Diploastrea 182

hemprichii, Acanthastrea 150

hemprichii, Lobophyllia 152, 155

heronensis, Porites 29,91

Herpetoglossa 128

Herpolitha 134

Herpolitha limax 134

Herpolitha stricta 134

Herpolitha weberi 134
Heterocyathus japonicus 193

Heteropsammia 202

Heteropsammia cochlea 202

hexagonalis, Cycloseris 124,127

hillae, Acanthastrea 150

hirsuta, Montipora 53

hirsutissima, Echinopora 189

hispida, Montipora 52

hoffmeisteri, Montipora 44

horizontalata, Porites 96

horrescens, Acrhelia 140

horrida, Acropora 68

horrida, Echinopora 189

humilis, Acropora $\quad 59,60$

hyacinthus, Acropora $\quad 73,74$

Hydnophora 157

Hydnophora bonsai $\quad 17,18,158$

Hydnophora exesa $\quad 29,158$

Hydnophora grandis 158

Hydnophora laxa 158

Hydnophora microconos 159

Hydnophora rigida 157

hystrix, Acropora 77

hystrix, Seriatopora 39

I

immersa, Turbinaria 199

inaequalis, Leptastrea $\quad 182,187$

incrassata, Montipora 48

incrustans, Astreopora 85

incrustans, Goniastrea 173

incrustans, Leptoseris 117

indentata, Montipora 51

informis, Montipora 50,52

insignis, Acropora $\quad 67,73,76$

interrupta, Gyrosmilia 197

irregularis, Acropora 62

irregularis, Leptoria $\quad$ 177, 178

irregularis, Parahalomitra 135

irregularis, Porites 97

irregularis, Turbinaria 201

ishigakiensis, Acanthastrea 151

iwayamaensis, Porites 97 
J

japonica, Alveopora 18, 29, 104

japonica, Antillia 148

japonica, Cyphastrea 185,187

japonica, Stylocoenia 33,34

japonicus, Heterocyathus 193

jardinei, Catalaphyllia $\quad$ 18, 195

K

kabiraensis, Cladocora 147

kabiraensis, Euphyllia 194

kauaiensis, Madracis 42

kirbyi, Madracis 42

kirstyae, Acropora 67

kusimotoensis, Coscinaraea 108, 109

I

lacera, Oxypora 17,143

laciniata, Pectinia 145

lacrymalis, Cynarina 148

lactuca japonica, Tridacophyllia 146

lactuca tanabensis, Tridacophyllia 146

lactuca, Pectinia 145

laevis, Coelogyra 178

lamellina, Coeloria 174

lamellina, Platygyra 174,175

lamellosa, Echinopora 188

lata. Pavona 112

latistella, Acropora 75

latistella, Porites 94

laxa, Favia 163, 167

laxa, Hydnophora 158

laxa,Merulina 158

Leptastrea 182

Leptastrea bewickensis 184

Leptastrea bottae 182

Leptastrea inaequalis $\quad 182,187$

Leptastrea pruinosa 183

Leptastrea purpurea 183

Leptastrea transversa 183

leptocyathus, Acropora 61

Leptoria 177

Leptoria gracilis 177,178

Leptoria irregularis 177,178
Leptoria phrygia 177,178

Leptoria ryukyuensis 176

Leptoseris 115

Leptoseris amitoriensis $\quad 18,115,116$

Leptoseris explanata 116

Leptoseris foliosa 118

Leptoseris gardineri 115,116

Leptoseris hawaiiensis 117

Leptoseris incrustans 117

Leptoseris mycetoseroides 117

Leptoseris papyracea 115

Leptoseris scabra 116

Leptoseris solida 118

Leptoseris yabei 118

levis, Montipora $\mathbf{5 1}$

lichen, Porites 95,96

lichtensteini, Physogyra 197

lilacea, Pavona 113

limax, Herpolitha 134

listeri, Acropora 63

listeri, Astreopora 86

Lithophyllon 123, 136

Lithophyllon edwardsi 136, 137

Lithophyllon elegans 137

Lithophyllon lobata $\quad 136,137$

Lithophyllon mokai 136

Lithophyllon undulatum 136, 137

lizardensis, Favia 64

lobata, Goniopora 97, 98

lobata, Lithophyllon 136, 137

lobata $a_{i}$ Porites 90

Lobophyllia 152, 153

Lobophyllia (Palauphyllia) hataii 153

Lobophyllia corymbosa 152

Lobophyllia costata 152

Lobophyllia hataii 153

Lobophyllia hemprichii 152,155

Lobophyllia pachysepta 153

Lobophyllia robusta 152, 153

longicyathus, Acropora 81

lordhowensis, Acanthastrea 17, 151

loricata, Acropora 75

loripes, Acropora $\quad 9,10,82$

lutea, Porites $\quad 90,91$ 
M

macrostoma, Astreopora 87
mactanensis, Montipora 47
Madracis 42
Madracis asanoi 42
Madracis kauaiensis 42
Madracis kirbyi 42
magnistellata, Favia 180
magnistellata, Montastrea 180
malampaya, Montipora 54
maldivensis, Pavona $111,113,114$
mammiformis, Echinopora 189
marenzelleri, Montipora 51
marginata, Cycloseris 126
maritima, Favia 167
matthai, Anacropora 57
matthaii, Favia 165
maxima, Favia 166
mayeri, Coeloseris 119
mayeri, Porites 92

meandrina nobilis, Pocillopora 38

meandrina, Pocillopora 38

merleti, Blastomussa 147

Merulina 159

Merulina ampliata 159

Merulina laxa 158

Merulina scabricula 159

Merulinidae 200

mesenterina, Turbinaria 72

microclados, Acropora 159

microconos, Hydnophora 159

microphthalma, Acropora 66

microphthalma, Cyphastrea 10, 186

millepora, Acropora $\quad 69,84$

millepora, Montipora 44

minikoiensis, Agaricia 117

minor, Goniopora 100

minuta, Pavona 114

mirabilis, Acropora 84

mirabilis, Barabattoia 168

modumanensis, Pocillopora 39

mokai, Lithophyllon 136 mollis, Montipora $\quad 44,46$

mollis, Turbinaria 200

moluccensis, Fungia 132

monasteriata, Montipora 43

monile, Coscinaraea 109

Montastrea 179

Montastrea annuligera 179

Montastrea curta 179, 180

Montastrea magnistellata 180

Montastrea multipunctata 180

Montastrea valenciennesi 180

monticulosa, Acropora 60

Montipora 43, 51

Montipora aequituberculata 55

Montipora altasepta $\quad 50,51$

Montipora angulata 49

Montipora cact us $\quad 50,52,54$

Montipora caliculata 49

Montipora capitata 48

Montipora cebuensis 55

Montipora challengeri 55

Montipora compressa 51

Montipora conferta 48

Montipora crista-galli 45

Montipora danae 47

Montipora digitata $\quad 9,50,51$

Montipora divaricata 51

Montipora efflorescens 52

Montipora effusa 46

Montipora florida 55

Montipora foliosa $\quad 54,55$

Montipora foveolata 48

Montipora friabilis 55

Montipora fruticosa 51

Montipora gaimardi 51

Montipora grisea 53

Montipora hirsuta 53

Montipora hispida 52

Montipora hoffmeisteri 44

Montipora incrassata 48

Montipora indentata 51

Montipora informis $\quad 50,52$ 
Montipora levis 51

Montipora mactanensis 47

Montipora malampaya 54

Montipora marenzelleri 51

Montipora millepora 44

Montipora mollis 44,46

Montipora monasteriata 43

Montipora peltiformis 45

Montipora prolifera $\quad 54,55$

Montipora pulcherrima 54, 55

Montipora ramosa $\quad 50,51$

Montipora rubra 51

Montipora samarensis $\quad 50,51$

Montipora sp. 54

Montipora spongodes 45

Montipora spumosa 46

Montipora stellata 50,53

Montipora tortuosa 51

Montipora tuberculosa 43

Montipora turgescens $\quad 45,46$

Montipora undata 46

Montipora venosa 49

Montipora verrilli 55

Montipora verrucosa $\quad 47,48$

mordax, Stylophora 40

motuporensis, Podabacia 138

multipunctata, Montastrea 180

murrayensis, Porites 90

musicalis, Galaxea 139

Mussidae 147

Mycedium 144

Mycedium elephantotus 17,144

Mycedium robokaki 145

Mycedium tubifex 144

mycetoseroides, Leptoseris 117

myriophthalma, Astreopora 84,85

$\mathrm{N}$

nana, Acropora 76

nasuta, Acropora $\quad 72,77$

negrosensis, Porites 95

nierstraszi, Psammocora 107

nigrescens, Porites 93 nishihirai, Echinophyllia 142

nobilis, Acropora 62

nomaensis, Antillia 148

ocellata, Astreopora 86

ocellina, Cyphastrea 185

octopera, Seriatopora 39

Oculinidae 139

okinawaensis, Catalaphyllia 193

okinawensis, Porites 29,92

Orbicella curta 179

orpheensis, Echinophyllia 142

Oulastrea 181

Oulastrea crispata $\quad 9,29,181$

Oulophyllia 178

Oulophyllia aspera 178

Oulophyllia bennettae 179

Oulophyllia crispa 178

Oxyphyllia 141

Oxyphyllia aspera 141

Oxyphyllia aspera sugiyamai 141

Oxyphyllia aspera tosaensis 141

Oxypora 143

Oxypora glabra 144

Oxypora lacera 17,143

Oxypora titizimaensis 143,144

P

pachysepta, Lobophyllia 153

Pachyseris 120

Pachyseris gemmae 121

Pachyseris rugosa 120,121

Pachyseris speciosa 120

pacificus, Echinopora 188

paeonia, Pectinia 146

Palauastrea 34, 41

Palauastrea ramosa 41

Palauastrea ramosa iwayamaensis 41

Palauphyllia hataii 153

Palauphyllia, hataii, Lobophyllia 153

palifera, Acropora 58

pallida, Favia 164 
pandoraensis, Goniopora 101

paniculata, Acropora 73

papyracea, Leptoseris 115

paraglabrescens, Euphyllia 193

Parahalomitra irregularis 135

Parahalomitra robusta 135

Parasimplastrea simplicitexta 184

parilis, Acropora 65

parvistella, Goniastrea 172

patelliformis, Cycloseris 125

patula, Echinophyllia 143

paumotensis, Fungia 132

Pavona 111

Pavona bipartita 114

Pavona cactus 111

Pavona clavus 113

Pavona danai 112

Pavona decussata $9,10,111,112$

Pavona explanata 112

Pavona frondifera $\quad 9,113$

Pavona lata 112

Pavona lilacea 113

Pavona maldivensis $111,113,114$

Pavona minuta 114

Pavona praetorta 111

Pavona varians 114

Pavona venosa 17,115

pectinata, Acropora 73, 74

pectinata, Goniastrea $\quad 172,173,174$

Pectinia 10,145

Pectinia alcicornis 146

Pectinia laciniata 145

Pectinia lactuca 145

Pectinia paeonia 146

Pectinia plicata 146

Pectinia teres 146

Pectiniidae 141

peltata, Turbinaria 199

peltiformis, Montipora 45

pendulus, Goniopora 98

pentagona, Favites 170,171

phrygia, Leptoria 177,178 phrygia, Platygyra 177,178

Phymastrea valenciennesi 180

Physogyra 197

Physogyra lichtensteini 197

Physophyllia 145

Physophyllia ayleni 145

pileus, Halomitra 135

pini, Platygyra 176

pistillata, Stylophora $\quad 39,40,41$

planci, Acanthaster 17, 26,39

planulata, Gardineroseris 119

planulata, Goniastrea 174

planulata, Goniopora 97

Platygyra 174

Platygyra contorta 157, 175

Platygyra daedalea 174,175

Platygyra gigantea 178

Platygyra lamellina 174,175

Platygyra phrygia 177,178

Platygyra pini 176

Platygyra rustica 174,175

Platygyra ryukyuensis 176

Platygyra sinensis 176

Platygyra verweyi 177

Platygyra yaeyamaensis 177

Plerogyra 194, 196

Plerogyra eurysepta 196

Plerogyra sinuosa 196

Plerogyra simplex 194

Plesiastrea 181

Plesiastrea curta 179

Plesiastrea versipora 181

plicata, Pectinia 146

Pocillopora 37

Pocillopora damicornis 37

Pocillopora eydouxi 38,39

Pocillopora meandrina 38

Pocillopora meandrina nobilis 38

Pocillopora modumanensis 39

Pocillopora setchelli 38

Pocillopora verrucosa 38,39

Pocillopora woodjonesi 38 
Pocilloporidae 37

Podabacia 138

Podabacia crustacea 138

Podabacia elegans formosa $\quad 136,137$

Podabacia elegans lobata 136, 137

Podabacia elegans lobata nomanensis

Podabacia elegans plicata 136,137

Podabacia elegans varians 136,137

Podabacia formosa 136

Podabacia motuporensis 138

Podabacia varians 136

polyformis, Goniopora 101

Polyphyllia 134

Polyphyllia talpina 134

ponderosa, Agaricia 119

Porites 89, 96

Porites andrewsi 93

Porites annae 96

Porites aranetai 96

Porites attenuata 94

Porites australiensis $\quad 90$

Porites compressa 96

Porites convexa 97

Porites cylindrica 27,93,94

Porites deformis 94

Porites eridani 96

Porites evermanni 92

Porites fragosa 90

Porites haddoni 91

Porites heronensis $\quad 29,91$

Porites horizontalata 96

Porites irregularis 97

Porites iwayamaensis 97

Porites latistella 94

Porites lichen $\quad 95,96$

Porites lobata 90

Porites lutea $\quad 90,91$

Porites mayeri 92

Porites murrayensis 90

Porites negrosensis 95

Porites nigrescens 93

Porites okinawensis $\quad 29,92$
Porites rus 97

Porites sillimaniani $\quad 94,96$

Porites solida 89

Porites stephensoni 92

Porites tenuis 91

137 Porites vaughani 95

Poritidae 89

praetorta, Pavona 111

profundacella, Psammocora $\quad 29,107$

prolifera, Montipora $\quad 54,55$

prostrata, Acropora 76

Protolobophyllia 148

pruinosa, Acropora 73,76

pruinosa, Leptastrea 183

Psammocora 105,108

Psammocora contigua 106

Psammocora decussata 106

Psammocora digitata 105

Psammocora exesa 106

Psammocora haimeana 107

Psammocora nierstraszi 107

$P_{\text {sammocora profundacella }} \quad 29,107$

Psammocora superficialis 29,106

Psammocora togianensis 105,106

Psammocora vaughani 108

Pseudocolumnastrea 111

Pseudocolumnastrea yamanarii 111

Pseudosiderastrea 105

Pseudosiderastrea tayamai 105

puertogalerae, Anacropora 56

pulchella, Diaseris 127

pulcherrima, Montipora 54,55

pulchra, Acropora $\quad 65,69$

purpurea, Leptastrea 183

pyramidalis, Acropora 60

0

quelchi, Acropora $\quad 74,77$

$\mathrm{R}$

radians, Symphyllia 154

radiata, Trachyphyllia 191

radiata, Wellsophyllia 191 
ramosa iwayamaensis, Palauastrea

ramosa, Montipora 50,51

ramosa, Palauastrea 41

ramosu, Turbinaria 201

rariseptala, Favia 162

raymeri, Acropora 82

recta, Symphyllia 154

reniformis, Turbinaria 201

repanda, Fungia 130

reticulala, Acropora 72

reticulata, Anacropora 57

retiformis, Goniastrea $\quad 10,171$

rigida, Hydnophora 157

robokaki, Mycedium 145

robusta, Acropora 62

robusta, Halomitra 135

robusta, Lobophyllia 152, 153

robusta, Parahalomitra 135

robusta, Sandalolitha 135

rosaria, Acropora 82

rotumana, Acropora 62

rotumana, Favia 166

rolundata, Favia 166

rotundoflora, Acanthastrea 150

rowoleyensia, Australomusan 149

rubra, Montipara 51

rugosa, Pachyseris 120,121

rugosa, Turbinaria 200

rus, Porites 97

russelli, Favites 171

rustica, Coeloria 174

rustion, Platygyra 174, 175

ryukyuensis, Leptoria 176

ryukyuensis, Platygyra 176

S

sabiuraensis, Catalaphyllia 196

sagamiensis, Goniopora 97

samarensis, Montipora 50,51

sampensis, Acropora 60

Sandalolitha 135

Sandalolitha dentata 135

Sandalolitha robusta 135
41

sarmentosa, Acropora

84

scabra, Fungia 130

scabra, Leptoseris 116

scabricula, Merulina 159

Scapophyllia 160

Scapophyllia cylindrica 160

scherzeriana, Acropora 68

Scolymia 148

Scolymia australis 148

Scolymia vitiensis $\quad 142,148,149$

scruposa, Fungia 130

scutaria placunaria, Fungia 132

scutaria, Fungia 129,132

secale, Acropora 78

securis, Acropora 59

sekiseiensis, Acropora 67

selaga, Acropora 70

serallia, Cyphastrea $29,184,185$

Seriatopora $\quad 39,41$

Seriatopora angulata 39

Seriatopara caliendrum 39,40

Seriatopora crassa 39

Seriatopora hystrix 39

Seriatopora octopera 39

setchelli, Pocillopora 38

Siderastrea 18

Siderastreldae 105

sillimaniani, Porites 94,96

Simplastrea 140

simplex, Fungia (Ctenactis) 133

simplicitexta, Parasimplastrea 184

sinensis, Cycloseris 124,127

sinensis, Fungia (Cycloseris) 124

sinensis, Platygyra 176

sinuosa, Plerogyra 196

smithi, Acropora 62

solida, Leptoseris 118

solida, Porites 89

solitaryensis, Acropora 79

somaliensis, Goniopona 99

someroillei, Cycloseris 17, 125

speciosa, Favia $\quad 29,164,180$ 
speciosa, Pachyseris 120

spectabilis, Goniastrea 173

spicifera, Acropora 80

spinifer, Fungia 131

spiniformis, Acropora 80

spinosa, Anacropora 57

spongiosa, Alveopora 103

spongodes, Montipora 45

spumosa, Montipora 46

squamosa, Acropora 70

squarrosa, Acropora 75,82

stellata, Montipora $\quad 50,53$

stelligera, Favia 163

stellulata, Turbinaria 201

stephensoni, Porites 92

stoddarti, Acropora 18,79

stokesi, Goniopora 98

striata, Acropora 74

stricta, Herpolitha 134

studeri, Acropora 69

stutchburyi, Goniopora 102

stylifera, Favites 171

Stylocoenia hanzawai 33,34

Stylocoenia japonica 33,34

Stylocoeniella33, 34, 41

Stylocoeniella armata 33,34

Stylocoeniella cocosensis 35

Stylocoeniella guentheri 33,34

Stylocoeniella hanzawai 34

Stylophora 40, 41

Stylophora dendritica 40

Stylophora flabellata 41

Stylophora mordax 40

Stylophora pistillata $39,40,41$

Stylophora sp. $\quad 40,41$

subglabra, Acropora 80

subulata, Acropora 76

suggesta, Astreopora 86

superficialis, Psammocora

surculosa, Acropora 75

symmetrica, Acropora 61

Symphyllia 154
Symphyllia agaricia 155

Symphyllia radians 154

Symphyllia recta 154

Symphyllia valenciennesii 155

syringodes, Acropora $\quad 78,81$

T

talpina, Polyphyllia 134

tanegashimensis, Acropora 74

tayamai, Pseudosiderastrea 105

tenella, Acropora 72

tenuidens, Goniopora 99

tenuis, Acropora $\quad 70,71$

tenuis, Porites 91

teres, Acropora 64

teres, Pectinia 146

titizimaensis, Oxypora 142,144

titizimaensis, Turbinaria 201

tizardi, Acropora 77

tizardi, Alveopora 104

togianensis, Psammocora $\quad 105,106$

tortuosa, Montipora 51

Trachyphyllia 10, 148, 191

Trachyphyllia amarantum 191

Trachyphyllia geoffroyi 191

Trachyphyllia radiata 191

Trachyphylliidae 191

transversa, Leptastrea 183

Tridacophyllia lactuca japonica 146

Tridacophyllia lactuca tanabensis 146

tuberculosa, Montipora 43

tubifera, Turbinaria 200

tubifex, Mycedium 144

tumida conglobata, Caulastrea 162

tumida multiseptata, Caulastrea 162

tumida, Acropora 75

tumida, Caulastrea 9,162

Turbinaria 199

Turbinaria auricularis 200

Turbinaria bifrons 202

Turbinaria brueggemanni 201

Turbinaria contorta 200

Turbinaria crater 200 
Turbinaria elegans 201

Turbinaria frondens 200

Turbinaria immersa 199

Turbinaria irregularis 201

Turbinaria mesenterina 200

Turbinaria mollis 200

Turbinaria peltata 199

Turbinaria ramosa 201

Turbinaria reniformis 201

Turbinaria rugosa 200

Turbinaria stellulata 201

Turbinaria titizimaensis 201

Turbinaria tubifera 200

Turbinaria undata 200

turgescens, Montipora $\quad 45,46$

$\mathrm{U}$

undata, Montipora 46

undata, Turbinaria 200

undulatum, Lithophyllon 136, 137

V

valenciennesi, Acropora 65

valenciennesi, Favia 180

valenciennesi, Montastrea 180

valenciennesi, Phymastrea 180

valenciennesii, Symphyllia 155

valida, Acropora 71,78

valida, Fungia 130

variabilis, Acropora 78

varians, Pavona 114

varians, Podabacia 136

vaughani, Acropora 68

vaughani, Cycloseris 125,126

vaughani, Porites 95

vaughani, Psammocora 108

venosa, Montipora 49 venosa, Pavona 17,115

veroni, Favia 167

verrilli, Montipora 55

verrilliana, Alveopora 103, 104

verrucosa, Montipora 47,48

verrucosa, Pocillopora 38,39

versipora, Plesiastrea 181

verweyi, Acropora 61

verweyi, Platygyra 177

virens, Favites 169,170

vitiensis, Scolymia $\quad 142,148,149$

W

wallaceae, Acropora 83

weberi, Herpolitha 134

wellsi, Blastomussa $\quad 17,30,147$

wellsi, Coscinaraea 109

Wellsophyllia radiata 191

willisae, Acropora 83

woodjonesi, Pocillopora 38

Y

yabei, Leptoseris 118

yaeyamaensis, Acropora 69

yaeyamaensis, Botryphyllia 195

yaeyamaensis, Euphyllia 195

yaeyamaensis, Goniastrea 177

yaeyamaensis, Platysyra 177

yamanarii, Goniastrea 173

yamanarii, $P_{\text {seudocolumnastrea }}$

111
Z

zhongjianensis, Cyphastrea 184

Zoopilus 136

Zoopilus echinatus $\quad 18,136$ 
. 


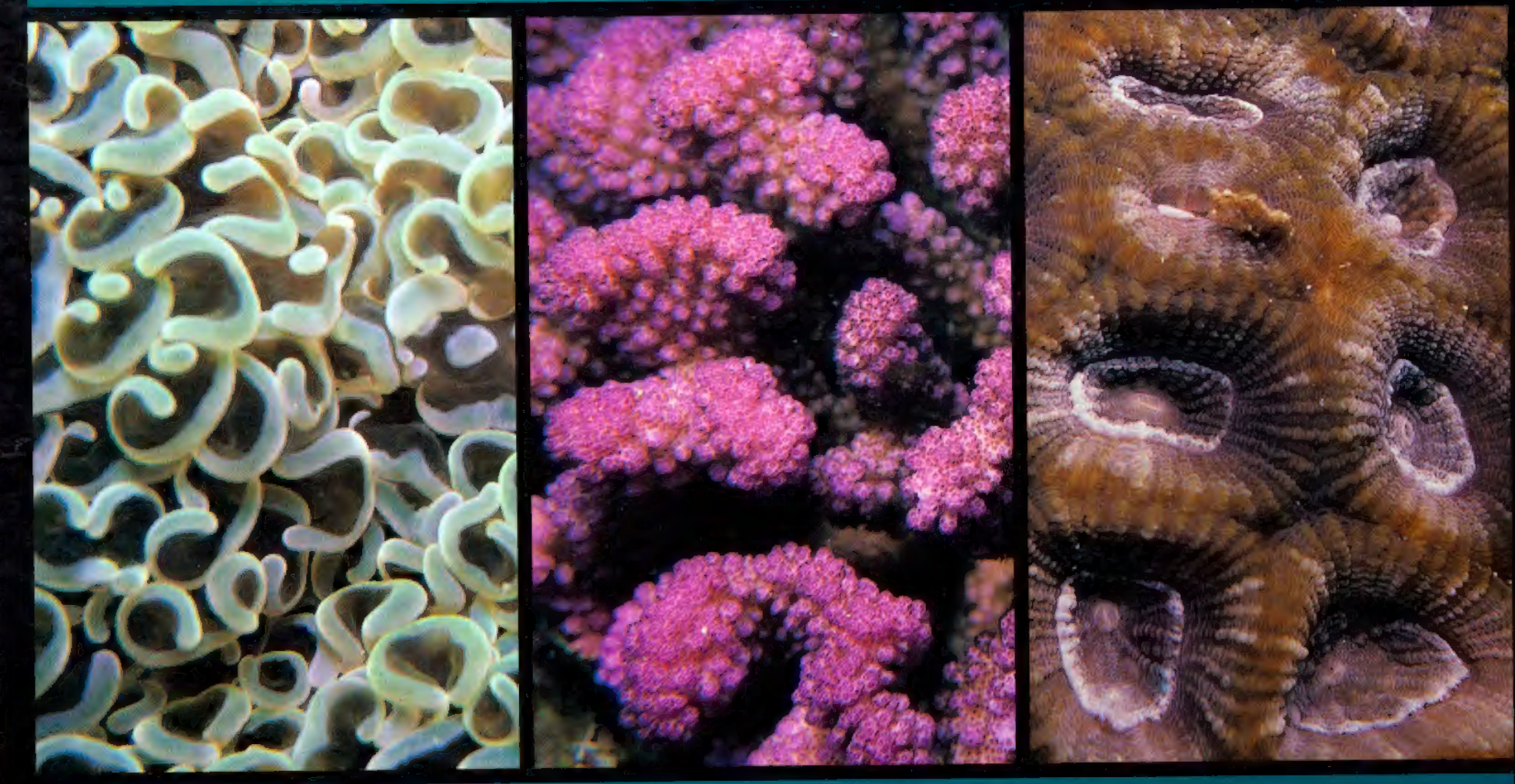